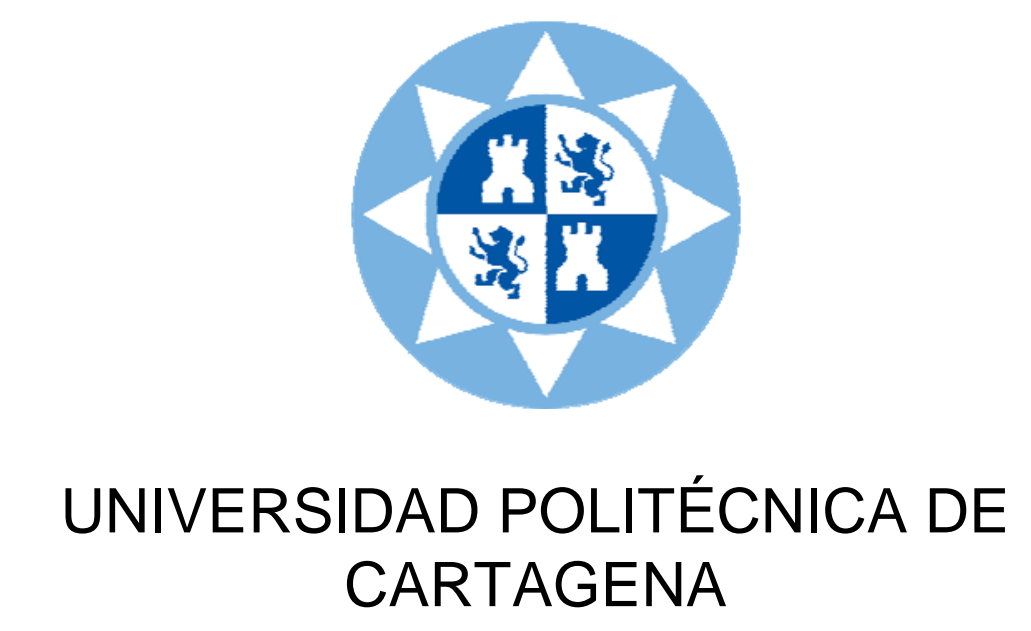

Departamento de Producción Vegetal

\title{
Riego deficitario en distintas etapas del desarrollo de plantas ornamentales cultivadas en maceta
}

Sara Álvarez Martín 


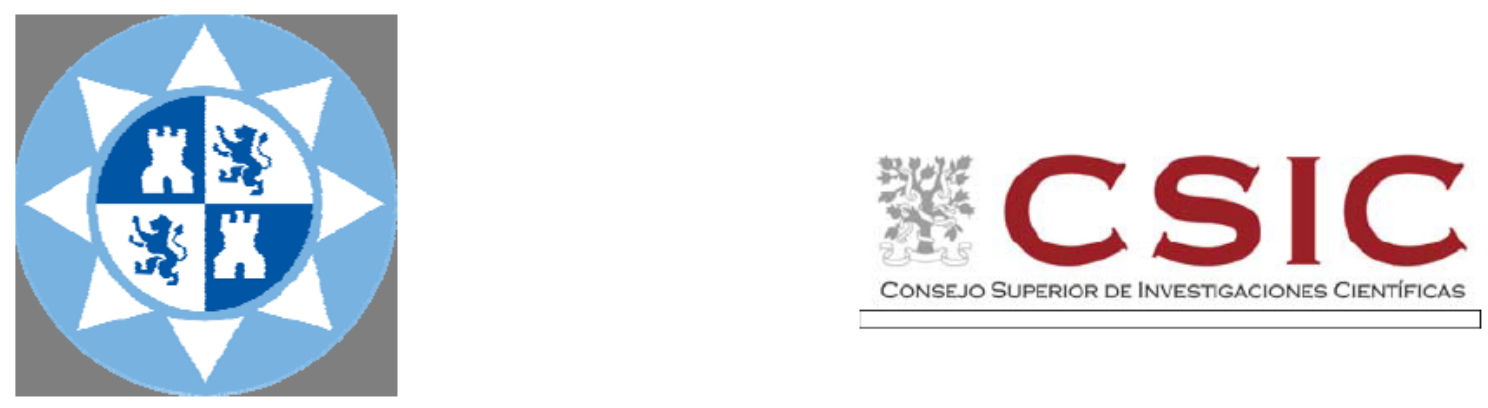

Universidad Politécnica de Cartagena

Departamento de Producción Vegetal

Riego deficitario en distintas etapas

del desarrollo de plantas

ornamentales cultivadas en maceta

\author{
Sara Álvarez Martín \\ Directores: \\ $M^{a}$ Jesús Sánchez Blanco \\ Sebastián del Pilar Bañón Arias
}





\section{AUTORIZACIÓN DE LA PRESENTACIÓN DE LA TESIS DOCTORAL POR LA COMISIÓN ACADÉMICA RESPONSABLE DEL PROGRAMA}

D. Marcos Egea Gutiérrez-Cortines, Coordinador de la Comisión Académica del Programa Técnicas Avanzadas en Investigación y Desarrollo Agrario Alimentario

\section{INFORMA:}

Que la Tesis Doctoral titulada "Riego deficitario en distintas etapas del desarrollo de plantas ornamentales cultivadas en maceta", ha sido realizada por Da . Sara Álvarez Martín, bajo la dirección y supervisión de $\mathrm{D}^{\mathrm{a}}$. $\mathrm{M}^{\mathrm{a}}$ Jesús Sánchez Blanco y $\mathrm{D}$. Sebastián del Pilar Bañón Arias y que la Comisión Académica ha dado su conformidad para que sea presentada ante la Comisión de Doctorado.

La rama de conocimiento por la que esta tesis ha sido desarrollada es:

囚Ciencias Básicas

$\square \quad$ Ciencias Sociales y Jurídicas

$\square \quad$ Ingeniería y Arquitectura

En Cartagena, a 26 de Mayo de 2011

EL COORDINADOR DE LA COMISIÓN ACADÉMICA DEL PROGRAMA

Fdo.: Marcos Egea Gutiérrez-Cortines

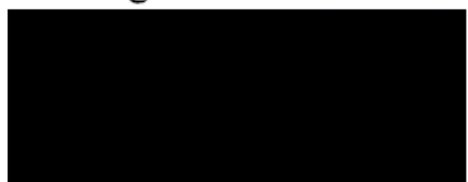

Comisión de Doctorado 



\section{AUTORIZACIÓN DE LA PRESENTACIÓN DE LA TESIS DOCTORAL POR LOS DIRECTORES DE TESIS}

$D^{a} . M^{a}$ Jesús Sánchez Blanco, Investigadora del CSIC, en el Departamento de Riego del Centro de Edafología Aplicada del Segura (CEBAS-CSIC) y D. Sebastián del Pilar Bañón Arias, Doctor del Área de Producción Vegetal y Catedrático de Universidad en el Departamento de Producción Vegetal de la Universidad Politécnica de Cartagena

\section{A U T O R I Z AN:}

La presentación de la Tesis Doctoral titulada "Riego deficitario en distintas etapas del desarrollo de plantas ornamentales cultivadas en maceta", realizada por $\mathrm{D}^{\mathrm{a}}$. Sara Álvarez Martín, bajo nuestra dirección y supervisión, en el Departamento de Riego Del Centro de Edafología y Biología Aplicada del Segura y en el Departamento de Producción Vegetal de la Universidad Politécnica de Cartagena (UPCT) y que presenta para la obtención del grado de Doctor por la Universidad Politécnica de Cartagena.

En Cartagena, a 26 de Mayo de 2011

LOS DIRECTORES DE TESIS

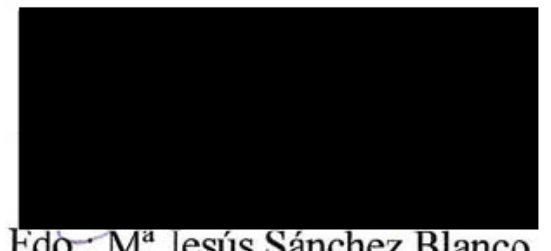

Fdo.: $M^{\mathrm{a}}$ Jesús Sánchez Blanco

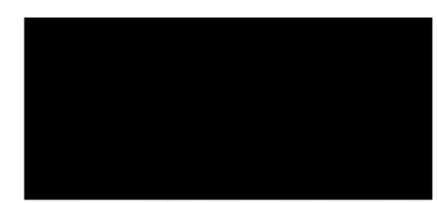

Sebastián del Pilar Bañón Arias 



\section{RECONOCIMIENTOS}

Este trabajo se encuadra dentro de las actividades del Departamento de Riego del CEBAS (CSIC) en los proyectos de investigación del CICYT 'Caracterización de las relaciones hídricas de plantas con fines ornamentales y paisajísticos' (AGL-2005-05588CO2-01-02/AGR), 'Manejo eficiente del agua en especies con fines ornamentales y paisajísticos por medio de distintas técnicas viverísticas (AGL-2005-05588-C02-01/AGR), en el proyecto de la de la Consejería de Agricultura y Agua de la Región de Murcia 'Desarrollo tecnológico en plantas ornamentales en maceta (CEBAS-UPCT), y en el proyecto de la Fundación Séneca de la Región de Murcia 'Estimación del consumo de agua de plantas ornamentales y su aplicación en riego de jardinería' (05660/PI/07).

Los resultados de la presente tesis doctoral han sido publicados en:

\section{Revistas científicas:}

- Sánchez-Blanco, M.J., Álvarez, S., Navarro, A., Bañón, S. 2009. Changes in leaf water relations, gas exchange, growth and flowering quality in potted geranium plants irrigated with different water regimes. Journal of Plant Physiology, 166: 467-476.

- Álvarez, S., Navarro, A., Bañón, S., Sánchez-Blanco, M.J. 2009. Regulated deficit irrigation in potted dianthus plants: effects of severe and moderate water stress on growth and physiological responses. Scientia Horticulturae, 122: 579-585.

- Álvarez, S, Ortuño, M.F., Rodríguez, P., Bañón, S., Sánchez-Blanco, M.J. 2009. Aspectos fisiológicos y ornamentales de plantas de geranio en condiciones de consumo hídrico limitado durante la fase de floración. Plantfor. 131: 70-73.

- Álvarez, S., Navarro, A., Nicolás, E., Sánchez-Blanco, M.J. 2011. Transpiration, photosynthetic responses, tissue water relations and dry mass partitioning in Callistemon plants during drought conditions. Scientia Horticulturae, 129: 306-312. 


\section{Congresos:}

- Sánchez-Blanco, M.J., Navarro, A., Álvarez, S., Bañón, S. 2007. Evaluación del riego deficitario controlado, en la respuesta de plantas de clavel en maceta. X Congreso Hispano-Luso de Fisiología Vegetal. (Alcalá de Henares). Libro de resúmenes, pp. 183.

- Álvarez, S., Navarro, A., Rodríguez, P., Bañón, S., Sánchez-Blanco, M.J. 2008. Transpiración, eficiencia fotosintética y distribución de biomasa en plantas de callistemon bien regadas y en condiciones de estrés hídrico. IX Simposium Hispano Portugués de Relaciones Hídricas en las Plantas. (Lloret de Mar). Libro de conferencias y comunicaciones, p 183-186.

- Álvarez, S., Ortuño, M.F., Rodríguez, P., Sánchez-Blanco, M.J. 2009. Aspectos fisiológicos y ornamentales de plantas de geranio en condiciones de consumo hídrico limitado durante la fase de floración. VI Congreso Ibérico de Ciencias Hortícolas. Pontevedra. Actas de Horticultura 52:324-329.

- Álvarez, S, Navarro, A., Sánchez-Blanco, M.J. 2008. Crecimiento, floración y estado hídrico de plantas de geranio regadas en condiciones deficitarias en distintos momentos fenológicos VI Congreso Ibérico, XII Nacional de Ciencias Hortícolas. Logroño, del 25 al 29 de mayo de 2009. Actas de Horticultura 54: 768-773.

- Álvarez, S., Bañón, S., Sánchez-Blanco, M.J. Junio 2011. Aspectos beneficiosos del riego deficitario en plantas cultivadas en maceta: relaciones hídricas y calidad ornamental. XII Congreso Hispano-Luso de Fisiología Vegetal. (Castellón) (Conferencia invitada).

- Álvarez, S., Acosta, J.R., Bañón, S., Sánchez-Blanco, M.J. Efecto del riego deficitario moderado y severo en la calidad y eficiencia en el uso del agua de plantas de callistemon en condiciones de vivero. $\mathrm{V}$ Jornadas Ibéricas de Horticultura Ornamental, 13 a 15 de Octubre de 2011. (Faro, Portugal). 
Resumen y Abstract 



\section{Resumen}

Los experimentos desarrollados en esta tesis doctoral abordan el efecto de diferentes estrategias de riego deficitario en tres especies ornamentales muy utilizadas en jardinería: clavel, geranio y callistemon. Se emplearon plántulas de 1 y 2 savias de edad en maceta, y los ensayos fueron realizados en condiciones controladas (cámara de crecimiento) y en condiciones de vivero (invernadero). La aplicación de estrategias de riego deficitario (riego deficitario moderado sostenido y riego deficitario fuera de la fase de máxima floración) en clavel no afectó a la floración y redujo el crecimiento excesivo de las plantas, proporcionándoles un porte más compacto, de mayor valor ornamental. Las plantas regadas deficitariamente respondieron disminuyendo la conductancia estomática y el área de las hojas. El descenso de los niveles de agua en las hojas vino acompañado por ajuste osmótico y cambios en la elasticidad de la pared celular, que previenen la pérdida de turgencia y daños visuales ante períodos de déficit hídrico. El geranio respondió al déficit hídrico reduciendo la fotosíntesis y la acumulación de biomasa, parámetros reversibles cuando se restableció el riego, aunque el tiempo necesario para la recuperación dependió del parámetro y del nivel de estrés. La respuesta de las plantas no solo estuvo influenciada por la cantidad de agua aportada a la planta, sino también por la fase en la que se aplicó la reducción del riego. El proceso de floración se modificó en función del momento en el que se produjo el estrés, resultando la fase de floración la más sensible al déficit hídrico. El riego deficitario en callistemon produjo una reducción de los valores de conductancia estomática desde las primeras semanas de aplicación de los tratamientos y un aumento progresivo de la eficiencia intrínseca en el uso del agua $\left(P_{n} / g_{s}\right)$. El consumo diario de agua en esta especie, además de estar estrechamente relacionado con las variables climáticas, depende de las fases de crecimiento activo y el período de formación de las inflorescencias. Los ensayos desarrollados en esta tesis permitieron conocer la respuesta, efectos y mecanismos de tolerancia de las plantas de estas especies al déficit hídrico y así poder aplicar estrategias de riego adecuadas para reducir consumo y mantener o incluso mejorar la calidad de la planta ornamental. Las plantas de estas especies pueden enfrentarse a situaciones moderadamente limitantes de agua, sin perder su valor ornamental, pero el grado de estrés impuesto por dicho riego es crítico para la respuesta de cada especie. 


\section{Abstract}

The experiments developed in this doctoral thesis look at the effect of different deficit irrigation techniques on three ornamental species widely used in gardening (carnation, geranium and callistemon). 1 and 2-year-old seedlings were grown in pots, and experiments were conducted in controlled conditions (growth chamber) and in nursery conditions (greenhouse). The application of deficit irrigation strategies (moderate deficit irrigation and deficit irrigation outside the maximum flowering phase) in carnation did not affect flowering and reduced excessive plant growth, resulting in a more compact bearing and plants of greater gardening and ornamental value. Plants exposed to deficit irrigation responded by reducing stomatal conductance and leaf area. A decrease in the water content of leaves was accompanied by osmotic adjustment and changes in cell wall elasticity, which prevented loss of turgor and visual damage during water deficit periods. Geranium responded to water deficit by reducing photosynthesis and biomass accumulation, both of which were reversed when irrigation was restored, although the time necessary for full recovery depended on the parameter and on the stress level. Plant response was not only influenced by the quantity of water supplied to the plant, but also by the moment when the reduction was applied. The extent to which flowering was modified depended on the moment when stress was produced, the flowering phase being the most sensitive to water deficit. Deficit irrigation in callistemon produced a reduction of stomatal conductance values from the first weeks following the application of stress and a gradual increase in intrinsic water use efficiency $\left(\mathrm{P}_{\mathrm{n}} / \mathrm{g}_{\mathrm{s}}\right)$. Daily water consumption in this species, beside being closely related with climatic variables, depends on the active growth phase and the period of inflorescences formation. Experiments developed in this thesis revealed the response, effects and tolerance mechanisms of these species to water deficit and will enable growers to apply suitable irrigation strategies to reduce consumption and to maintain or even to improve ornamental plant quality. Plants of these species are able to withstand periods of moderate water stress, without losing their ornamental value, but the degree of the water stress imposed is critical for the response of each species. 
Índice 



\section{ÍNDICE}

Pág.

1. Objetivos

2. Antecedentes 5

$\begin{array}{ll}2.1 \text { Situación del sector ornamental } & 7\end{array}$

2.2 Estrategias de riego deficitario para ahorrar agua y mejorar la calidad de la planta en especies ornamentales 10

$\begin{array}{ll}2.3 \text { Especies estudiadas } & 14\end{array}$

2.3.1 Dianthus caryophyllus 14

2.3.2 Pelargonium x hortorum 15

2.3.3 Callistemon citrinus 17

3. Respuesta de plantas de clavel a distintos niveles de riego. Aplicación de riego deficitario a lo largo del cultivo y en $\begin{array}{ll}\text { distintos momentos fenológicos } & 19\end{array}$

3.1 Introducción

3.2 Efecto del riego defitario moderado y severo en el comportamiento agronómico y fisiológico en plantas de clavel 22

3.2.1 Material y métodos

3.2.1.1 Material vegetal y condiciones experimentales 22

3.2.1.2 Tratamientos y diseño experimental 24

3.2.1.3 Crecimiento y parámetros ornamentales $\quad 25$

3.2.1.4 Potencial hídrico foliar y sus componentes, intercambio gaseoso y curvas presión-volumen 27

3.2.1.5 Análisis estadístico 31

3.2.2 Resultados y discusión 31

3.2.2.1 Efectos del riego deficitario moderado y severo en el crecimiento y parámetros ornamentales en plantas de clavel

3.2.2.2 Efectos del riego deficitario y severo en las relaciones hídricas (curvas $\mathrm{P}-\mathrm{V}$ ) e intercambio gaseoso en plantas de clavel

3.3 Efecto del riego deficitario aplicado en las fases de inicio de la floración y posfloración (fuera de la máxima floración) en plantas de clavel 
3.3.1.1 Material vegetal y condiciones experimentales 39

3.3.1.2 Tratamientos y diseño experimental $\quad 40$

3.3.1.3 Crecimiento y parámetros ornamentales

3.3.1.4 Humedad del sustrato, potencial hídrico foliar y sus componentes e intercambio gaseoso

3.3.1.5 Análisis estadístico 43

3.3.2 Resultados y discusión

3.3.2.1 Efectos del riego deficitario controlado en el crecimiento y parámetros ornamentales en plantas de clavel

3.3.2.2 Efectos del riego deficitario controlado en el estado hídrico, regulación estomática y ajuste osmótico en plantas de clavel

4. Respuesta de plantas de geranio regadas con distintos niveles de déficit y durante un periodo de recuperación. Aplicación de riego deficitario en distintos momentos fenológicos en condiciones controladas

4.1 Introducción

4.2 Efecto de distintos distintos niveles de déficit hídrico y grado de de recuperación en plantas de geranio

4.2.1 Material y métodos

4.2.1.1 Material vegetal y condiciones experimentales 58

4.2.1.2 Tratamientos y diseño experimental 59

4.2.1.3 Crecimiento y parámetros ornamentales

4.2.1.4 Consumo, relaciones hídricas, intercambio gaseoso y fluorescencia

4.2.1.5 Análisis estadístico 65

4.2.2 Resultados y discusión

4.2.2.1 Efectos del riego deficitario en el crecimiento y parámetros ornamentales en plantas de geranio durante la fase de déficit hídrico y de recuperación 65

4.2.2.2 Efectos del riego deficitario en el consumo de agua en plantas de geranio durante la fase de déficit hídrico y de recuperación

4.2.2.3 Efectos del riego deficitario en las relaciones hídricas en plantas de geranio durante la fase de déficit hídrico y de recuperación

4.2.2.4 Efectos del riego deficitario en el intercambio gaseoso y fluorescencia en plantas de geranio durante la fase de déficit hídrico y de recuperación 80 
4.3 Efecto del riego deficitaio en las distintas fases de crecimiento vegetativo y floración en plantas de geranio $\quad 86$

4.3.1 Material y métodos

4.3.1.1 Material vegetal y condiciones experimentales 86

4.3.1.2 Tratamientos y diseño experimental

4.3.1.3 Crecimiento y parámetros ornamentales

4.3.1.4 Consumo de agua y relaciones hídricas

5.3.1.5 Análisis estadístico

4.3.2 Resultados y discusión

4.3.2.1 Efectos del riego deficitario en distintos momentos fenológicos en el crecimiento y parámetros ornamentales en plantas de geranio 95

4.3.2.2 Efectos del riego deficitario en distintos momentos fenológicos en el consumo de agua en plantas de geranio

4.3.2.3 Efectos del riego deficitario en distintos momentos fenológicos en las relaciones hídricas en plantas de geranio

\section{Respuesta de plantas de callistemon al riego deficitario en distintas condiciones medioambientales}

5.1 Introducción

5.2 Efecto de distintos niveles de riego en aspectos fisiológicos en plantas de callistemon en condiciones controladas

5.2.1 Material y métodos

5.2.1.1 Material vegetal y condiciones experimentales 127

5.2.1.2 Tratamientos y diseño experimental

5.2.1.3 Cuantificación de la biomasa de la planta y medida de la pérdida de electrolitos

5.2.1.4 Nivel de transpiración, conductancia estomática y respuesta fotosintética

5.2.1.5 Curvas $A-C_{i}$ y limitaciones de la tasa de fotosíntesis máxima

5.2.1.6 Relaciones hídricas

5.2.1.7 Análisis estadístico

5.2.2 Resultados y discusión

5.2.2.1 Efectos del riego deficitario en la acumulación de biomasa y pérdida de electrólitos en plantas de callistemon en condiciones controladas 
5.2.2.2 Efectos del riego deficitario en la transpiración, conductancia estomática y respuesta fotosintética en plantas de callistemon en condiciones controladas

5.2.2.4 Efectos del riego deficitario en las relaciones hídricas en plantas de callistemon en condiciones controladas

5.3 Efecto del riego deficitario moderado y severo en plantas de callistemon en condiciones de vivero

5.3.1 Material y métodos

5.3.1.1 Material vegetal y condiciones experimentales 165

5.3.1.2 Tratamientos y diseño experimental 168

5.3.1.3 Crecimiento y parámetros ornamentales $\quad 169$

5.3.1.4 Riego, humedad volumétrica y consumo 172

5.3.1.5 Potencial hídrico e intercambio gaseoso $\quad 173$

5.3.1.6 Análisis estadístico 174

5.3.2 Resultados y discusión $\quad 175$

5.3.2.1 Efectos del riego deficitario moderado y severo en el crecimiento y parámetros ornamentales en plantas de callistemon en invernadero

5.3.2.2 Efectos del riego deficitario moderado y severo en la humedad del sustrato y consumo en plantas de callistemon en invernadero

5.3.2.3 Efectos del riego deficitario moderado y severo en las relaciones hídricas en plantas de callistemon en invernadero

6. Conclusiones

7. Bibliografía

8. Índice de tablas, figuras y fotografías

9. Abreviaturas y símbolos 
Capítulo 1

Objetivos 

El sector de la planta ornamental ha experimentado un crecimiento muy rápido en las últimas décadas coincidiendo con el desarrollo de la jardinería y el paisajismo. En los viveros se produce planta ornamental, cuyo destino principal es el embellecimiento de espacios públicos o privados, ya sean interiores o exteriores. El valor económico final de la planta ornamental se fija en función de su calidad y presentación final, esto explica la necesidad de un ajuste riguroso en la nutrición, riegos, plagas, calendarios de comercialización, manejo del clima, etc.

El cultivo del clavel como planta en maceta es reciente y es una de las principales alternativas al cultivado para flor de corte. Su característica principal es la presencia de un gran número de pequeñas flores al final de los tallos florales, que son rodeados por un follaje denso de color verde claro, lo que le imprime un valor estético importante. El geranio es una planta ornamental, que se puede encontrar en todo el mundo adornando jardines, fachadas y balcones. Se usa como planta en maceta o planta para ser trasplantada y presenta una floración muy prolongada y vistosa, de ahí su uso extendido en los proyectos de jardinería. La planta de callistemon es muy apreciada en jardinería por su espectacular floración y es una de las especies ornamentales australianas más importante, que se usa en condiciones mediterráneas por su adaptación a los estreses ambientales.

El manejo del riego en plantas en maceta es más difícil que en suelo debido al limitado volumen de sustrato disponible para las raíces y a que las plantas están expuestas a fluctuaciones térmicas más rápidas, lo que repercute sensiblemente en las relaciones hídricas sustrato-planta. En estas condiciones, las plantas pueden sufrir mayores niveles de estrés hídrico. No obstante, un déficit hídrico controlado, mediante el riego, puede por un lado economizar el empleo del agua, factor a tener en cuenta en zonas de recursos hídricos limitados y, por otro, controlar el desarrollo de las plantas, manteniendo su valor ornamental.

Los aspectos que se abordan en esta tesis se refieren a la respuesta de las especies anteriormente mencionadas a diferentes niveles de riego, identificando los cambios producidos en distintos parámetros fisiológicos, morfológicos y ornamentales de la planta. También, se evalúa la aplicación de un déficit hídrico sostenido a lo largo de todo el ciclo y en determinadas fases del cultivo de estas especies. Los resultados pueden resultar de importancia para elaborar estrategias 
viverísticas de riego deficitario que permitan variar las cantidades de agua conforme a las exigencias de las sucesivas fases fenológicas. Así podrían ser útiles como una técnica para obtener plantas más compactas y de mayor calidad. 
Capítulo 2

Antecedentes 



\subsection{Situación del sector ornamental}

En la actividad agrícola, conforme un país avanza mayores cotas de desarrollo, la producción de planta ornamental tiende a aumentar. El sector de la jardinería y la producción de plantas ornamentales están cobrando cada vez mayor importancia debido a determinados factores como el aumento del nivel de vida o la mayor presencia de la vegetación y las zonas verdes en el urbanismo actual.

La producción de flores y plantas ornamentales comenzó a tener cierto peso específico a partir de las décadas de los setenta y ochenta, debido al desarrollo económico de muchos países que demandaban este producto y por la entrada en el mercado de nuevos países exportadores.

La aportación del sector ornamental a la producción final agraria (PFA) nacional ha aumentado en los últimos años. Ello ha dado lugar a que actualmente el valor de la producción de flor y planta ornamental representa cerca de un 4\% de la PFA en España (MARM, 2009), con una superficie cultivada que asciende a más de 5500 ha y con un valor de producción en origen de aproximadamente 600 millones de euros.

El sector ornamental puede dividirse en dos subsectores: el subsector de la flor cortada (rosa y clavel principalmente) y el subsector de la planta ornamental, que incluye la planta viva vendida en maceta. La superficie ocupada por especies de flor cortada (rosa, clavel y otras flores) ha descendido de forma gradual en los últimos años (Figura 2.1) como consecuencia de la competencia de terceros países. Este descenso progresivo en los últimos años y las previsiones apuntan a una continuidad de dicha tendencia. Sin embargo, el subsector de la planta ornamental atraviesa una situación bien diferente y ha experimentado un crecimiento muy rápido en las últimas décadas coincidiendo con el gran desarrollo de la jardinería y el paisajismo (Figura 2.1). En las especies para este fin, el valor económico se fija en función de la calidad y presentación final de la planta (Fernández-Zamudio y col., 2010). Esto explica la necesidad de un ajuste riguroso en la nutrición, riegos, plagas, calendarios de comercialización, manejo del clima, etc., más fácil de controlar en vivero. Es en los viveros donde se produce planta ornamental, cuyo destino principal es el embellecimiento de espacios públicos o privados, ya sean interiores o exteriores. 


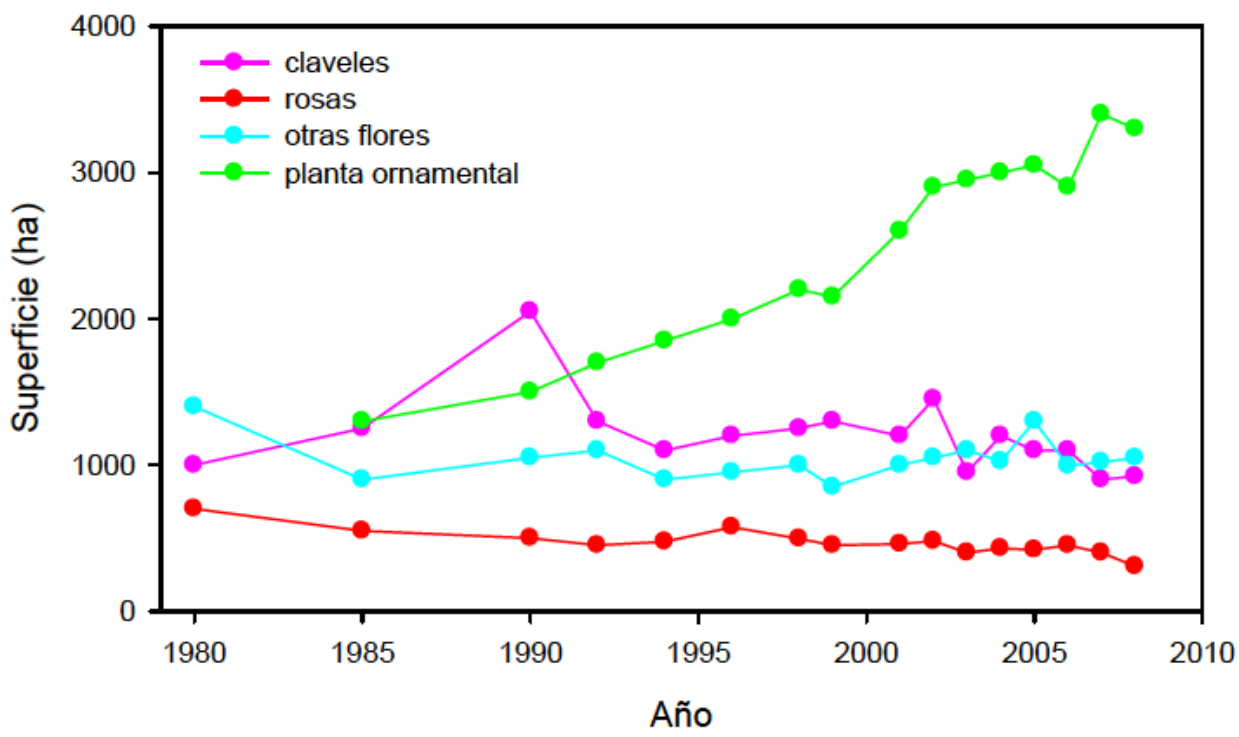

Figura 2.1- Evolución de la superficie española de ornamentales. Fuente: Anuarios del MARM.

En España, la presencia del sector de la flor cortada y de las plantas ornamentales está claramente repartido geográficamente: el mayor peso del subsector de flor cortada está en Andalucía (63\% de la producción), Galicia (14\%) y Región de Murcia (8\%), mientras que el cultivo de planta ornamentales se concentra en la Comunidad Valenciana (31.7\%), Andalucía (31.3\%), Cataluña (24.8\%), Canarias (3.5\%) y Región de Murcia (2.8\%), fuente Anuario de Estadística 2009 del Ministerio de Medio Ambiente y Medio Rural y Marino, (Figura 2.2).

En Murcia, actualmente se encuentran en ascenso las plantas de maceta y jardín: ficus, palmeras, poinsetia, hortensia, cipreses, adelfa, hibiscos, buganvilla, entre otros (Ochoa y col., 2008). La mejor eficiencia en el uso del agua que poseen estos cultivos frente a otros intensivos como los hortícolas es un factor a tener en cuenta en una región con un importante déficit hídrico. Este sector tiene una destacable importancia socioeconómica, ya que la productividad de las especies ornamentales tanto por hectárea como por metro cúbico de agua utilizada es muy superior a la mayoría de los cultivos hortícolas. Ello puede representar una clara alternativa a los mismo, sobre todo, en regiones con déficit hídrico, como es el caso de la Región de Murcia (Arcas y Romero, 2000). En este sentido, en Murcia, en los últimos años se observa un descenso de la superficie y producción de flor cortada, y un aumento de la producción en plantas ornamentales, cultivos para su uso como planta en 
maceta (MARM, 2009). El clavel ha sido la especie predominante desde el inicio del desarrollo del sector de la flor cortada en Murcia. La adaptación al cultivo en maceta de especies empleadas en la producción de flor cortada se planteó en su día como una herramienta interesante para paliar la problemática anteriormente comentada, especialmente en el monocultivo del clavel (planta muy conocida a nivel del agricultor y del consumidor).

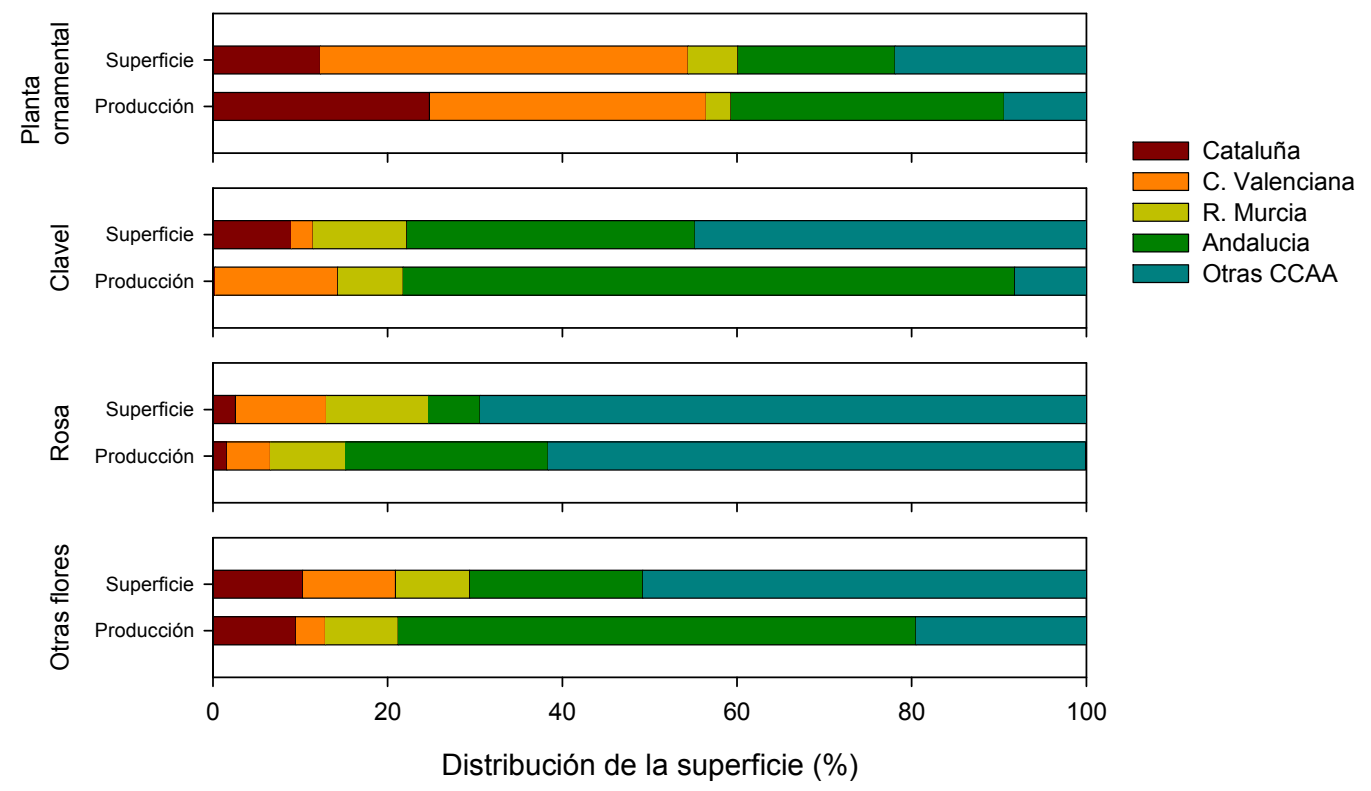

Figura 2.2- Distribución de la producción y la superficie de especies ornamentales en España. Año 2008. Fuente: Anuario Estadística 2009, MARM.

Como ya se ha mencionado anteriormente, los cultivos ornamentales no tienen una gran extensión en la agricultura española, pero sí tienen una importancia económica y social incuestionable, teniendo en cuenta, además, que no cuentan con excesivas ayudas ni medidas de protección a nivel nacional ni europeo (Fernández-Zamudio y col., 2010).

Entre los factores más importantes para el desarrollo del sector ornamental se pueden destacar las excelentes condiciones climáticas en las zonas costeras de la geografía española, con altas intensidades de luz diurnas y temperaturas nocturnas suaves en el periodo invernal, si las comparamos con otras zonas centroeuropeas tradicionalmente productoras. 


\subsection{Estrategias de riego deficitario para ahorra agua y mejorar calidad de la planta en especies ornamentales}

El agua, principal componente de las plantas, es un elemento imprescindible para su crecimiento y desarrollo y es el factor más limitante para el cultivo de las plantas.

Del agua absorbida por las plantas una pequeña parte es retenida y utilizada en los procesos de crecimiento y en la realización de la fotosíntesis, el resto se pierde por transpiración. La cantidad de agua retenida por las plantas es casi insignificante frente a la transpirada, por lo que se puede considerar que el consumo de agua es equivalente a la transpiración. Además, desde el suelo se produce una evaporación a la atmósfera de agua de las capas más superficiales. Por tanto, se considera que las necesidades de agua de las plantas están representadas por la suma de la evaporación directa desde el suelo y de la transpiración de las plantas, en lo que se denomina evapotranspiración (ET). El valor de ET depende del clima y del tipo de planta, así la evapotranspiración es el producto de un valor que representa el clima, evapotranspiración de referencia $\left(\mathrm{ET}_{0}\right)$, por un valor que representa a la planta, el coeficiente de cultivo $\left(\mathrm{K}_{\mathrm{c}}\right)$. En general, la evapotranspiración se expresa en $\mathrm{ml}$ de agua evapotranspirada cada día.

Hay estudios realizados en plantas con fines ornamentales en los que los tratamientos de riego se basaron en aplicar porcentajes de la evapotranspiración y así conocer los efectos fisiológicos, morfológicos o agronómicos en esas especies (Henson y col., 2006; De Lucía, 2009). Hay que tener en cuenta que además de la especie, estos efectos dependerán de la reducción del riego y duración del ensayo. Con estos ensayos se demuestra que la aplicación de dosis inferiores a las consideradas óptimas (riego deficitario) puede ser utilizada para el riego en plantas ornamentales.

El cultivo de planta ornamental en maceta es una alternativa de interés dentro de la horticultura ornamental en el sureste de la península ibérica (González y col., 2002). Sin embargo, la producción de planta en contenedor requiere una atención más cuidada que la producción en campo. Las raíces de las plantas en maceta están expuestas a fluctuaciones térmicas más rápidas y grandes que las cultivadas en suelo, lo que repercute sensiblemente en las relaciones hídricas sustrato-planta. 
También hay que tener en cuenta que las plantas crecidas en macetas pueden sufrir condiciones de estrés hídrico más frecuentes que las que crecen en el suelo, debido al limitado volumen de sustrato disponible para las raíces (Lenzi y col., 1999; Lombarda y col., 2003).

El manejo del riego, mediante una reducción del mismo, puede por un lado, economizar el empleo del agua, factor a tener en cuenta en zonas de recursos hídricos limitados y, por otro, controlar el desarrollo de las plantas, manteniendo el valor ornamental de dichas plantas (Sach y col., 1992).

Sin embargo, una de las consecuencias de exponer la planta a regímenes de sequía prolongados o severos en términos de crecimiento de planta es la producción de hojas más pequeñas, entrenudos más cortos y reducciones del número de flores (Sánchez-Blanco y col., 2002; Cameron y col., 1999). También, se han descrito respuestas fisiológicas a la sequía tales como: cierre estomático, disminución de la tasa fotosintética, cambios en la elasticidad celular, ajuste osmótico (Davies y col., 2002; Sánchez-Blanco y col., 2004).

El interés del riego deficitario controlado (RDC) se ha centrado en el ahorro de agua y/o en controlar el crecimiento vegetativo excesivo en frutales y cultivos de frutos secos. Ello se ha realizado mediante la aplicación de riego deficitario en determinados momentos no críticos para la producción y calidad de la cosecha (Goldhamer y Beede, 2004; RuizSánchez y col., 2010). Sin embargo, su aplicación a cultivos ornamentales hasta ahora ha recibido una atención limitada (Cameron y col., 2006). El riego deficitario controlado en plantas ornamentales implica la restricción del riego para aplicar un estrés hídrico controlado que sea suficiente para reducir el crecimiento vegetativo, pero sin llegar a reducir la calidad de planta.

En el cultivo de planta en maceta hay una tendencia de los brotes primarios a alargarse en exceso, de modo que las flores quedan demasiado separadas de la roseta, lo que baja el valor comercial de planta. Las plantas demasiado altas generalmente son consideradas de baja calidad debido al aumento de los costes de transporte y el aumento de la vulnerabilidad frente al trasplante. En los últimos años se han estudiado varias estrategias para controlar el crecimiento potencial de las plantas: alterar la calidad de la luz (Cerny y col., 2003), imponer un régimen de luz y temperatura específica (Myster y Moe, 1995), alteración 
en el cultivo para producir tignomorfogénesis (Moontgomery y col., 2004), y especialmente, la aplicación de reguladores de crecimiento para el control del desarrollo y crecimiento excesivo de plantas de clavel en maceta (Bañón y col., 2002) y en geranio (Bañón y col., 2009). Sin embargo, estas estrategias requieren sofisticadas condiciones, las cuales son demasiado caras para ser aplicadas en la producción de la mayoría de las plantas ornamentales (Cameron y col., 2006). Por el contrario, el manejo del riego y, en particular, el riego deficitario puede resultar una técnica más efectiva y menos costosa para estos cultivos.

El control del riego y la modificación de los patrones de crecimiento de los cultivos son de importancia extrema en el manejo del vivero para producir plantas de alta calidad. También, puede inducir mayor resistencia de las plantas a la manipulación y transporte (Lang y Trellinger, 2001), mayor capacidad de sobrevivir y crecer mejor tras el trasplante en diferentes condiciones ambientales (Leskovar y Stoffella, 1995; Franco y col., 2008; Navarro y col., 2011). En este sentido, un cierto nivel de déficit hídrico además de producir plantas más compactas, las hace, también, más resistentes al estrés. Sin embargo, si la restricción de agua es demasiado severa, las plantas pueden morir o son sobreendurecidas, retrasando el crecimiento de nuevos brotes o raíces (Liptay y col., 1998).

Se deduce, por tanto, de todo lo expuesto, que la supervisión en los viveros de los niveles de humedad y el conocimiento de la respuesta morfológica y fisiológica de los brotes y las raíces de las plantas a la gestión del agua son críticas para optimizar la producción de plantones de alta calidad (Franco y col., 2006). En este sentido, una determinación gravimétrica del consumo de agua aporta datos sobre la cantidad exacta de agua de riego para ser aplicada y proporciona información en función de las condiciones climáticas y de la planta (Andersson, 2001).

En el contexto de la agricultura sostenible, es interesante para los viveristas el uso de plantas que necesiten menos agua para crecer y también para los consumidores, quienes no siempre son conscientes de la cantidad de agua que sus plantas necesitan y, con frecuencia, piden plantas que toleren largos períodos de sequía (Anónimo, 2001). En este contexto, seleccionar plantas tolerantes a la sequía es de gran interés, aunque es sabido que la respuesta de las plantas al déficit hídrico 
depende de la especie y del genotipo, además de la duración y de la severidad/ intensidad del estrés.

El riego deficitario controlado (RDC), como hemos comentado, implica reducciones en las dosis de agua, para aplicar un estrés controlado, suficiente para reducir el crecimiento vegetativo sin reducir el valor ornamental y económico del cultivo. Los trabajos sobre RDC en plantas ornamentales son escasos. Existen algunos trabajos en los que se modifica la cantidad de agua aplicada durante todo el ciclo de la planta: Sánchez-Blanco y col. (2002) en Cistus, Lenzi y col. (2009) en adelfa, Chylińsky y col. (2007) en geranio. Algunos autores (Cameron y col., 2008) hablan sobre RDC, pero realmente el cambio de fase no se realiza con ningún criterio basado en el estado de la planta. Por el contrario, Sharp y col. (2009) realizaron un trabajo con Rhododendron en el que estudian los efectos del riego deficitario impuesto en la fase de iniciación floral. Silber y col. (2007) hacen un estudio en una planta ornamental destinada a flor de corte, en el que aplica el riego deficitario en varios momentos fenológicos, fase de crecimiento vegetativa o fase de desarrollo de las flores.

Otra estrategia de riego es el riego parcial de raíces (PRD), la cual puede controlar el crecimiento e incrementar la eficiencia en el uso del agua por influir en la regulación de la conductancia. La ventaja de esta técnica es que la planta no esta expuesta a déficit hídrico sustanciales, así que existe poco riesgo de daño. Hay evidencias que la parte de las raíces expuesta a sequía generan señales químicas (probablemente $A B A$ ) para regular la apertura estomática (Stoll y col., 2000). La otra parte del sistema radical esta suficientemente hidratada para evitar daños, pero existen pocos estudios realizados en especies ornamentales (Cameron y col., 2008; Sharp y col., 2009). 


\subsection{Especies estudiadas}

\subsubsection{Dianthus caryophyllus}

El clavel (Dianthus caryophyllus L.) pertenece a la familia Cariophyllaceae, que es originaria de la cuenca mediterránea y al género Dianthus (Fotografía 2.1). Es una planta perenne de base leñosa con tallos de hasta $80 \mathrm{~cm}$ de altura, glabros y de día largo, hojas: lineares de 0.8-1.5 cm de longitud, planas y blandas, acuminadas y glaucas, con la base envainadora, flores: en grupos de 1-5, muy olorosas, epicáliz con 46 brácteas anchas, abruptamente acuminadas, mucho más cortas que el cáliz. Cáliz de $2.5-3 \mathrm{~cm}$ de longitud, con dientes triangulares y pétalos dentados de forma irregular, no barbados, de 1-1.5 cm de longitud, de color rosado-púrpura en las especies silvestres. Esta especie es probablemente la progenitora de todos los claveles actuales, a partir de la que se han obtenido muchísimos híbridos y cultivares provistos de grandes corolas de diferentes colores y tonalidades, utilizados para flor cortada o como planta en maceta.
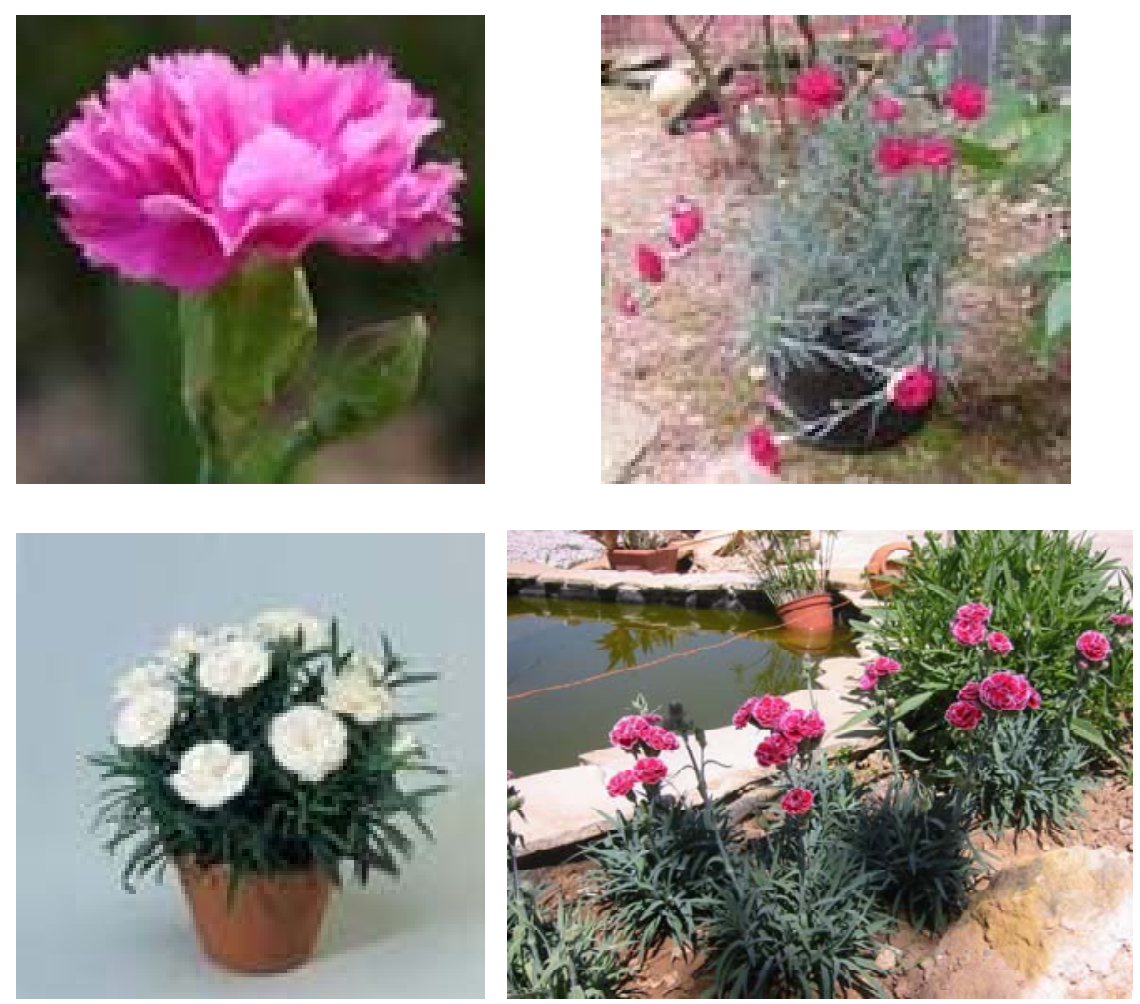

Fotografía 2.1- Plantas de Dianthus caryophyllus.

Los claveles se han cultivado como flor de corte en muchas áreas de nuestro país desde hace mucho tiempo, aunque su cultivo como planta en maceta es más reciente (Bañón y col., 2002). El clavel miniatura, clavel 
enano o miniclavel para su cultivo en maceta, es una de las principales alternativas al cultivo de clavel para flor de corte. Este tipo de clavel para su cultivo en maceta tiene un amplio éxito comercial en EE.UU., Japón y Europa. Su característica principal es la presencia de un gran número de pequeñas flores al final de los tallos florales, que son rodeados por un follaje denso de color verde claro.

\subsubsection{Pelargonium x hortorum}

El geranio zonal, (Pelargonium x hortorum) pertenece a la familia Geraniaceae y al género Pelargonium (Fotografía 2.2). El género Pelargonium ssp tiene unas 280 especies y es ampliamente cultivado.

Los geranios (Pelargonium spp.) son plantas ornamentales que se pueden encontrar en todo el mundo adornando jardines, fachadas y balcones y sus ventas alcanzan un valor elevado (Mithila y col., 2001), ventas anuales que alcanzan los 700 millones de dólares en EE.UU.). Su popularidad se debe a su abundante floración con una gran diversidad de colores, a sus diferentes patrones de hojas y a su facilidad de cultivo, adaptándose fácilmente a diferentes condiciones ambientales (Abo El-Nil, 1990). Desde la introducción de los geranios en Europa en el S. XVII, se han producido muchos cultivares comerciales de Pelargonium por selección, mutación o hibridación (Abo El Nil, 1990).

Las especies de Pelargonium de mayor importancia económica en la industria de la planta ornamental son: el geranio zonal o común (Pelargonium $\times$ hortorum), el geranio de pensamiento $(P \times$ peltatum), el geranio de hiedra $(P \times$ domesticum) y los geranios de olor (Abo El-Nil, 1990; Fonteno, 1992). Además, las especies del género Pelargonium que poseen aceites aromáticos se utilizan en la industria alimentaria, en perfumería y cosmética $\mathrm{e}$ incluso como repelentes de insectos (Zimmerman, 1998), fungicidas (Chandravadana y Nidiry, 1994; Lis Balchin y col., 1995) y nematicidas (Chandravadana y col., 1996).

El geranio zonal (Pelargonium $\mathrm{x}$ hortorum) es un cultivo muy popular sobre todo en Europa y en el norte de América. Es uno de los principales cultivos ornamentales a nivel europeo comercializándose anualmente del orden de ochocientos millones de geranios. En España la producción industrial del Pelargonium se inició alrededor de los años 70. En la actualidad se estima una producción anual de 15 millones de plantas en todo el territorio nacional, lo que supone alrededor de 5.000 
millones de pesetas (69.876,71 euros) de volumen de negocio. Un $60 \%$ de la producción geranio corresponde al Pelargonium x hortorum, un 35\% a Pelargonium peltatum, un 5\% a Pelargonium grandiflorum y menos de un $1 \%$ a geranios de olor (Calvo Vergés, 2001). La evolución del mercado en los últimos años se encuentra en un constante crecimiento del $5 \%$ anual.
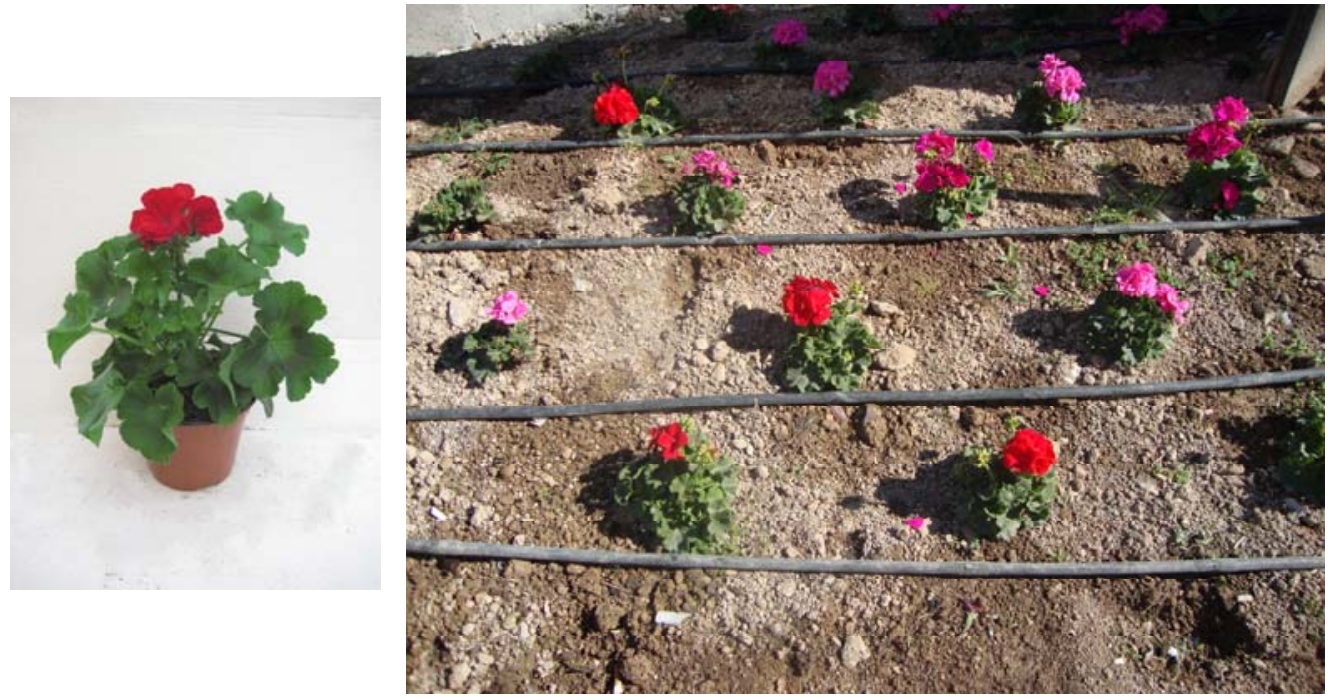

Fotografía 2.2- Plantas de Pelargonium x hortorum.

El geranio zonal ( $P$ x hortorum $\mathrm{L}$. H. Bailey), uno de los grupos más importantes en la horticultura), es un híbrido de $P$. inquinans y $P$. zonale y es usada como planta en maceta o planta para ser trasplantada (Bailey Hortorium Staff, 1976) (Fotografía 2.2).

Pelargonium x hortorum (geranio zonal o común) tienen porte arbustivo y recto y puede alcanzar unos $60 \mathrm{~cm}$ de altura. Presenta una floración muy prolongada; ciertas variedades florecen desde primavera hasta mediados de otoño, e incluso buena parte del invierno si la temperatura no desciende demasiado. Las hojas son redondeadas y suelen presentar una zonación paralela al borde de la hoja. Los geranios tienen una base leñosa pero los nuevos brotes son tiernos. Toda la planta está cubierta por una fina capa pilosa. Los pelos glandulares del tallo, peciolo y hoja producen las características fragancias de terpenos de estas especies.

Las hojas son gruesas con un aspecto aterciopelado. Pueden llegar a tener más de diez centímetros de envergadura, son palmeadas y tienen de tres a cinco lóbulos poco profundos con un borde ondulado. Se unen al tallo mediante un pecíolo largo (Nessmann, 1998). La superficie de la hoja no es lisa, está curvada en la base haciendo que el agua se 
deslice hacia la parte baja de la hoja donde se une con el peciolo. Las tonalidades verdes varían en función de la variedad y suelen tener una 'zona' característica en el centro del haz y paralela al borde de la hoja. A esta característica le debe su nombre el de geranio zonal (Pelargonium $\mathrm{x}$ hortorum). La banda es debida a la presencia de antocianinas y puede ser de color negro, castaño, rojo, bronce o carmín. Las inflorescencias contienen docenas de flores pentámeras y están agrupadas en umbelas densas y compactas situadas al final de un largo pedúnculo floral (Nessmann, 1998).

\subsubsection{Callistemon citrinus}

El callistemon o limpiatubos (Callistemon citrinus) pertenece a la familia Myrtaceae y al género Callistemon (Fotografía 2.3). El género Callistemon comprende arbustos y algunos árboles, siempreverdes con la corteza fisurada, Comprende una treintena de especies nativas de Australia. Las más frecuentes son Callistemon citrinus (Curtis) Skeels, Callistemon rigidus $\mathrm{R}$. Br., Callistemon salignus y algunos de sus cultivares. Su nombre proviene de las palabras griegas kalli = hermoso y stemon $=$ estambre.
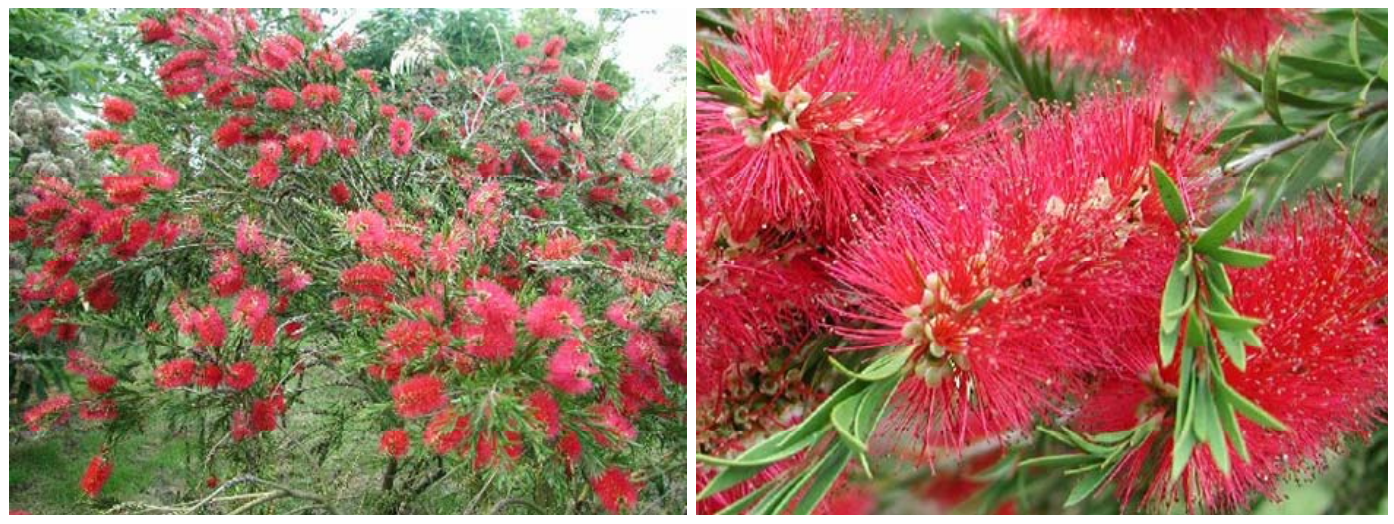

Fotografía 2.3- Plantas de Callistemon citrinus.

Callistemon citrinus es muy apreciado en jardinería por su espectacular floración. Se puede cultivar como un arbusto perennifolio de 2-6 $\mathrm{m}$ de altura, a veces con las ramas arqueadas, con los brotes nuevos lanosos, de rosados a rojizos. Hojas lineales, lanceoladas, alternas y coriáceas de 3.5-15 cm x 3-7 mm de color verde grisáceo, con el eje ligeramente velloso, con glándulas esenciales y olor a limón y el nervio central marcado. Las inflorescencias están formadas por espigas pseudoterminales compuestas de pequeñas flores insertas a lo largo del tallo, a semejanza de un limpiatubos, lo que les da su nombre popular 
Presenta flores con los sépalos algo rosados y los pétalos verdosos o rojizos, con pelos en los bordes; tanto los sépalos como los pétalos son diminutos y caducos. El androceo, que es lo que hace vistosa a la inflorescencia, está formado por numerosos estambres mucho más largos que los pétalos de color rojo brillante a rosados, rara vez blancos. Anteras de color rojo oscuro. Estilo algo más corto que estambres. El eje de la inflorescencia continúa creciendo después de la floración formando un nuevo tallo con hojas. Los frutos son cápsulas leñosas de 3-9 mm de ancho, que persisten a lo largo de los tallos durante varios años conteniendo numerosas semillas muy pequeñas.

Al cultivar Callistemon citrinus 'Splendens' también se la denomina Callistemon laevis. Tiene espigas cilíndricas y densas, con los filamentos más largos y de color rojo carmín. 
Capítulo 3

Respuesta de plantas de clavel a distintos niveles de riego. Aplicación de riego deficitario a lo largo del cultivo y en distintos momentos fenológicos 



\subsection{Introducción}

En los viveros se produce gran variedad de especies y cultivares de planta ornamental que difieren mucho en sus condiciones de cultivo y en sus requerimientos hídricos. El uso del agua en el sector ornamental es un factor cada vez más importante debido a la disponibilidad limitada de los recursos hídricos, y a la presión que existe sobre la industria productora de planta ornamental para producir cultivos de forma más eficiente y reducir el gasto de agua (Sweatt y Davies, 1984). Además, el manejo del riego y la modificación de los patrones de crecimientos son de importancia extrema para promover la calidad ornamental de la planta (Morvant y col., 1998).

En los últimos años se han estudiado varias estrategias de control del crecimiento usando diferentes métodos (Cerny y col., 2003; Montgomery y col., 2004), sobre todo implicando la aplicación de reguladores del crecimiento (Bañón y col., 2002). La restricción en el aporte de agua también ha sido usado como una técnica para evitar el crecimiento vegetativo excesivo en muchas especies (Cameron y col., 2006). Sin embargo, se han identificado diferencias de sensibilidad al déficit hídrico entre especies diferentes y/o cultivares (Zollinger y col., 2006; Clary y col., 2004; Savé y col., 2000) e incluso entre etapas y momentos de crecimiento para muchas plantas (Sionit y col., 1987; Mingeau y col., 2001). En este sentido, se ha valorado la importancia de factores como el grado de estrés hídrico impuesto, y el tiempo y la duración en función de la especie estudiada. Así, un nivel aceptable de riego deficitario puede producir efectos beneficiosos como plantas más compactas y de mayor resistencia a los estreses ambientales (Cameron y col, 2006), pero, si la restricción de agua es demasiado severa los efectos pueden ser negativos, como una disminución importante del valor ornamental, e incluso la muerte de la planta (Franco y col., 2006).

Por todo esto, el aumento de nuestro conocimiento sobre las respuestas morfológicas y fisiológicas de las raíces y parte aérea de las plantas en respuesta al manejo del riego son críticas para optimizar la producción de plantas de calidad. 
Entre la planta ornamental en maceta, el clavel (Dianthus caryophyllus L.) reúne una serie de condiciones que lo hacen una alternativa de interés dentro de la horticultura ornamental en el sureste de la península ibérica (González y col., 2002). El cultivar Trinidad, catalogada por Barberet \& Blanc, es una planta bien ramificada con flores de color violeta y un follaje verde claro más o menos denso, sin embargo estas características y otras muchas pueden variar en función de las técnicas de cultivo utilizadas. El objetivo de este estudio fue analizar la respuesta fisiológica y morfológica de plantas de clavel a diferentes niveles de riego (estrés hídrico moderado y severo) e identificar los cambios producidos en distintos parámetros. También se evaluó si la aplicación de un déficit hídrico en determinadas fases del ciclo de cultivo de esta especie (fase inicio de la floración y senescencia) podría ser útil como una técnica o estrategia viverística para ahorrar agua, controlar el crecimiento y obtener una planta de calidad.

\subsection{Efecto del riego deficitario moderado y severo en el comportamiento agronómico y fisiológico en plantas de clavel}

\subsubsection{Material y métodos}

\subsubsection{Material vegetal y condiciones experimentales}

En esta experiencia se emplearon plantas de clavel enano o miniclavel (Dianthus caryophyllus L.), especie que pertenece a la familia Caryophyllaceae. Se utilizó la variedad Trinidad, con flores violeta con un borde exterior blanco. Las plantas estaban cultivadas en bandejas multialveolares de polietileno negro y dimensiones por alveolo de $50 \times 50 \times 115 \mathrm{~mm}$ y, previo al trasplante, se realizó una selección de las plántulas con el fin de utilizar en el ensayo material vegetal lo más homogéneo posible, eligiéndose para ello plántulas de altura y desarrollo similar (Fotografía 3.1). Se transplantaron en macetas con diámetro de 12 $\mathrm{cm}$ y $10 \mathrm{~cm}$ de altura $(1.1 \mathrm{I})$, que contenían una mezcla de turba negra, perlita y fibra de coco (4:4:1), añadiéndose $2 \mathrm{~g} \mathrm{I}^{-1}$ sustrato de osmocote (abono de lenta liberación, 14:13:13 N, P, K + microelementos). 


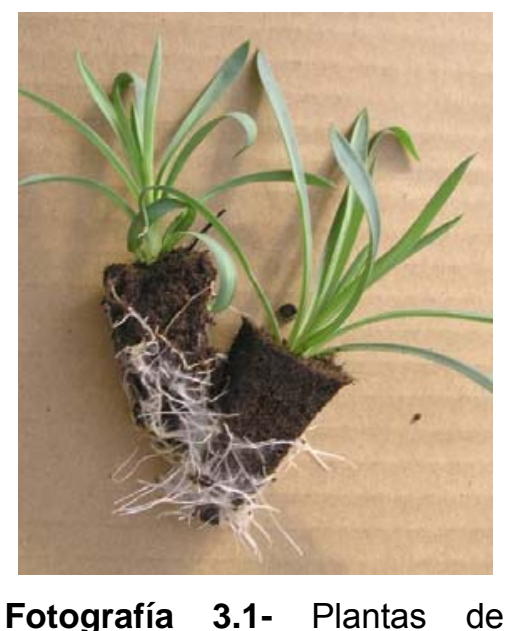

clavel antes de iniciar el ensayo.

Después del trasplante, las macetas fueron trasladadas a un invernadero en la finca experimental del CEBAS, ubicada en Santomera, Murcia (Fotografía 3.2). El invernadero estaba provisto de un sistema de humificación y enfriamiento (cooling system) constituido por tres ventiladores extractores de un caudal de $38000 \mathrm{~m}^{3} / \mathrm{h}$ y un panel humificador de $18.48 \mathrm{~m}^{2}$ de superficie útil. La programación del sistema de enfriamiento garantizaba su funcionamiento cuando la temperatura superaba los $22^{\circ} \mathrm{C}$.

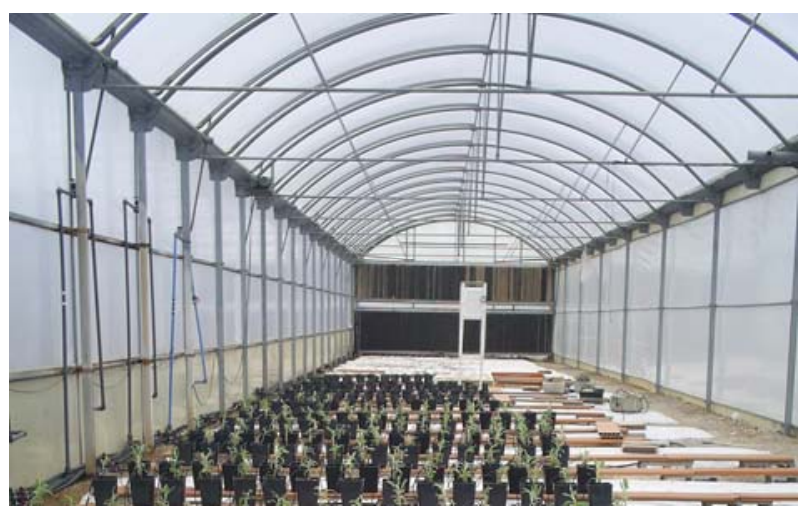

Fotografía 3.2- Vista general del invernadero.

El experimento se llevó a cabo de noviembre de 2005 a marzo de 2006. Las condiciones climáticas en el invernadero durante el cultivo fueron registradas con un medidor de datos HOBO data logger (Fotografía 3.3). Las temperaturas mínimas diarias oscilaron entre $5-12{ }^{\circ} \mathrm{C}$, las máximas variaron entre $18-29^{\circ} \mathrm{C}$, y la humedad relativa osciló entre 25 y $75 \%$. Según Wurr y col. (2000), la temperatura es el factor más importante en el desarrollo de la floración. En clavel la temperatura media diaria necesaria para que se produzca la floración está entre 3.9 y $35.0^{\circ} \mathrm{C}$, siendo $20-30^{\circ} \mathrm{C}$, el rango óptimo para que el desarrollo floral se produzca 
más rápidamente (Blanchard y Runkle, 2011). En este ensayo, los valores de temperatura en el invernadero han estado dentro de este intervalo, aunque hay que tener en cuenta que en la floración además de la temperatura media diaria, influyen otros factores como el fotoperíodo, la radiación, la oscilación de temperaturas entre el día y la noche o las condiciones previas al trasplante (Pramuk y Runkle, 2005) o incluso la frecuencia de riego (Katsoulas y col., 2006).

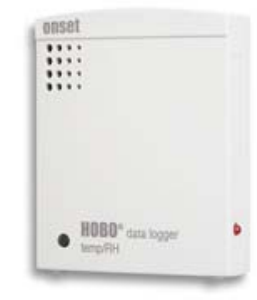

Fotografía 3.3- HOBO U12 que registra datos de temperatura y humedad relativa en el interior del invernadero.

\subsubsection{Tratamientos y diseño experimental}

Las plantas se dividieron en tres grupos de 75 plantas por tratamiento y se regaron de 3 a 5 veces por semana, mediante un sistema automático de riego por goteo programable, disponiendo cada maceta de un emisor autocompensante de $2 \mathrm{I} \mathrm{h}^{-1}$ (Fotografía 3.4).

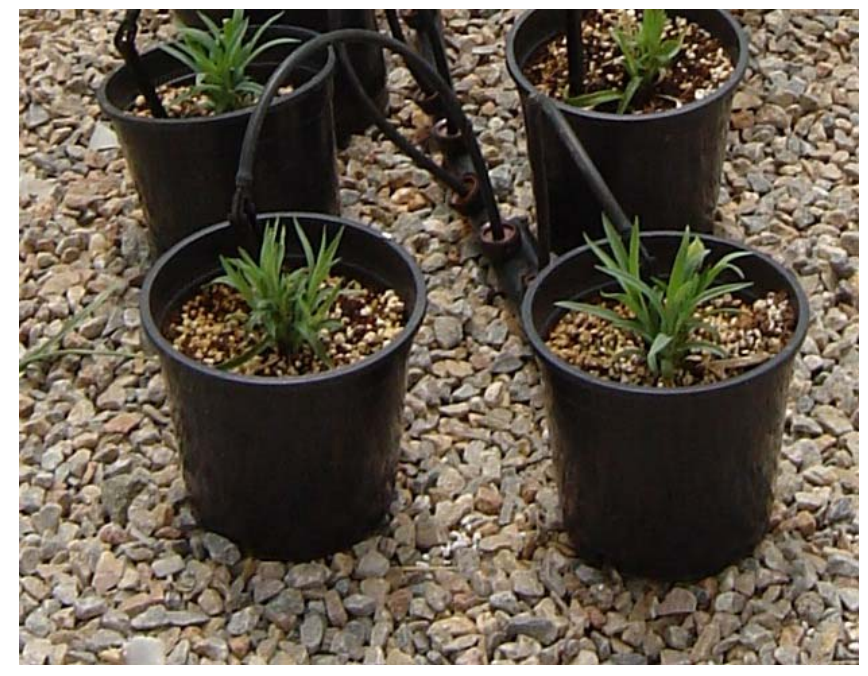

Fotografía 3.4- Plantas de clavel y gotero. 
Los distintos tratamientos de riego se realizaron por medio del manejo del riego, aplicando distintas dosis de agua. Las plantas del tratamiento control (Control) se regaron hasta completar las necesidades hídricas, mientras que las plantas del riego deficitario recibieron el $70 \%$ de la cantidad de agua aportada al control (Riego deficitario moderado, RDM) - $35 \%$ de la cantidad de agua aportada al control (Riego deficitario severo, RDS). Se modificó el riego según la climatología y desarrollo de las plantas, buscando aplicar la cantidad de agua necesaria para obtener alrededor de un $15 \%$ de drenaje del agua aplicada en cada riego, tomando como referencia las plantas control. Los drenajes se determinaron mediante la colocación de bandejas debajo de las macetas. Se colocaron al azar 5 bandejas en el tratamiento control y los drenajes se recogieron periódicamente (Fotografía 3.5).

La cantidad de agua aplicada al control varió entre 140 y $630 \mathrm{ml}$ por planta y semana. La media de agua aportada fue $58 \mathrm{ml} /$ día para el control y 41 y $20 \mathrm{ml} /$ día para RDM y RDS, respectivamente.

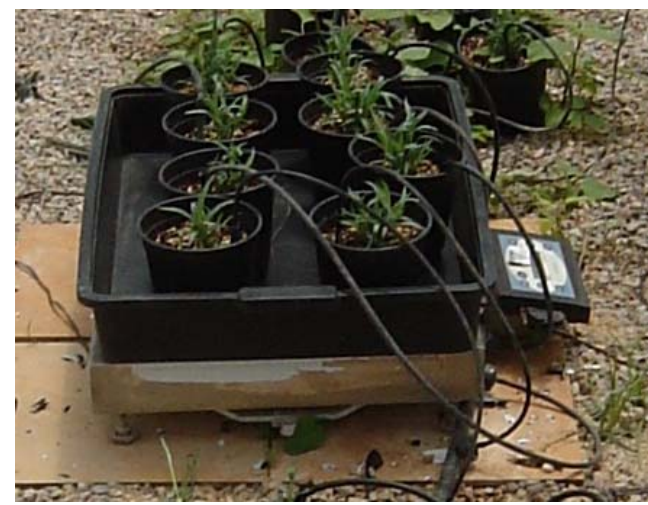

Fotografía 3.5- Bandejas para la recogida del drenaje en plantas de clavel.

\subsubsection{Crecimiento y parámetros ornamentales}

Para la evaluación del crecimiento en biomasa seca de los distintos órganos de la planta ( $\mathrm{g}$ planta ${ }^{-1}$ ), el substrato fue cuidadosamente retirado de las raíces y las plantas se separaron en parte aérea (tallos, hojas y flores) y raíces. Después se secaron en una estufa a $80^{\circ} \mathrm{C}$ hasta peso constante y se midieron los respectivos pesos secos (PS).

La evaluación del crecimiento en biomasa seca de los distintos órganos de las plantas se determinó en 5 plantas por tratamiento, al final del período de estrés (marzo). En estas plantas también se midió la altura y anchura de la planta, altura de la roseta, (según el siguiente esquema), 
número de brotes por planta, área foliar total y contenido relativo de clorofila (CRC) en hojas.

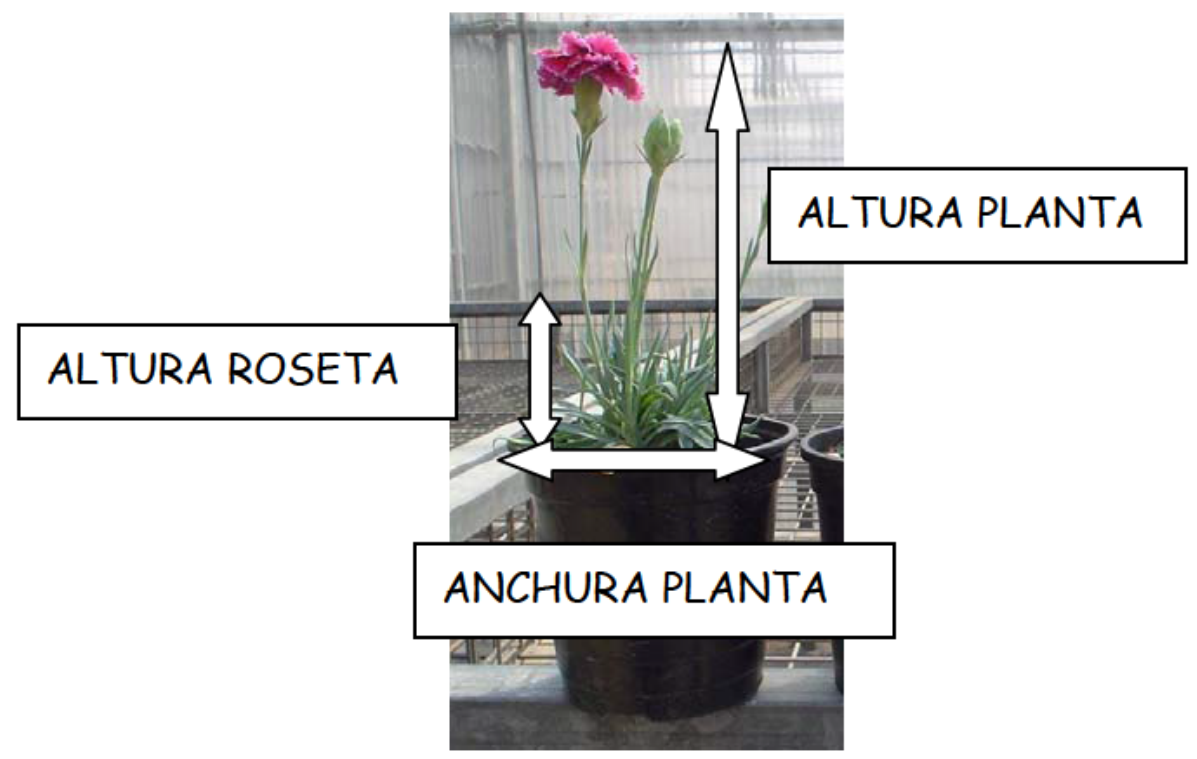

Se midió el área foliar total usando un medidor de área foliar AM 200 (ADC BioScientific Ltd., Herts, England), (Fotografía 3.6).

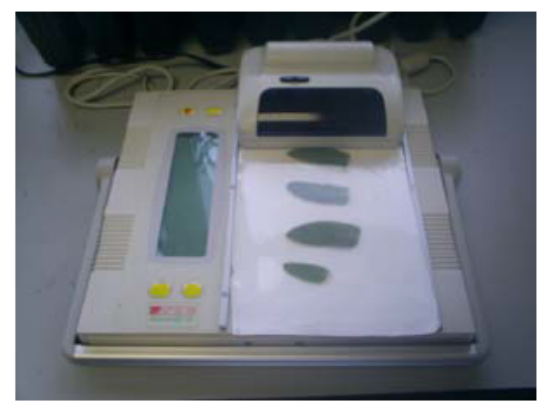

Fotografía 3.6- Medidor de área foliar AM 200.

La determinación de la cantidad relativa de clorofila (CRC) en hoja se hizo con un medidor Minolta SPAD-502 (Konica Minolta Sensing Inc., Osaka, Japan), (Fotografía 3.7).

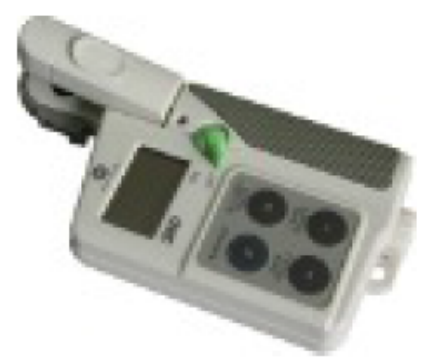

Fotografía 3.7- Medidor de clorofila Minolta SPAD-502. 
También se controlaron parámetros relacionados con la floración, como el color de las flores y número de flores abiertas por planta.

Las determinaciones analíticas del color se realizaron con un colorímetro Minolta CR-10 (Fotografía 3.8) y fueron expresadas por luminosidad (L), ángulo hue (HUE) y croma (C). Las características del color fueron estudiadas basándonos en las coordenadas de color de la Comisión Internacional de L'Eclaire $L^{*}, a^{*}, b^{*}$ (CIELAB).

Las medidas del ángulo hue y croma son medidas de absorción selectiva de luz visible. (McGuire, 1992).

La luminosidad (L) tiene valores de 0 (negro) a 100 (blanco) La luminosidad mide la capacidad de reflectar la luz de una superficie, es decir, la mayor o menor claridad. Croma (C) representa la saturación del color o intensidad; los valores bajos indican colores mates y los valores altos colores vivos e intensos. El croma describe en que grado esta absorción selectiva ocurre, lo que determina la mayor o menor viveza (saturación/palidez) del color. El ángulo hue (HUE) describe en que longitud de onda el color es absorbido e indica el tono o color, que puede ser amarillo, verde amarillento, azul verdoso, azul, etc.

La determinación del color de las flores y las hojas se realizó al final del ensayo en 3 flores y hojas por planta y 5 plantas por tratamiento. Cada medida se realizó apoyando el visor en el centro de una hoja con el color uniforme. El número de flores por planta se determina en 5 plantas por tratamiento al final del período experimental.

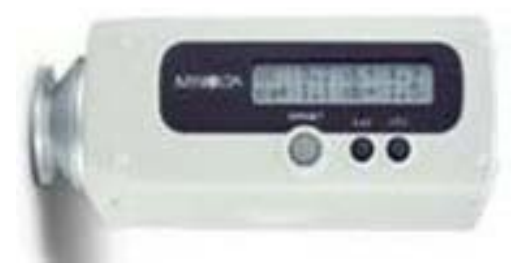

Fotografía 3.8- Colorímetro Minolta CR 10.

\subsubsection{Potencial hídrico foliar y sus componentes, intercambio gaseoso y curvas presión-volumen}

Al final del experimento se midió potencial hídrico foliar $\left(\Psi_{\mathrm{h}}\right)$, potencial osmótico actual $\left(\Psi_{\mathrm{o}}\right)$, potencial de presión $\left(\Psi_{\mathrm{p}}\right)$, conductancia estomática $\left(g_{s}\right)$ y tasa de fotosíntesis neta $\left(P_{n}\right)$ en 10 plantas por tratamiento al mediodía. 
El potencial hídrico foliar se midió en hojas maduras, las cuales habían estado expuestas a luz directa al menos una hora antes de la medida. $\Psi_{\mathrm{h}}$ se estimó de acuerdo con la técnica descrita por Scholander y col. (1965), usando una cámara de presión tipo Scholander Hammel Soil Moisture, mod.3000-Soil Moisture Equipment Co; Santa Barbara, CA, USA, (Fotografía 3.9) para lo cual las hojas se cortan a nivel del peciolo y se colocaron rápidamente en la cámara (Turner, 1988). La presión se incrementó a razón de $0.02 \mathrm{MPa} \mathrm{s}^{-1}$ utilizando gas nitrógeno.
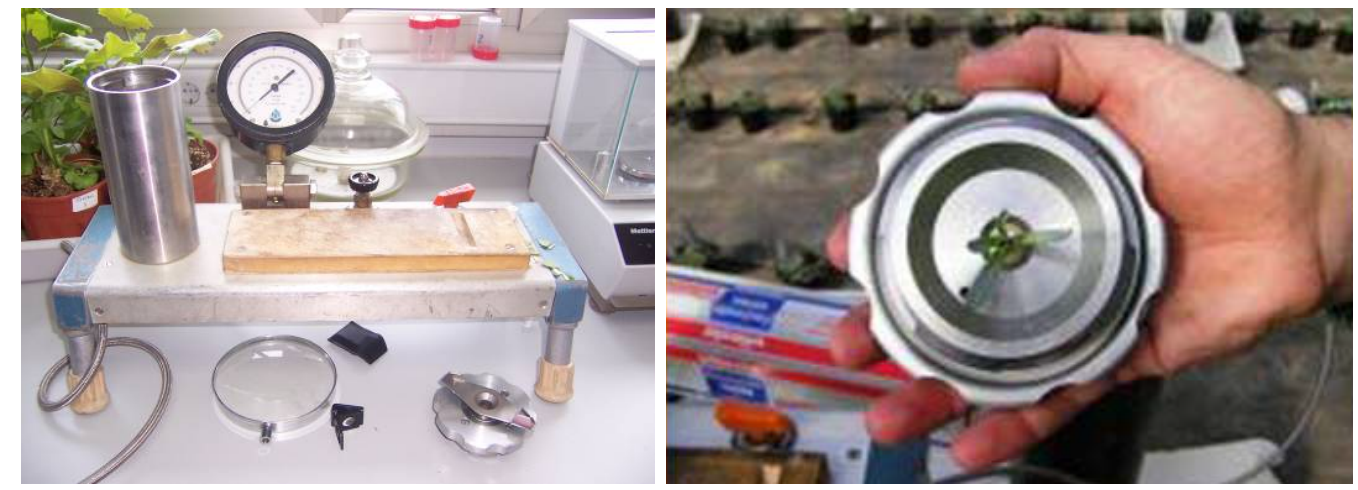

Fotografía 3.9- Cámara de presión Soil Moisture modelo 3000 (Izda) y medida del potencial hídrico en plantas de clavel (Dcha).

El potencial osmótico $\left(\Psi_{0}\right)$ fue medido con un osmómetro de presión de vapor Wescor 5520, (Wescor Inc., Logan, UT, USA) (Fotografía 3.10), el cual había sido previamente calibrado con soluciones de osmolalidad conocida. Las hojas recién cortadas eran envueltas en papel de aluminio, introducidas en nitrógeno líquido $\left(-196{ }^{\circ} \mathrm{C}\right)$ y almacenadas a $-30{ }^{\circ} \mathrm{C}$ para romper las membranas celulares, con lo que el componente de turgencia se anula $\left(\Psi_{\mathrm{p}}\right)$ y el potencial hídrico resulta análogo al osmótico. Previamente a realizar las medidas, las muestras se descongelaron a temperatura ambiente, se colocaron en una jeringa, y en el jugo celular exprimido se midió el potencial osmótico de acuerdo con Gucci y col. (1991).

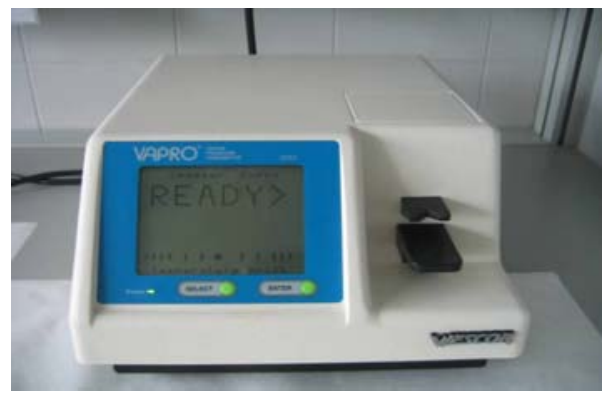

Fotografía 3.10- Osmómetro de presión de vapor Wescor 5520. 
El potencial de presión $\left(\Psi_{\mathrm{p}}\right)$ se calculó como la diferencia entre el potencial hídrico y el potencial osmótico.

La tasa de fotosíntesis neta $\left(P_{n}\right)$ y la conductancia estomática $\left(g_{s}\right)$ se midieron utilizando un aparato de intercambio gaseoso portátil, LI6400, LI-COR Inc , Li-cor Inc., Lincoln, NE, USA (Fotografía 3.11). La velocidad del flujo de aire circulante dentro del sistema, durante el período de medida fue de aproximadamente $350 \mathrm{mmol} \mathrm{s}^{-1}$, con un déficit de presión de vapor de la hoja al aire de aproximadamente $2 \mathrm{KPa}$.

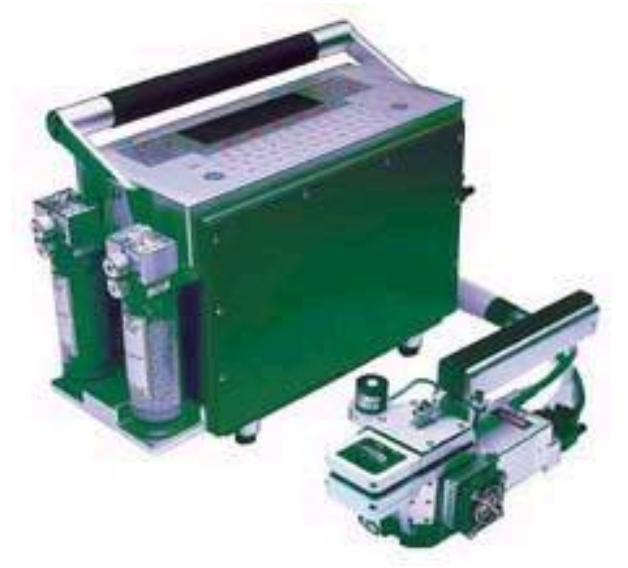

Fotografía 3.11- Aparato de intercambio gaseoso portátil LI-COR Inc., LI-6400.

Al final de los tratamientos de riego (período de estrés), se procedió al muestreo de hojas para la elaboración de curvas presiónvolumen $(\mathrm{P}-\mathrm{V})$, en cinco hojas por planta y 5 plantas por tratamiento. Las hojas fueron cortadas al inicio del día y se procedió a su completa saturación durante 24 horas en oscuridad, sumergiendo sus pecíolos en un vaso con agua destilada (Davies y Money, 1986; Yoon y Ritcher, 1990). Al día siguiente se elaboraron las curvas P-V por el método de la libre deshidratación o libre transpiración, ya que con este proceso se pueden procesar varias hojas a la vez en una misma cámara, y se simula mejor el modo natural de la deshidratación vegetal (transpiración estomática y cuticular), en vez de un empuje artificial para llevar el agua por el tallo o pecíolo hasta la superficie del corte (Hinckley y col., 1980). La técnica de libre transpiración para la obtención de curvas P-V (Tyree y Hammel, 1972) constituye un método fiable para la cuantificación de parámetros hídricos y es, por tanto, una herramienta muy empleada en la investigación de las relaciones hídricas en las plantas. Con este procedimiento se permite que la hoja se seque bajo las condiciones ambientales del laboratorio (Hinckley y col., 1980; Kikuta y col., 1985). 
El contenido hídrico se determina midiendo los cambios de peso fresco que ocurren durante el período de desecación.

Una vez hidratada la hoja, se cortó la base del pecíolo con una cuchilla y se obtuvo el peso de la hoja con una balanza de $0.1 \mathrm{mg}$ de precisión y el potencial hídrico $(\Psi)$ inicial con la cámara de presión. La hoja se secó progresivamente fuera de la cámara bajo las condiciones ambientales del laboratorio y se midió su peso fresco y potencial hídrico a intervalos regulares, midiendo sucesivamente el potencial hídrico y el peso fresco de la hoja (durante varias horas). La velocidad de presurización y despresurización es de $0.02 \mathrm{MPa} \mathrm{s}^{-1}$. En cada medición de $\Psi$ se obtuvo una medición de peso fresco justo inmediatamente después, que se empleó para el cálculo del contenido relativo de agua. Tras la realización de las medidas, las hojas se secaron en estufa a $70^{\circ} \mathrm{C}$ durante 72 horas y se obtuvo el peso seco para el cálculo de los parámetros relativos al contenido de agua (Turner, 1988).

La variable representada frente a la inversa del potencial hídrico $\left(\Psi^{-1}\right)$ es el contenido relativo de agua (CRA) (Kikuta y col., 1985; Saruwatari y Davis, 1989; Turner y col., 1987, Wilson y col., 1979, 1980). A partir de las isotermas de $\Psi$ se estimaron los siguientes parámetros: el contenido relativo de agua apoplástica $\left(\mathrm{CRA}_{\mathrm{a}}\right)$, el potencial osmótico a máxima saturación ( $\Psi_{\mathrm{os}}$ ), el contenido relativo de agua en el punto de pérdida de turgencia ( $\mathrm{CRA}_{\mathrm{ppt}}$ ), el potencial hídrico en el punto de pérdida de turgencia $\left(\Psi_{\mathrm{ppt}}\right)$ y el módulo de elasticidad al $100 \%$ del CRA $(\varepsilon)$ (Turner, 1988). $\mathrm{CRA}_{a}$ se calculó mediante la extrapolación al eje de abscisas de la porción lineal de la curva correspondiente a la representación $\Psi^{-1}$ vs CRA y $\Psi_{\text {os }}$ se estimó extrapolando la parte de la curva que es lineal hasta el eje de las ordenadas. El punto de inflexión de la curva en que ésta comienza a ser lineal corresponde al inicio de la pérdida de turgencia, en donde el potencial de presión $\left(\Psi_{\mathrm{p}}\right)$ se anula, obteniéndose el potencial hídrico y el contenido relativo de agua, $\Psi_{\mathrm{ppt}}$ y $\mathrm{CRA}_{\mathrm{ppt}}$ respectivamente, ambos en el punto de pérdida de turgencia. El módulo de elasticidad de un tejido, $\varepsilon$, se define como el cambio en la presión de turgencia para un cambio determinado en el peso de agua simplástica (Tyree y Hammel, 1972; Cheung y col., 1975). $\varepsilon$ aumenta de forma no lineal con la presión de turgencia, hasta un máximo a partir del cual se hace constante (Cheung y col., 1976). El módulo de elasticidad ( $\varepsilon$ ) al 100\% de CRA se estimó suponiendo una relación casi lineal entre el potencial de presión $\left(\Psi_{\mathrm{p}}\right)$ y CRA, de acuerdo con el método de Wilson y col. (1979). 
El modulo de elasticidad $(\varepsilon)$ al $100 \%$ del CRA se estimó usando la fórmula:

$$
\varepsilon=\left(\mathrm{CRA}_{\mathrm{ppt}} \mathrm{X} \Psi_{\mathrm{os}}\right) /\left(100-\mathrm{CRA}_{\mathrm{ppt}}\right)
$$

La determinación del $\mathrm{CRA}_{a}$, por extrapolación en una curva P-V se ha cuestionado como ambigua (Ritcher y col., 1979) dado el alto error que se puede cometer al estimar este parámetro (Wilson y col., 1980), debido a la larga extrapolación implicada (Wenkert y col., 1978) y a la repetida compresión y descompresión que supone el procedimiento de la libre deshidratación. Por ello y a pesar de que la determinación del $\mathrm{CRA}_{a}$ por análisis de las curvas P-V es uno de los métodos más ampliamente aceptado (Andersen y col., 1991; Rascio y col., 1990, Santakumari y Berkowitz, 1989; Corcuera, 2003), los valores de $\mathrm{CRA}_{a}$ obtenidos no son mostrados.

\subsubsection{Análisis estadístico}

La significación de los efectos de la dosis de riego fue analizada mediante un análisis de varianza simple (ANOVA), usando Statgraphics Plus para Windows. Las medias de los tratamientos fueron separadas con la Prueba de Rango Múltiple de Duncan $(P<0.05)$. Antes del análisis estadístico, cocientes y datos en porcentajes fueron previamente transformados mediante una transformación arcoseno raíz cuadrada, para asegurar la homogeneidad de la varianza.

\subsubsection{Resultados y discusión}

\subsubsection{Efectos del riego deficitario moderado y severo en el crecimiento y parámetros ornamentales en plantas de clavel}

En primer lugar se presentan los resultados correspondientes al efecto de los distintos niveles de déficit hídrico sobre el crecimiento vegetativo, floración y calidad ornamental de las plantas de clavel al final del período experimental. En general, el riego deficitario redujo el peso seco aéreo y el de las raíces de las plantas (Tabla 3.1). Esta respuesta también se vio al considerar la altura de la planta y el área foliar total, parámetros que disminuyeron proporcionalmente al nivel de déficit hídrico impuesto (Tabla 3.1). 
Tabla 3.1- Crecimiento de plantas de clavel en maceta sometidas a distintos tratamientos de riego al final del período experimental.

\begin{tabular}{|c|c|c|c|c|c|c|c|c|c|c|c|}
\hline \multirow{2}{*}{$\begin{array}{l}\text { Tratamiento } \\
\text { Control }\end{array}$} & \multirow{2}{*}{$\begin{array}{c}\begin{array}{c}\text { PS } \\
\text { aéreo } \\
\left(\mathrm{g} \mathrm{pl}^{-1}\right)\end{array} \\
13.65\end{array}$} & \multirow{2}{*}{$\begin{array}{c}\begin{array}{c}\text { PS raíz } \\
\left.(\mathrm{g} \mathrm{pl})^{-1}\right)\end{array} \\
\mathrm{c} 10.73 \mathrm{C}\end{array}$} & \multicolumn{2}{|c|}{$\begin{array}{l}\text { Altura planta } \\
\text { (cm) }\end{array}$} & \multicolumn{2}{|c|}{$\begin{array}{c}\text { Altura roseta/altura } \\
\text { planta }\end{array}$} & \multicolumn{2}{|c|}{$\begin{array}{c}\text { Anchura } \\
\text { roseta }(\mathrm{cm})\end{array}$} & \multicolumn{2}{|c|}{$\begin{array}{l}N^{0} \text { brotes } \\
\text { planta }^{-1}\end{array}$} & \multirow{2}{*}{$\begin{array}{c}\begin{array}{c}\text { Área } \\
\text { foliar } \\
\left(\mathrm{cm}^{2}\right)\end{array} \\
141.44\end{array}$} \\
\hline & & & 14.93 & c & 0.49 & a & 8.85 & b & 2.70 & b & \\
\hline RDM & 11.0 & b $9.90 \mathrm{~b}$ & 12.89 & $b$ & 0.54 & b & 7.78 & b & 2.60 & $b$ & $109.67 \mathrm{~b}$ \\
\hline RDS & 9.08 & a $8.25 \mathrm{a}$ & 10.93 & a & 0.51 & a & 5.04 & a & 1.90 & a & $98.56 \mathrm{a}$ \\
\hline $\mathrm{P}$ & $* * *$ & $* *$ & $* * *$ & & * & & $* * \star$ & & $* *$ & & ** \\
\hline
\end{tabular}

Distintas letras dentro de una misma columna indican diferencias significativas según el test de Duncan. (P: nivel de significación, ${ }^{*} \mathrm{P}<0.05$, ${ }^{* *} \mathrm{P}<0.01,{ }^{* * *} \mathrm{P}<0.001$ ).

Sin embargo, el número de brotes por planta y la anchura de la planta sólo fueron significativamente inhibidos en las plantas del tratamiento de riego deficitario severo (RDS) en comparación con el tratamiento control y el riego deficitario moderado (RDM). Este último tratamiento produjo valores más altos del cociente altura de la roseta/altura planta que los otros tratamientos estudiados. Como ha sido aportado por otros autores, las limitaciones en el aporte hídrico producen un impacto en el crecimiento de las plantas (Franco y col., 2006), aunque el efecto producido es variable y depende de la intensidad del estrés hídrico impuesto, duración y momento que se aplique (Cameron y col., 1999), sin olvidar a la especie que estemos estudiando. En nuestro caso, los dos niveles de riego deficitario aplicados redujeron la altura de los brotes florales, lo que provocó un control del crecimiento excesivo de la planta. No obstante, sólo el RDM aumentó el cociente altura roseta en relación a la altura total de la planta y se sitúa más cerca del valor umbral ideal (0.7), produciendo una planta más compacta, más proporcionada y de más calidad ornamental en el mercado. Por el contrario, el tratamiento de RDS reduce la altura total, pero también reduce el tamaño de la roseta, es decir produce plantas más pequeñas y menos vistosas.

Por otra parte, la menor superficie foliar de las plantas regadas deficitariamente, lo cual pudimos observar en nuestro ensayo, supone una ventaja en cuanto a una menor superficie transpirante y contribuye a reducir el consumo de agua. Como es sabido, la transpiración de la planta es función de la absorción neta de energía solar, lo que supone que una menor área foliar reduce la interceptación de la luz a través del follaje (De Herralde y col., 1998, Bañón y col., 2002). 
Si atendemos a los parámetros ornamentales, relacionados con la floración (Tabla 3.2), podemos ver cómo el número de flores por planta descendió en las plantas que recibían menos agua (RDS) y no se encontraron diferencias entre las plantas del tratamiento control y las de riego deficitario moderado. Tampoco hubo diferencias en los parámetros de color de las flores (L, C, HUE) entre estos dos tratamientos. El contenido relativo de clorofila (CRC) fue menor en el tratamiento RDS y las flores de estas plantas presentan un mayor valor de $L$ y menor valor de $\mathrm{C}$, es decir flores más claras, con un color más mate, menos vivo, menos intenso que las de las plantas control. Todo ello supone que el valor ornamental de las plantas del RDS disminuye por producir flores de menor calidad visual. Por todo ello, podemos decir que el grado de déficit hídrico influyó en el desarrollo floral, pero que en nuestra condiciones las plantas de clavel pueden enfrentarse a situaciones moderadamente limitantes de agua, sin perder su valor ornamental (Brawner, 2003; Henson y col., 2006).

Tabla 3.2- Parámetros ornamentales en plantas de clavel en maceta sometidas a distintos tratamientos de riego al final del período experimental.

\begin{tabular}{|c|c|c|c|c|c|}
\hline \multirow{2}{*}{ Tratamientos } & \multirow{2}{*}{$\begin{array}{c}\mathrm{N}^{0} \text { flores } \\
\text { planta-1 }^{-1}\end{array}$} & \multicolumn{3}{|c|}{ Color de las flores } & \multirow{2}{*}{ CRC (hoja) } \\
\hline & & $\mathrm{L}$ & $\mathrm{C}$ & HUE & \\
\hline Control & $3.02 \mathrm{~b}$ & $46.59 \mathrm{a}$ & $39.87 \mathrm{~b}$ & 342.52 & $39.70 \mathrm{~b}$ \\
\hline RDM & $2.80 \mathrm{~b}$ & $48.70 \mathrm{a}$ & $33.10 \mathrm{~b}$ & 346.30 & $38.90 \mathrm{~b}$ \\
\hline RDS & $1.30 \mathrm{a}$ & $49.82 a b$ & $30.43 \mathrm{a}$ & 342.18 & $34.39 \mathrm{a}$ \\
\hline$P$ & $* *$ & * & * & ns & * \\
\hline
\end{tabular}




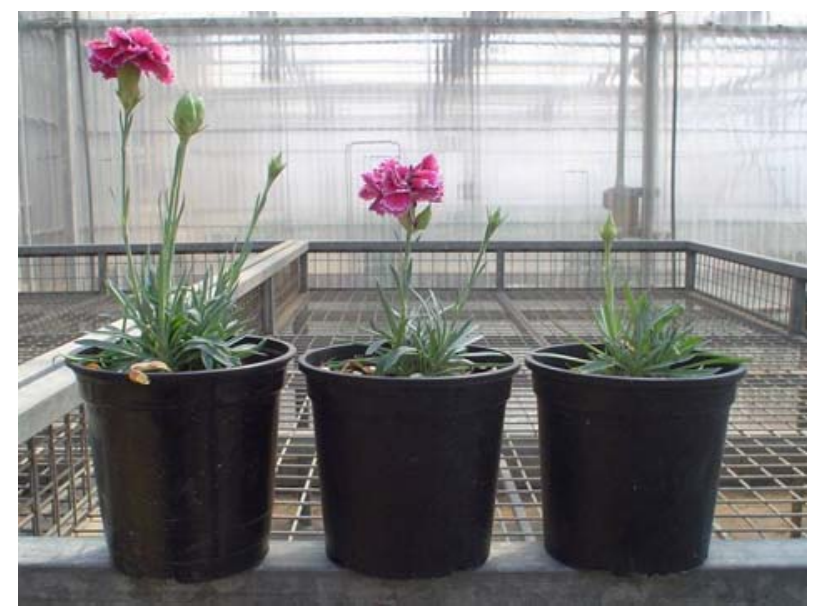

Fotografía 3.12- Aspecto de las plantas de clavel al final del ensayo.

\subsubsection{Efectos del riego deficitario y severo en las relaciones hídricas (curvas P-V) e intercambio gaseoso en plantas de clavel}

El efecto de los distintos tratamientos de riego sobre los parámetros hídricos puede observarse en la Figura 3.1. Al final del período experimental, el potencial hídrico foliar $\left(\Psi_{\mathrm{h}}\right)$ se redujo en ambos tratamientos deficitarios, mostrando valores de $-0.62 \mathrm{MPa},-0.84 \mathrm{MPa}$ y $0.86 \mathrm{MPa}$ en Control, RDM y RDS, respectivamente. El potencial osmótico foliar descendió por la aplicación del riego deficitario, aunque este efecto fue más marcado en RDS, lo que indujo valores mayores de potencial de presión en este último tratamiento (Figura 3.1). 

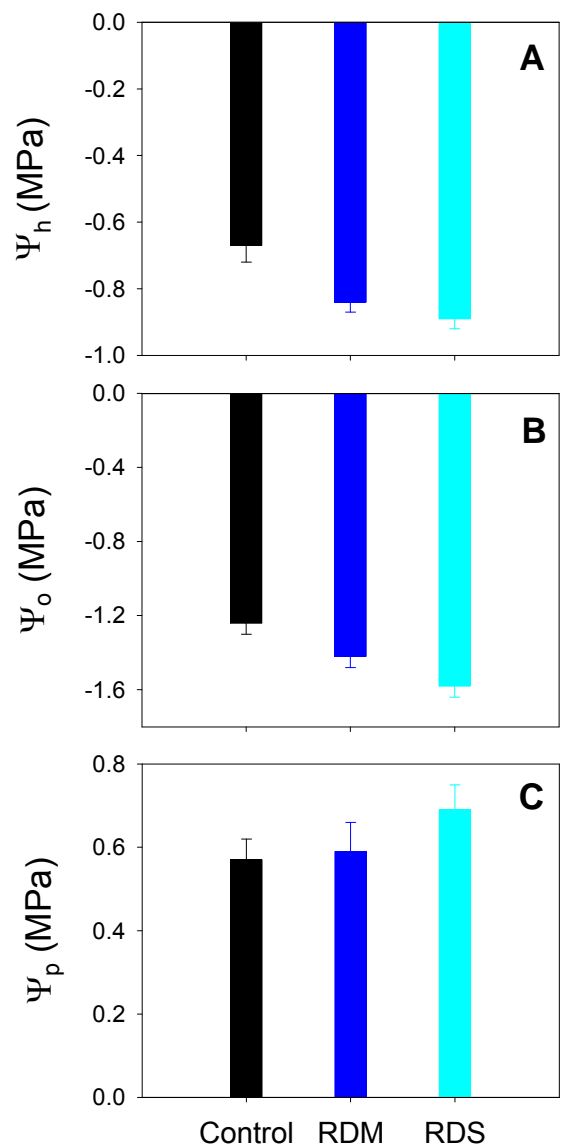

Tratamientos

Figura 3.1- Potencial hídrico foliar $\left(\Psi_{\mathrm{h}}, \mathrm{A}\right)$, potencial osmótico foliar $\left(\Psi_{0}, \mathrm{~B}\right)$ y potencial de presión foliar $\left(\Psi_{p}, C\right)$ al mediodía en plantas de clavel en maceta sometidas a distintos tratamientos de riego al final del período experimental.

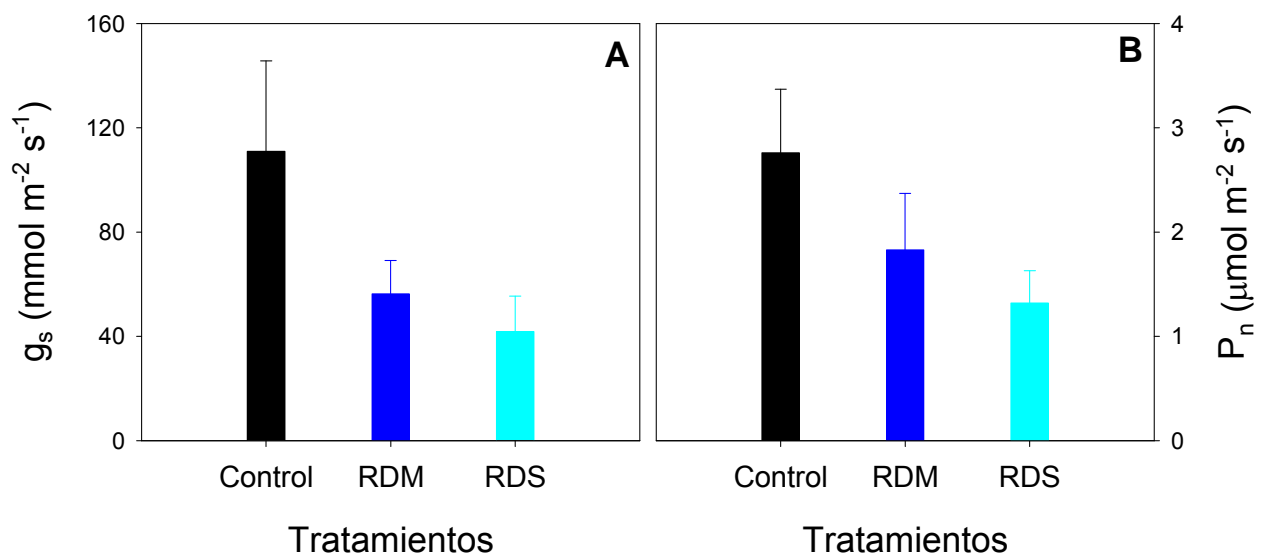

Figura 3.2- Conductancia estomática $\left(g_{s}, A\right)$ y tasa de fotosíntesis neta $\left(P_{n}, B\right)$ al mediodía en plantas de clavel en maceta sometidas a distintos tratamientos de riego al final del período experimental. 
En la Figura 3.2 se representan los niveles de intercambio gaseoso de las plantas de clavel bajo distintas condiciones de riego. La conductancia estomática $\left(g_{s}\right)$ y la tasa de fotosíntesis neta $\left(P_{n}\right)$ descendieron en las plantas regadas deficitariamente, aunque las reducciones de $g_{s}$ fueron más marcadas que las reducciones de $P_{n}$ en relación a las plantas control. La mayoría de las especies estudiadas frente a una situación de déficit hídrico responden con una reducción de la apertura estomática como consecuencia de un descenso de los niveles de la energía libre del agua en los tejidos foliares, es decir de un descenso en el potencial hídrico de las hojas. También este comportamiento puede venir acompañado por otras adaptaciones fisiológicas tales como una menor área foliar, con lo que ambas respuestas pueden contribuir a reducir el consumo total de agua (Kang y col., 2000; Jaleel y col., 2008). Ambas respuestas fueron observadas en las plantas de clavel que recibían aportes hídricos más bajos. La reducción de la conductancia estomática como resultado de un descenso del potencial hídrico foliar se ha observado en numerosas especies (Gollan y col., 1985, Pereira y Chaves, 1993, Munné-Bosch y col., 1999).

En nuestras condiciones, los valores de potencial hídrico foliar en torno a -0.8 MPa encontrados en las plantas de riego deficitario pueden haber causado un importante descenso en la conductancia estomática (aproximadamente del 60\%). En este sentido, se ha publicado que el nivel de umbral del potencial hídrico para causar un descenso en la apertura estomática oscila entre -0.7 y $-1.2 \mathrm{MPa}$ según distintas especies ornamentales (Ackerson, 1985; Hsiao, 1973).

El hecho de que en las plantas que recibían menos agua, el nivel de fotosíntesis permaneciera proporcionalmente más alto que las pérdidas de vapor de agua a través de los estomas indica un aumento de la eficiencia intrínseca en el uso del agua cómo medida adicional de adaptación al estrés (Chaves y col., 2002). Este tipo de respuestas se han asociado con estrategias de riego deficitario (RD sostenido, RDC y PRD) en distintos cultivos, donde una reducción pequeña en la producción, pero con posibles incrementos en la calidad, puede ir acompañado de amplios ahorros en el uso del agua (Goldhamer y Beede, 2004; Liu y col., 2006). 
Los parámetros derivados de las curvas presión volumen al final de ensayo se presentan en la Tabla 3.3. Los valores de potencial osmótico saturado ( $\left.\Psi_{\mathrm{os}}\right)$ fueron más bajos en los tratamientos de riego deficitario y no hubo diferencias entre ambos tratamientos, lo que indica que se produce un ajuste osmótico debido al déficit hídrico, independientemente del nivel del estrés aplicado. La diferencia entre los valores obtenido en las plantas control y las de riego deficitario fue tomado como una estimación de este ajuste (0.36 MPa y $0.46 \mathrm{MPa}$ para RDM y RDS, respectivamente). El potencial hídrico en el punto de pérdida de turgencia ( $\left.\Psi_{\mathrm{ppt}}\right)$ se redujo significativamente sólo en las plantas que recibían un nivel de riego más bajo (Tabla 3.3). El módulo de elasticidad $(\varepsilon)$ aumentó en ambos tratamientos de riego deficitarios, siendo los valores de este parámetro estadísticamente iguales en ambos niveles de déficit estudiados (Tabla 3.3). Mejorar la resistencia a la sequía mediante ajuste osmótico ha sido observado en muchas especies (Hinckley y col., 1980, Serrano y col., 2005). Esto, unido a incrementos en el módulo de elasticidad, indica que además de la acumulación de solutos, hubo cambios en la rigidez de las paredes celulares de las plantas, lo que resultó en una pérdida de turgencia a potenciales hídricos más bajos (2.33 MPa para las plantas de los tratamientos Control y RDM y $-2.9 \mathrm{MPa}$ para las de RDS).

Tabla 3.3- Parámetros derivados de las curvas $P$ $\checkmark$ en plantas de clavel en maceta sometidas a distintos tratamientos de riego al final del período experimental.

\begin{tabular}{|c|c|c|c|}
\hline Tratamientos & $\Psi_{0 \mathrm{~S}}(\mathrm{MPa})$ & $\Psi_{\mathrm{ppt}}(\mathrm{MPa})$ & $\varepsilon(\mathrm{MPa})$ \\
\hline Control & $-1.776 \mathrm{~b}$ & $-2.337 b$ & $4.89 \mathrm{a}$ \\
\hline RDM & $-2.143 \mathrm{a}$ & $-2.413 b$ & $9.17 \mathrm{~b}$ \\
\hline RDS & $-2.244 a$ & $-2.915 \mathrm{a}$ & $8.55 \mathrm{~b}$ \\
\hline$P$ & $*$ & $*$ & $* *$ \\
\hline
\end{tabular}

Distintas letras dentro de una misma columna indican diferencias significativas según el test de Duncan. ( $P$ : nivel de significación, ${ }^{*} P<0.05$, $\left.{ }^{* *} P<0.01\right)$. 
El mantenimiento de la turgencia puede ser logrado por la acumulación de solutos o por cambios en la elasticidad de la pared (Radin, 1983). La falta de agua puede causar tanto aumentos como descensos de la elasticidad de la pared celular (Serrano y col., 2005, Schulte, 1993). En nuestras condiciones, las plantas de clavel realizaron ajuste osmótico y descendió significativamente la elasticidad de sus paredes en respuesta al déficit hídrico, tal y como Meinzer y col. (1990) observaron en café y Sánchez-Blanco y col. (2009) en plantas de geranio.

En especies que muestran ajuste osmótico, una mayor rigidez de la pared celular puede ser necesaria para mantener la integridad del tejido celular cuando supuestamente hay una rehidratación seguida de una situación de estrés (Clifford y col., 1998). Por otro lado, no se encontraron en las plantas regadas deficitariamente valores de potencial hídrico foliar por debajo del valor de $\Psi_{\mathrm{ppt}}$ en ningún momento del ensayo. Por lo que la turgencia se mantuvo e incluso, en algunos momentos, fue mayor para las plantas de los tratamientos de riego deficitario. De este modo, la inhibición del crecimiento en ambos niveles de déficit no estuvo asociada con la turgencia foliar (Nabil y Coudret, 1995), sino, con una reducción de la fotosíntesis y una menor síntesis de asimilados. 


\subsection{Efecto del riego deficitario aplicado en las fases de inicio de la floración y de posfloración (fuera de la fase de máxima floración) en plantas de clavel}

\subsubsection{Material y métodos}

\subsubsection{Material vegetal y condiciones experimentales}

Este ensayo se realizó con el material vegetal cuyas características se detallan en el apartado 3.2.1.1. En cuanto a las condiciones experimentales, el trasplante se realizó a finales de mayo y 5 semanas después se implantaron los tratamientos de riego. El experimento se realizó en el mismo invernadero del ensayo anterior, descrito en el apartado 3.2.1.1.

El ensayo se llevó a cabo de junio a septiembre de 2006 (Fotografía 3.13). Las condiciones climáticas en el invernadero durante el cultivo fueron obtenidas con un registrador de datos Hoboware. Las temperaturas medias diarias oscilaron entre 21 y $30^{\circ} \mathrm{C}$, y la humedad relativa osciló entre 21 y $84 \%$. La temperatura media de las máximas fue de $33.3^{\circ} \mathrm{C}$ y la media de las mínimas fue de $20.9^{\circ} \mathrm{C}$. Con estos datos se calculó el déficit de presión de vapor (DPV) a lo largo de todo el ensayo, cuyos valores quedan recogidos en la Figura 3.3.

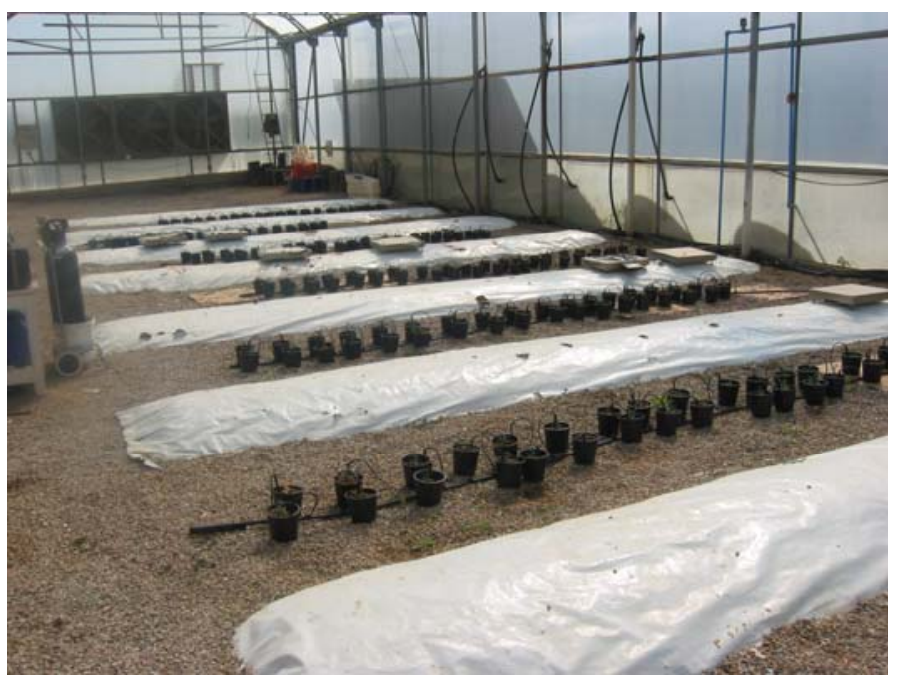

Fotografía 3.13- Vista general del ensayo en el interior del invernadero. 

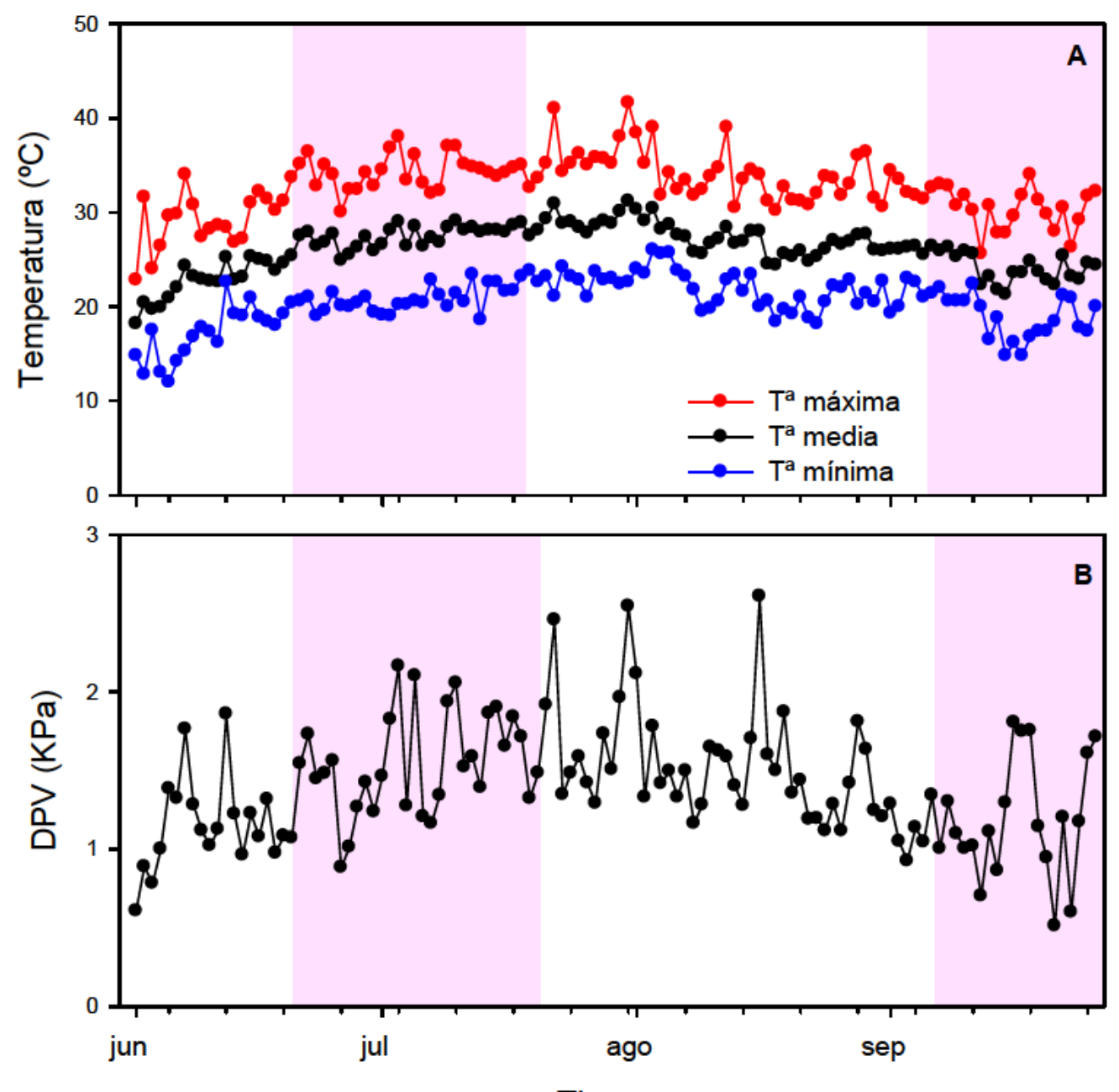

Tiempo

Figura 3.3- Datos climáticos correspondientes al periodo del ensayo, temperatura media, máxima y mínima diaria $(A)$ y déficit de presión de vapor medio diario (B).

\subsubsection{Tratamientos y diseño experimental}

A partir del 22 de junio y durante cuatro meses, las plantas se dividieron en tres lotes y se aplicaron tres tratamientos de riego, las plantas del tratamiento control (Control) se regaron hasta conseguir un $15 \%(\mathrm{v} / \mathrm{v})$ de drenaje, las plantas de riego deficitario recibieron el $50 \%$ de la cantidad suministrada al control durante todo el experimento (riego deficitario, RD) y el tratamiento de riego deficitario controlado (RDC) consistió en un período de riego deficitario durante la fase de desarrollo inicial hasta inicio de la floración (botón apretado, flor semiabierta) (fase I, cuatro semanas), seguido de un riego como tratamiento control durante la fase de máxima floración (flor abierta completamente) (fase II, siete semanas) y después se aplicó otra fase de riego deficitario (RD, 50\%) después de la floración (marchitamiento de flor, caída de pétalos) (fase III, 
tres semanas). Las plantas se regaban con un sistema de riego por goteo programable de tres a siete veces por semana, dependiendo de la demanda evaporativa, el control del drenaje se realizó según se describe en el apartado 3.2.1.2. El volumen de agua osciló entre 840 y $1050 \mathrm{ml}$ por planta y semana para el control, mientras que la media fue de $160 \mathrm{ml} /$ día para las plantas del tratamiento control y 120 y $80 \mathrm{ml} /$ día para las de los tratamientos de RDC y RD, respectivamente.

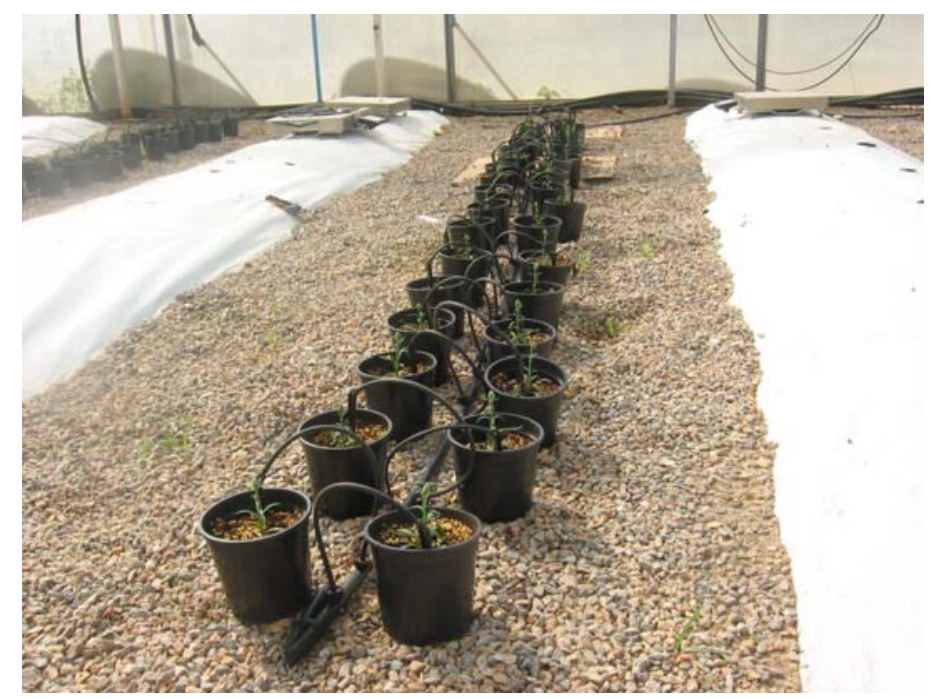

Fotografía 3.14- Plantas de clavel en el interior del invernadero.

\subsubsection{Crecimiento y parámetros ornamentales}

La evaluación del crecimiento en biomasa seca de los distintos órganos de la planta se realizó según la metodología descrita en el apartado 3.2.1.3 de esta memoria. En cada muestreo se utilizaron 5 plantas por tratamiento y se hicieron 4 muestreos; final fase I, inicio y final fase II y final fase III, (semanas 4, 6, 10 y 14 desde inicio de los tratamientos).

A lo largo del ensayo se efectuaron 6 controles para evaluar el desarrollo de las plantas (semana 0, 4, 6, 10 y 14 desde inicio de los tratamientos). En cada uno de estos controles se midió altura y anchura de la planta, altura de la roseta y área foliar en 5 plantas por tratamiento, tal y como se explica en el apartado 3.2.1.3 de esta memoria.

En cuanto a los parámetros ornamentales se evaluó periódicamente el número de brotes y el número de flores abiertas en la totalidad de las plantas (Fotografía 3.15). El color de las flores y las hojas se midió en tres flores/hojas por planta y 5 plantas por tratamiento en distintos momentos del ensayo. Las medidas de todos estos parámetros 
fueron realizadas de acuerdo con la metodología ya descrita en el apartado 3.2.1.3 de esta memoria.
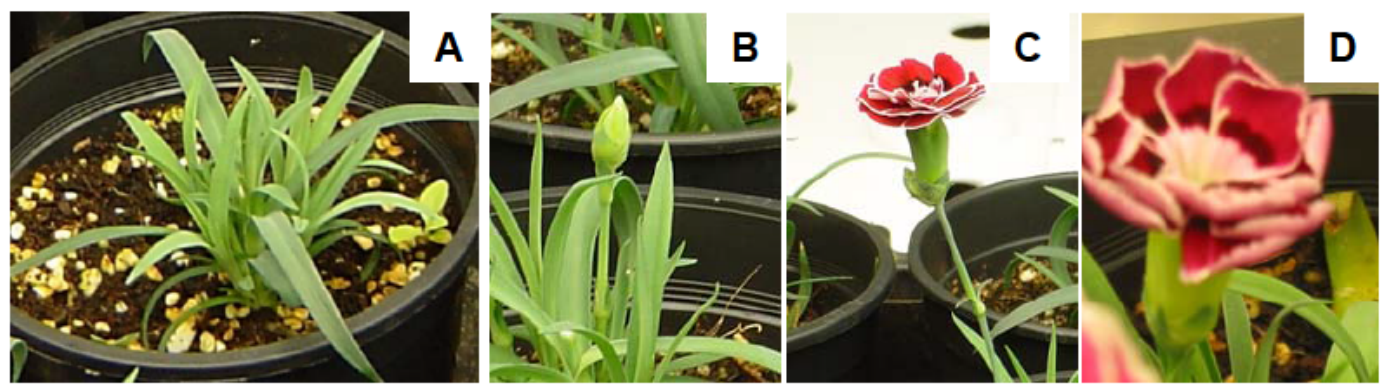

Fotografía 3.15- Fases del clavel, fase de desarrollo inicial hasta botón floral (A y B: Fase I), flor abierta completamente (C: Fase II) y fase de marchitamiento (D: Fase III).

\subsubsection{Humedad del sustrato, potencial hídrico foliar y sus componentes e intercambio gaseoso}

Para medir el contenido de agua en el suelo, se realizaban medidas periódicas de la humedad del sustrato, una vez implantados los tratamientos, midiendo el contenido volumétrico de agua en el medio $\left(\theta_{\mathrm{v}}\right)$ a $9 \mathrm{~cm}$, mediante la técnica de reflectometría en dominio del tiempo (TDR) a través de un equipo TEKTRONIX modelo 1502C (Fotografía 3.16).

El método TDR fue desarrollado por Topp y col. (1980 y 1982) y Topp y Davis (1985), y se basa en la determinación de la constante dieléctrica del suelo $\left(\mathrm{K}_{\mathrm{a}}\right)$, la cual está relacionada con el contenido de agua en el suelo $\left(\theta_{\mathrm{v}}\right)$. El TDR en nuestras medidas en el campo nos muestra en pantalla el valor de $K_{a}$, y $\theta_{v}\left(\mathrm{~cm}^{3} / \mathrm{cm}^{3}\right)$ se calcula a través de la ecuación:

$$
\theta_{v}=-5.3 .10^{-2}+2.9210^{-2} \mathrm{k}_{\mathrm{a}}+5.510^{-4} \mathrm{ka}^{2}+4.310^{-6} \mathrm{k}_{\mathrm{a}}{ }^{3}
$$

Las medidas del contenido volumétrico de humedad se realizaron semanalmente en 5 macetas por tratamiento en el momento del mediodía.

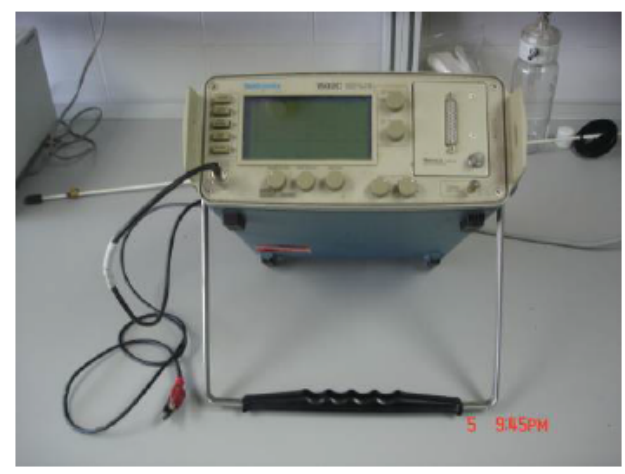

Fotografía 3.16- Equipo TEKTRONIX mod. 1502C. 
El estado hídrico de la planta se evaluó basándonos en medidas del potencial hídrico foliar y sus componentes. Se determinó el potencial hídrico foliar $\left(\Psi_{\mathrm{h}}\right)$, potencial osmótico $\left(\Psi_{\mathrm{o}}\right)$ y potencial de presión $\left(\Psi_{\mathrm{p}}\right)$ al mediodía varias veces a lo largo del período experimental en 10 plantas por tratamiento, según la metodología descrita en el apartado 3.2.2.4 de esta memoria.

A lo largo del ensayo, también se evaluó semanalmente el potencial osmótico a máxima saturación en 10 plantas por tratamiento. Las hojas tomadas para la determinación del potencial osmótico saturado $\left(\Psi_{\text {os }}\right)$ fueron introducidas por el pecíolo en vasos de agua destilada a $4^{\circ} \mathrm{C}$, en la oscuridad, para alcanzar la completa turgencia. Una vez alcanzada la máxima turgencia, unas 24 horas, las hojas se secaron con papel de filtro para eliminar el agua superficial, y se envolvieron en papel de aluminio e introdujeron en nitrógeno líquido, determinándose, posteriormente, el potencial osmótico a máxima saturación mediante el mismo procedimiento utilizado para el potencial osmótico actual, señalado anteriormente, apartado 3.2.1.4.

La tasa de fotosíntesis neta $\left(P_{n}\right)$ y la conductancia estomática $\left(g_{s}\right)$ se midieron siguiendo el procedimiento descrito en el apartado 3.2.1.4. Estas medidas se realizaron al final del ensayo en cinco plantas por tratamiento.

\subsubsection{Análisis estadístico}

La significación de los efectos de la dosis de riego fue analizada mediante un análisis de varianza simple (ANOVA), usando Statgraphics Plus para Windows. Las medias de los tratamientos fueron separadas con la Prueba de Rango Múltiple de Duncan $(P<0.05)$. Antes del análisis estadístico, cocientes y datos en porcentajes fueron previamente transformados mediante una transformación arcoseno raíz cuadrada, para asegurar la homogeneidad de la varianza. 


\subsubsection{Resultados y discusión}

\subsubsection{Efectos del riego deficitario controlado en el crecimiento y parámetros ornamentales en plantas de clavel}

En la Figura 3.4 se representan los datos relativos al desarrollo de las plantas de clavel bien regadas (Control), regadas deficitariamente durante todo el ciclo de cultivo (RD) y sometidas a riego deficitario durante la primera (Fase I, iniciación de la floración) y tercera fase (Fase III, después de la máxima floración) de crecimiento y a riego control durante la fase II (floración máxima) (RDC). Durante la fase de floración (fase II) los valores del peso seco aéreo para el tratamiento control y RDC fueron similares, pero fueron distintos en la fase III, presentando las plantas de RDC valores más bajos que las del control (Figura 3.4A). Las plantas de $\mathrm{RD}$ fueron las más pequeñas durante todo el ensayo (Figura 3.4A).

El efecto de los tratamientos sobre el sistema radical solo fue significativo al final del período experimental, donde se redujo el peso seco de las raíces en RD comparado con el control (Figura 3.4B). Sin embargo, se produce un reparto de asimilados a favor de las raíces (mayores valores del cociente PS raíz/PS aéreo) en este tratamiento, sobre todo en las primeras etapas del ciclo vegetativo (Figura 3.4C). Esta redistribución de la materia seca a favor de las raíces a expensas de la parte aérea (Brugnoli y Bjorkman, 1992, Montero y col., 2001) es probablemente debida a la necesidad de las plantas de mantener un mayor desarrollo radical para absorber agua desde el sustrato cuando éste presenta limitación de agua (Bradford y Hsiao, 1982). 

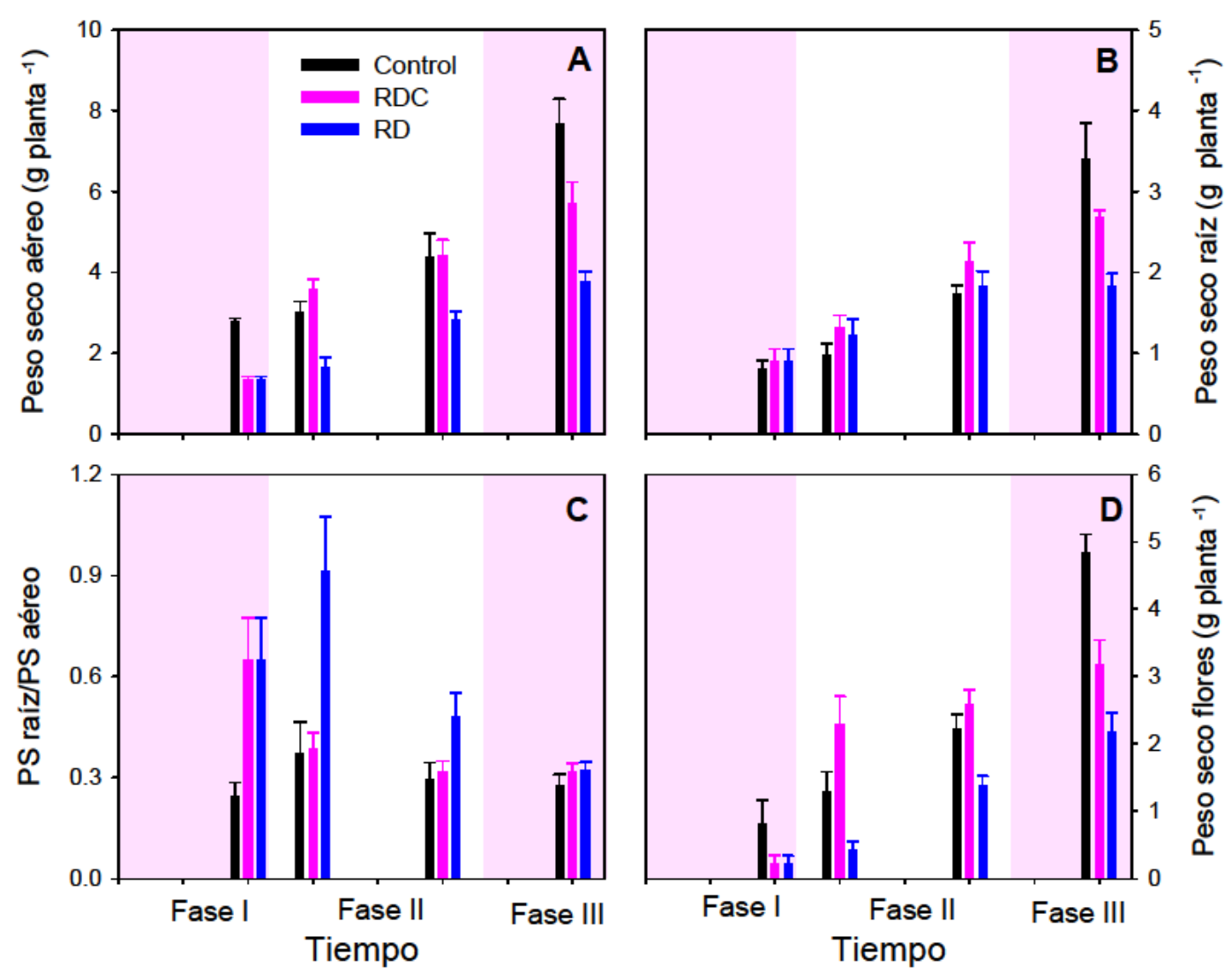

Figura 3.4- Evolución del peso seco aéreo (A), peso seco raíz $(B)$, cociente $P S$ raíz/PS aéreo (C) y peso seco flores (D) en plantas de clavel en maceta sometidas a distintos tratamientos de riego durante el período experimental. Las zonas sombreadas indican el riego deficitario en las plantas del tratamiento RDC.
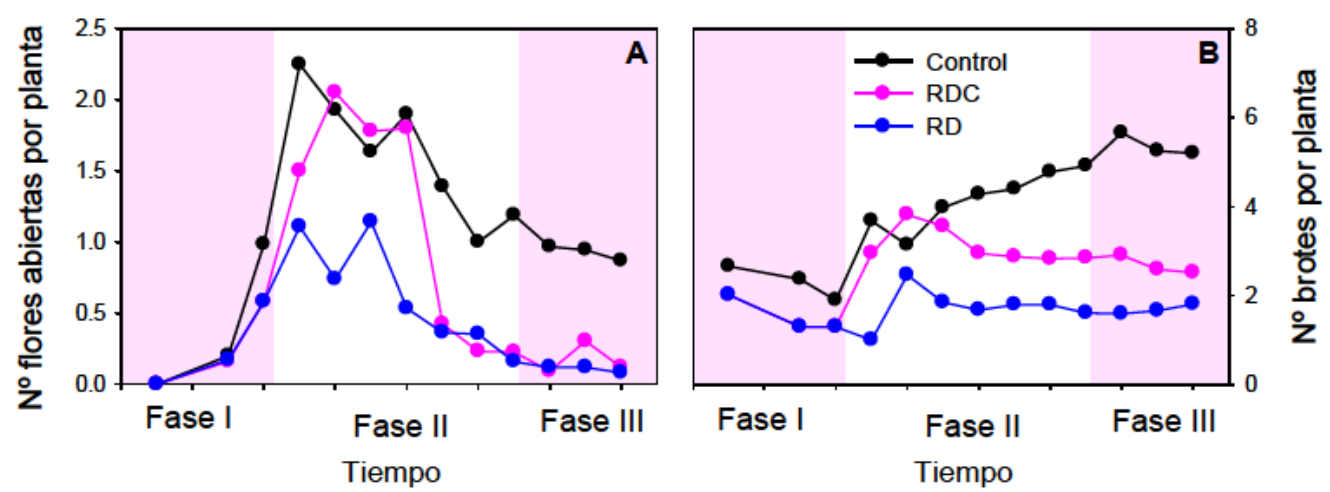

Figura 3.5- Evolución del número de flores abiertas (A) y número de brotes $(B)$ en plantas de clavel en maceta sometidas a distintos tratamientos de riego durante el período experimental. Las zonas sombreadas indican el riego deficitario en las plantas del tratamiento RDC. 
El riego deficitario sostenido disminuyó el número de flores abiertas por planta desde el inicio de la fase de floración (Figura 3.5). Para las plantas sometidas a RDC, la disminución del número de flores se produce al finalizar la fase de floración, durante esta fase alcanzan valores similares a los de las plantas control, pero durante menos tiempo. Al final del ensayo, solo las plantas en condiciones controles presentan alguna flor. También hay que reseñar que los pesos secos de las flores son similares en las plantas de RDC y las controles en la fase II y que estos valores disminuyen en las de RDC en la ultimas fase en relación a las plantas controles (Figura 3.4D). Según Cameron y col. (1999) el mayor número de flores por planta en Rhododendron tuvo lugar después de una sequía moderada, lo cual se ha observado en otras especies ornamentales (Carden, 1995).

El déficit hídrico puede influir en la floración inhibiendo el crecimiento vegetativo (Cameron, 2006), y el efecto se ha visto que puede ser positivo (Sharp y col., 2009) o negativo (Mingeau y col., 2001) y depende de la especie y del periodo de exposición al déficit. También, ha sido aportado que el déficit hídrico reduce cronológicamente y fisiológicamente el periodo de floración. No obstante otros factores como el fotoperiodo pueden ser dominantes sobre cualquier efecto del déficit hídrico en la inducción floral (Lozhnikova y col., 1981).

En cuanto a los parámetros de color medidos en las flores (Figura 3.6), se observaron diferencias significativas en el parámetro croma, para el que RD mostró generalmente los valores más bajos, dando, flores más mates, colores menos vivos, menos intensos. En los otros parámetros de color (luminosidad y ángulo hue) no se detectaron diferencias. En general, RDC no modifica el color de las flores en relación a las plantas control. También se estudió los posibles cambios en el color de las hojas de los distintos tratamientos $\mathrm{y}$, en general, los parámetros de color no se modificaron por efecto del riego (Figura 3.6). 

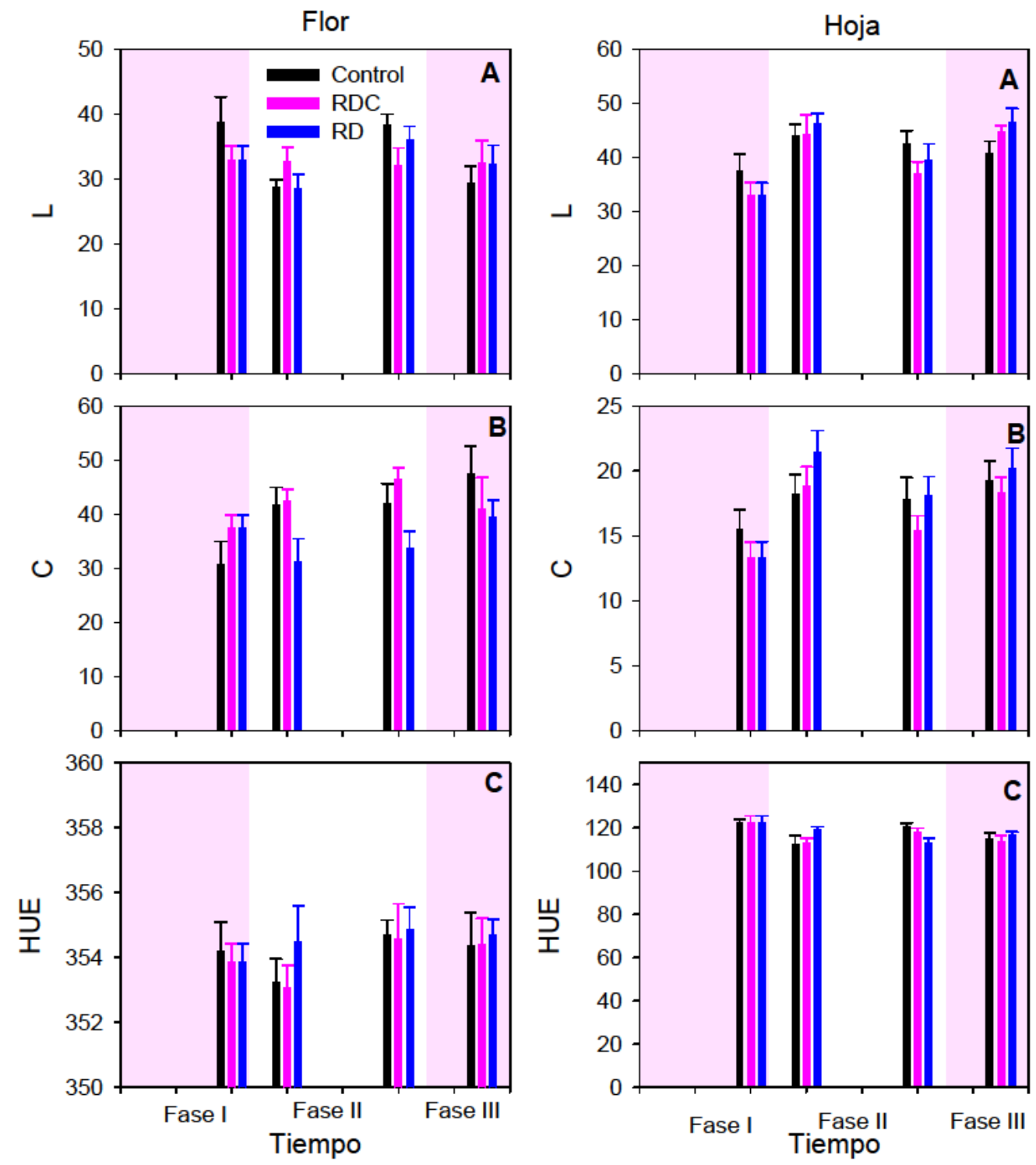

Figura 3.6- Evolución de los parámetros de color: luminosidad (L, A), croma (C, B) y ángulo hue (HUE, C) en flores (Izda) y hojas (Dcha) de clavel en maceta sometidas a distintos tratamientos de riego durante el período experimental. Las zonas sombreadas indican el riego deficitario en las plantas del tratamiento RDC.

En esta especie el área foliar resultó ser un parámetro muy sensible a déficit hídrico. En las plantas sometidas a RD se redujo el área foliar prácticamente durante todo el ciclo, mientras que aquellas sometidas a RDC mantuvieron valores similares a las plantas control durante la fase que recibían la misma cantidad de agua. Ello no ocurrió en las fases donde se reducen los aportes hídricos (Figura 3.7). Al final del experimento, las plantas regadas en condiciones control durante todo el ciclo presentaron los mayores índices de área foliar. 

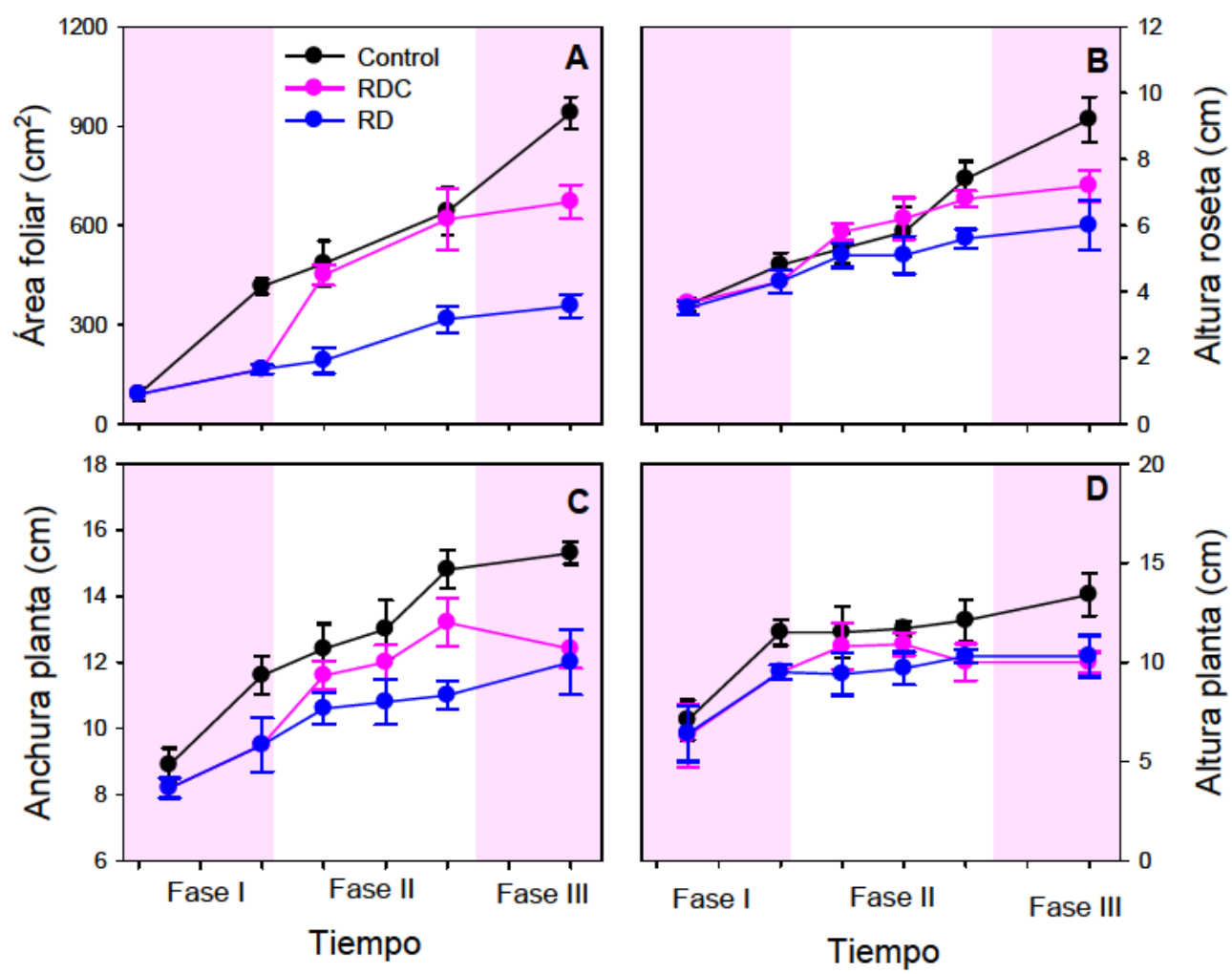

Figura 3.7- Evolución del área foliar (A), altura de la roseta (B), anchura de la planta (C) y altura de la planta (D) en plantas de clavel en maceta sometidas a distintos tratamientos de riego durante el período experimental Las zonas sombreadas indican el riego deficitario en las plantas del tratamiento RDC.

La altura de la planta y la anchura tuvieron una repuesta muy similar entre ellas y dependió de los tratamientos de riego. El mayor desarrollo fue para las plantas bien regadas, las cuales fueron más altas, con mayor número de brotes, más largos y mayor anchura de la planta y más tamaño de roseta (Figura 3.4 y 3.7). Ambos tratamientos de riego deficitario provocaron una disminución de la altura, pero solo RDC mejora la relación entre el tamaño de la roseta y la planta. Por tanto, este último tratamiento reduce un crecimiento excesivo de la planta y proporciona una planta más equilibrada y compacta (valores del cociente altura roseta/altura planta de $0.61,0.67$ y 0.55 que corresponden a las plantas del tratamiento Control, RDC y RD, respectivamente). La reducción de la longitud de los brotes bajo condiciones de riego deficitario controlado también ha sido observado en otras especies ornamentales (Silber y col., 2007) y este descenso en la tasa de elongación de los brotes depende de la duración, intensidad y momento en el que se aplique la fase de estrés. 
De todo ello, se deduce que la respuesta del crecimiento y desarrollo de la planta al riego deficitario estuvo influenciada por el tiempo y distribución de riego (Cameron y col., 1999). Las plantas regadas deficitariamente durante el período fase I y después de la floración (fase III), con una reducción del $25 \%$ del agua aplicada comparado con las del control, tuvieron un área foliar y peso seco total similares al tratamiento control durante la fase de floración. Al final del período experimental presentaron un descenso de lo valores de estos parámetros menos pronunciado que las plantas estresadas durante todo el período. También, durante la fase II se produce una mayor intensidad de la floración, sin un marcado descenso de altura y anchura del follaje. Durante todo el periodo experimental no se observaron síntomas visuales de lesiones en las hojas por efecto del riego deficitario.

\subsubsection{Efectos del riego deficitario controlado en el estado hídrico, regulación estomática y ajuste osmótico en plantas de clavel}

El contenido de agua en el medio $\left(\theta_{\mathrm{v}}\right)$ se midió durante todo el ciclo mediante TDR (Figura 3.8). En dicho gráfico se observa que no hubo un comportamiento estable de los distintos tratamientos ensayados, y presenta una variabilidad importante, independientemente de las dosis de agua aplicadas. Si bien, podemos detectar que la tendencia durante todo el ensayo fue a que las plantas que recibieron el tratamiento de riego deficitario sostenido tuvieron los valores más bajos de $\theta_{v}$, presentando los otros dos tratamientos (Control y RDC) valores similares durante la fase II. 


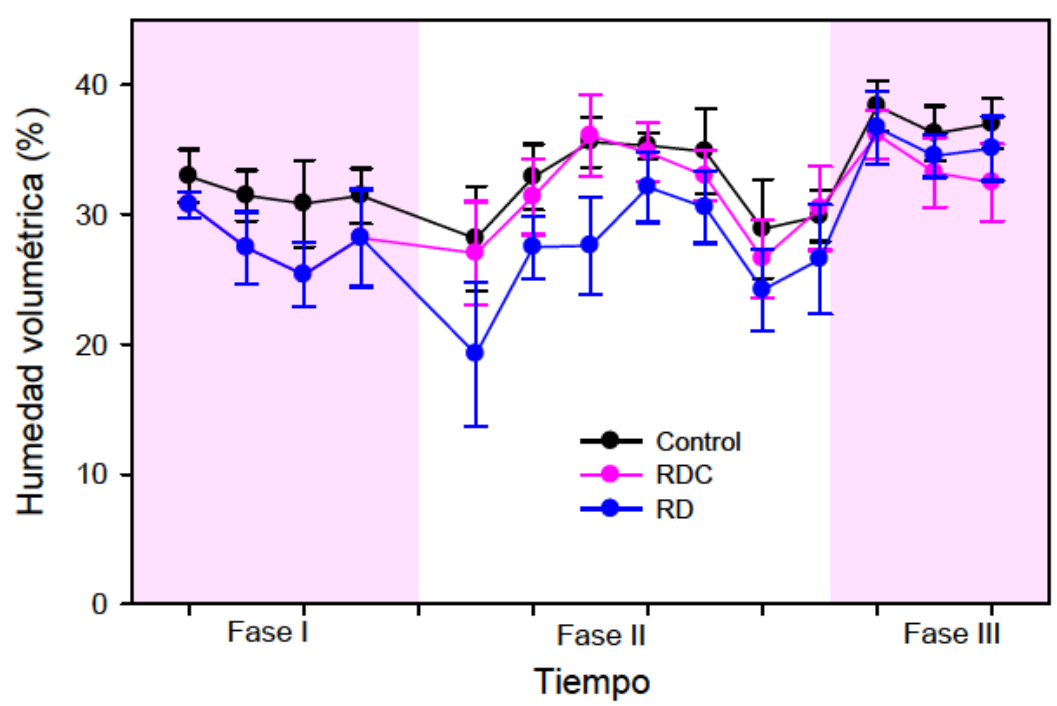

Figura 3.8- Evolución de la humedad volumétrica al mediodía en plantas de clavel en maceta sometidas a distintos tratamientos de riego durante el período experimental. Las zonas sombreadas indican el riego deficitario en las plantas del tratamiento RDC.

En momentos puntuales del ensayo, al inicio y al final de la fase II, se produce en todos los tratamientos un descenso del valor de humedad en el sustrato al mediodía, debido posiblemente a una mayor evaporación de agua desde dicho sustrato (Navarro y col., 2007), ya que en estas fechas hubo varios días con alta demanda evaporativa, en los que el promedio del déficit de presión de vapor estuvo en torno a $2.5 \mathrm{KPa}$ (Figura 3.3). No obstante, hay que tener en cuenta que aunque esta metodología es válida para un amplio rango de suelos (Topp y Davis, 1985), nuestra experiencia es que trabajando con este tipo de sustratos se puede producir falta de contacto entre las varillas y el sustrato cuando hay una desecación del mismo. En este caso, las medidas pueden no ser muy fiables.

Para saber si los cambios en los aportes hídricos de los tratamientos deficitarios se reflejaban en el estado hídrico de la plantas, se procedió a controlar el potencial hídrico foliar a lo largo de todo el ensayo, cubriendo las distintas fases que habíamos establecido en el ciclo de cultivo del clavel (Figura 3.9). 

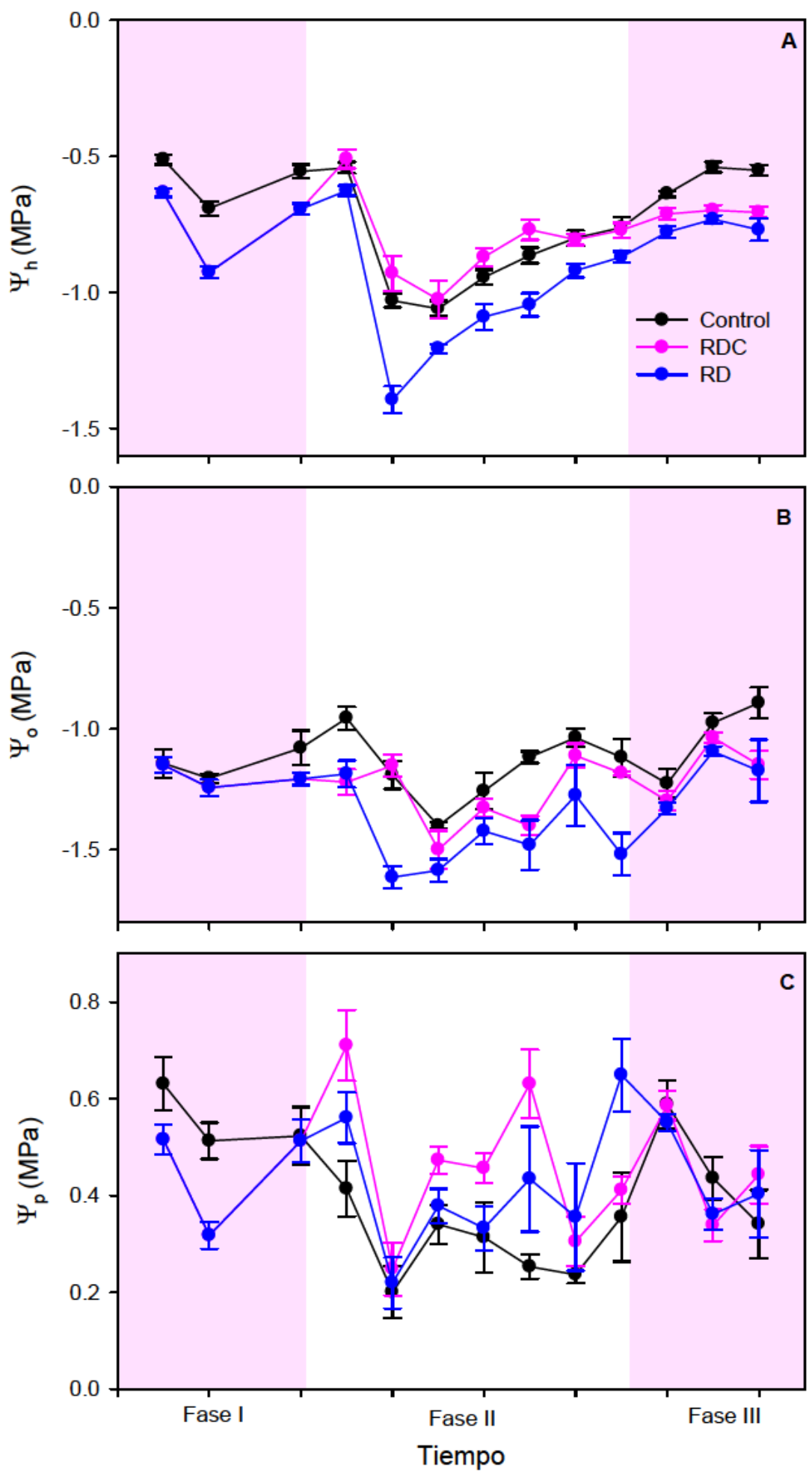

Figura 3.9- Evolución del potencial hídrico foliar $\left(\Psi_{\mathrm{h}} ; \mathrm{A}\right)$, osmótico $\left(\Psi_{\mathrm{o}} ; \mathrm{B}\right)$ y de presión $\left(\Psi_{\mathrm{p}} ; \mathrm{C}\right)$ al mediodía en plantas de clavel en maceta sometidas a distintos tratamientos de riego durante el período experimental. Las zonas sombreadas indican el riego deficitario en las plantas del tratamiento RDC. 
En general los valores de $\Psi_{\mathrm{h}}$ reflejan tanto las diferentes condiciones hídricas del substrato cómo las condiciones ambientales (Figura 3.9A). Durante la fase I y fase III se observaron los valores máximos de $\Psi_{\mathrm{h}}$ en todos los tratamientos. Al inicio de la fase de floración (fase II) y coincidiendo con finales del mes de Julio, se inicia un importante descenso de los niveles de $\Psi_{\mathrm{h}}$, independientemente del tratamiento aplicado. Se obtuvieron valores entre -1.0 MPa para el control y RDC y -1.4 MPa para RD, debido en parte al aumento del número de brotes florales y a las severas condiciones climáticas, lo que provocó una rápida evaporación del agua del sustrato después del riego y el descenso del agua disponible para la planta al mediodía en todos los tratamientos. Este hecho se observó, incluso, en el tratamiento control donde la cantidad de agua suministrada al inicio del día era suficiente para que el sustrato alcanzara la capacidad de campo. Esto fue seguido por un aumento gradual de $\Psi_{\mathrm{h}}$ hasta el final de esta fase, en donde aunque las diferencias entre tratamientos existen, éstas se hacen más pequeñas. Durante la fase III, cuando de nuevo se reducen las cantidades de agua en el tratamiento RDC, las plantas de este tratamiento presentan valores de $\Psi_{\mathrm{h}}$ similares a las del tratamiento RD y menores a las del control.

La evolución del potencial osmótico a lo largo del ensayo (Figura 3.9B) siguió un comportamiento parecido al potencial hídrico, aunque con mayor variabilidad, que hace que en algunos momentos las diferencias significativas entre los tratamientos desaparezcan. En relación al potencial de presión, sólo se apreciaron algunas pequeñas diferencias entre los tratamientos ensayados (Figura 3.9C). En este sentido, se produce un descenso de la turgencia foliar durante la fase II, debido quizás al momento de estimar dichas medidas, ello coincidió con los momentos de máxima demanda evaporativa, (primera semana de Agosto, a mediodía).

En cuanto a los valores de potencial osmótico a máxima saturación a lo largo de las distintas fases del ciclo de cultivo del clavel (Figura 3.10) observamos cómo las mayores diferencias entre los tratamientos se detectan en la fase II, presentando las plantas del tratamiento RD los valores más bajos. Las plantas del tratamiento de RDC, que durante esta fase recibían la misma cantidad de agua que las plantas control, presentan valores similares a las mismas. Solamente al inicio de esta fase y en algún momento puntal hay ligeras diferencias, quizás por el historial hídrico previo de las plantas en la fase I, cuando se redujo el riego en estas. 


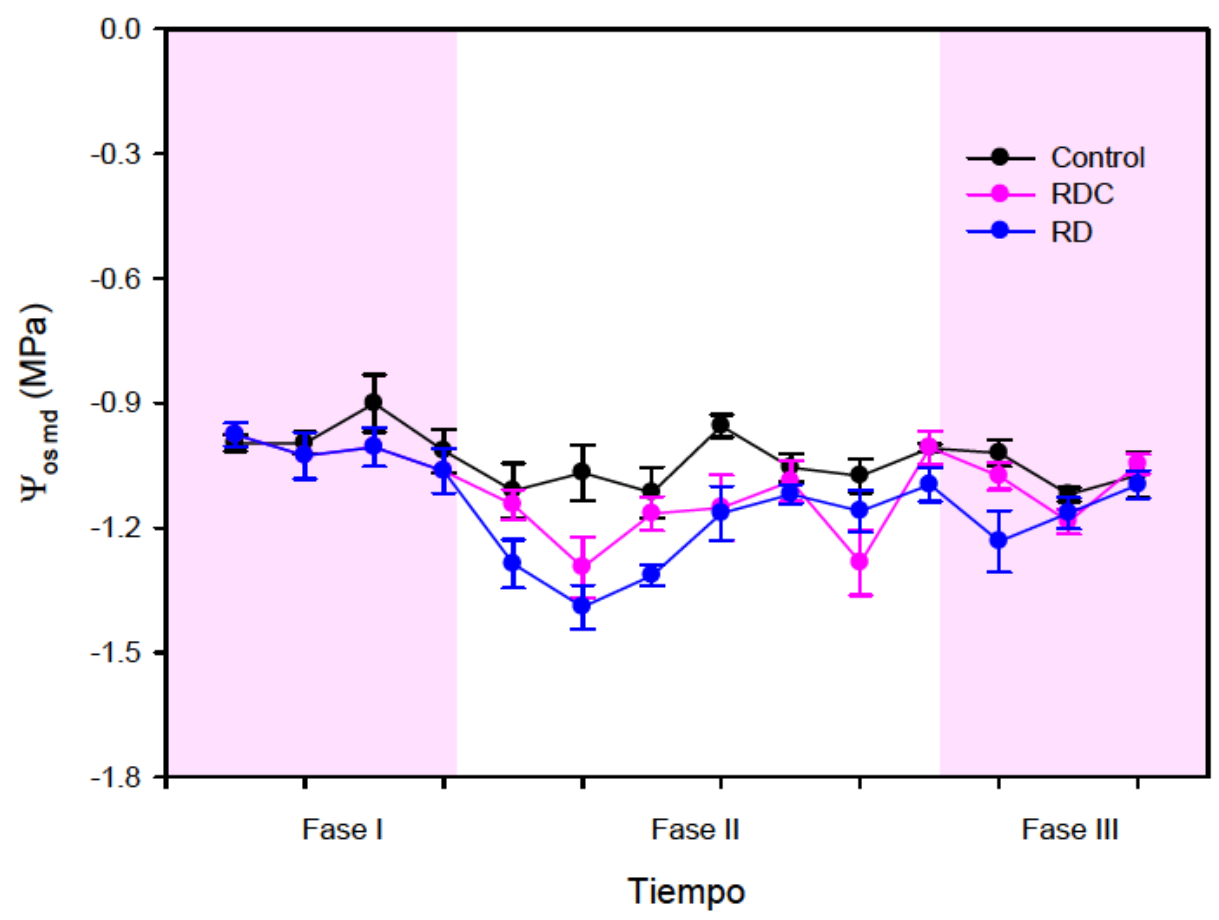

Figura 3.10- Evolución del potencial osmótico saturado $\left(\Psi_{\text {os }}\right)$ al mediodía en plantas de clavel en maceta sometidas a distintos tratamientos de riego durante el período experimental. Las zonas sombreadas indican el riego deficitario en las plantas del tratamiento RDC.

La eficiencia intrínseca del uso del agua $\left(P_{n} / g_{s}\right)$ indicó que dicho parámetro tendió a aumentar en el tratamiento más deficitario, ya que la reducción de fotosíntesis fue menor que la de la conductancia estomática por efecto del estrés hídrico (valores de $\mathrm{P}_{\mathrm{n}} / \mathrm{g}_{\mathrm{s}}$ de 25 y $32 \mu \mathrm{mol} \mathrm{CO}_{2} \mathrm{~mol}^{-1}$ $\mathrm{H}_{2} \mathrm{O}$ para las plantas del tratamiento Control y RD, respectivamente). La ventaja en este contexto es que dicha situación puede permitir una mayor acumulación de reservas en forma de carbohidratos en la planta, lo cual, junto con un incremento en el cociente raíz/ parte aérea, podría promover un más rápido establecimiento de las plantas ornamentales a las condiciones de jardín o campo (Cameron y col., 2006).

Aumentos de los valores de $\mathrm{P}_{\mathrm{n}} / \mathrm{g}_{\mathrm{s}}$ en plantas sometidas a riego deficitario han sido encontrados en otros trabajos (Mugnai y col., 1995). Otros autores, sin embargo, encuentran que la fotosíntesis se reduce más que la conductancia, con lo que se produce un descenso $\mathrm{P}_{\mathrm{n}} / \mathrm{g}_{\mathrm{s}}$ (Anyia y Herzog, 2004). Estos autores sugieren que en este caso, además del cierre estomático, el aparato fotosintético (acción enzimática) es también parcialmente inhibido. Los resultados obtenidos por Anyia y Herzog (2004) no concuerdan con los encontrados por Hall y col. (1992) en la 
misma especie, quienes encontraron que la fotosíntesis en plantas sometidas a estrés hídrico descendió menos que la conductancia. Estas diferencias pueden deberse a diferencias en la intensidad y duración del estrés hídrico (Anyia y Herzog, 2004). Según Lenzi y col. (2009) en plantas de adelfa, el estrés hídrico afecta a ambos términos $\left(P_{n}\right.$ y $\left.g_{s}\right)$. En los primeros estados, el efecto en la transpiración puede ser mayor que el efecto en la fotosíntesis, pudiendo resultar en un aumento de la eficiencia intrínseca $\left(\mathrm{P}_{\mathrm{n}} / \mathrm{g}_{\mathrm{s}}\right)$. Pero después, si el estrés continúa y llega a ser severo, frecuentemente la eficiencia disminuye.

De los resultados obtenidos en estos ensayos podemos concluir que el riego deficitario puede mejorar la eficiencia en el uso del agua reduciendo el consumo de agua y puede servir de herramienta para regular el crecimiento excesivo de las plantas de clavel cultivadas en maceta, pero el grado de estrés impuesto por dicho riego es crítico para la respuesta de esta especie. El grado de inhibición del crecimiento está relacionado con la severidad del estrés, pero una apropiada programación del riego deficitario en relación al estado de desarrollo puede mejorar la calidad final de la planta, promoviendo la formación de una planta compacta con una estructura proporcionada a su tamaño final.

Las adaptaciones de la planta ante un aporte de agua reducido fueron logradas a través de un descenso de la conductancia estomática y, a más largo plazo, de una reducción en el área de las hojas. Aunque el descenso de los niveles de agua de las hojas fue bastante evidente, respuestas fisiológicas como ajuste osmótico, acompañado de descensos en la elasticidad muestran que esta especie previene la pérdida de turgencia y de daños visuales ante períodos de déficit hídrico. A pesar de los útiles resultados obtenidos en estos ensayos, se requieren estudios adicionales para determinar la distribución, duración, frecuencia e intensidad de estrés más adecuados durante cada fase de crecimiento para optimizar el desarrollo vegetativo y floral. 
Capítulo 4

Respuesta de plantas de geranio regadas con distintos niveles de déficit hídrico y durante un período de recuperación. Aplicación de riego deficitario en distintos momentos fenológicos en condiciones controladas 



\subsection{Introducción}

El riego deficitario $(R D)$ se ha utilizado como técnica para reducir el crecimiento vegetativo en las plantas ornamentales, donde un excesivo vigor de los brotes no es conveniente para la calidad de la planta (Cameron y col., 1999; 2006). El RD reduce la disponibilidad del agua en el medio de cultivo por la limitación de la cantidad de agua aplicada, normalmente como una reducción del porcentaje de la evapotranspiración. Conforme el déficit progresa, la conductancia y la transpiración descienden y también se producen alteraciones en el potencial hídrico, potencial osmótico y elasticidad de las paredes celulares como mecanismos de adaptación. Sin embargo, estas modificaciones, una vez se haya restaurado la condiciones de buen riego, pueden mantenerse o no, ello dependerá de la severidad del grado de déficit hídrico aplicado, periodo de tiempo o de la especie en estudio. La aplicación de RD tiene implicaciones no solo como efecto en la regulación del crecimiento, si no como una preadaptación de las plantas a posteriores eventos de estrés. A pesar de todo esto, las plantas ornamentales en maceta no han sido objeto de estudio frecuente y poco ha sido publicado en cuanto al comportamiento de determinadas plantas ornamentales al déficit hídrico y a su recuperación, a pesar de que tales plantas constituyen una parte importante de la producción hortícola. En este sentido, Arora y col. (1998) aportan que los geranios presentan una significativa tolerancia al déficit hídrico, aunque hay pocos datos disponibles sobre este aspecto.

El geranio zonal (Pelargonium $\mathrm{x}$ hortorum) es una planta ornamental muy popular por su vistosa y prolífera floración, siendo utiliza como planta en maceta. Como hemos visto en el capitulo anterior, el riego deficitario puede ser una herramienta eficaz para controlar el crecimiento y desarrollo de la planta. Sin embargo, es importante conocer el porcentaje de reducción del agua aportada necesaria para que el valor ornamental de las plantas en cada especie no se vea mermado (Chyliński y col., 2007).

El objetivo de este estudio es analizar el funcionamiento de estas plantas regadas con distintos niveles de riego, dos de ellos deficitarios, y evaluar el efecto del historial hídrico previo de una planta durante una fase de recuperación con riego control. Esto se hizo en términos de 
crecimiento, caracteres ornamentales, fotosíntesis, conductancia estomática y parámetros hídricos. Estos estudios pueden resultar de gran importancia, lo cual es importante para elaborar estrategias de déficit hídrico que permitan variar las cantidades de riego conforme a las exigencias de las sucesivas fases fenológicas.

\subsection{Efecto de distintos niveles de déficit hídrico y grado de recuperación en plantas de geranio}

\subsubsection{Material y métodos}

\subsubsection{Material vegetal y condiciones experimentales}

El material estudiado fue geranio zonal (Pelargonium x hortorum L.H. Bailey) adaptado para maceta provisto de flores rojas. Los esquejes llegaron enraizados en cepellón formado por turba y perlita, con una altura aproximada entre 6 y $8 \mathrm{~cm}$ y con $6-7$ hojas. Las plantas se transplantaron en macetas con diámetro de $14 \mathrm{~cm}$ y $12.8 \mathrm{~cm}$ de altura (1.2 I de volumen), que contenían una mezcla de turba rubia, perlita y fibra de coco (6:3:1), añadiéndose $2 \mathrm{~g} \mathrm{I}^{-1}$ sustrato de osmocote (abono de lenta liberación, 14:13:13 N, P, K + microelementos). El experimento se llevó a cabo en una cámara de crecimiento (Fotografía 4.1), en condiciones controladas, durante 16 semanas. Las condiciones ambientales de la cámara fueron seleccionadas para simular los cambios naturales en temperatura y luz (PAR) y teniendo en cuenta las condiciones necesarios para que se produzca la floración en $P$. hortorum (Armitage y col., 1981; Rouphael y col., 2008; Blanchard y Runkle, 2011).

Ambos parámetros, luz y PAR, aumentaban gradualmente a partir de las $6 \mathrm{~h}$ hasta alcanzar los valores máximos de temperatura y luz y después disminuir progresivamente hasta oscuridad, según condiciones de la Tabla 4.1. La humedad relativa osciló entre 40 y $60 \%$. Todas las plantas se regaron hasta capacidad de campo antes de empezar los tratamientos durante 5 semanas. 
Tabla 4.1- Evolución diaria de las condiciones de luz y temperatura en la cámara de crecimiento.

\begin{tabular}{cccc}
\hline Hora & Fase & Temperatura $\left({ }^{\circ} \mathrm{C}\right)$ & PAR $\left(\mu \mathrm{mol} \mathrm{m}^{-2} \mathrm{~s}^{-1}\right)$ \\
\hline 22:00-06:00 & Oscuridad & 22 & 0 \\
06:00-08:00 & Luz I & 23 & 100 \\
08:00-11:00 & Luz II & 24 & 200 \\
11:00-17:00 & Luz III & 26 & 350 \\
17:00-20:00 & Luz II & 24 & 200 \\
20:00-22:00 & Luz I & 23 & 100 \\
\hline
\end{tabular}

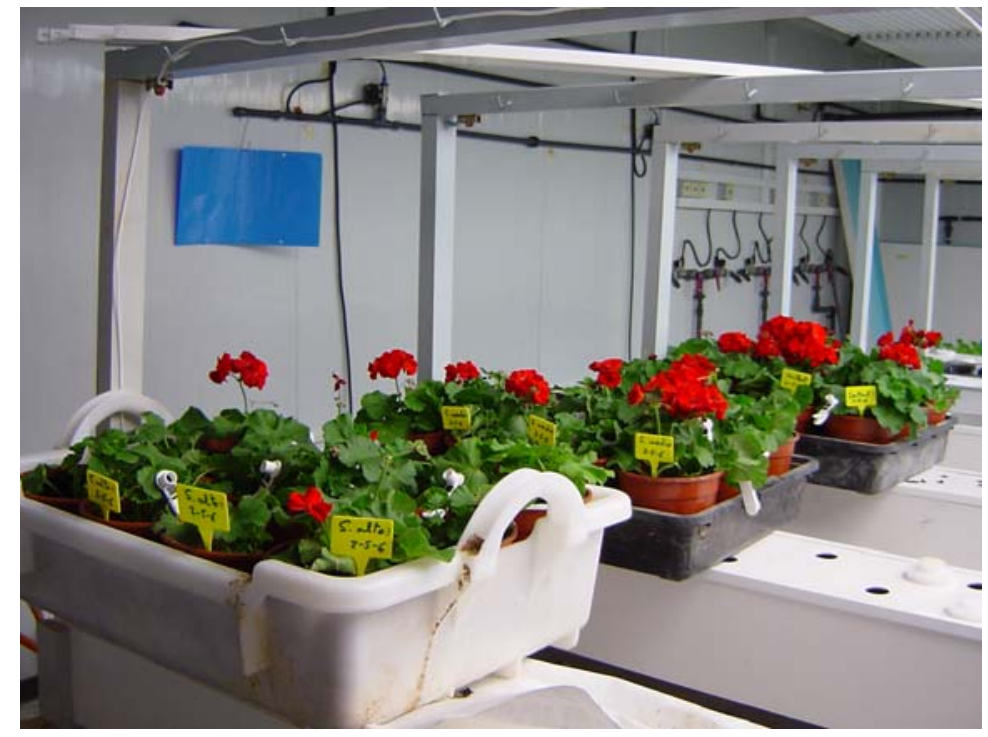

Fotografía 4.1- Cámara de crecimiento, vista general de las plantas de geranio en la cámara de crecimiento durante el período experimental.

\subsubsection{Tratamientos y diseño experimental}

Las plantas se agruparon en tres repeticiones con seis plantas por tratamiento (54 plantas en total) y durante seis semanas se aplicaron tres tratamientos de riego con distintas dosis de agua: capacidad de campo (Control), 60\% del control (riego deficitario moderado, RDM) y 40\% del control (riego deficitario severo, RDS). Todas las plantas se regaban 2 días a la semana. El riego de las plantas control se iba modificando a lo largo del ensayo para mantener estas plantas cercanas a su peso a capacidad de campo (Figura 4.1), el riego se ajustaba buscando una cantidad de drenaje, en torno al $15 \%$ del agua aplicada para asegurarnos que en esas plantas se cubría el total de las necesidades hídricas. Después del riego no se obtenía drenaje en los tratamientos de riego deficitario. En esta fase, la cantidad de agua aplicada al control varió entre 
200 y $350 \mathrm{ml}$ por planta y semana. La media de agua aportada fue 41 $\mathrm{ml} /$ día para el control y 24 y 16 ml/día para RDM y RDS, respectivamente.

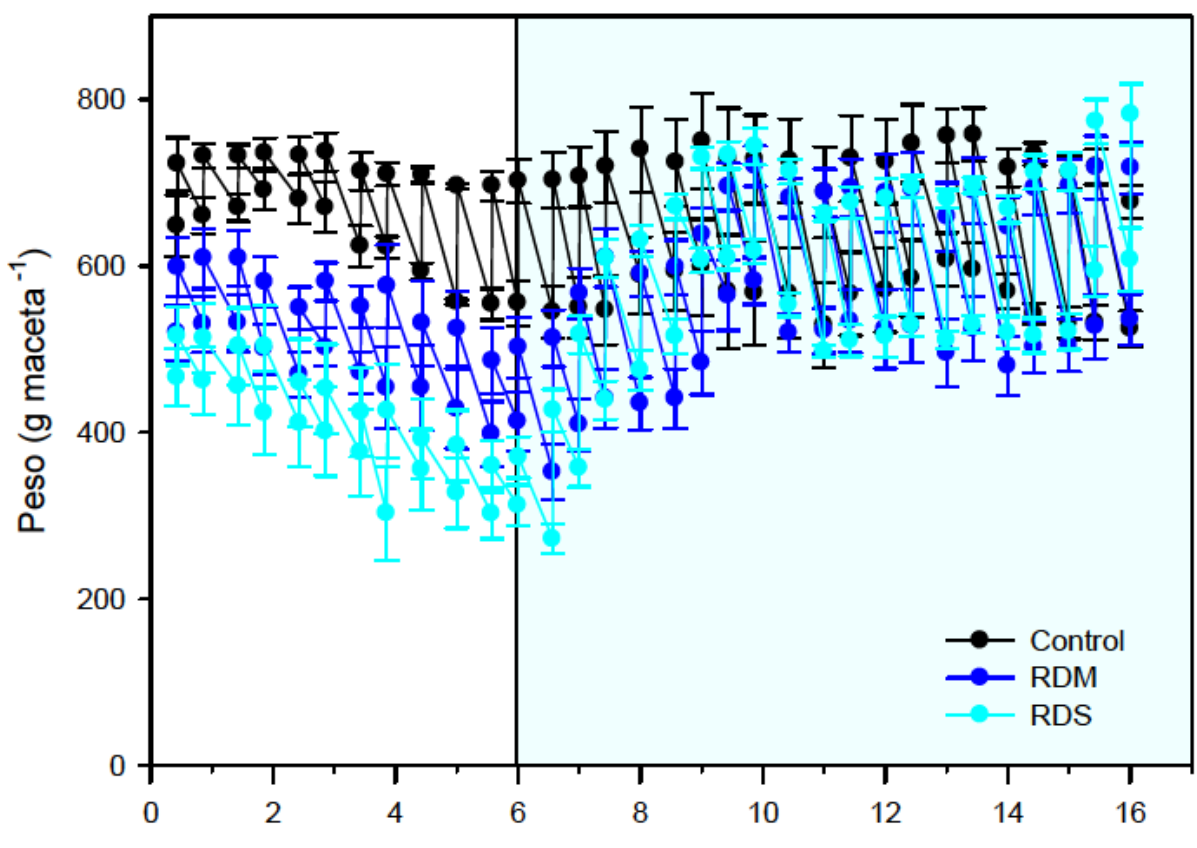

Tiempo desde inicio tratamientos (semanas)

Figura 4.1- Evolución del peso (promedio de 5 macetas por tratamiento) antes y después de cada riego en plantas de geranio sometidas a distintos tratamientos de riego durante el periodo experimental. La zona sombreada indica la fase de recuperación.

A partir de ahí y hasta el final del ensayo, todas las plantas se sometieron a un período de recuperación de 10 semanas, regándose con la misma cantidad agua que se aplicaba a las plantas control. En esta fase la cantidad de agua aplicada varió ente 340 y $400 \mathrm{ml}$ por planta y semana y la media diaria de agua aportada fue $50 \mathrm{ml}$ por planta.

Las plantas del tratamiento control se regaban en función de su consumo. El peso de las macetas iba descendiendo debido a la evapotranspiración hasta el riego siguiente, momento en el que se volvían a pesar las macetas y se restablecía el peso, compensando las pérdidas de agua que se habían producido desde el riego anterior. De esta forma, durante todo el ensayo las plantas control tuvieron un peso después del riego más o menos estable, cercano a capacidad de campo. Ello nos lo aseguraba que después de cada riego se produjera drenaje (15\% del riego). Sin embargo las plantas de los tratamientos deficitarios no se regaban en función de su consumo, se regaban en base a un porcentaje de la cantidad de las plantas control. Las plantas sometidas a RD fueron 
perdiendo peso sucesivamente, las plantas del tratamiento RDM durante las 6 semanas de la fase de estrés descendieron su peso hasta el $70 \%$ de este umbral, y las plantas del tratamiento RDS redujo su peso tiempo hasta llegar al $50 \%$ de su peso a capacidad de campo al final de la fase de estrés. Durante la fase de recuperación, siguiendo con el mismo protocolo de riego, las plantas del tratamiento control continuaron regándose en función de su consumo, para restaurar el agua perdida por evapotranspiración y los tratamientos previamente recibieron la misma cantidad de agua que el control. De este modo, las plantas previamente estresadas tardan 3-4 semanas en alcanzar capacidad de campo.

\subsubsection{Crecimiento y parámetros ornamentales}

La biomasa seca de los distintos órganos de las plantas (raíz, tallos, hojas y flores) se determinó en 7 plantas por tratamiento, al final del período de estrés (semana 6 desde el inicio de los tratamientos) y al final del período de recuperación (semana 16), según se describe en el apartado 3.2.1.3.de esta memoria (Fotografía 4.2).
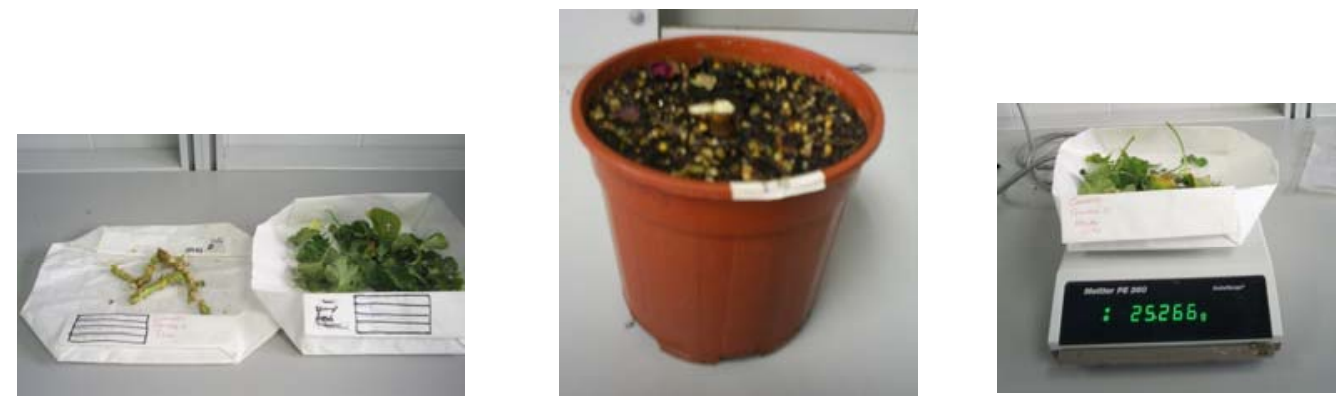

Fotografía 4.2- Muestreo destructivo en plantas de geranio al final de la fase de estrés y de recuperación.

En estas plantas también se midió el área del limbo foliar con la ayuda de un medidor del área foliar, tal y como se explica en el apartado 3.2.1.3 de esta memoria (Fotografía 4.3).

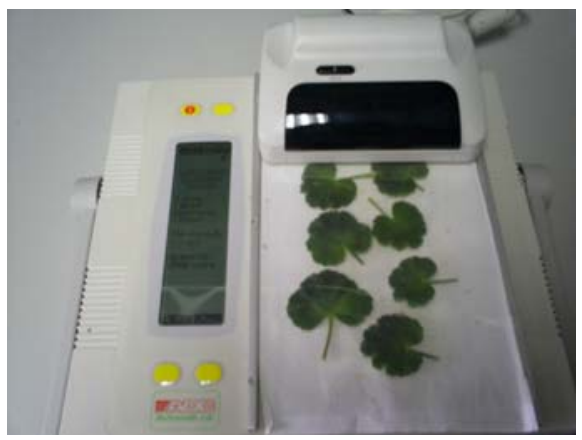

Fotografía 4.3- Midiendo área foliar en hojas de geranio. 
Semanalmente se midió la altura máxima de los brotes y la anchura de la planta en todas las plantas del ensayo (18 plantas por tratamiento) de acuerdo con la Fotografía 4.4.

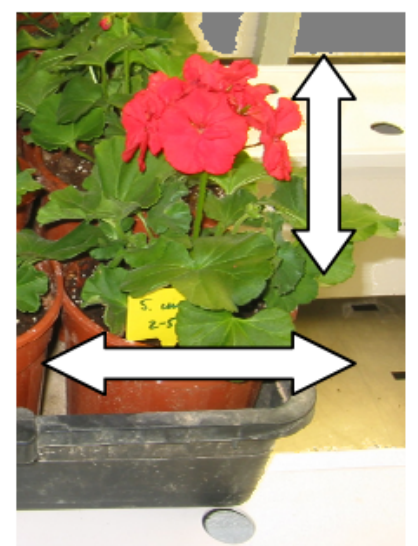

Fotografía 4.4- Esquema de la medida de altura máxima (longitud de los brotes) y anchura de la planta.

A lo largo del ensayo se realizo también un seguimiento de la floración en todas las plantas. Se controló el número de inflorescencias sin abrir, el número de inflorescencias abiertas y el número de hojas caídas por planta (Fotografía 4.5) durante todo el periodo experimental.
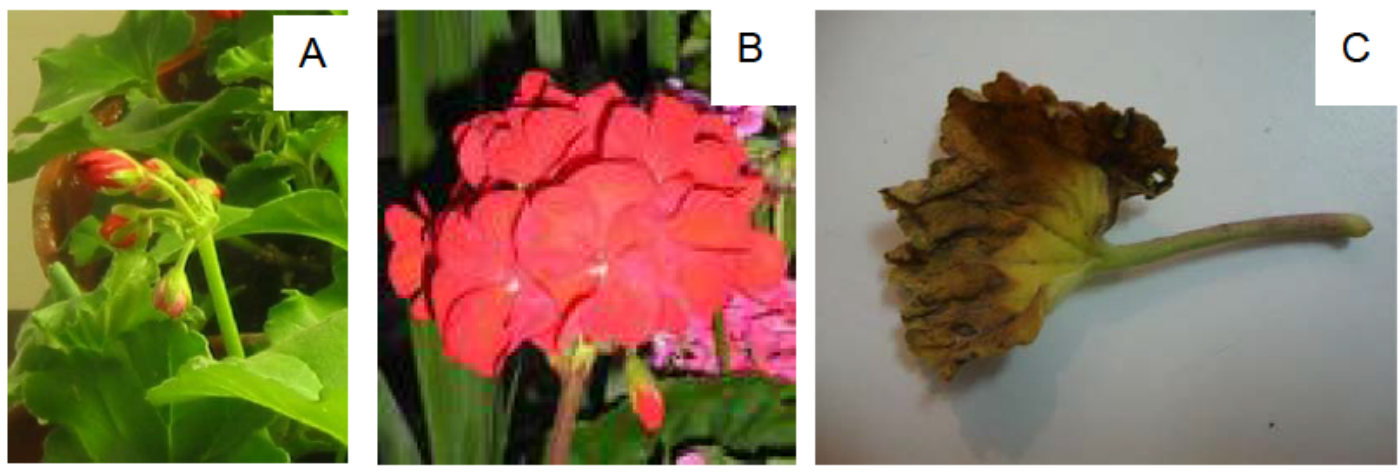

Fotografía 4.5- Inflorescencia sin abrir (A), inflorescencia abierta (B) y pérdida de hojas (C).

Periódicamente se determinaron los parámetros relacionados con el color en hojas y flores en 8 plantas por tratamiento. La descripción de las coordenadas de color se explica detalladamente en el apartado 3.2.1.3. 


\subsubsection{Consumo, relaciones hídricas, intercambio gaseoso y fluorescencia}

El consumo de agua se midió gravimétricamente durante todo el período experimental y se determinó por diferencia de pesos (peso después del riego, hasta que deja de drenar y peso antes del riego siguiente). Cada maceta (5 plantas por tratamiento) se colocaba sobre una balanza (capacidad $5.2 \mathrm{Kg}$ y precisión de $0.01 \mathrm{~g}$, Sartorius, modelo 5201).

En tres momentos de la de fase estrés, (semana $0.57,2.57$ y 4.86 ), se midió potencial hídrico foliar $\left(\Psi_{h}\right)$, potencial osmótico actual $\left(\Psi_{0}\right)$, potencial de presión $\left(\Psi_{\mathrm{p}}\right)$, conductancia estomática $\left(\mathrm{g}_{\mathrm{s}}\right)$, y tasa de fotosíntesis neta $\left(P_{n}\right)$ a intervalos de $3 \mathrm{~h}$ (evolución diaria). Durante la fase de recuperación, semana 7,8 y 10 , también se midieron $\Psi_{h}, \Psi_{\circ}$ y $\Psi_{p}$, antes de la fase luminosa y en la fase de máxima luminosidad. La conductancia estomática y fotosíntesis se determinaron en la fase de máxima luminosidad. Todos estos parámetros se midieron en 5 plantas por tratamiento según la metodología descrita en el apartado 3.2.1.4.

Las medidas del contenido relativo de agua (CRA) y potencial osmótico saturado $\left(\Psi_{\text {os }}\right)$ se realizaron en las horas centrales del período luminoso y en 5 plantas por tratamiento a lo largo del período experimental

El contenido relativo de agua foliar (Fotografía 4.6) se determinó según Barrs (1968) a partir de la siguiente expresión: CRA= [(PF-PS)/(PTPS)] ${ }^{*} 100$, donde PF es el peso fresco, PS es el peso seco y PT el peso turgente. El peso fresco corresponde al peso foliar en el momento del muestreo, el peso turgente es el peso de las hojas tras su saturación en agua destilada a $4{ }^{\circ} \mathrm{C}$ en la oscuridad, para evitar pérdidas de peso por respiración y síntesis de biomasa, y el peso seco es el peso de las hojas tras colocarlas en la estufa a $80^{\circ} \mathrm{C}$ hasta peso constante.
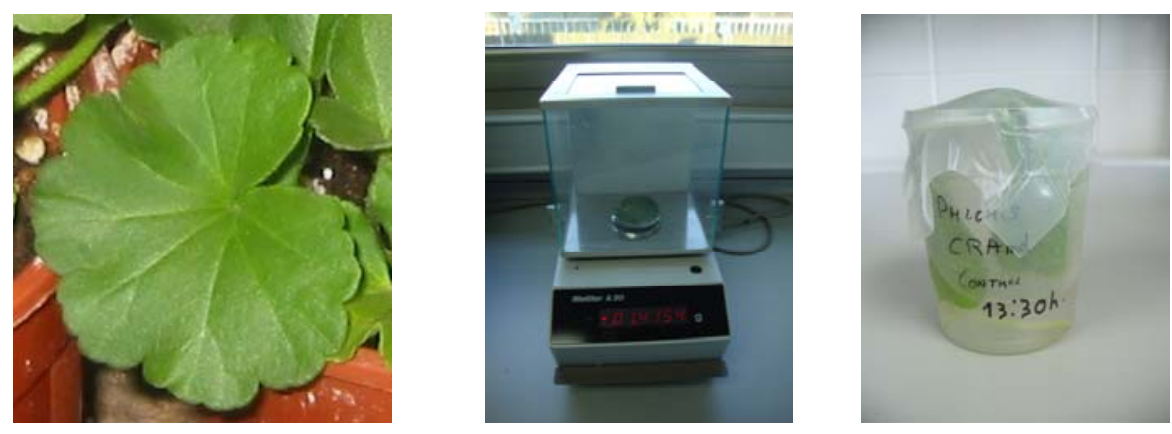

Fotografía 4.6- Medida del contenido relativo de agua en plantas de geranio. 
Las hojas tomadas para la determinación del potencial osmótico saturado fueron introducidas por el pecíolo en vasos de agua destilada a $4{ }^{\circ} \mathrm{C}$, en la oscuridad, para alcanzar la completa turgencia. Una vez alcanzada la máxima turgencia, unas 24 horas, las hojas se secaron con papel de filtro para eliminar el agua superficial, y se envolvieron en papel de aluminio e introdujeron en nitrógeno líquido, determinándose posteriormente, el potencial osmótico a máxima saturación mediante la misma metodología empleada para el potencial osmótico actual $\left(\Psi_{\circ}\right)$, previamente descrita en el apartado 3.2.1.4.

Al final de los tratamientos de riego (período de estrés), se procedió al muestreo de hojas para la elaboración de curvas presiónvolumen, en tres hojas por planta y 5 plantas por tratamiento, a partir de las que se determinaron los siguientes parámetros: potencial osmótico saturado ( $\left.\Psi_{\mathrm{os}}\right)$, potencial en el punto de pérdida de turgencia ( $\left.\Psi_{\mathrm{ppt}}\right)$, contenido relativo de agua en el punto de pérdida de turgencia $\left(\mathrm{CRA}_{\mathrm{ppt}}\right)$ y el módulo de elasticidad $(\varepsilon)$. La realización de las medidas y la obtención de todos estos parámetros derivados de las curvas presión volumen fueron realizadas de acuerdo a la metodología ya descrita en el apartado 3.2.1.4.

Los valores de fluorescencia fueron medidos en la superficie foliar $\left(F_{\mathrm{v}} / F_{\mathrm{m}}\right)$ y se tomaron con un fluorímetro portátil OptiScience (Modelo OS 30; Opti-Sciences Inc., Tyngsboro, MA, USA), (Fotografía 4.7). Las medidas de fluorescencia se realizaron en cinco plantas por tratamiento al mediodía y las hojas estuvieron previamente en la oscuridad durante 20 minutos (Camejo y col., 2005).

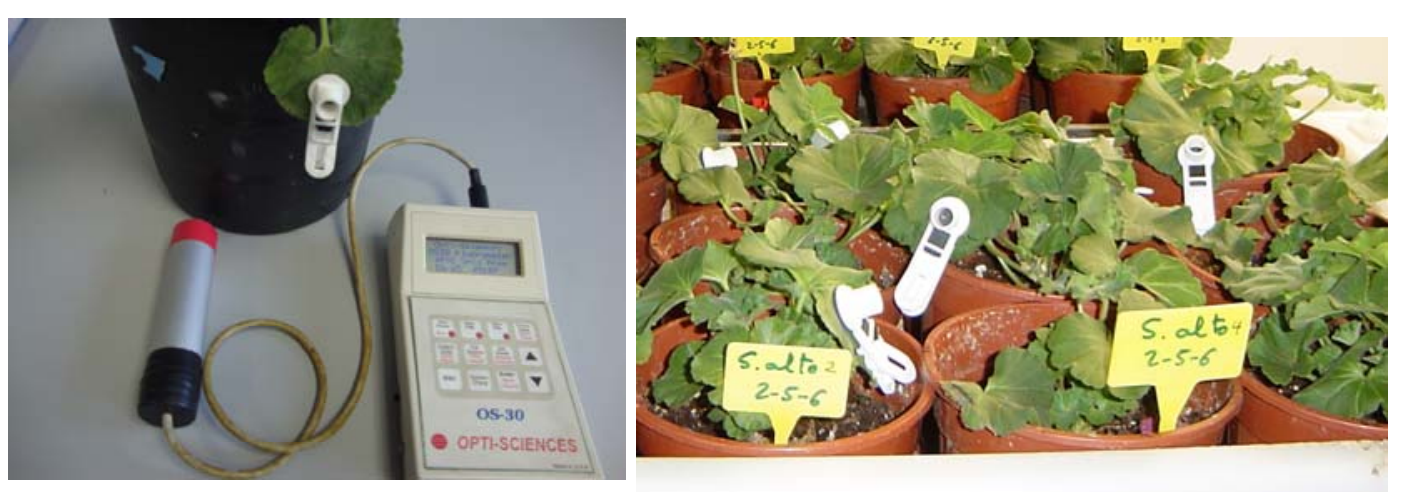

Fotografía 4.7- Fluorímetro portátil OptiScience, Modelo OS 30 y medida de fluorescencia en hojas de geranio. 


\subsubsection{Análisis estadístico}

La significación de los efectos de la dosis de riego fue analizada mediante un análisis de varianza simple (ANOVA), usando Statgraphics Plus para Windows. Las medias de los tratamientos fueron separadas con la Prueba de Rango Múltiple de Duncan $(P<0.05)$. Antes del análisis estadístico, cocientes y datos en porcentajes fueron previamente transformados mediante una transformación arcoseno raíz cuadrada, para asegurar la homogeneidad de la varianza.

\subsubsection{Resultados y discusión}

\subsubsection{Efectos del riego deficitario en el crecimiento y parámetros ornamentales en plantas de geranio durante la fase de déficit hídrico y de recuperación}

La reducción del desarrollo de las plantas sometidas a riego deficitario fue, por lo general, significativa y proporcional al nivel de déficit aplicado, aunque no hubo diferencias para todos los parámetros estudiados (Tabla 4.2 y Figura $4.2 \mathrm{~A}-\mathrm{B}$ ).

Al final del periodo de déficit hídrico, las plantas del tratamiento control experimentan un mayor crecimiento como lo indican los valores de peso seco de hojas, tallos y flores (PS aéreo) y éste decreció en las plantas sometidas a riego deficitario (Tabla 4.2). Sin embargo, no hubo diferencias significativas en el crecimiento radical (PS raíz) de las plantas de geranio por efecto del riego, lo que generó un aumento del cociente PS raíz/PS aéreo en las plantas sometidas a riego deficitario.

Tabla 4.2- Crecimiento en plantas de geranio en maceta sometidas a distintos tratamientos de riego al final del período de estrés y de recuperación.

\begin{tabular}{|c|c|c|c|c|}
\hline Parámetros & Fase & Control & RDM & RDS \\
\hline PS raíz & Estrés & $2.72 \pm 0.39 a$ & $3.22 \pm 0.55 a$ & $2.89 \pm 0.10 \mathrm{a}$ \\
\hline (g planta-1) & Recuperación & $2.36 \pm 0.23 \mathrm{a}$ & $2.76 \pm 0.55 a$ & $2.67 \pm 0.10 a$ \\
\hline PS hojas y tallo & Estrés & $3.97 \pm 0.47 b$ & $2.61 \pm 0.44 a$ & $1.65 \pm 0.18 a$ \\
\hline (g planta-1) & Recuperación & $8.78 \pm 0.41 c$ & $6.79 \pm 0.42 b$ & $5.38 \pm 0.30 a$ \\
\hline PS flores & Estrés & $1.00 \pm 0.22 b$ & $0.20 \pm 0.17 \mathrm{a}$ & $0.03 \pm 0.01 \mathrm{a}$ \\
\hline (g planta-1) & Recuperación & $2.29 \pm 0.29 a$ & $2.29 \pm 0.12 \mathrm{a}$ & $2.20 \pm 0.24 a$ \\
\hline \multirow[t]{2}{*}{ PS raíz/PS aereo } & Estrés & $0.56 \pm 0.08 \mathrm{a}$ & $1.19 \pm 0.22 b$ & $1.78 \pm 0.17 c$ \\
\hline & Recuperación & $0.21 \pm 0.02 \mathrm{a}$ & $0.31 \pm 0.02 b$ & $0.35 \pm 0.02 b$ \\
\hline \multirow[t]{2}{*}{$\mathrm{N}^{0}$ de hojas planta-1 } & Estrés & $28.00 \pm 2.97 b$ & $24.50 \pm 1.19 a b$ & $18.50 \pm 0.96 a$ \\
\hline & Recuperación & $63.90 \pm 4.19 \mathrm{a}$ & $60.17 \pm 4.28 \mathrm{a}$ & $65.19 \pm 6.39 a$ \\
\hline \multirow{2}{*}{$\begin{array}{l}\text { Área foliar unitaria } \\
\left(\mathrm{cm}^{2}\right)\end{array}$} & Estrés & $20.03 \pm 0.69 b$ & $14.45 \pm 2.06 \mathrm{a}$ & $12.57 \pm 1.25 \mathrm{a}$ \\
\hline & Recuperación & $30.57 \pm 2.21 \mathrm{~b}$ & $28.69 \pm 2.81 b$ & $19.86 \pm 1.24 \mathrm{a}$ \\
\hline
\end{tabular}

Distintas letras dentro de una misma fila indican diferencias significativas. 
Los valores de peso seco de la parte aérea (hojas + tallo + flores) fueron aproximadamente de $5.0 \mathrm{~g}$ para el tratamiento control frente a los 2.8 y 1.7 g para RDM y RDS, respectivamente. Estos valores equivalen a unos porcentajes de crecimiento del 57\% y $34 \%$ para RDM y RDS, respectivamente, en relación a las plantas control. Estas diferencias se reducen a $82 \%$ y $68 \%$ al final de la fase de recuperación.

La diferente cantidad de agua aportada a las plantas influye en su morfología, fisiología y distribución de la biomasa entre parte aérea y la raíz (Franco y col., 2006). Nuestros resultados indican que los brotes y las raíces de las plantas de geranio reaccionaron de forma diferente ante una situación de déficit hídrico (Rasoul Sharifi y Rudel, 1993; Chylińsky y col., 2007), como así lo confirman los mayores valores de cociente peso seco raíz/aéreo en las plantas que reciben menos agua (Sánchez-Blanco y col., 2002; Bargali y Tewari, 2004). La redistribución de la materia seca a favor de las raíces a expensas de la parte aérea (Brugnoli y Bjorkman, 1992) es probablemente debido a la necesidad de las plantas de mantener, por un lado, la superficie radical con mayor capacidad para absorber agua del sustrato, cuando hay menor volumen de agua (Bradford y Hsiao, 1982) y, por otro, para reducir la superficie evaporativa (De Herralde y col., 1998).

El número de hojas por planta se redujo en ambos tratamientos deficitarios, aunque estas diferencias solo son significativas en el tratamiento de déficit hídrico más severo, sin embargo, el área unitaria fue menor en ambos tratamientos durante la fase de estrés, aunque estas diferencias desaparecen en el RDM al final de la fase de recuperación. En este punto, las plantas del tratamiento RDS se igualan en número de hojas, pero siguen siendo más pequeñas (Tabla 4.2).

La producción y pérdida de hojas son parámetros sensibles al déficit hídrico y se ven afectadas cuando desciende la disponibilidad de agua en el suelo (Amer y Williams, 1958; Sánchez-Blanco y col., 2002; Bargali y Tewari, 2004). Según Hassanein y Dorion (2006), cuando disminuye la disponibilidad de agua en el sustrato, la producción de hojas es uno de los parámetros que primero se reduce. La sensibilidad al déficit hídrico del área foliar es mayor que otros parámetros, que solo se afectan cuando se alcanzan potenciales hídricos en el suelo más bajos. 
Las plantas desarrollan diferentes estrategias de crecimiento y anatómicas (área foliar, pérdida de hojas, densidad de estomas, etc.) para adaptarse al estrés hídrico y han sido utilizadas para evaluar la tolerancia a la sequía de diferentes cultivares de Pelargonium $x$ hortorum (Hassanein y Dorion, 2006; Metwally y col., 1970).

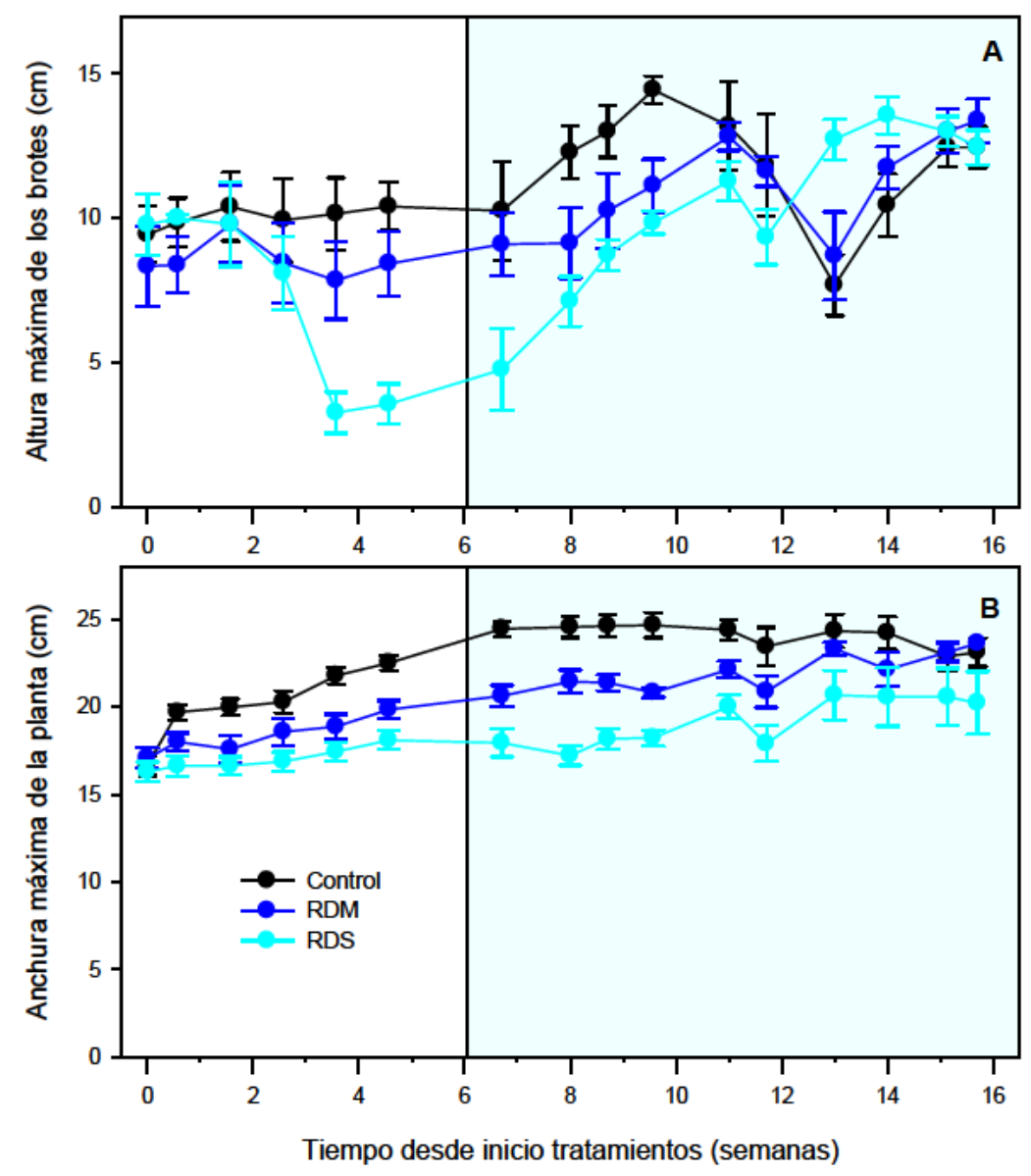

Figura 4.2- Evolución de los parámetros de crecimiento (altura, A; anchura, B) en plantas de geranio en maceta sometidas a distintos tratamientos de riego durante el periodo experimental. La zona sombreada indica la fase de recuperación.

El riego deficitario redujo la altura de los brotes y la anchura máxima de la planta (Figura 4.2). Esta disminución fue proporcional al nivel de déficit hídrico impuesto. El tratamiento de RDM reduce la altura de sus brotes al $83 \%$ del control y el RDS al 73\% (Figura 4.2A), mientras la anchura de la planta se reduce al 88 y al $80 \%$ en RDM y RDS respectivamente (Figura 4.2B), lo que indica un mayor efecto sobre el crecimiento vertical que sobre el horizontal (Fotografía 4.8). Este resultado es uno de los aspectos positivos de la aplicación del riego deficitario, ya que la reducción de la altura de la planta facilita el manejo 
de la planta en el transporte y posterior transplante, (Lang y Trellinger, 2001; Van lersel y Nemali, 2004).

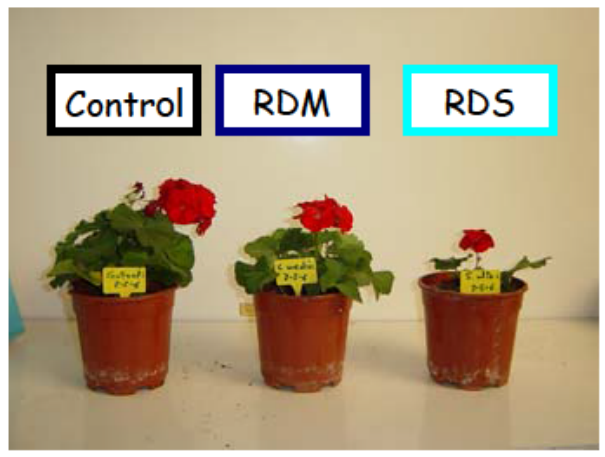

Fotografía 4.8- Aspecto de plantas de geranio al final de la fase de estrés.

Cinco semanas después del inicio de la fase de recuperación, las plantas del tratamiento deficitario moderado presenta brotes similares a los de las plantas control y la recuperación de la anchura de la planta se retrasa al final del periodo experimental. Sin embargo, las plantas del tratamiento RDS recuperan la longitud de los brotes, pero al final del ensayo siguen siendo más pequeñas, presentan menos anchura que las plantas control.

La compacidad es un parámetro de calidad de la planta, y se puede medir a partir de distintos índices de crecimiento, dependiendo de la especie que estemos estudiando. Si atendemos a la relación altura y anchura, como hemos comentado anteriormente, podemos decir que el riego deficitario da como resultado plantas más equilibradas. Sin embargo, como podemos observar, en nuestros condiciones, el riego deficitario redujo más el área foliar que la altura, es decir las plantas menos regadas fueron menos compactas. Este efecto es similar al observado por Bañón y col. (2009) cuando se aplica paclobutrazol en geranio. Esta respuesta resulta reversible cuando se restaura el riego en las plantas de geranio, pero sólo en las que habían recibido un riego deficitario moderado.

Las plantas del tratamiento RDS tuvieron menor número de inflorescencias sin abrir (Figura 4.3A) y abiertas (Figura 4.3B) que las plantas control $y$, en general, que las plantas sometidas a estrés moderado a lo largo del período de ensayo. El número de hojas caídas (Figura 4.3C) fue mayor en las plantas del tratamiento control y aumentó en todos los tratamientos en la semana 7-11 y al final del ensayo, coincidiendo con un aumento en el número de inflorescencias sin abrir y 
abiertas por planta (Figura 4.3A-B). Las plantas del control tienen más pérdida de hojas, pero también son las que presentan un mayor número de hojas verdes. La relación hojas caídas con hojas totales es igual en todos los tratamientos, no depende del déficit hídrico, además no ocurre en la fase de estrés, las hojas se caen principalmente en las últimas semanas del ensayo, en la fase de recuperación.
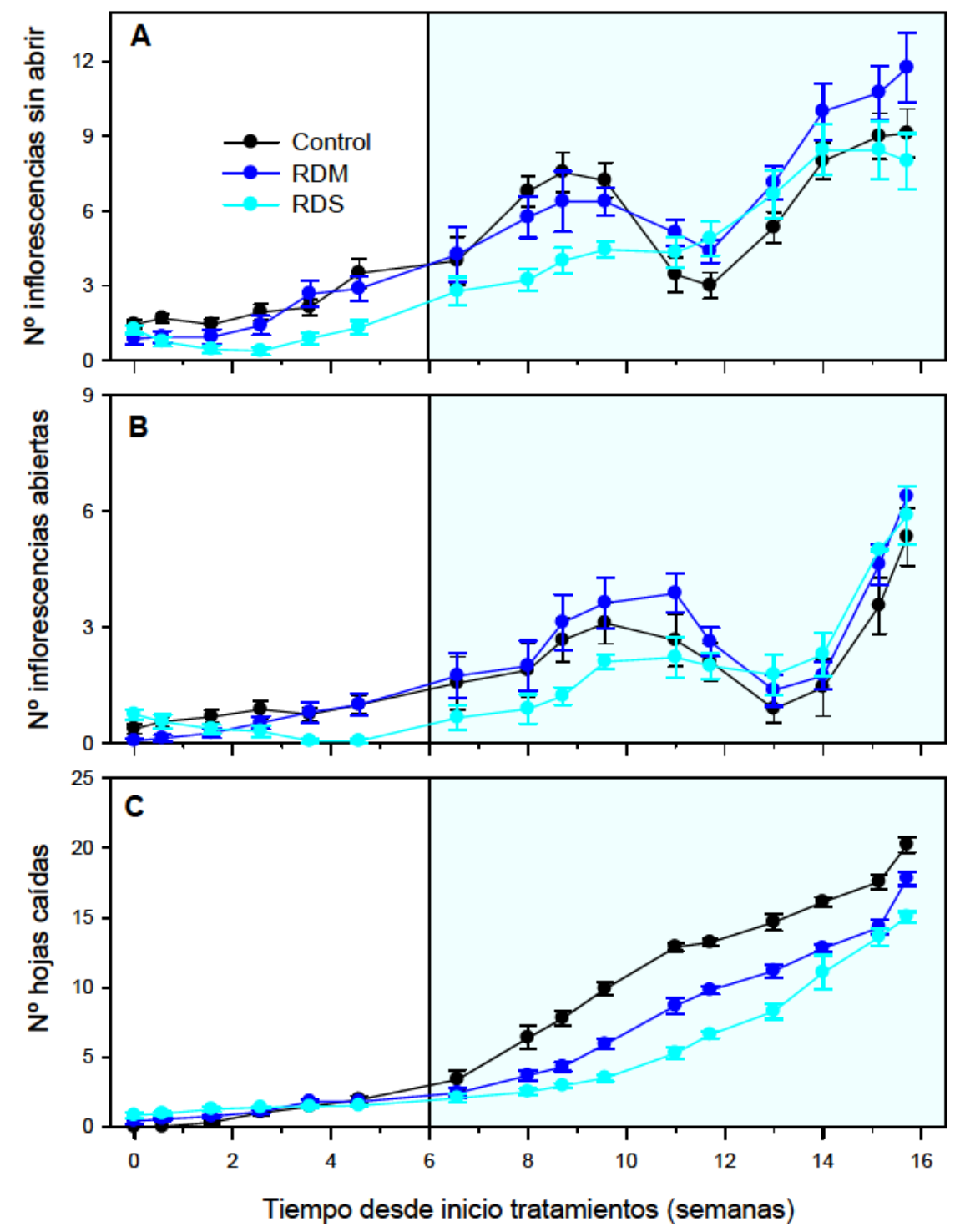

Figura 4.3- Evolución de la floración en plantas de geranio. número de inflorescencias sin abrir (A), número de inflorescencias abiertas $(B)$, y número de hojas caídas por planta(C), en plantas de geranio sometidas a distintos niveles de riego. La zona sombreada indica la fase de recuperación. 
En cuanto a los parámetros de color en hojas y flores, no se aprecian importantes diferencias en las coordenadas de color (L, C, HUE) a lo largo del ensayo entre tratamientos (Figura 4.4), estas sólo se detectan en momentos muy puntuales.
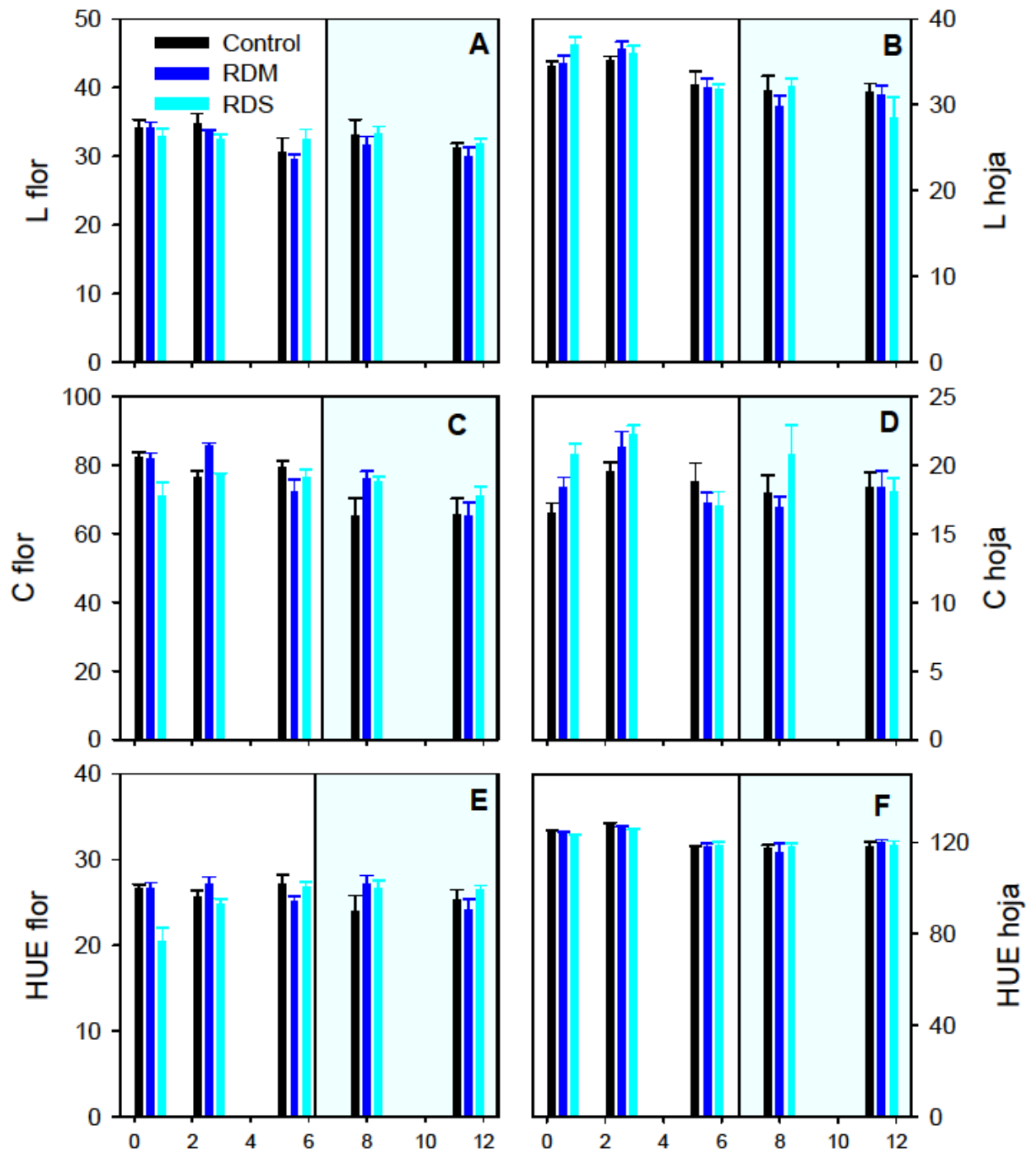

Tiempo desde inicio tratamientos (semanas)

Figura 4.4- Evolución de los parámetros de color: luminosidad (L; A y B), croma (C; C y D) y ángulo hue (HUE; $E$ y $F$ ) en flores ( $A, C$ y $E$ ) y hojas ( $B, D$ y $F)$ de plantas de geranio en macetas sometidas a diferentes tratamientos de riego durante el período experimental. La zona sombreada indica la fase de recuperación.

La aplicación de tratamientos de riego deficitario durante la fase de vivero puede usarse como una técnica para reducir el crecimiento excesivo en plantas ornamentales sin aplicar retardadores del crecimiento (Hansen y Petersen, 2004; Andersson, 2011). Sin embargo, las plantas sometidas a déficit hídrico pueden reducir y retrasar la floración con el 
objetivo de ahorrar asimilados (Augé y col., 2003), lo cual debería ser tenido en cuenta en el caso de plantas ornamentales, ya que las flores son normalmente el principal elemento decorativo. El riego deficitario moderado no afectó a la floración de las plantas de geranio y no se observaron diferencias en los valores de las coordenadas de color, lo que sugiere que el color no fue modificado por el riego deficitario y significa que estas plantas pueden enfrentarse a la escasez de agua sin perder su valor ornamental (Chylińsky y col., 2007). Según Henson y col. (2006), las plantas de geranio requieren el $75 \%$ de la evapotranspiración para mantener una calidad aceptable. Estos autores elaboraron una clasificación de calidad según sus resultados. Las plantas regadas al $100 \%$ tienen una calidad (índice visual) de planta muy buena, las plantas regadas al $75 \%$ están entre plantas buenas a muy buenas, con mínimos signos de estrés y las plantas regadas menos del $50 \%$, están por debajo de lo que se considera planta comercial.

La pérdida de hojas observada en las plantas de geranio durante el período experimental no fue debida al efecto del déficit hídrico, ya que ocurrió en todos los tratamientos, incluido el control. Según Hassanein y Dorion (2006), el área foliar se reduce a niveles de estrés menos intensos que otros parámetros (-40 kPa), el amarillamiento de las hojas en geranio, el paso previo a la caída de las hojas, se produce a partir de -40 o $-50 \mathrm{kPa}$ y la caída de las hojas a partir de $-60 \mathrm{kPa}$. En nuestro ensayo, en la fase de estrés se reduce el área foliar, pero no se detectan cambios de color y no se producen pérdidas significativas de hojas, según Bargali y Tewari (2004), la pérdida de hojas ocurre cuando el estrés hídrico es más severo. Nuestra reducción del área foliar en los tratamientos deficitarios no se ha producido por caída de hojas, sino por menor producción.

La floración aumentó gradualmente hasta la semana 9 y las mayores tasas de pérdida de hojas se producen justo después del aumento de brotes y flores, quizás tal vez porque la mayoría de los asimilados habían sido usados para este proceso. El efecto, entonces, fue probablemente debido a una caída de la clorofila junto con otros factores, como la ontogenia (Brawner, 2003). 


\subsubsection{Efectos del riego deficitario en el consumo de agua en plantas de geranio durante la fase de déficit hídrico y de recuperación}

La evolución de la evaporación del sustrato y la transpiración de la planta mediante gravimetría ha sido empleada en la producción de planta ornamental. Esta técnica nos permite conocer el consumo de agua por la planta y ha sido usada exitosamente en distintas especies ornamentales: Pelargonium (Andersson, 2001; Montero y col., 2001), Dianthus (Valdés y col., 2007), Catharanthus, (Jaleel y col., 2008), Rhododendron (Sharp y col., 2009) y Viburnum (Million y col., 2010), etc.

La evapotranspiración estacional (ET), medida periódicamente durante todo el ensayo, queda recogida en la Figura 4.5.

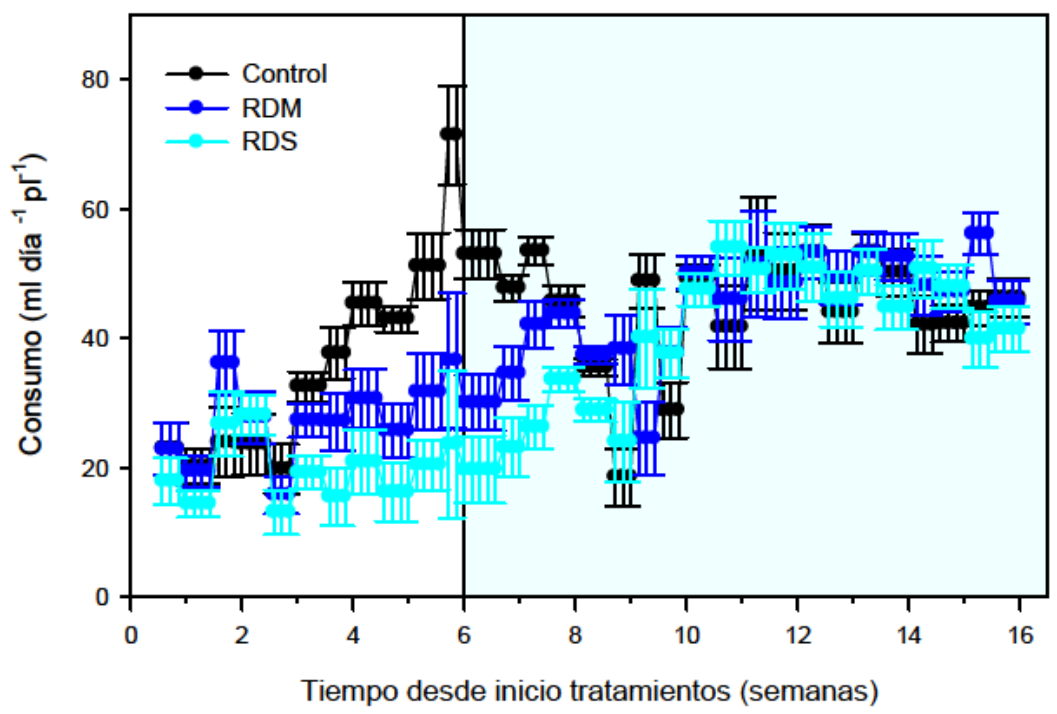

Figura 4.5- Evolución del consumo diario (evapotranspiración) de plantas de geranio en maceta sometidas a distintos tratamientos de riego durante el período experimental. La zona sombreada indica la fase de recuperación.

La cantidad de agua aportada por maceta durante todo el período diferencial de riego fue de 1750,1070 y $700 \mathrm{ml} \mathrm{pl}^{-1}$ para el tratamiento control, RDM y RDS, respectivamente. El consumo en el mencionado periodo fue de 1450, 1160 y $970 \mathrm{ml}$ para las plantas control, RDM y RDS, respectivamente. Las plantas de los tratamientos deficitarios tienen menor consumo que las plantas control, pero aún así, su consumo superó la cantidad de agua que fue aportada con el riego, con lo que se produjo un descenso progresivo del peso de las macetas de RDM y RDS a lo largo del ensayo (Figura 4.1). Durante el periodo de estrés la ET diaria osciló 
entre 20 y $70 \mathrm{ml}$ para el control, entre 15 y $36 \mathrm{ml}$ para el RDM y entre 18 y $53 \mathrm{ml}$ para el RDS.

Durante la fase de recuperación la cantidad de agua añadida fue la misma en todos los tratamientos $(3520 \mathrm{ml})$, cantidad suficiente para satisfacer las necesidades y permitir el drenaje en el tratamiento control, cuyo consumo en esta fase se situó en torno a $3200 \mathrm{ml}$, al igual que el consumo del RDM, sin embargo el de RDS fue menor $(2800 \mathrm{ml})$. Durante el periodo de recuperaciónl a ET diaria osciló entre 20 y $55 \mathrm{ml}$.

En este ensayo el riego se ajusta al consumo del control más un porcentaje de drenaje. La evapotranspiración de las 4 primeras semanas desde el restablecimiento del riego presenta diferencias entre tratamientos, las plantas que en la fase anterior se habían regado de forma deficitaria consumen menos a pesar de tener el mismo riego. Al inicio de la fase de recuperación, las plantas previamente regadas de forma deficitaria se encuentran por debajo de capacidad de campo, tardan 4 semanas en alcanzar el contenido de humedad en el sustrato de las plantas control, durante este tiempo prácticamente no se produce drenaje en las plantas de RDM y RDS. Cuando alcanzan el mismo peso que las plantas control (semana 10), los valores del consumo también se igualan.

Las tasas de ET están estrechamente relacionadas con las condiciones climáticas y especialmente con la temperatura ambiente (Valdés y col., 2007; Bañón y col., 2009) y con la radiación (Montero y col., 2001). En nuestras condiciones, los parámetros ambientales fueron constantes a lo largo del todo el ensayo, por lo que las variaciones de ET entre tratamientos fueron debidas a las distintas cantidades de agua aportadas, que conllevan distintas evaporaciones y distintas transpiraciones (menor área foliar y una efectiva regulación estomática). Esto ha sido observado en especies ornamentales (Sánchez-Blanco y col., 2002; Jaleel y col., 2008) y en otros cultivos no ornamentales (Costa França y col., 2000; Anyia y Herzog, 2004; Liu y col., 2006; Costa y col., 2007).

También, las distintas fases de crecimiento de las plantas pudieron inducir diferencias en el consumo de agua del ciclo del geranio a lo largo de todo el ensayo (Montero y col., 2001). En este sentido, desde el inicio del ensayo hasta la semana 6 , la evapotranspiración de las plantas va aumentando progresivamente hasta alcanzar el máximo y luego desciende y se mantiene más o menos estable. Esto coincide con el 
patrón que sigue la altura de los brotes (Figura 4.2A), anchura de la planta (Figura 4.2B), número de inflorescencias sin abrir (Figura 4.3A) y número de inflorescencias abiertas (Figura 4.3B), parámetros, todos ellos, relacionados con el crecimiento y floración de la planta. El periodo de máxima demanda coincide con la formación de los brotes.

\subsubsection{Efectos del riego deficitario en las relaciones hídricas en plantas de geranio durante la fase de déficit hídrico y de recuperación}

Durante el periodo diferencial de riego se realizaron tres evoluciones a lo largo del ciclo luz-oscuridad del potencial hídrico y sus componentes, (Figura 4.6). La evolución del potencial hídrico foliar $\left(\Psi_{\mathrm{h}}\right)$ (Figura 4.6A) muestra un comportamiento similar en todos los tratamientos, con valores más altos antes de iniciar las condiciones de día y más bajos en horas de máxima luminosidad, y a partir de este momento se observa una cierta recuperación. Por lo general el descenso de $\Psi_{\mathrm{h}}$ fue proporcional al nivel de déficit aplicado y este parámetro refleja el contenido de agua de las macetas en el momento de la medida (Figura 4.7). Según Costa França y col. (2000), los valores de $\Psi_{\mathrm{h}}$ antes de iniciar el ciclo de luz tienen una correlación positiva con el contenido de humedad del suelo. Es una medida útil del estado hídrico de la planta e indica como la planta integra la disponibilidad del agua en el suelo y el nivel de humedad del cual parte y a partir de ahí empieza a desarrollar su déficit hídrico diario (Bargali y Tewari, 2004).

El $\Psi_{\mathrm{h}}$ en las horas centrales de máxima luminosidad siguió el mismo patrón descrito para el $\Psi_{\mathrm{h}}$ antes del inicio de las condiciones de día, pero los valores son más negativos. El descenso diario en el potencial hídrico depende de la cantidad de agua disponible en el sustrato, y está relacionado con el comportamiento del cierre estomático (Bargali y Tewari, 2004). En nuestro ensayo la amplitud de la variación diaria del potencial hídrico en la tercera medida es mayor que en las anteriores (Figura 4.6Aiii), este día también se aprecian unos valores más altos de evapotranspiración (Figura 4.5). Cuando la transpiración es mayor (mayor nivel de conductancia), el potencial hídrico se hace más negativo, los cambios diarios en el potencial hídrico aumentan, hay más diferencias entre el $\Psi_{\mathrm{h}}$ del alba y del mediodía. 
El potencial osmótico actual (Figura 4.6B) presenta un comportamiento similar al $\Psi_{\mathrm{h}}$, ampliándose las diferencias entre tratamientos conforme avanza el ensayo, aunque en esta ocasión, los valores para cada tratamiento son más similares entre si a lo largo del ciclo luz-oscuridad. Las plantas de los tratamientos deficitarios consiguen mantener la turgencia (Figura 4.6C), debido a un menor valor de potencial osmótico. Sin embargo, independientemente del tratamiento, en el momento más demandante del ciclo (mayor temperatura y luz de la cámara), las plantas presentan los valores menores de turgencia a lo largo del período luminoso.
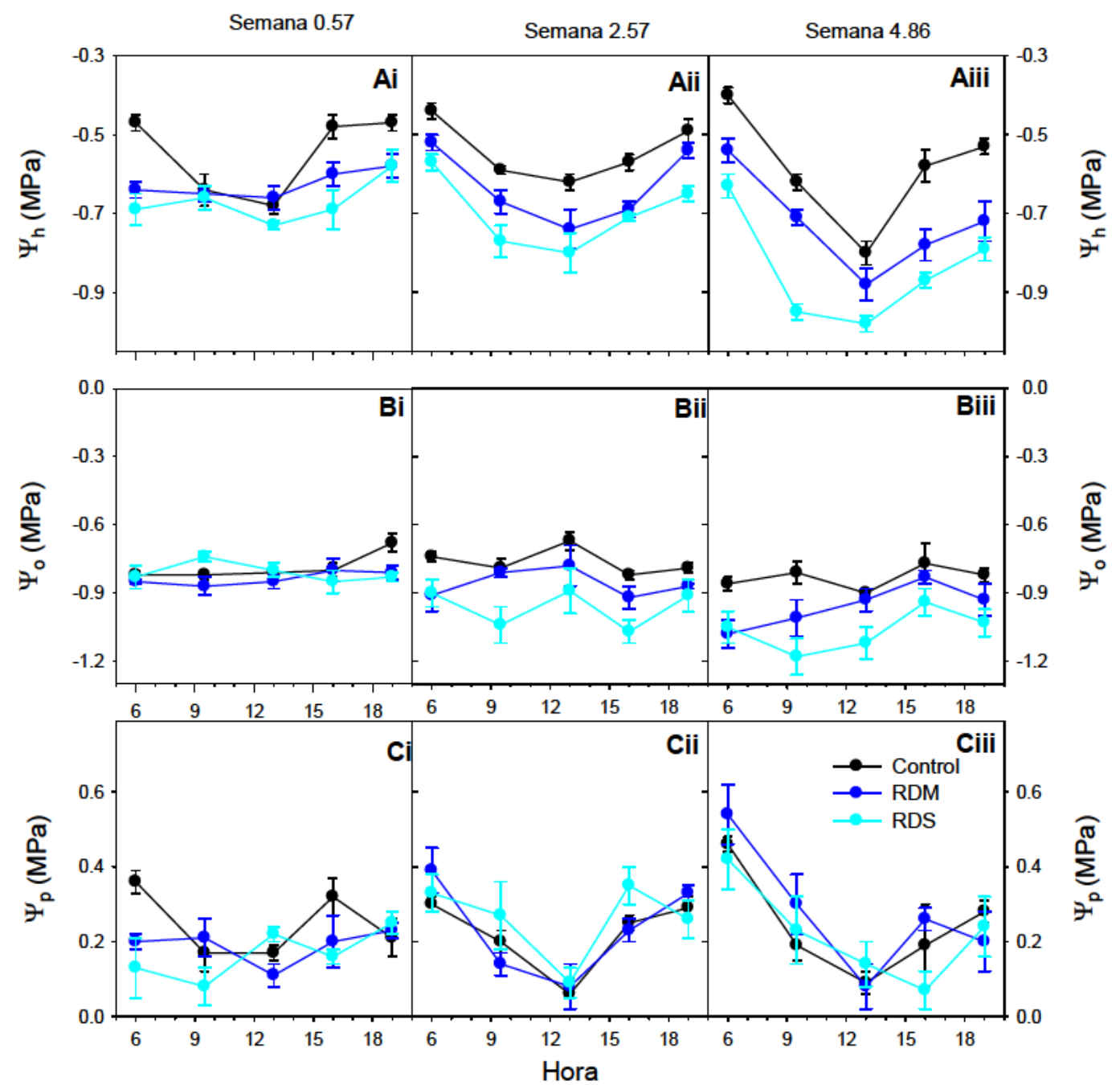

Figura 4.6- Evolución a lo largo de un día (horaria) y diaria (a lo largo del ensayo) del potencial hídrico foliar $\left(\Psi_{\mathrm{h}} ; \mathrm{A}\right)$, potencial osmótico $\left(\Psi_{\mathrm{o}} ; \mathrm{B}\right)$ y de presión $(\Psi \mathrm{p} ; \mathrm{C})$ en plantas de geranio en maceta sometidas a distintos tratamientos de riego en varios momentos de la fase de estrés: semana 0.57 desde inicio tratamientos (i), semana 2.57 (ii) y semana 4.86 (iii). 


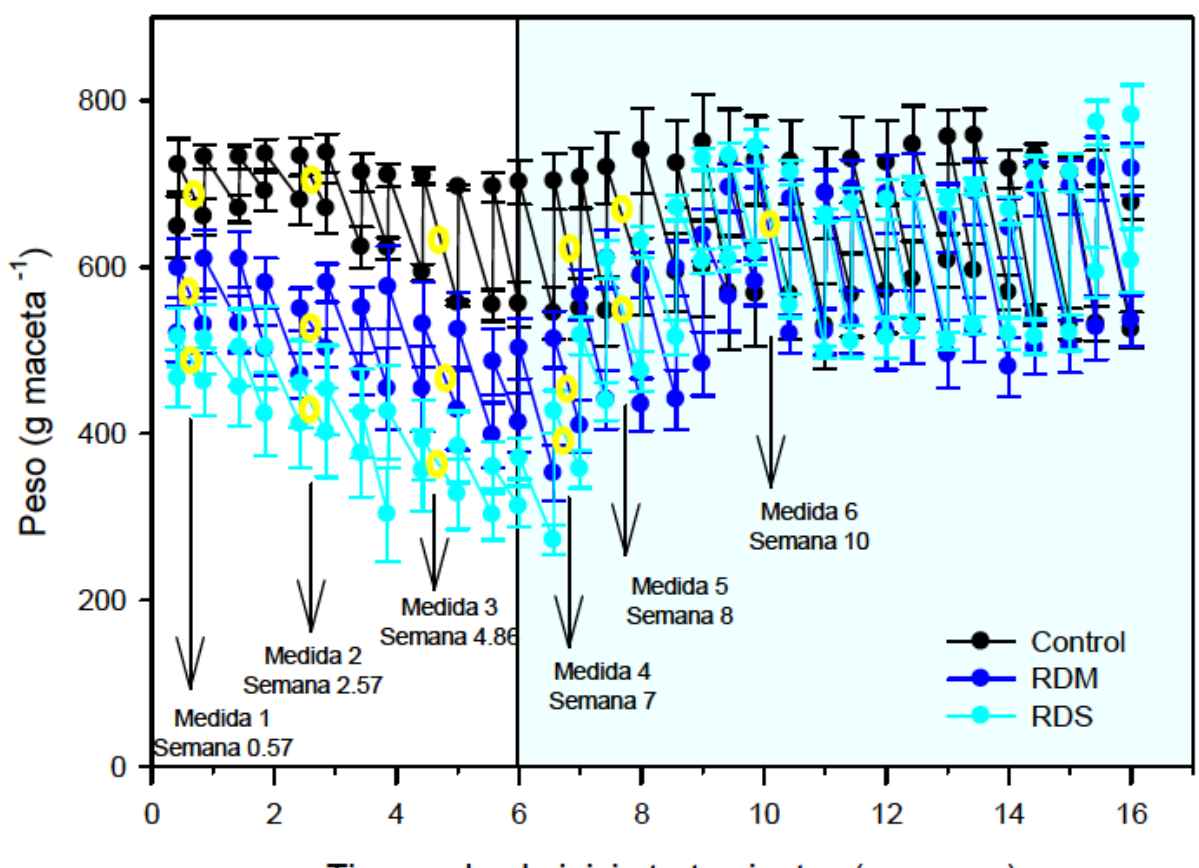

Tiempo desde inicio tratamientos (semanas)

Figura 4.7- Evolución del peso promedio de varias macetas en plantas de geranio sometidas a distintos tratamientos de riego, donde aparecen marcado el valor correspondiente a los días de medida de potenciales hídricos. La zona sombreada indica la fase de recuperación.

De acuerdo con Auge y col. (2003), las plantas de geranio presentan un potencial hídrico letal en torno a -2.1 $\mathrm{MPa}$, muy lejos de nuestros valores. El potencial hídrico letal es determinado cuando las plantas tienen menos de 8 hojas y en eso momento, aunque se restablezca el riego, la plantas mueren. Esto evidentemente no ocurrió en nuestras condiciones. De hecho pocas semanas después de restablecer el riego control en todos los tratamientos (Figura 4.8), los valores de $\Psi_{\mathrm{h}}$, $\Psi_{\mathrm{o}}$ y $\Psi_{\mathrm{p}}$ de las plantas que habían sido expuestas a déficit hídrico fueron igualándose a las del tratamiento control, las diferencias cada vez son menores y los potenciales siguen una evolución similar al contenido de agua en el suelo, que debido al protocolo de riego no se iguala de manera inmediata. Las plantas de los tratamientos deficitarios van subiendo progresivamente de peso, pero este aumento no es inmediato, tardan unas 3-4 semanas en alcanzar el nivel del control (Figura 4.7). Similar a lo encontrado por otros autores (Costa França y col., 2000; Bargali y Tewari, 2004), la evolución de la humedad del sustrato se refleja en la evolución del potencial hídrico. En este sentido, 4 días después del inicio de la fase de recuperación (Figura 4.8Ai), las diferencias entre tratamientos se mantienen. En la semana 8 (Figura 4.8Aii), el tratamiento que en la 
primera fase fue sometido a riego deficitario moderado tiene valores de $\Psi_{\mathrm{h}}$ similares al control y la semana 10 (Figura 4.8iii), los valores de potencial hídrico antes del inicio de la fase luminosa y en horas de máxima luminosidad se igualan en todos los tratamientos (-0.4 MPa para $\Psi_{\text {pd }}$ y $0.65 \mathrm{MPa}$ para $\left.\Psi_{\mathrm{md}}\right)$.
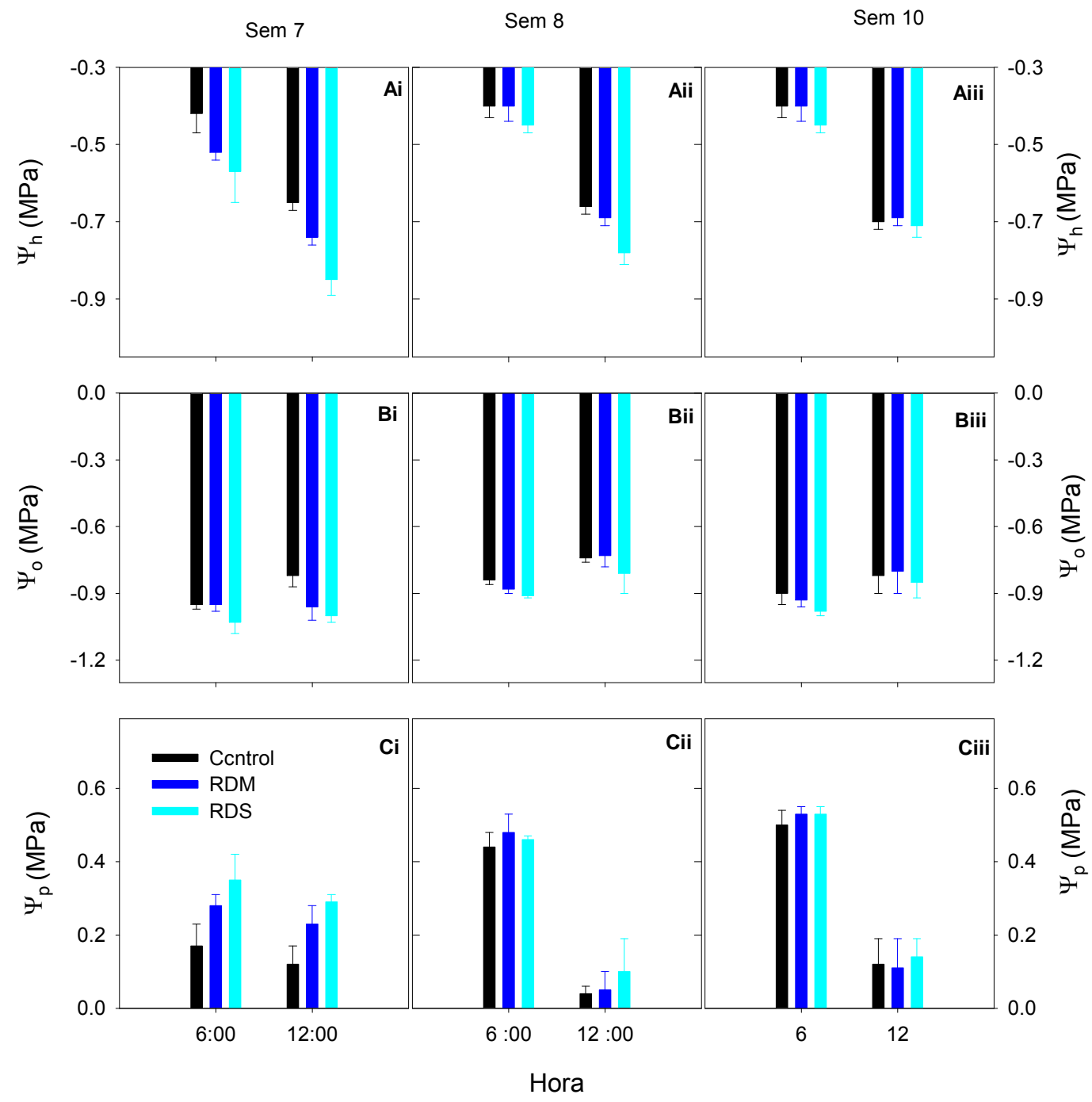

Figura 4.8- Evolución del potencial hídrico foliar $\left(\Psi_{\mathrm{h}} ; \mathrm{A}\right)$, potencial osmótico $\left(\Psi_{\mathrm{o}} ; \mathrm{B}\right)$ y de presión $\left(\Psi_{p} ; C\right)$ antes de la luz y en plena luminosidad en plantas de geranio en maceta, que previamente habían estado expuestas a distintos niveles de riego, en distintos momentos de la fase de recuperación: semana 7 desde inicio tratamientos (i), semana 8 (ii) y semana 10 (iii), (1,2 o 4 semanas desde cambio de riego).

La reducción en el $\Psi_{\text {os }}$ (Figura 4.9) en las plantas del tratamiento RDS indica la existencia de una acumulación activa de solutos (ajuste osmótico). Destacar que en el momento donde se igualan los potenciales hídricos de todas las plantas, los valores de $\Psi_{\text {os }}$ también resultaron similares (Figura 4.9). Esto indica la capacidad del geranio de capturar agua cuando se restablece el riego normal, lo que hace aumentar la 
actividad radicular y mejorar el estado hídrico de la planta (Gebre y Kuhns, 1993). Esto último se refleja en la evolución que experimenta a lo largo de todo el ensayo el contenido relativo de agua (CRA; Figura 4.10), en horas de máxima luminosidad. Este parámetro se ve reducido en los tratamientos deficitarios pero se produce una recuperación cuando las plantas están bien regadas (Chyliński y col., 2007; Cameron y col., 2008).

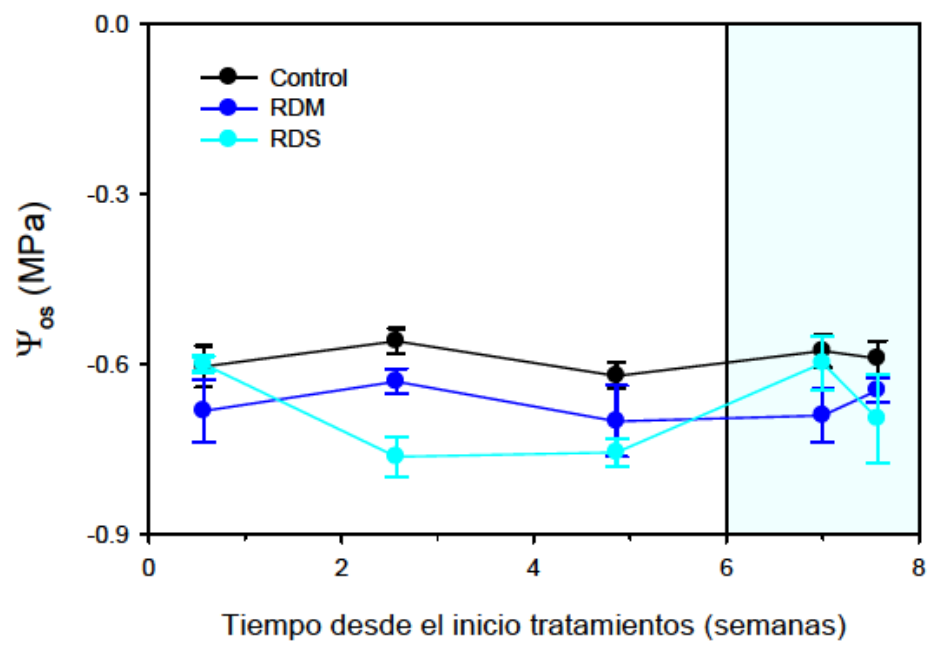

Figura 4.9- Evolución del potencial osmótico saturado ( $\left.\Psi_{\mathrm{os}}\right)$ en plantas de geranio en maceta sometidas a distintos tratamientos de riego durante el período experimental. La zona sombreada indica la fase de recuperación.

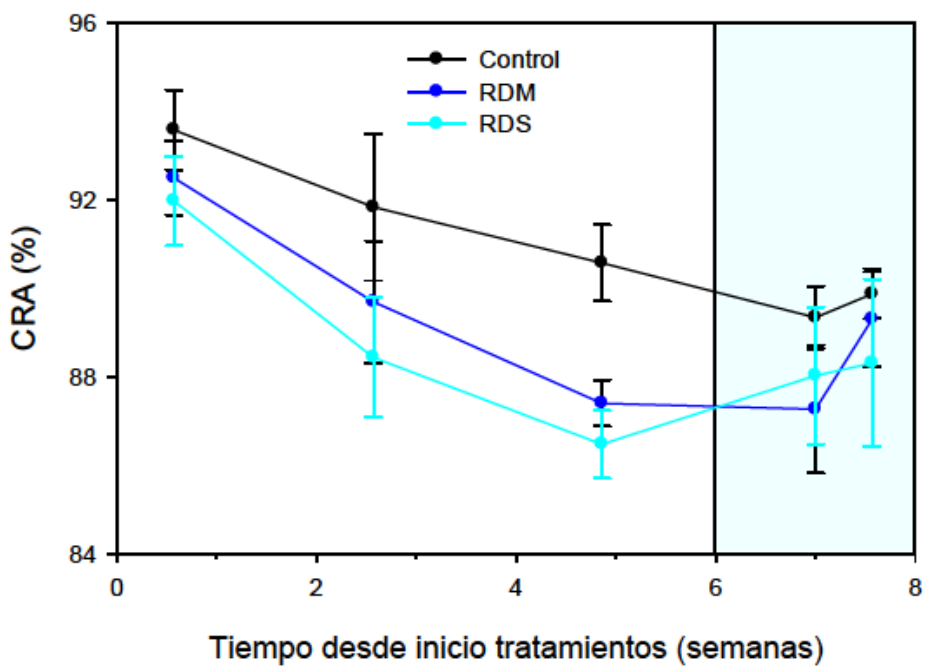

Figura 4.10- Evolución del contenido relativo de agua (CRA) en plantas de geranio sometidas a distintos tratamientos de riego durante el período experimental. La zona sombreada indica la fase de recuperación. 
Los parámetros derivados de las curvas presión-volumen, que fueron determinados al final de la fase diferencial de riego, se muestran en la Tabla 4.3.

Tabla 4.3- Parámetros derivados de las curvas P-V en plantas de geranio en maceta sometidas a distintos tratamientos de riego al final de periodo de estrés.

\begin{tabular}{|c|c|c|c|c|}
\hline Tratamientos & $\Psi_{\text {os }}(\mathrm{MPa})$ & $\Psi_{\text {ppt }}(\mathrm{MPa})$ & $\mathrm{CRA}_{\mathrm{ppt}}(\%)$ & $\varepsilon(\mathrm{MPa})$ \\
\hline Control & $-0.73 \pm 0.07 \quad b$ & $-1.05 \pm 0.11 b$ & $86.65 \pm 0.48 \mathrm{a}$ & $3.74 \pm 0.64 a$ \\
\hline RDM & $-0.73 \pm 0.06 \quad b$ & $-0.92 \pm 0.10 b$ & $89.65 \pm 2.00 \mathrm{a}$ & $6.65 \pm 0.69 b$ \\
\hline RDS & $-0.93 \pm 0.04 a$ & $-1.38 \pm 0.08 a$ & $85.94 \pm 1.24 \mathrm{a}$ & $5.83 \pm 0.56 b$ \\
\hline
\end{tabular}

Distintas letras dentro de una misma columna indican diferencias significativas.

Los valores del potencial osmótico a máxima saturación ( $\Psi_{\text {os }}$ ) fueron similares a los determinados por el osmómetro (Figura 4.9). Dichos valores fueron más bajos en RDS, indicando la presencia de un limitado ajuste osmótico (0.2 MPa). El potencial hídrico en el punto de pérdida de turgencia $\left(\Psi_{\mathrm{ppt}}\right)$ se redujo significativamente por el nivel de riego más bajo (Tabla 4.3). La pérdida de turgor se produce a menor potencial hídrico foliar (-1.38 MPa), es decir, el mantenimiento de un potencial de turgencia positivo a valores más bajos de potencial hídrico, favoreciendo el crecimiento celular. Sin embargo, el contenido relativo de agua en el punto de pérdida de turgencia $\left(\mathrm{CRA}_{\mathrm{ppt}}\right)$ no resultó afectado por el tratamiento. No se encontraron valores de potencial hídrico por debajo del $\Psi_{\text {ppt }}$ para las plantas estresadas en ningún momento del ensayo.

El módulo de elasticidad $(\varepsilon)$ aumentó en ambos tratamientos de riego deficitario, independientemente del nivel de déficit hídrico aplicado, lo que implica que la elasticidad de las paredes celulares fue reducida por la disminución del aporte hídrico. Observaciones similares se han descrito en otras especies (Lo Gullo y col., 1986; Savé y col., 1993; Álvarez y col., 2009; Navarro y col., 2009). 
Descensos e incrementos de $\varepsilon$ como respuesta a la sequía han sido también descritos en otras especies (Lemcoff y col., 2002; DaMatta y col., 2003; Bacelar y col., 2006). Ambas respuestas pueden ayudar a la supervivencia durante condiciones de estrés hídrico. Un descenso en $\varepsilon$ puede reflejar cambios en la composición de la pared (Muñoz y col., 1993). Paredes celulares más elásticas pueden disminuir de tamaño más fácilmente cuando son sometidas a estrés, ayudando al mantenimiento de un mayor turgor y protegiendo a las células de una posible ruptura (Joly y Zaerr, 1987). Con mayores valores del módulo de elasticidad, los tejidos se convierten en menos elásticos (Cheung y col., 1975) y este efecto permite menores potenciales hídricos, que se alcanzan por los cambios en el volumen de agua celular, es decir, un aumento en el gradiente del potencial hídrico entre el suelo y la planta, facilitando continuar la toma de agua de suelos más deshidratados y acelerando la recuperación tras el restablecimiento del riego (Bowman y Roberts, 1985).

En las especies que realizan ajuste osmótico, una mayor rigidez de las paredes celulares puede reducir la pérdida de volumen y turgor, sugiriendo una reducción del tamaño de las células (Lemcoff y col., 2002). Paredes más rígidas pueden también ayudar a mantener potenciales hídricos más bajos para un cambio dado en el volumen de agua que las paredes más elásticas (Clifford y col., 1998; Patakas y col., 2002). Un incremento del módulo de elasticidad junto con la realización de ajuste osmótico serían mecanismos efectivos para contrarrestar los efectos negativos del estrés osmótico en el balance hídrico de las plantas de $P$. hortorum.

\subsubsection{Efectos del riego deficitario en el intercambio gaseoso y fluorescencia en plantas de geranio durante la fase de déficit hídrico y de recuperación}

Las evoluciones a lo largo del ciclo diurno de la conductancia estomática $\left(g_{s}\right)$ y la tasa de fotosíntesis $\left(P_{n}\right)$ en la fase de estrés se representan en la Figura 4.11. Los valores máximos de gs (Figura 4.11A) se observan entre las $13 \mathrm{~h}$ y $16 \mathrm{~h}$ en el tratamiento control y coinciden con las horas de mayor intensidad luminosa, es decir el comportamiento de $\mathrm{g}_{\mathrm{s}}$ sigue el mismo patrón que las condiciones de luz del ensayo. Mientras, ambos tratamientos deficitarios tuvieron menores valores de $g_{\mathrm{s}} \mathrm{y}$ más estables, independientemente del momento de la medida, lo cual fue debido a una apertura estomática limitada. 
El nivel de fotosíntesis (Figura 4.11B) también disminuyó en relación al tratamiento control; aunque las diferencias entre tratamientos fueron menores que en el caso de $g_{s}$ (Figura 4.11A). Hay que destacar que en la semana quinta desde el inicio de los tratamientos de riego, los valores de fotosíntesis y conductancia son mayores (Figura 4.11A-Biii). En este momento el consumo de agua también es mucho mayor que en semanas anteriores (Figura 4.5) y coincide con un incremento de la anchura de la planta (Figura 4.2B) y del número de brotes (Figura 4.3A), lo que supone una aumento de la interceptación de la radiación por la planta.

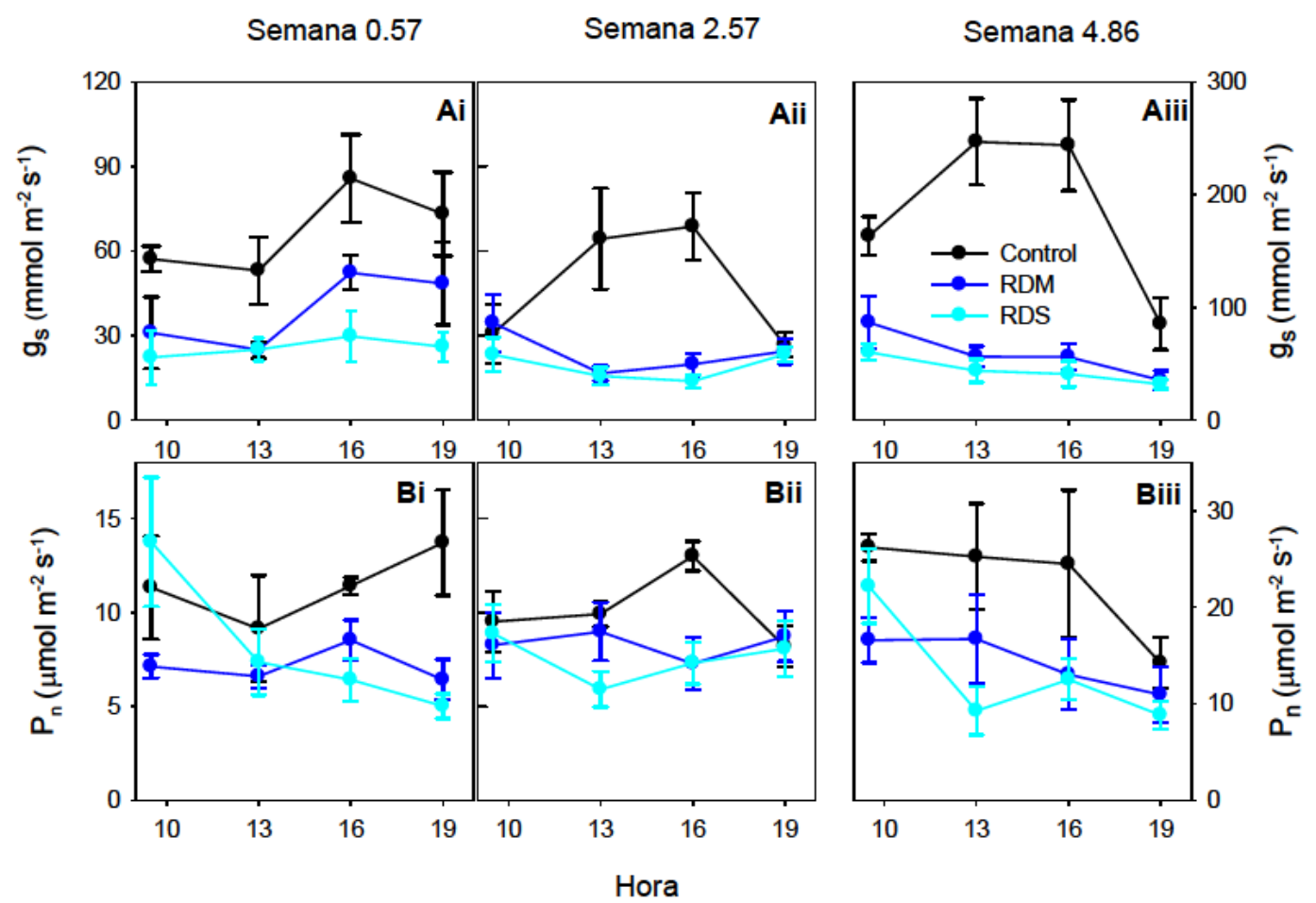

Figura 4.11- Evolución a lo largo de un día de la conductancia estomática $\left(\mathrm{g}_{\mathrm{s}} ; \mathrm{A}\right)$ y tasa de fotosíntesis neta $\left(P_{n} ; B\right)$ en plantas de geranio en maceta sometidas a distintos tratamientos de riego en varios momentos de la fase de estrés, semana 0.57 (i), semana 2.57 (ii) y semana 4.86 desde el inicio de los tratamientos (iii).

Por otro lado, según aumentan los días de estrés, la diferencia entre la conductancia del control y los tratamientos deficitarios es mayor, las diferencias de la fotosíntesis no son tan evidente, con lo que, con el tiempo, aumenta la eficiencia intrínseca en el uso del agua $\left(P_{n} / g_{s}\right)$ de los tratamientos deficitarios (más reducción de conductancia que de la fotosíntesis, respecto del control). 
El cierre estomático, junto con la reducción del área foliar es uno de los principales mecanismos más efectivos para controlar las pérdidas de agua (Hassanein y Dorion, 2006). De nuestros resultados se deduce que la $\mathrm{g}_{\mathrm{s}}$, medida en momentos de máxima intensidad luminosa debería ser tomada como un indicador eficaz del déficit hídrico en plantas de geranio, ya que al contrario que con la $\mathrm{P}_{\mathrm{n}}$, las diferencias de $\mathrm{g}_{\mathrm{s}}$ por el riego deficitario son muchos más evidentes. En numerosos estudios ha sido observado que el riego deficitario reduce la conductancia estomática y disminuye el potencial hídrico foliar (Gollan y col., 1985; Pereira y Chaves, 1993; Munné-Bosch y col., 1999). En este ensayo, el valor de potencial hídrico foliar (cercano a $-0.8 \mathrm{MPa}$ ) pudo haber causado un importante descenso en la conductancia estomática. Los umbrales del potencial hídrico a partir del cual causa un descenso en la apertura estomática oscilan entre -0.7 a $-1.2 \mathrm{MPa}$ para diferentes especies (Ackerson, 1985; Hsiao, 1973). En este sentido, Arora y col. (1998) encontraron que plantas de geranio bajo estrés hídrico, que presentaban valores de potencial hídrico foliar en torno a $-0.8 \mathrm{MPa}$, inducían cierre estomático, sugiriendo que estas plantas tenían estomas muy sensibles, lo que está de acuerdo con nuestros resultados.

Cuando se cambia el riego y todas las plantas reciben la misma cantidad de agua, ambos parámetros, $g_{\mathrm{s}}$ y $\mathrm{P}_{\mathrm{n}}$ (Figura 4.12) mostraron una recuperación respecto al tratamiento control, y cuatro semanas después del cambio de riego, los valores de $P_{n}$ y $g_{s}$ se igualan en todos los tratamientos, lo que sugiere que son los factores estomáticos los que están más directamente implicados en la respuesta de la fotosíntesis en los niveles de déficit hídrico estudiados. La recuperación de estos parámetros cuando se restablece el riego también ha sido observada en otras especies ornamentales por Cameron y col. (2008). La recuperación de la conductancia (Figura 4.12A) de los tratamientos deficitarios, al igual que el potencial hídrico, está estrechamente relacionada con el modo en el que las plantas recuperan el contenido de agua en el sustrato (Figura 4.1), y con el consumo de agua de las plantas en el momento de la medida (Figura 4.5). 

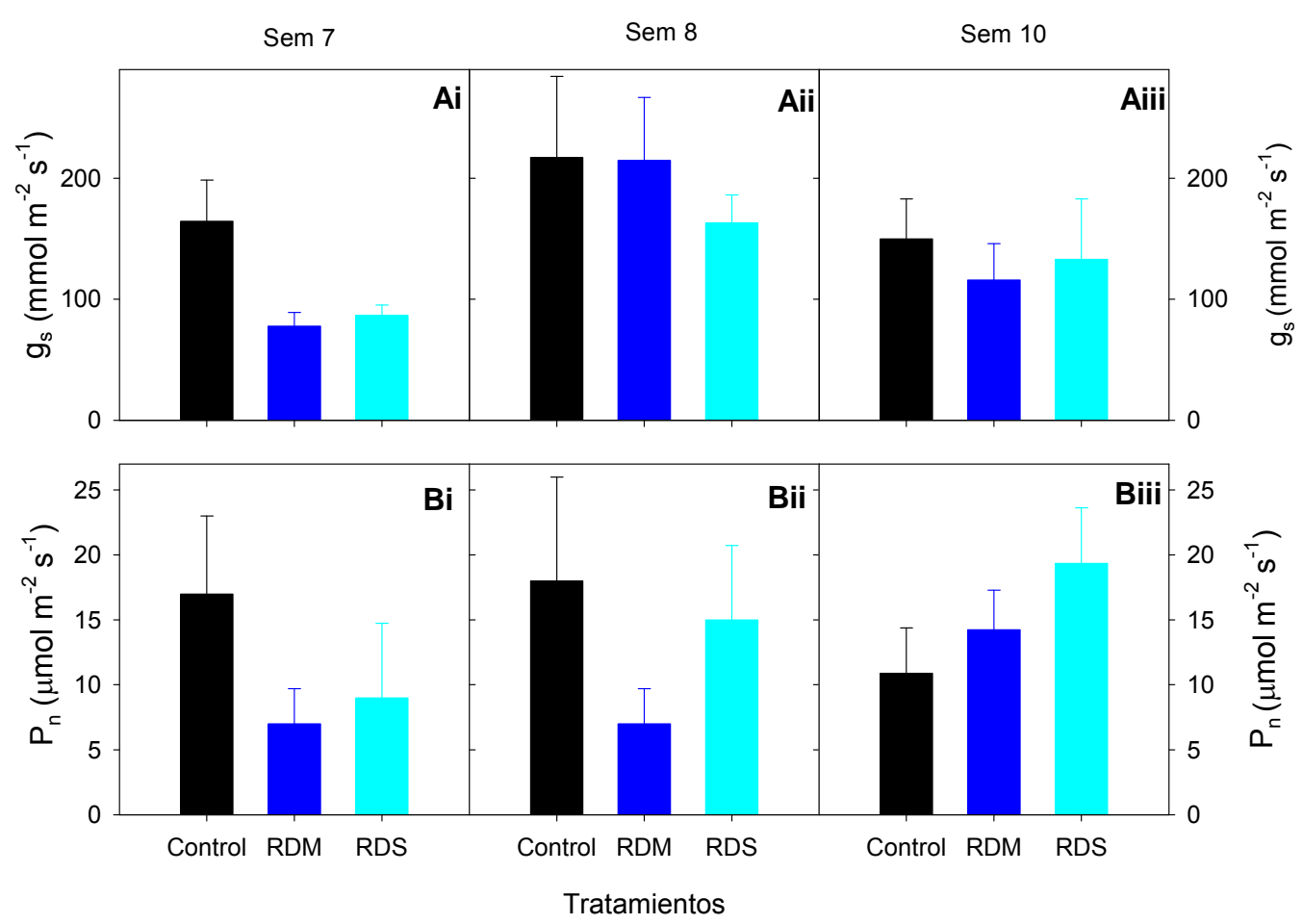

Figura 4.12- Evolución de la conductancia estomática $\left(g_{s} ; A\right)$ y tasa de fotosíntesis neta $\left(P_{n} ; B\right)$ en plantas de geranio en maceta sometidas previamente a varios niveles de estrés en tres momentos de la fase de recuperación: semana 7 (i), semana 8 (ii) y semana 10 desde el incio de los tratamientos (iii), semana 1, 2 y 4 desde el inicio de la fase de recuperación.

La eficiencia fotosintética del fotosistema II $\left(F_{\mathrm{v}} / F_{\mathrm{m}}\right)$ (Figura 4.13 y Figura 4.14) no se modificó por efecto del riego. En condiciones de riegos deficitarios, los valores permanecieron en niveles similares a los de las plantas control. Por lo tanto, el hecho que los valores de $F_{v} / F_{m}$ se mantuvieron cercanos a 0.80 en todos los tratamientos durante todo el experimento demuestra la ausencia de daños inducidos por el estrés en el fotosistema PSII, tal y como ha sido ya reportado para otras especies (Cornic, 1994; Genty y col., 1987). 


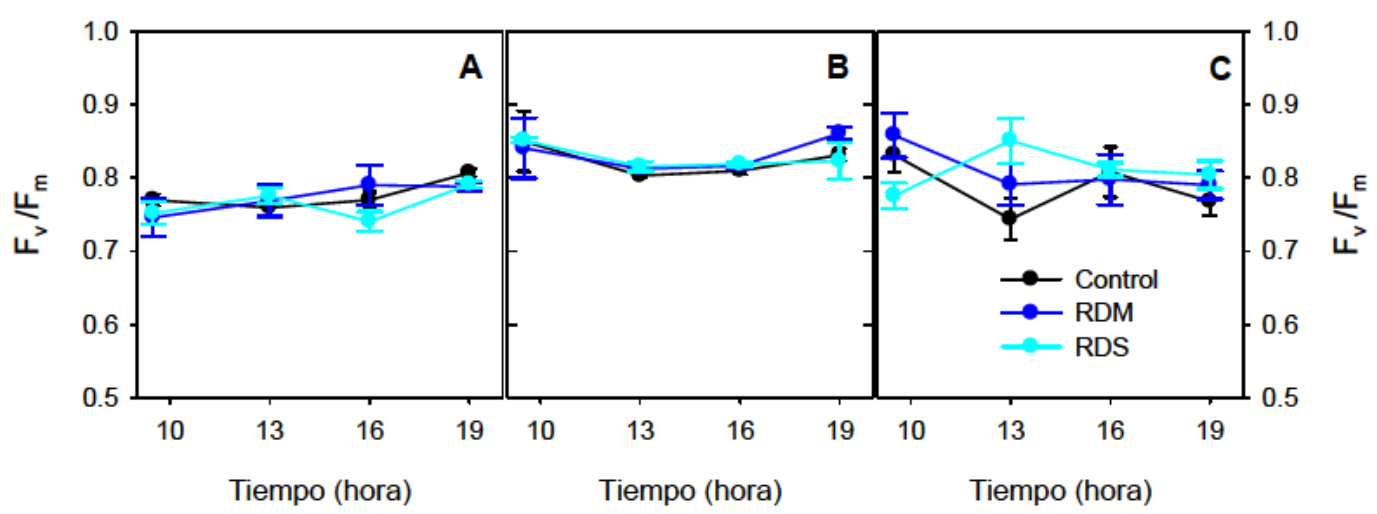

Figura 4.13- Evolución diaria de la eficiencia del fotosistema II, $F_{v} / F_{m}$, en plantas de geranio en maceta sometidas a distintos tratamientos de riego en tres momentos durante la fase de estrés; semana 0.57 (A), semana 2.57 (B) y semana 4.86 desde el inicio de los tratamientos $(\mathrm{C})$.

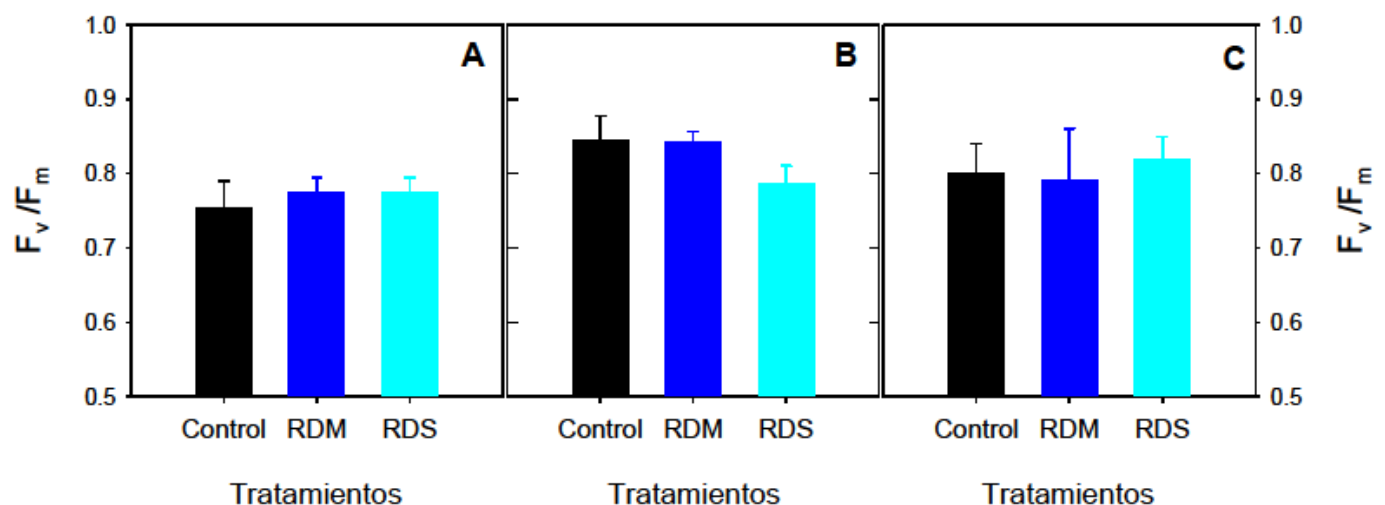

Figura 4.14- Evolución de $\mathrm{F}_{\mathrm{v}} / \mathrm{F}_{\mathrm{m}}$ en plantas de geranio en maceta sometidas previamente a varios niveles de estrés en tres momentos durante la fase de recuperación, semana $7(A)$, semana $8(B)$ y semana 10 desde el inicio de los tratamientos $(\mathrm{C})$.

La inhibición del crecimiento en ambos niveles de déficit no estuvo asociada con una pérdida de turgor (Nabil y Coudret, 1995) ya que esta se produce a potenciales hídricos en torno a -1.0 MPa para las plantas control y RDM y a -1.38 MPa para RDS, valores que no se dieron en todo el ensayo, sino con una reducción de la fotosíntesis. Las reducciones de crecimiento y de intercambio gaseoso en plantas de geranio expuestas a estrés indican un relación estrecha entre ambos parámetros (SánchezBlanco y col., 2002). En este sentido, el déficit hídrico podría afectar a la difusión del $\mathrm{CO}_{2}$ en las hojas a través de reducciones en la conductancia estomática (Flexas y col., 2004). 
Pelargonium respondió al déficit hídrico reduciendo la fotosíntesis y la acumulación de biomasa. El riego deficitario moderado podría usarse de forma satisfactoria en la producción de plantas de geranio, lo que reduciría el consumo de agua, mientras mantiene una buena calidad global en su valor ornamental. El riego deficitario severo disminuyó la calidad ornamental del geranio debido a la reducción del número de flores. Las modificaciones de las plantas de geranio en condiciones de riego deficitario se traducen en cierre estomático, menor transpiración, menor área foliar, ajuste osmótico, descensos en la elasticidad. Cuando se restablece el riego normal las plantas de geranio recuperan los parámetros del estado hídrico e intercambio gaseoso a corto plazo, sin embargo los parámetros de crecimiento necesitan más tiempo para alcanzar los de las plantas control. 


\subsection{Efecto del riego deficitario en las distintas fases de crecimiento vegetativo y floración en plantas de geranio}

El efecto de la aplicación de tratamientos de riego deficitario durante la estación de crecimiento en especies ornamentales para diferentes fines se ha estudiado por varios autores (Silber y col., 2007; Cameron y col., 2006), pero es comprensible considerar que no todas las fases de crecimiento de una planta resultan igualmente sensibles al déficit hídrico, además de que la duración de cada fase en la cual se aplica el déficit puede ser importante. Aunque, se conoce que un estrés prolongado y severo es perjudicial para la formación de flores y el proceso de floración (Kozlowski y Pallardy, 2002), también se ha observado que un estrés moderado puede inducir un adelanto de la floración y un mayor intensidad de la misma (Silber y col., 2007), pero ello dependerá del momento y modo en el que se aplique el mismo. La evapotranspiración del complejo sustrato-planta, mediante la variación del peso de las macetas, es un método sencillo, aplicado a la producción de planta ornamental (Evans, 2004; Andersson, 2001) y nos permite recoger información del nivel de consumo de la planta en cada momento de su ciclo vital y estaremos en condiciones de poder reducir dichos aportes en función de las necesidades hídricas de los distintos estados fenológicos de cada especie.

En este ensayo se aplican tres tratamientos de riego deficitario, en donde las diferencias se deben al momento de aplicación y no a las cantidades de agua. De esta manera, podremos conocer las fases fenológicas más críticas del geranio.

\subsubsection{Material y métodos}

\subsubsection{Material vegetal y condiciones experimentales}

Se emplearon 100 ejemplares de Pelargonium x hortorum L.H. Bailey con las características iniciales similares a las plantas del ensayo anterior. Las plantas se trasplantaron el 1 de Junio de 2007 en las mismas condiciones descritas en el apartado 4.2.1.1. Después del trasplante, las macetas fueron trasladadas a una cámara de crecimiento, ajustada a 18 ${ }^{\circ} \mathrm{C}$ y oscuridad (00:00 a 08:00) y a $24{ }^{\circ} \mathrm{C}$ y $250 \mu \mathrm{mol} \mathrm{m} \mathrm{m}^{-2} \mathrm{~s}^{-1}$ en la fase luminosa (08:00 a 00:00). La humedad relativa osciló entre $65-80 \%$. 
Todas las plantas se regaron hasta capacidad de campo antes de empezar los tratamientos durante 5 semanas.

\subsubsection{Tratamientos y diseño experimental}

Las plantas fueron distribuidas en grupos de 25 , cada uno correspondiente a un tratamiento. Durante 24 semanas las plantas fueron sometidas a cuatro tratamientos de riego, regándose 5 días a la semana, con distintas dosis de agua; un tratamiento control hasta alcanzar el 95$100 \%$ del peso de la maceta en base a su peso a capacidad de campo durante todo el ensayo (Control), y tres tratamientos deficitarios, hasta alcanzar el $70-75 \%$ de este umbral: uno durante todo el ciclo (RD Sostenido), otro durante todo el ciclo excepto en la fase de floración (RDC I) y otro durante la fase de floración (RDC II) con el fin de comprobar si dicha fase resultaba crítica. El tratamiento RDC I se regó como control durante la fase de floración y deficitario el resto del ensayo, mientras que el RDC II se regó como el control durante todo el ciclo y deficitario en la fase de floración. No se consideró necesario la obtención de drenaje ya que el agua utilizada para el riego fue agua de buena calidad ( $\left.0.8 \mathrm{dS} \mathrm{m}^{-1}\right)$ y el tiempo que duró el ensayo no fue muy prolongado para que se produjera acumulación de sales.

Al inicio del ensayo se regaron todas las plantas hasta saturación y se dejaron drenar libremente para obtener el peso de cada maceta a capacidad de campo, y a partir de este valor, calcular el umbral de peso a alcanzar en cada fase de riego. También se determinó la humedad volumétrica (61\%) del sustrato utilizado en este ensayo en condiciones de capacidad de campo. De este modo, con los datos de humedad volumétrica del sustrato a capacidad de campo y el volumen y el peso a capacidad de campo de cada maceta, se pueden transformar los valores de peso de cada planta en humedad volumétrica en ese momento. Los valores de peso de una planta son mucho más sencillos, precisos y fiables de medir que otras metodologías que determinan humedad en el sustrato. Se despreció el aumento de peso de la maceta debido al crecimiento de la planta, ya que el aumento de peso de la planta fue muy poco respecto al peso total de una maceta, (el peso fresco aéreo final estuvo entre 15 y 30 gramos y el peso de la maceta a capacidad de campo era aproximadamente de $800 \mathrm{~g}$ ). 
El riego aportado a cada maceta se obtuvo gravimétricamente durante todo el periodo experimental, pesando todas y cada una de las macetas antes del riego (Balanza Sartorius modelo 5201; Fotografía 4.9), con lo que se calculó la cantidad de agua necesaria (riego) para llegar al umbral preestablecido según la fase $(100 \%$ o $70 \%$ del peso a capacidad de campo de cada maceta). En la Figura 4.15A y B se representa la evolución del peso y la humedad volumétrica de las plantas de los distintos tratamientos a lo largo del ensayo y los umbrales de riego en cada fase.

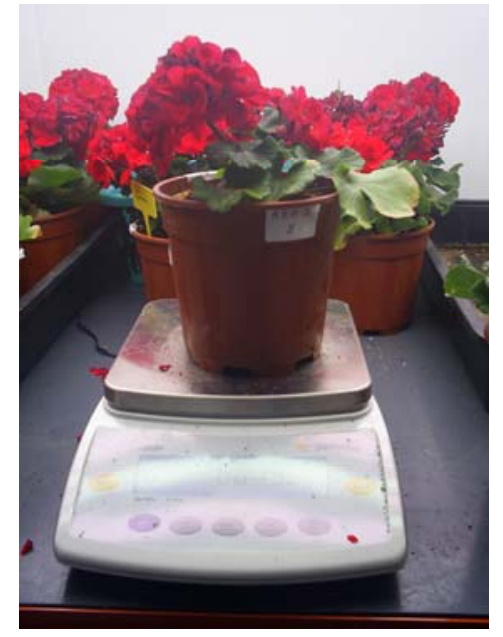

Fotografía 4.9- Medida diaria del peso de cada maceta antes del riego para calcular la cantidad de agua necesaria. 

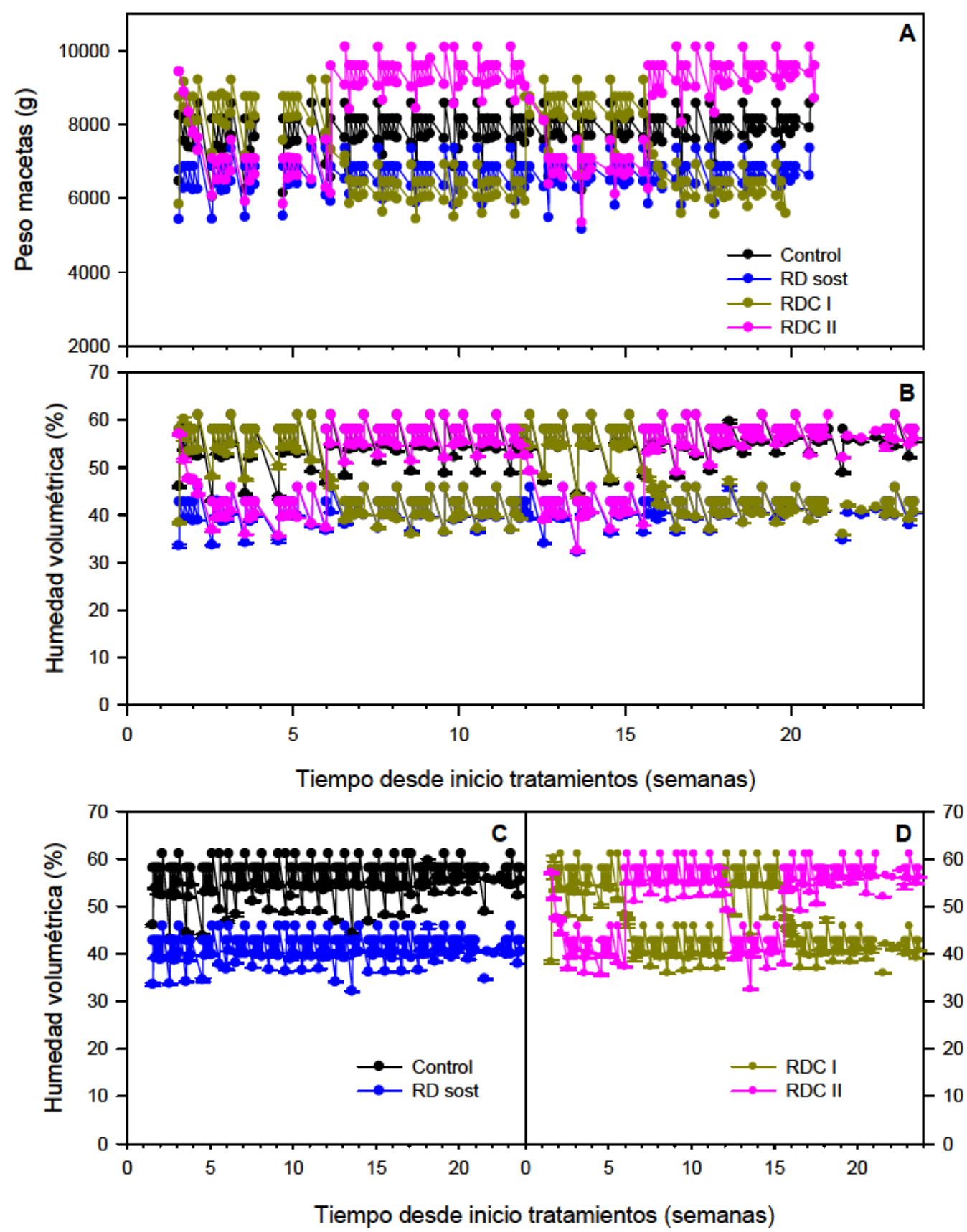

Figura 4.15- Evolución del peso total de 12 macetas por tratamiento $(A)$ y humedad volumétrica $(B)$ en plantas de geranio sometidas a distintos tratamientos de riego durante el periodo experimental.

Se consideraba fase de floración cuando más del $80 \%$ de las plantas del tratamiento control presentaban botones florales (inflorescencias sin abrir) (Figura 4.16). Esto sucedió por primera vez, una semana y media después de iniciar los tratamientos de riego, con lo que en ese momento se produjo el primer cambio de riego en las plantas del RDC, a partir de ahí y durante 4 semanas, estas plantas se regaron en base a su umbral de fase de floración (Figura 4.17). La semana 11.8 
desde inicio tratamientos hubo una segunda fase de floración, que duró aproximadamente 3 semanas (Figura 4.16).

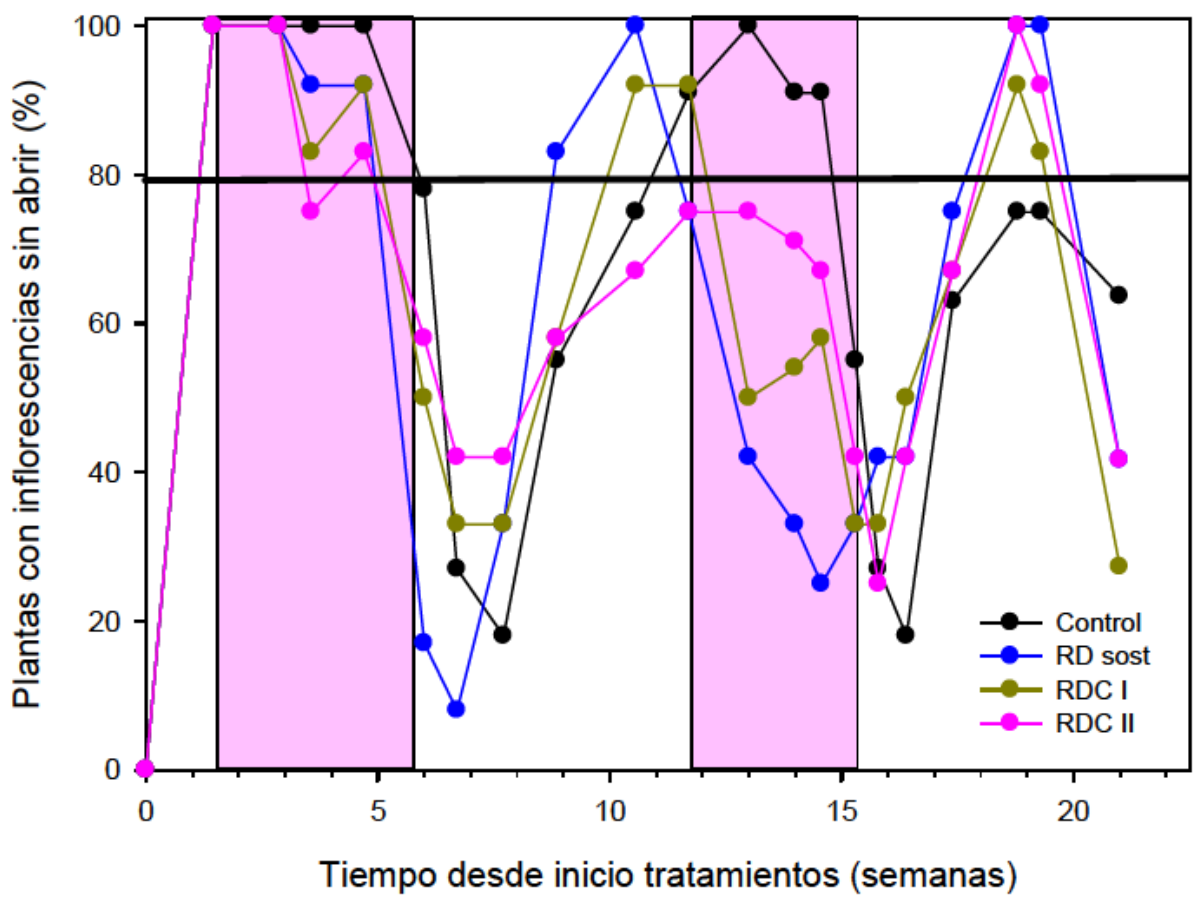

Figura 4.16- Evolución del porcentaje de plantas con inflorescencias sin abrir en plantas de geranio en maceta sometidas a distintos tratamientos de riego durante el período experimental. Las zonas sombreadas indican las fases de floración y las líneas verticales indican cambio de riego en las plantas de los tratamientos RDC, según nuestro protocolo de riego.

\begin{tabular}{|c|c|c|c|c|c|}
\cline { 2 - 5 } \multicolumn{1}{c|}{} & No flor & flor & No flor & flor & No flor \\
\hline $\begin{array}{c}\text { Tiempo desde inicio } \\
\text { tratamientos (semanas) }\end{array}$ & $0-1.5$ & $1.5-5.8$ & $5.8-11.8$ & $11.8-15.4$ & $15.4-24$ \\
\hline
\end{tabular}

\begin{tabular}{|c|c|c|c|c|c|}
\hline TRATAMIENTO & \multicolumn{5}{|c|}{ PESO DESPUES DEL RIEGO/ PESO A CAPACIDAD DE CAMPO (\%) } \\
\hline Control & $95-100$ & 100 & 100 & 100 & 100 \\
\hline RD sost & $70-75$ & 70 & 70 & 70 & 70 \\
\hline RDC I & 70 & 100 & 70 & 100 & 70 \\
\hline RDC II & 100 & 70 & 100 & 70 & 100 \\
\hline
\end{tabular}

Figura 4.17- Esquema de las fases fenológicas de las plantas de geranio y umbrales de riego de los distintos tratamientos de riego a lo largo del ensayo. 


\subsubsection{Crecimiento y parámetros ornamentales}

Se realizaron medidas semanales de crecimiento (altura y anchura de la planta) en 25 plantas por tratamiento y un muestreo final en el que se determinó el peso fresco y seco, área foliar y número de hojas en 5 plantas por tratamiento, siguiendo la metodología descrita en el apartado 3.2.1.3.

También se hicieron controles semanales de floración, midiendo, en la totalidad de las plantas del ensayo (25 plantas por tratamiento): el número de inflorescencias sin abrir, número de inflorescencias abiertas y número de inflorescencias secas por planta (Fotografía 4.10). Además, se hizo un seguimiento del porcentaje de plantas con presencia de inflorescencias a lo largo del ensayo para programar el riego.
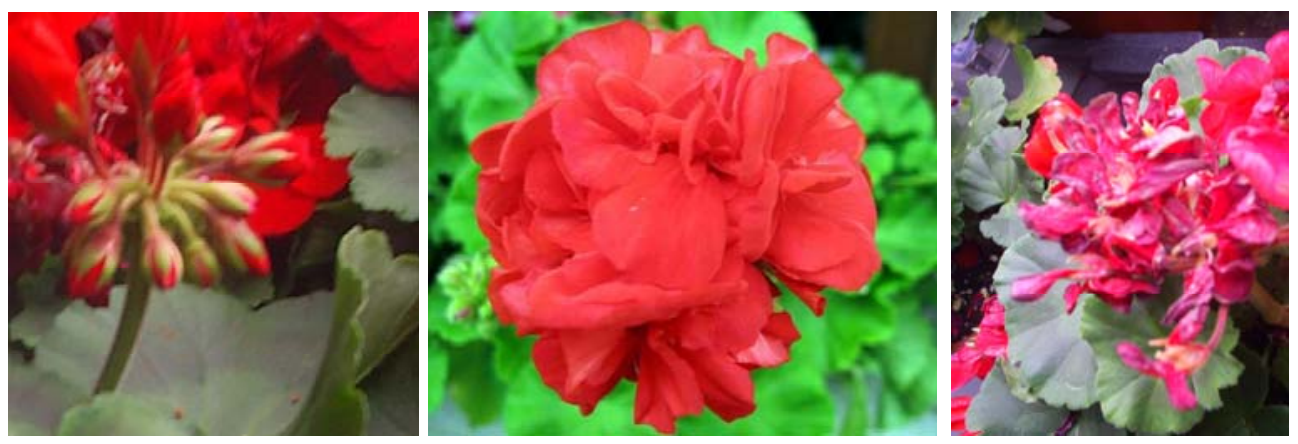

Fotografía 4.10- Control de la floración: inflorescencia sin abrir, abierta y seca.

Periódicamente se midió el número de hojas caídas por planta (25 repeticiones por tratamiento) y el color en hojas y flores en 7 plantas por tratamiento, tal y como se explica en el apartado 3.2.1.3.de esta memoria Las determinaciones de los parámetros de color en hojas se realizaron en la zona exterior (parte oscura) y en la zona interior (parte clara) de la hoja de geranio (Fotografía 4.11).

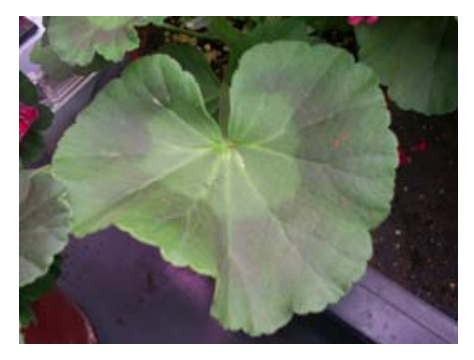

Fotografía 4.11- Detalle de una hoja bicolor de geranio.

El contenido relativo de clorofila (CRC) se midió en varios momentos del ensayo en 7 hojas por tratamiento con un medidor de 
clorofila Minolta SPAD-502 (Konica Minolta Sensing Inc., Osaka, Japan), (Fotografía 4.12).

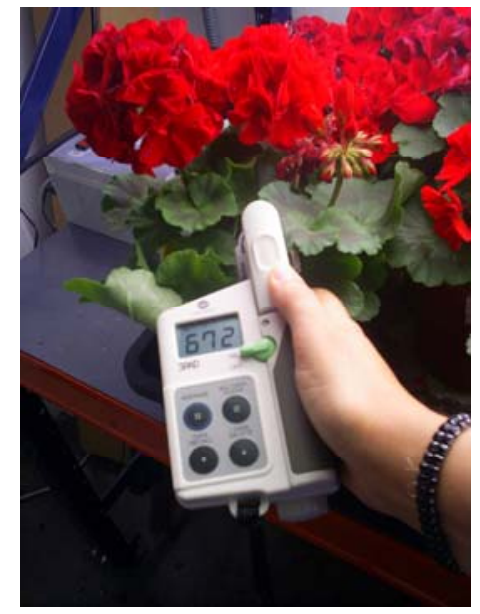

Fotografía 4.12- Medida del contenido relativo de clorofila en hojas de geranio con un medidor Minolta SPAD-502.

\subsubsection{Consumo de agua y relaciones hídricas}

El consumo de agua se midió gravimétricamente durante todo el periodo experimental, usando una balanza Sartorius modelo 5201. El consumo diario se determinó por diferencias de peso en todas y cada una de las macetas (peso después del riego y peso antes del riego siguiente). Además, había tres macetas de los tratamientos control y RD que estaban continuamente sobre una balanza conectada a una mitra, que registraba el peso de estas macetas a intervalos de 30 minutos, lo que nos permitió obtener la evolución del consumo a lo largo del día (Fotografía 4.13).

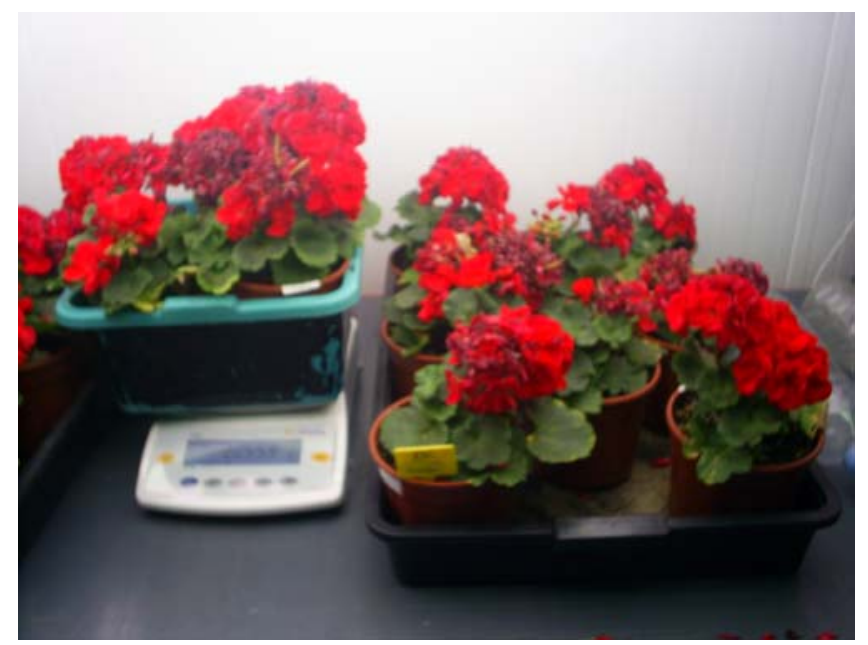

Fotografía 4.13- Balanza que registraba el peso de las macetas de geranio cada 30 minutos. 
El potencial hídrico foliar $\left(\Psi_{\mathrm{h}}\right)$ y sus componentes $\Psi_{\circ}$ y $\Psi_{\mathrm{p}}$ fueron medidos en condiciones de máxima luz en distintos momentos del ciclo del geranio. Se evaluaron cinco hojas para cada tratamiento. Dichas medidas fueron determinadas de acuerdo con la metodología que se explica detalladamente en el apartado 3.2.1.4.

Se hizo un seguimiento de la evolución del potencial osmótico saturado $\left(\Psi_{o s}\right)$ y el contenido relativo de agua (CRA) según apartado 4.2.1.4, para lo cual se emplearon 5 hojas por tratamiento. Además se realizó una prueba para ver como las hojas de los distintos tratamientos perdían el agua desde el momento de saturación. Esta prueba se realizó en dos momentos del ensayo, en plena fase floración (semana 4.5) y en fase de no floración (semana 10.5), en 5 hojas por tratamiento. Las hojas se llevaron a saturación y después de obtener el peso turgente de cada hoja, se dejaron a temperatura ambiente y se pesaron periódicamente durante varios días para determinar la pérdida de agua. Al final de la prueba, las hojas se metieron en la estufa para obtener su peso seco.

Se realizó una medida de conductividad hidráulica en 5 plantas por tratamiento al final del ensayo, distinguiéndose la parte aérea de las raíces, usando un equipo Dynamax High Pressure Flow Meter (HPFM) (Fotografía 4.14).

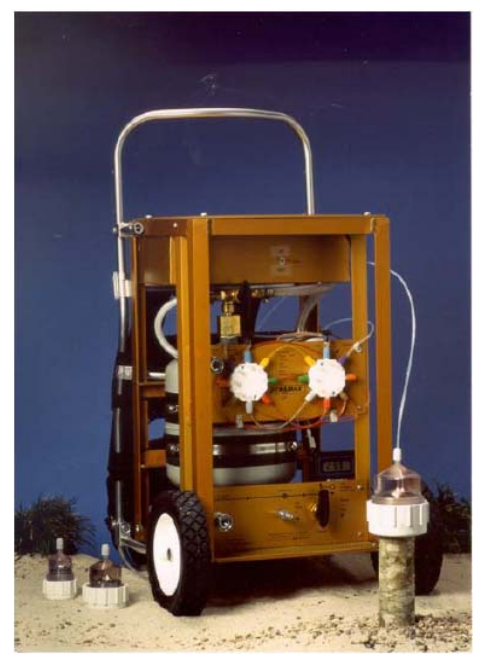

Fotografía 4.14- Equipo High Pressure Flow Meter para la medida de conductividad hidráulica

Periódicamente se midió la conductancia estomática $\left(\mathrm{g}_{\mathrm{s}}\right)$ y la fotosíntesis neta $\left(P_{n}\right)$ en 5 repeticiones por tratamiento. Estas medidas fueron realizadas en las horas centrales de la fase luminosa, según se explica previamente en el apartado 3.2.1.4. 


\subsubsection{Análisis estadístico}

La significación de los efectos de la dosis de riego fue analizada mediante un análisis de varianza simple (ANOVA), usando Statgraphics Plus para Windows. Las medias de los tratamientos fueron separadas con la Prueba de Rango Múltiple de Duncan $(P<0.05)$. Antes del análisis estadístico, cocientes y datos en porcentajes fueron previamente transformados mediante una transformación arcoseno raíz cuadrada, para asegurar la homogeneidad de la varianza. 


\subsubsection{Resultados y discusión}

\subsubsection{Efectos del riego deficitario en distintos momentos fenológicos en el crecimiento y parámetros ornamentales en plantas de geranio}

Al final del periodo de estudio, el crecimiento y desarrollo de las plantas se alteró de forma significativa por la aplicación de los tratamientos de riego, los cuales modificaron un amplio número de los parámetros medidos (Tabla 4.4). Las plantas del tratamiento control experimentaban un mayor crecimiento como lo indican los valores de peso seco de la parte aérea. Mientras el riego deficitario, independientemente del momento de su aplicación, disminuyó el peso seco aéreo, el número de hojas, el área foliar total y se produjo un aumento del cociente peso seco raíz/peso seco aéreo de las plantas de geranio. Sin embargo, las raíces no se vieron modificadas (Tabla 4.4). Estas misma respuestas son encontradas por Jaleel y col. (2008), en C. roseus, por Henson y col. (2006) y Hassanenin y Dorion (2006) en $P$. hortorum, por Andersson (2001) en P. zonale y por Andersson (2011) en $I$. walleriana y Petunia $x$ hybrid.

Tabla 4.4- Estudio del crecimiento en plantas de geranio en maceta sometidas a diferentes tratamientos de riego al final del período experimental.

\begin{tabular}{|c|c|c|c|c|}
\hline \multirow{2}{*}{ Parámetros medidos } & \multicolumn{4}{|c|}{ Tratamientos } \\
\hline & Control & RD Sostenido & $\mathrm{RDCl}$ & RDC II \\
\hline Peso fresco aéreo $\left(\mathrm{g} \mathrm{pl}^{-1}\right)$ & $29.71 \pm 2.11 b$ & $18.09 \pm 1.88 \mathrm{a}$ & a $17.91 \pm 1.42 \mathrm{a}$ & $15.13 \pm 1.60 a^{* * k}$ \\
\hline Peso seco aéreo (g pl-1) & $5.33 \pm 0.37 b$ & $\pm 0.40 \mathrm{a}$ & a $3.22 \pm 0.26 \mathrm{a}$ & $2.65 \pm 0.31 a^{* k}$ \\
\hline Peso seco raíz (g pl-1) & $2.25 \pm 024$ & \pm 0.41 & $1.94 \pm 0.07$ & $1.65 \pm 0.10 \mathrm{~ns}$ \\
\hline PS raíz/PS aéreo & $0.42 \pm 0.04 \mathrm{a}$ & $\pm 0.07 \mathrm{~b}$ & b $0.62 \pm 0.05 b$ & $0.68 \pm 0.04 b$ * \\
\hline $\mathrm{N}^{0}$ hojas por planta & $68 \pm 4.10 b$ & $\pm 4.43 \mathrm{a}$ & a $45 \pm 2.44 a$ & $45 \pm 6.36 \mathrm{a}$ ** \\
\hline Área foliar total $\left(\mathrm{cm}^{2}\right)$ & $446 \pm 35 b$ & $\pm 42 \mathrm{a}$ & a $279 \pm 28$ a & $284 \pm 27 a^{* *}$ \\
\hline
\end{tabular}

Si consideramos los valores de peso fresco de la parte aérea se observa que las diferencias entre el tratamiento RD sostenido y el control son algo mayores que las que presentan los valores de peso seco (Tabla 4.4). Posiblemente, el efecto producido por el déficit hídrico produjo una ligera deshidratación de los tejidos de las plantas, como más adelante veremos al considerar los parámetros hídricos. En otras especies 
ornamentales, en petunia, se ha observado este mismo efecto (Andersson, 2011).

Las evoluciones de la altura y la anchura de la planta a lo largo del período experimental quedan reflejadas en la Figura 4.18. El comportamiento de estos parámetros fue más parecido entre las plantas control y las de RDC I, es decir cuando se aplicaba el riego deficitario fuera de la fase de la floración. Las plantas que presentaban menor altura y anchura correspondieron a aquellas donde la reducción del riego se aplicaba en la fase de floración (Figura 4.18A y B). Esto nos indica que esta fase resultó ser la más sensible al déficit hídrico. Concretamente, la reducción de la altura media con respecto a las plantas control fue significativa en los plantas de los tratamientos RD sostenido y de forma más acentuada en las plantas a las que se redujo el aporte hídrico en la fase de floración (RDC II) (Figura 4.18A), este efecto fue desde las primeras semanas. La evolución de la anchura (Figura 4.18B) fue similar a la altura (Figura 4.18A), aunque en este parámetro las diferencias fueron menos evidentes. Como se puede ver, existe una tendencia a reducir la anchura en las plantas de los tratamientos RD sostenido y RDC II. Las plantas del tratamiento RDC I presenta en algunos momentos del ensayo plantas con menor anchura que las del control, aunque al final del ensayo ambas son similares. 


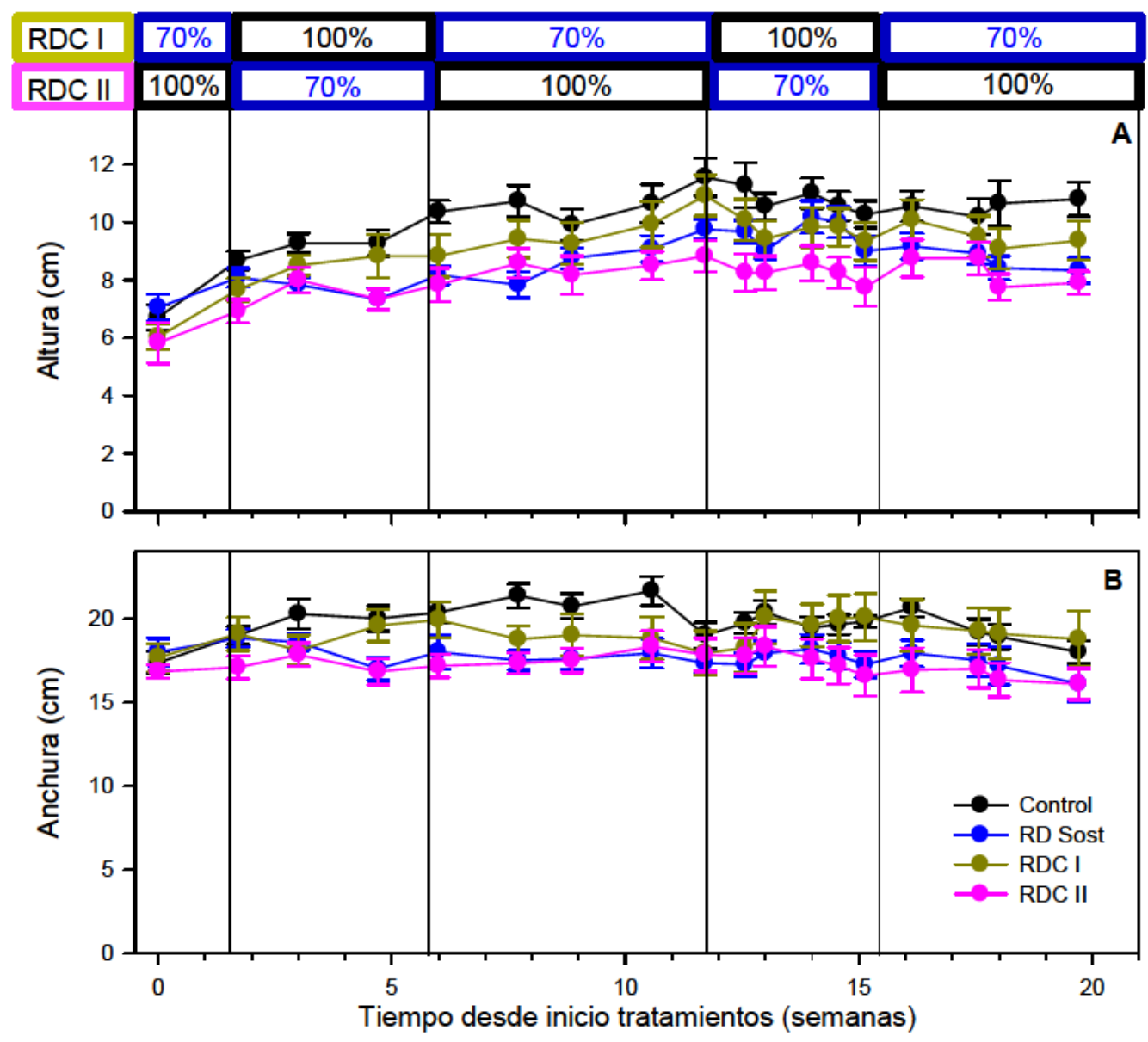

Figura 4.18- Evolución de los parámetros de crecimiento (altura, A; anchura, B) en plantas de geranio en maceta sometidas a distintos tratamientos de riego durante el periodo experimental. Las líneas verticales indican los cambios de riego en los tratamientos de RDC.

En estas condiciones, el riego deficitario en general reduce en mayor proporción la altura que la anchura, por lo que estas plantas ganan en compacidad, lo cual ocurría también en el ensayo de geranio descrito anteriormente. No obstante, la intensidad de reducción del crecimiento en plantas ornamentales sometidas a riego deficitario depende de la especie, duración y grado del estrés (Van lersel y Nemali, 2004; Hassanein y Dorion, 2006, Hansen y Petersen, 2004; De Lucia, 2009; Andersson, 2011; Sharp y col., 2009; Bernal y col., 2011).

Atendiendo al proceso de floración, en la Figura 4.19 se muestra en cada momento de muestreo el número de inflorescencias sin abrir (A) y el número de inflorescencias abiertas (B), así como la evolución a lo largo de todo el ensayo de el número de inflorescencias sin abrir (C), el número de inflorescencias abiertas (D) y el número de inflorescencias secas (E). En general, la intensidad de floración fue mayor para las plantas del tratamiento control y para las del RDC I y menor para las 
plantas del tratamiento RDC II (Figura 4.19C). Las plantas de este último tratamiento fueron las que presentaron menor número de inflorescencias sin abrir en cada momento (Figura 4.19A) y a lo largo del ensayo (Figura 4.19C) y menor número de inflorescencias abiertas en cada momento (Figura 4.19B) y a lo largo de todo el ensayo (Figura 4.19D).

En el primer periodo de floración (semana 2 a 6), las plantas del tratamiento RDC II tuvieron menos flores que las controles (Figura 4.19B), mientras que para el RD sostenido y RDC I no hubo diferencias, aunque la duración de la floración fue más corta que la de las plantas control. En cuanto al segundo periodo de floración (semana 12 a 15), las plantas del tratamiento RDC II siguieron teniendo menor intensidad de floración y las plantas de los otros dos tratamientos de riego deficitario adelantaron la floración (Figura 4.19B). Al final del ensayo parece que habría otro periodo de floración (semana 19), en la que todas las plantas florecen a la vez y con la misma intensidad, pero en este momento no se procedió al cambio de riego en los RDC I y II, ya que, las plantas del tratamiento control no alcanzaron el $80 \%$ de plantas con presencia de inflorescencias, independientemente del número de inflorescencias por planta y prácticamente se había dado por terminado el ensayo. 


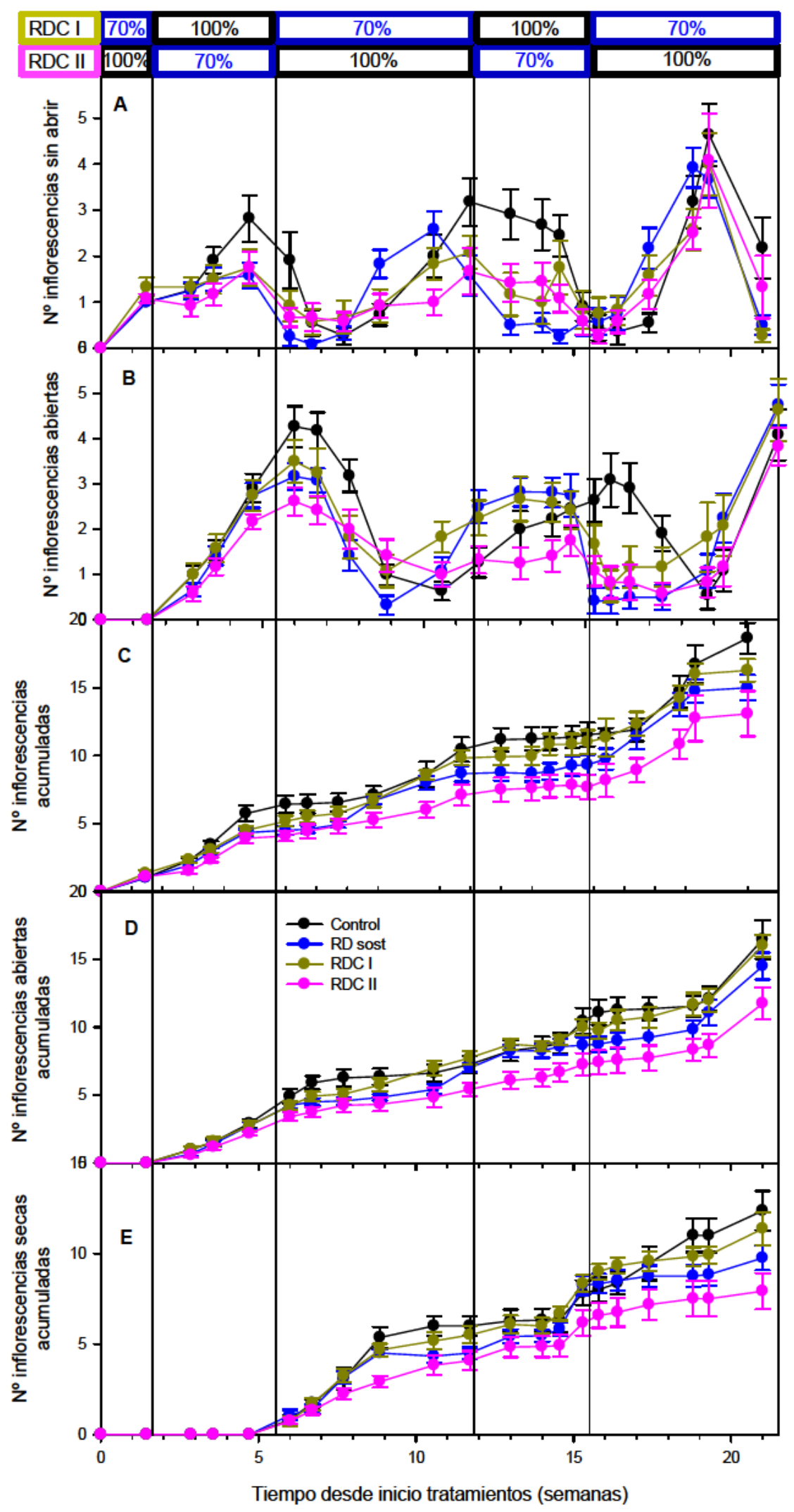

Figura 4.19- Evolución de la floración: número de inflorescencias sin abrir $(A)$, número de inflorescencias abiertas (B), numero de inflorescencias sin abrir acumuladas (C), número de inflorescencias abiertas acumuladas (D) y numero de inflorescencias secas acumuladas (E) en plantas de geranio en maceta sometidas a distintos tratamientos de riego durante el período experimental. Las líneas verticales indican los cambios de riego en los tratamientos de RDC. 
Teniendo en cuenta el número de inflorescencias acumuladas por planta, (Figura 4.19D), las plantas del tratamiento RDC II son las que tienen menos inflorescencias, mientras que la floración de las plantas del tratamiento RDC I y RD sostenido no se modificó respecto a las plantas del tratamiento control, aunque al final del ensayo se aprecia una tendencia en las plantas del tratamiento RD sostenido a reducir este parámetro.

La aplicación del riego deficitario supone un ahorro de agua y una reducción del crecimiento, pero puede modificar el proceso de floración; retrasar, adelantar y/o acortar la floración (Bernal y col., 2001; Cuevas y col., 2009). Según Henson y col. (2006), en Pelargonium hortorum, el riego deficitario reduce la calidad de la planta de manera proporcional a la reducción del riego, pero en nuestro ensayo vemos que no sólo depende de la cantidad de agua aplicada a la planta, sino también del momento en el que se aplique la reducción del riego. De acuerdo con Sharp y col. (2009), trabajando con Rhododendron, obtiene distintos resultados, dependiendo de la fase donde se aplica el déficit hídrico; si el RDC es antes de la iniciación floral se forman menos entrenudos antes del cambio de los meristemos apicales a iniciación floral, y cronológicamente la iniciación floral ocurre antes, y si es después de la iniciación floral se estimulan el desarrollo de más flores en cada inflorescencia. Sin embargo, si el déficit hídrico continúa a lo largo de los estados de desarrollo floral, la antesis (apertura de las flores) puede ocurrir antes, en plena formación floral de los brotes o yemas.

El déficit hídrico puede afectar a la floración, por eso es necesario optimizar en cada especie, la duración, el momento adecuado para reducir la disponibilidad hídrica e intensidad del déficit para evitar los efectos negativos sobre la calidad ornamental. En numerosos trabajos se ha estudiado como afectan a la floración estos factores por separado o combinados entre si (especie, duración del estrés, momento del ciclo o porcentaje de reducción): Hansen y Petersen (2004), Henson y col. (2006), Katsoulas y col. (2006), Chylińsky y col. (2007), Silber y col. (2007), De Lucia (2009), Álvarez y col. (2009), Sánchez-Blanco y col. (2009), Bolla y col. (2010), Andersson (2011), Bernal y col. (2011).

Existe gran variedad de parámetros para evaluar la calidad ornamental de las plantas (diámetro flores, número flores, número de flores por inflorescencia, tiempo optimo de floración, duración de la 
floración, número de tallos florales, longitud de los tallos florales, color de las flores etc.). La elección del parámetro empleado para evaluar la calidad ornamental depende de cada especie y de las características que se pretende obtener en función de la demanda de los consumidores y mercado, aunque según el índice utilizado pueden variar los resultados obtenidos (Sharp y col., 2009).

El número de hojas caídas a lo largo del ensayo fue mayor en las plantas del tratamiento control (Figura 4.20), aunque es también el que tuvo mayor follaje. Ello significa que en valor absoluto tuvo una mayor producción de hojas y una mayor pérdida de las mismas. Sin embargo, en valor relativo, teniendo en cuenta el número de hojas caídas en relación al número de hojas existentes en la planta (Tabla 4.4), las plantas del RD sostenido y el RDC I tuvieron un mayor porcentaje de pérdida de hojas (36\% y $40 \%$ ) que las plantas control (32\%). No obstante, el número de hojas necróticas aumentó al final del ensayo en todos los tratamientos (semana 20), hecho que también ocurrió en el ensayo de geranio presentado anteriormente, posiblemente como resultado del efecto ontogénico de las plantas (Brawner, 2003). Los tramos donde la recta, que expresa el número de hojas necróticas tiene más pendiente; semanas 4-5, 14-15, y especialmente 18-20, (Figura 4.20) coinciden con un aumento en la tasa de crecimiento absoluto de los brotes (Figura 4.19), justo después de los picos de inflorescencias (numero de inflorescencias sin abrir) (Figura 4.19A) y en el momento de máxima floración, mayor número de inflorescencias abiertas por planta (Figura 4.19B). También al final del ensayo hubo un ligero descenso de la clorofila en las hojas de todos los tratamientos por efecto de la senescencia (Figura 4.22). Este descenso no fue debida al efecto del déficit hídrico, ya que ocurrió en todos los tratamientos, y se aseguró que las plantas control tuvieran suficiente agua para prevenir el amarillamiento. 


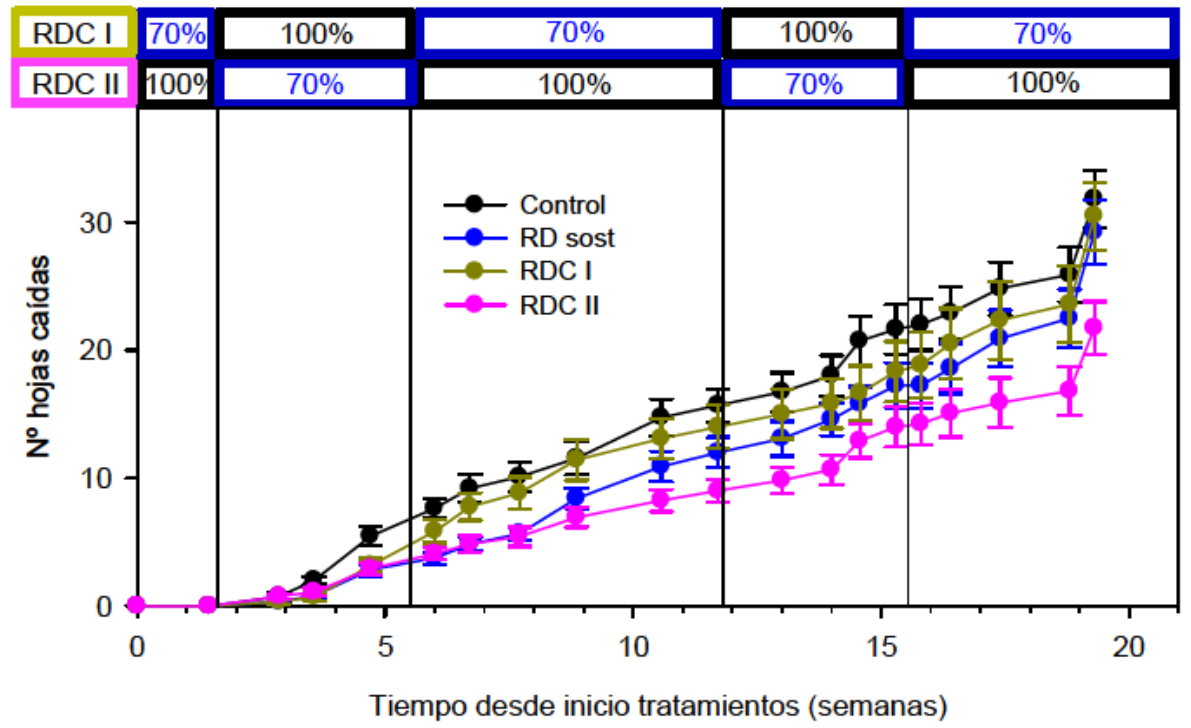

Figura 4.20- Evolución de la pérdida de hojas acumuladas en plantas de geranio en maceta sometidas a distintos tratamientos de riego a lo largo del período experimental. Las líneas verticales indican los cambios de riego en los tratamientos de RDC.

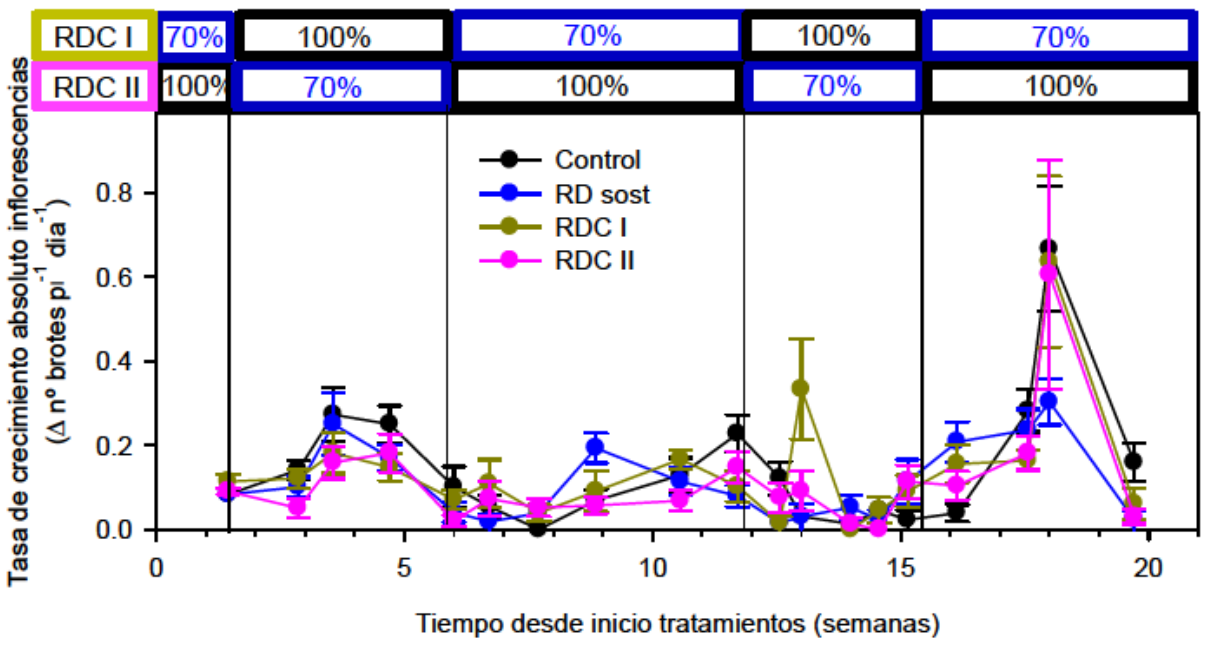

Figura 4.21- Evolución de la tasa de crecimiento absoluto del número de inflorescencias en plantas de geranio en maceta sometidas a distintos tratamientos de riego a lo largo del período experimental. Las líneas verticales indican los cambios de riego en los tratamientos de RDC. 


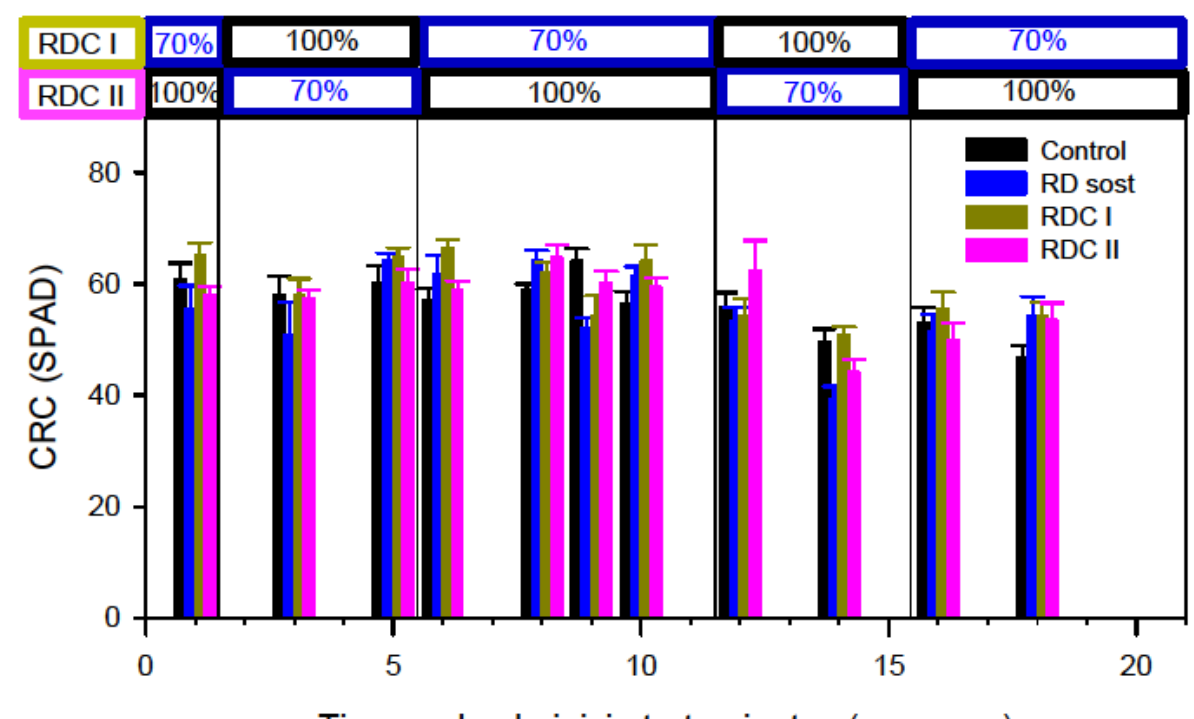

Tiempo desde inicio tratamientos (semanas)

Figura 4.22- Evolución del contenido relativo de clorofila (CRC) en plantas de geranio en maceta sometidas a distintos tratamientos de riego a lo largo del período experimental. Las líneas verticales indican los cambios de riego en los tratamientos de RDC.

Los parámetros de color (luminosidad, croma y ángulo hue) de las hojas y flores de geranio se muestran en la Figura 4.23, en la que podemos apreciar que no se observan diferencias importantes por efecto de los tratamientos, éstas sólo se detectan en momentos muy puntuales (Sánchez-Blanco y col., 2009). Sin embargo, se mantienen las diferencias entre los dos colores de las hojas, es decir hojas bicolores, lo que les da a estas plantas un valor añadido al aspecto ornamental (Figura 4.23A y B; i y ii). La zona exterior de la hoja se conserva más oscura (menos $L$ ) y de un color más mate, menos pálido (menos $\mathrm{C}$ ) que la parte central de la hoja. 

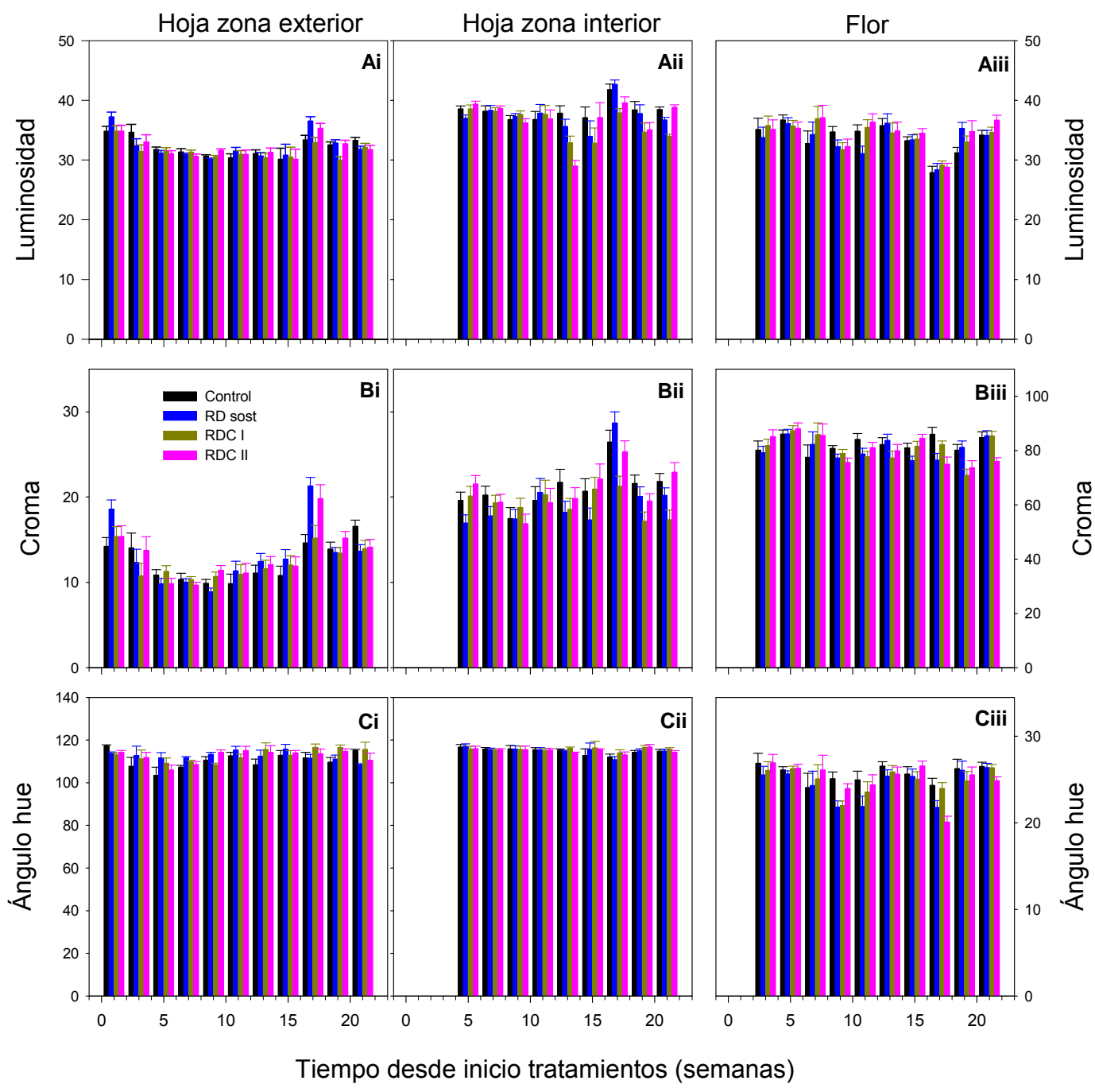

Figura 4.23- Evolución de los parámetros de color, luminosidad (L; A), croma (C; B) y ángulo hue (HUE; C) en la zona exterior de las hojas (i), en la zona interior (ii), y en las flores (iii) de plantas de geranio en maceta sometidas a diferentes tratamientos de riego a lo largo del período experimental.

Las diferencias de ángulo hue entre hojas y flores se mantienen a lo largo del ensayo. El contraste de color entre las hojas y flores, en nuestro caso hojas verdes y flores rojas no se ve modificado por efecto del riego.

\subsubsection{Efectos del riego deficitario en distintos momentos fenológicos en el consumo de agua en plantas de geranio}

Los valores de riego correspondieron a un total de 7890,6260 , 6250 y $6320 \mathrm{ml}$ por planta para los tratamientos control, RD sostenido, $\mathrm{RDCl}$ y $\mathrm{RDCll}$, respectivamente (Figura 4.24). Aunque el riego total fue similar en los tres tratamientos de riego deficitario, aproximadamente un $80 \%$ del agua que se aplica al tratamiento control, $(79.4,79.2$ y $80.1 \%$ 
que corresponden a RD sostenido, RDC I y RDC II, respectivamente), el momento de aplicación varió a lo largo del ensayo y dependió de la fase en la que las plantas se encontraban (Figura 4.24).

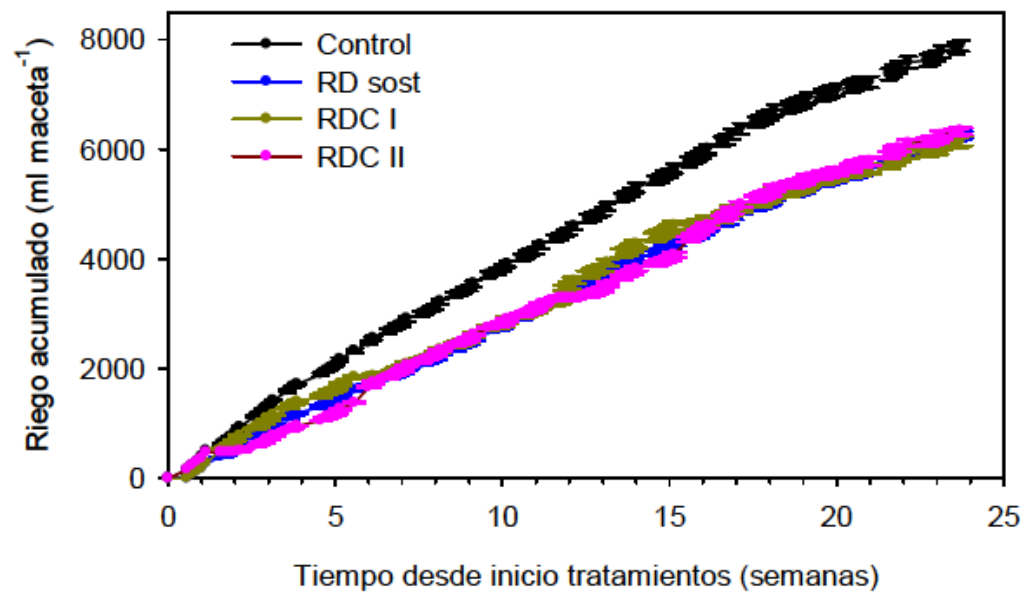

Figura 4.24- Riego acumulado a lo largo del periodo experimental en plantas de geranio en maceta sometidas a diferentes tratamientos de riego.

Los valores totales del consumo, al igual que el riego, se reducen en los tres tratamientos deficitarios con respecto al control, aproximadamente un $80 \%$ del consumo total de las plantas del tratamiento control, pero los valores de consumo de agua diarios varían a lo largo del ciclo para los distintos tratamientos y se representan en la Figura 4.25.

Las reducciones en el consumo de agua por las plantas son atribuibles a una menor superficie transpirante, como consecuencia de una disminución del área foliar (Tabla 4.4) y menor apertura estomática como veremos más adelante, ya que las condiciones ambientales ( $\mathrm{T}^{\mathrm{a}}, \mathrm{HR}$, y radiación), parámetros estrechamente relacionados con la ET (Montero y col., 2001; Bañón y col., 2009) fueron constantes a lo largo del ensayo. De acuerdo con Liu y col. (2006), el riego deficitario reduce la evapotranspiración y la conductancia, aunque los días con déficit de vapor bajo, las diferencias entre tratamientos desaparecen y estas diferencias aumentan cuando el DVP es alto, lo cual no pudimos ver en nuestro ensayo por no presentar diferencias en las condiciones ambientales entre los distintos días. Aunque si pudimos observar estas variaciones en las diferencias entre el consumo del control y de las plantas deficitarias en función de las fases fenológicas y de las distintas exigencias de agua en cada ciclo del cultivo. 


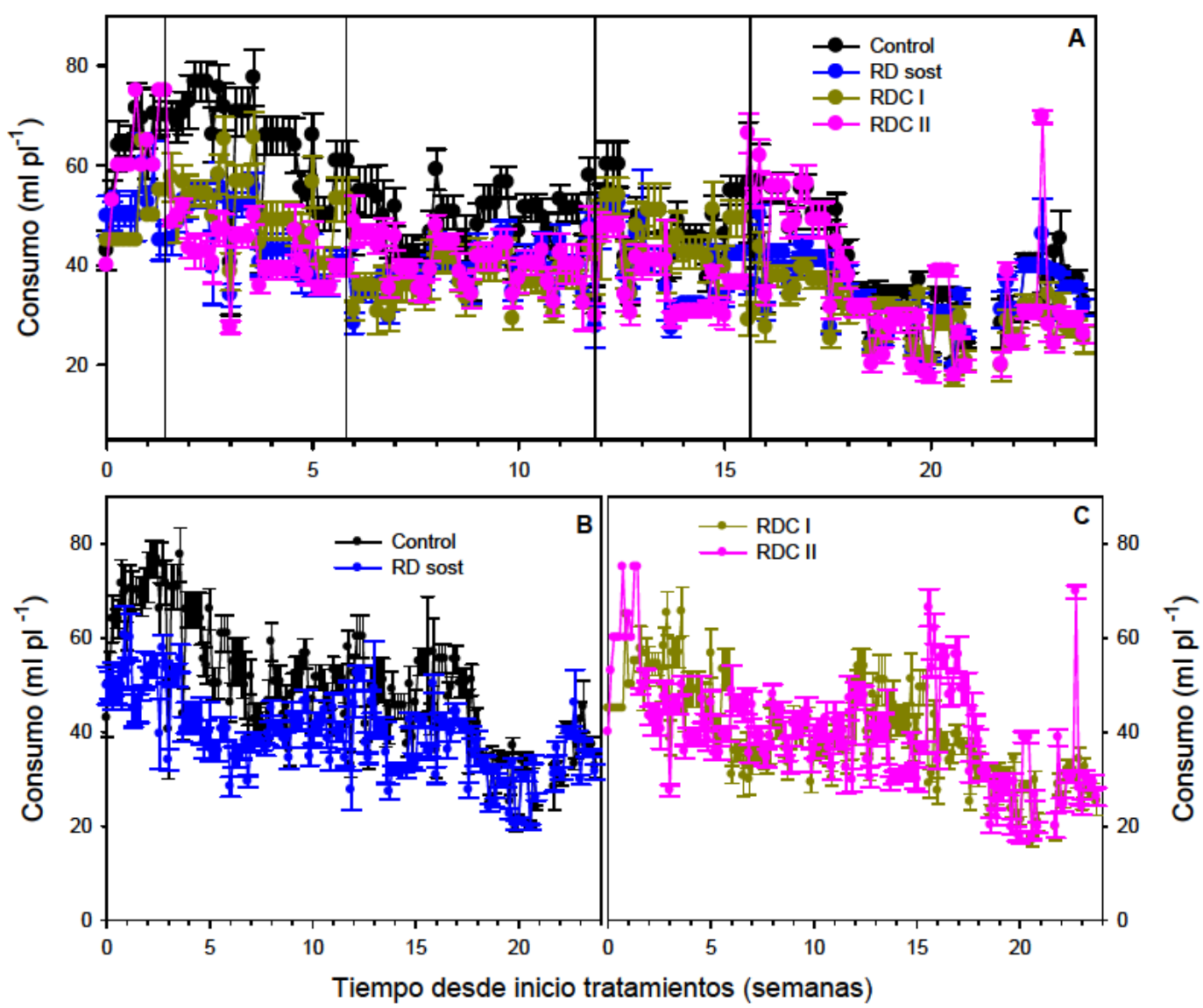

Figura 4.25- Evolución del consumo diario (evapotranspiración) en plantas de geranio en maceta sometidas a distintos tratamientos de riego durante el período experimental. Valores de los 4 tratamientos (A), Control y deficitario (B) y RDC I y RDC II (C). Las líneas verticales indican los cambios de riego en las plantas de los tratamientos de RDC.

Atendiendo a la evolución de la evapotranspiración (ET) (Figura 4.25A), los mayores valores se observan al inicio del ensayo (3-4 primeras semanas) en relación al resto del ensayo. Este hecho coincidió con un aumento en el número de inflorescencias sin abrir (Figura 4.19A) y apertura de flores (Figura 4.19B) y con un aumento de la altura (Figura 4.18A). Bañón y col. (2009), trabajando con geranio observaron que la transpiración diaria varió a lo largo del ensayo y aumentó al inicio de la fase de floración, como consecuencia de la formación de inflorescencias. En nuestro ensayo, en los siguientes periodos de floración no se produce este incremento de la $\mathrm{ET}$, quizás porque estos períodos de floración ya no coinciden con el crecimiento en altura y anchura de la planta y las plantas están fisiológicamente menos activas (Lorenzo y col., 1996).

En general, y si tenemos en cuenta las diferencias entre tratamientos de riego, la transpiración fue mayor en las plantas del tratamiento control y menor en las de riego deficitario (Figura 4.25B), lo 
cual ha sido observado por Bolla y col. (2010) en rosal. Sin embargo, estas diferencias no fueron constantes a lo largo del ensayo; en la semana $7-8$ y a partir de la semana 15 , el consumo de las plantas de RD sostenido es prácticamente igual al de las plantas control, a pesar de tener menos humedad en el sustrato, esto puede deberse a que la segunda y la tercera floración se adelantan en las plantas del tratamiento $\mathrm{RD}$ sostenido con respecto al control (Figura 4.19A).

Cuando se aplica el cambio de riego a los tratamientos RDCl y RDCII (Figura 4.26), las plantas aumentan o disminuyen su consumo y se adaptan a las nuevas condiciones, aunque con alguna peculiaridad. En el paso de condiciones control a riego deficitario (de 100\% a 70\%) (Figura $4.15 \mathrm{~A}$ y B) (zona amarilla), el ajuste de la humedad del sustrato no es inmediato, pero el consumo de agua de las plantas del tratamiento RDC y $\mathrm{RD}$ sostenido se iguala al día siguiente de dicho cambio, y durante esta fase la transpiración de las plantas del tratamiento RDC se iguala e incluso es más baja que la del tratamiento de riego deficitario sostenido (zona amarilla). Este efecto sucede en ambos tratamientos de RDC (I y II), y es más marcado cuando se aplica el primer cambio de riego.

En el paso de condiciones de riego deficitario a control (de $70 \%$ a $100 \%$ ), (zona verde) el cambio de humedad del sustrato se produce de forma inmediata, pero el consumo de agua de las plantas del tratamiento RDC se queda por debajo del tratamiento control (zona verde). Estas diferentas entre ambos tratamientos se van reduciendo y en el segundo cambio de riego de $70 \%$ a $100 \%$, ambos tratamientos presentan similares niveles de consumo de agua. 

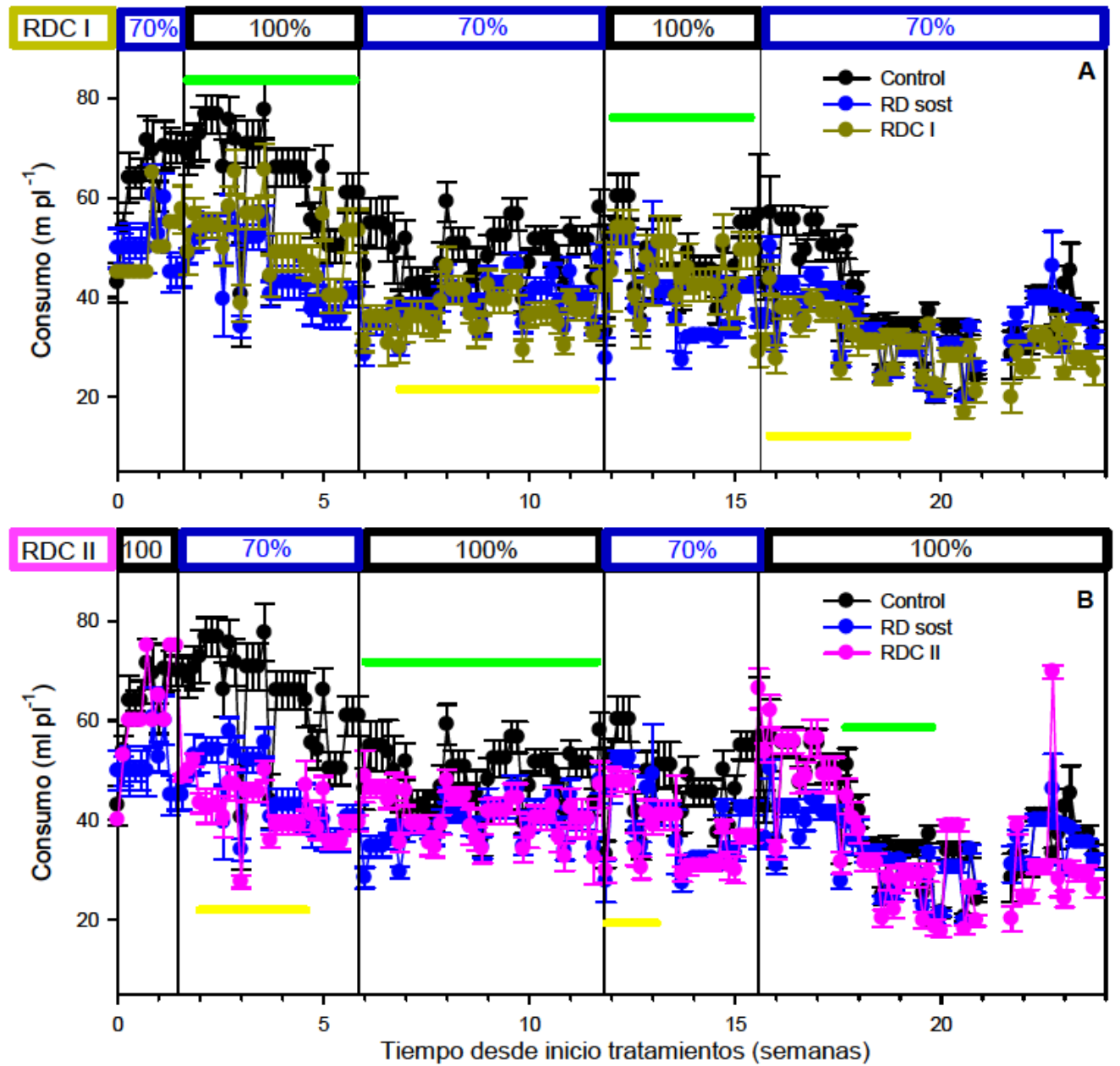

Figura 4.26- Evolución del consumo en plantas de geranio en maceta sometidas a distintos tratamientos de riego. Comparación de las plantas de los tratamientos de RDC I (A) y RDC II (B) con las plantas de los tratamientos Control y RD sostenido y su comportamiento en los cambios de riego. Las líneas verticales indican los cambios de riego en las plantas de los tratamientos de RDC.

Según García-Navarro y col. (2004), que estudian el consumo de varias especies ornamentales en maceta en condiciones control y de déficit hídrico, aportan que por lo general las plantas deficitarias tienen menos consumo ( $\mathrm{ml}$ por planta). El tiempo que las plantas sometidas a riego deficitario tardan en reducir el consumo y la magnitud de esta diferencia entre el consumo del control y las plantas deficitarias depende de la especie. Si en lugar de comparar el consumo diario por planta, comparan el consumo diario en relación al área foliar, observan que algunas especies reducen la tasa de transpiración por área foliar y otras no.

En nuestro caso, calculando el consumo en relación al área foliar, cabe destacar que, al inicio ensayo, las plantas del tratamiento de RD tuvieron menor transpiración que las plantas del control, mientras que el área foliar era similar, con lo que la tasa de transpiración de las plantas 
del tratamiento RD fue menor, pero las ultimas semanas del ensayo las diferencias en transpiración entre el consumo de las plantas del tratamiento control y RD sostenido fueron menores y además al final del ensayo las plantas del tratamiento RD tuvieron menor área foliar $(60 \%$ del control, Tabla 4.4), con lo que las diferencias en las tasas de transpiración entre estos dos tratamientos fueron mucho menores. Esto se observó también en el comportamiento de la conductancia estomática, como veremos más adelante.

En cuanto a la evolución de la ET a lo largo de un día en los tratamientos control y RD sostenido (Figura 4.27), vemos cómo se relaciona el consumo de agua con las condiciones de la cámara (temperatura y luz). El consumo fue prácticamente nulo durante las horas de oscuridad y aumentó en las horas de luz (Montero y col., 2001), supuestamente cuando la planta transpira y el suelo pierde agua por evaporación. No obstante, la componente mayoritaria del término evapotranspiración en nuestro caso fue la transpiración de la planta, ya que la evaporación desde el sustrato quedo muy limitada, debido a que usamos macetas pequeñas con poca superficie evaporativa. En definitiva, la evapotranspiración diaria dependió de la cantidad de agua disponible en el sustrato (Figura 4.27D) y de la radiación (Figura 4.27C) y aunque la cantidad de agua consumida es menor en el tratamiento de RD (Figura 4.27D), el patrón de consumo fue el mismo para ambos tratamientos (Figura 4.27E). Trabajos realizados en plantas de geranio dan como resultado que la $\mathrm{ET}$, además, depende de la frecuencia de riego, es decir a mayor frecuencia, mayor ET (Eiasu y col., 2009). Para Henson y col. (2006), la reducción de la transpiración está más estrechamente relacionada con el porcentaje de reducción del riego. French y col. (2009) calculando la evapotranspiración en plantas en condiciones control y a distintos niveles de estrés hídrico llegan a la conclusión que la ET de las plantas sometidas a estrés hídrico es menor según aumenta la severidad del estrés y/o según se disminuye la frecuencia del riego. 

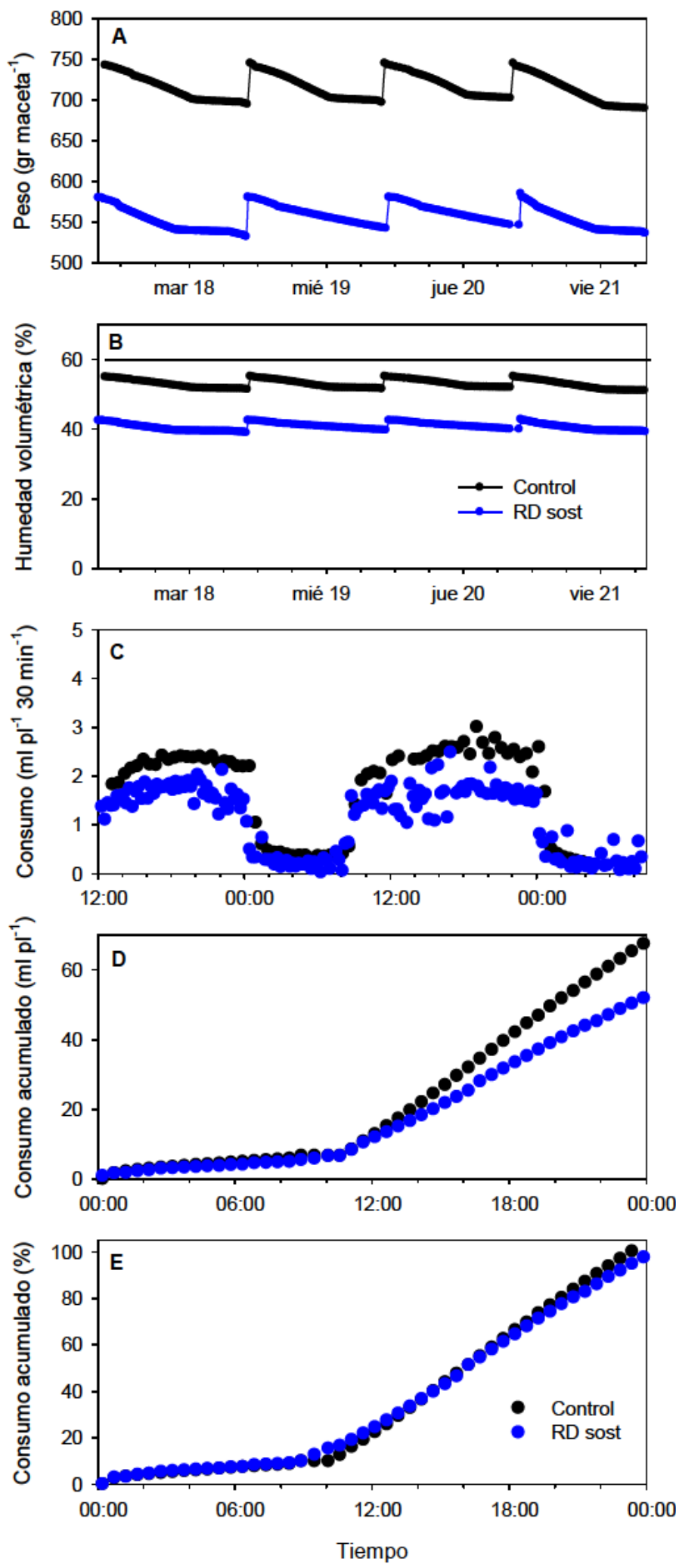

Figura 4.27- Evolución horaria del peso $(A)$, humedad volumétrica $(B)$, consumo $(C)$, consumo acumulado (D) y distribución del consumo (E) a lo largo de un día representativo en plantas de geranio en maceta de los tratamientos control y RD sostenido. 


\subsubsection{Efectos del riego deficitario en distintos momentos fenológicos en las relaciones hídricas en plantas de geranio}

La Figura 4.28 muestra la evolución del potencial hídrico $\left(\Psi_{\mathrm{h}}\right)$ y sus componentes de las plantas a lo largo del ensayo durante las distintas fases de riego. El potencial hídrico de las hojas refleja el agua aportada en los distintos momentos y presentó valores altos en todos los tratamientos, no alcanzando los valores umbrales para el cierre estomático, que se sitúa en torno a $-0.8 \mathrm{MPa}$ (Arora y col., 1998) (Figura 4.28A). Las plantas de RD sostenido presentaron los valores más bajos y los más altos correspondieron a las plantas control. Los valores de $\Psi_{\mathrm{h}}$ en las plantas de los tratamientos RDCl y RDCll cambiaron según se modificaba el riego. 

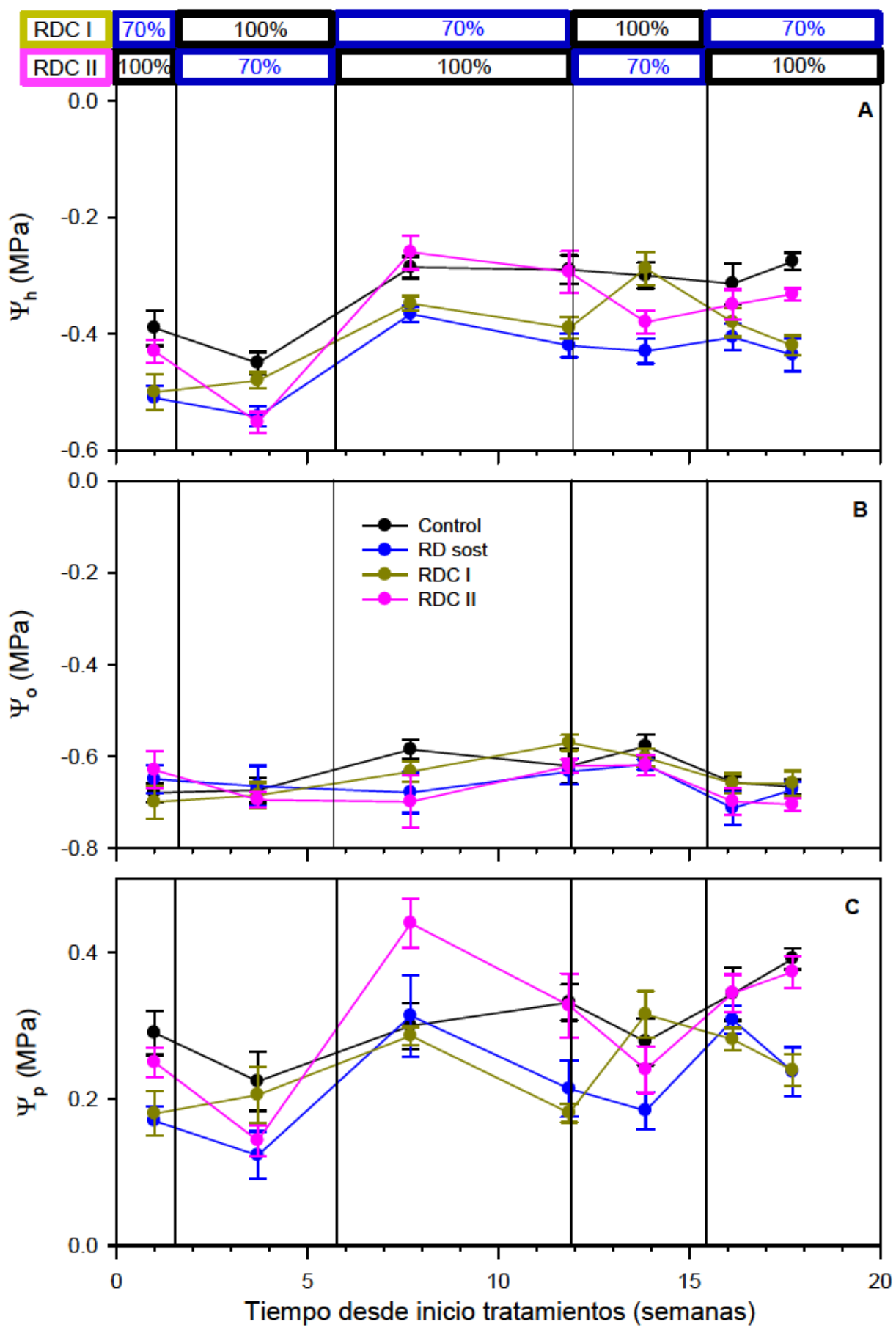

Figura 4.28- Evolución del potencial hídrico $\left(\Psi_{\mathrm{h}} ; \mathrm{A}\right)$, potencial osmótico actual $\left(\Psi_{0}\right.$; B) y potencial de presión $\left(\Psi_{\mathrm{p}} ; \mathrm{C}\right)$ en plantas de geranio en maceta sometidas a diferentes tratamientos de riego durante el período experimental. Las líneas verticales indican los cambios de riego en las plantas de los tratamientos de RDC.

La evolución del potencial de presión (Figura 4.28C) fue similar a la del potencial hídrico, presentando, en algunos momentos descenso de la turgencia de las hojas cuando las plantas recibían menos agua. No obstante, el estrés alcanzado en las plantas de los distintos tratamientos deficitarios resulto ser moderado. Debido a ello, no hubo ajuste osmótico 
como así lo indican los valores de potencial osmótico a máxima saturación (Figura 4.29) (Sánchez-Blanco y col., 2009). Tampoco hubo efecto significativo del RD sobre el contenido relativo de agua (CRA) (Figura 4.30), debido también a que el estrés desarrollado por las plantas fue suave, posiblemente porque las condiciones ambientales donde se desarrollaba el ensayo no fueron severas. Hassanein y Dorion (2006) encuentran que distintas variedades estudiadas de Pelargonium hortorum realizan ajuste osmótico, pero en este caso el estrés impuesto fue severo.

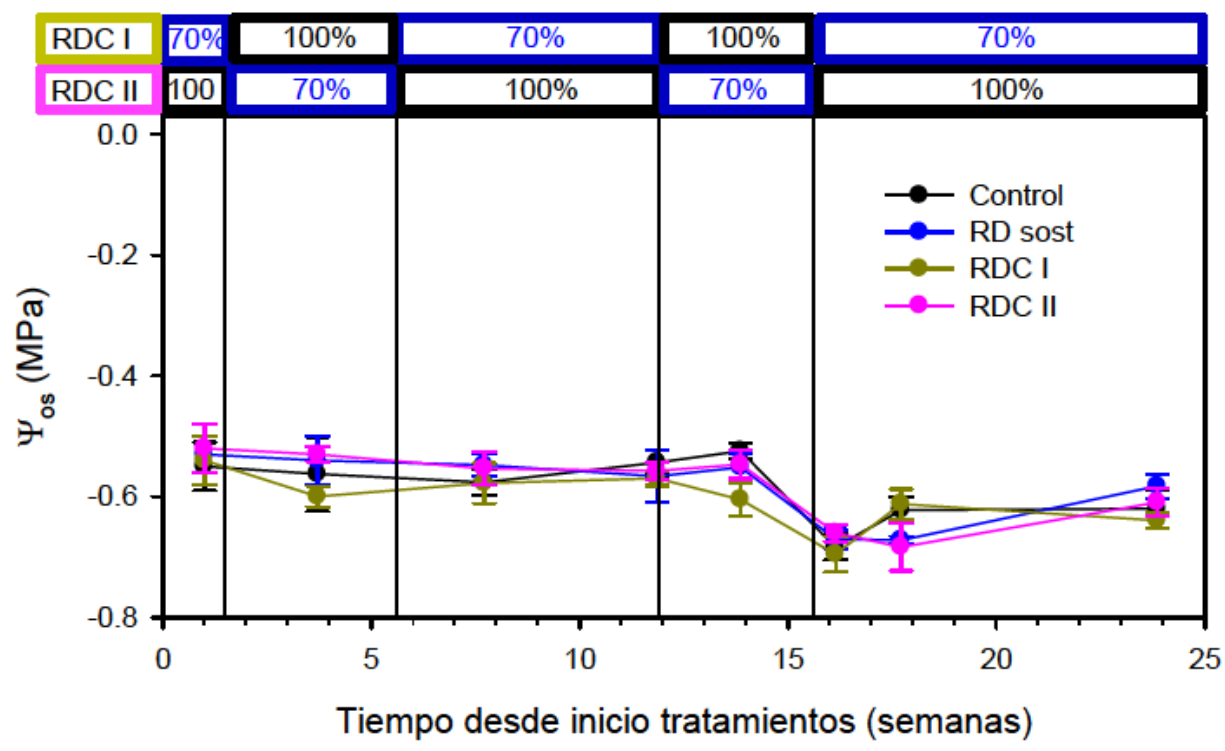

Figura 4.29- Evolución del potencial osmótico saturado $\left(\Psi_{\text {os }}\right)$ en plantas de geranio en maceta sometidas a diferentes tratamientos de riego durante el período experimental. Las líneas verticales indican los cambios de riego en las plantas de los tratamientos de RDC. 


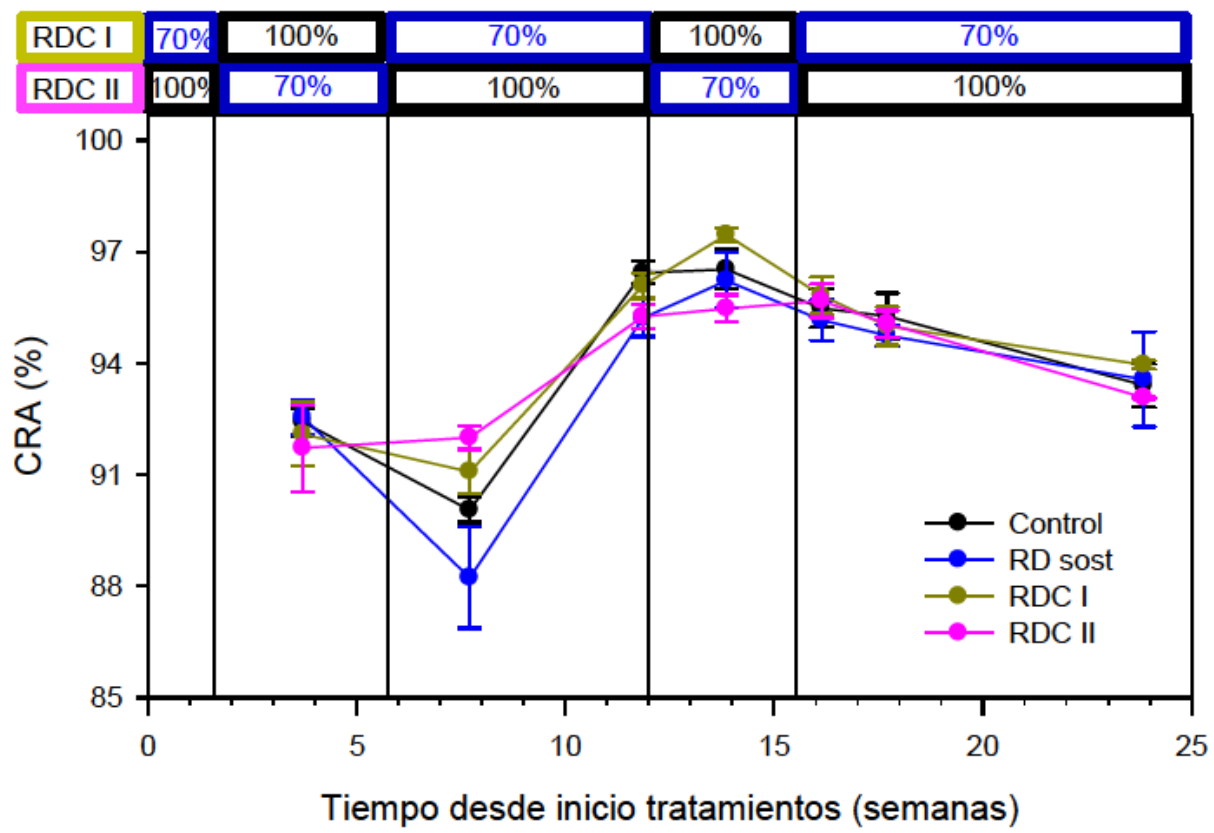

Figura 4.30- Evolución del contenido relativo de agua (CRA) en plantas de geranio en maceta sometidas a diferentes tratamientos de riego durante el período experimental. Las líneas verticales indican los cambios de riego en las plantas de los tratamientos de RDC.

Sin embargo, aunque el contenido de agua en las hojas de los distintos tratamientos fue similar, se observó que las condiciones de riego a las que habían estado sometidas las plantas tenían un efecto sobre la cinética de la pérdida del contenido relativo de agua de las hojas en distintos momentos del ciclo (fase de floración y de no floración) (Figura 4.31A y B). Las hojas del tratamiento control perdían el agua más rápidamente que las del $\mathrm{RD}$ sostenido, quizás mas adaptadas a retener agua y con menor transpiración cuticular en las hojas. En la fase de floración (Figura 4.31A), los tratamientos de RDC I y II, después de 3 semanas del cambio de riego, RDC I (de $70 \%$ a $100 \%$ ) y RDC II (de $100 \%$ a 70\%), se comportan el RDC I de manera similar al control y el RDC II similar al RD sostenido. En la segunda fase de no floración (Figura 4.31B), las diferencias entre control y RD sostenido siguen manteniéndose. En el caso del RDC II, a pesar de llevar cuatro semanas regándose como el control, las diferencias entre estos dos tratamientos no están tan claramente diferenciadas como en la fase anterior. Las plantas del tratamiento RDC II disminuyen su contenido relativo de agua de manera más lenta que las plantas control. Parece ser que el historial hídrico previo condiciona el comportamiento en cuanto a la retención de agua por los tejidos foliares y puede existir una pre-adaptación por los 
periodos de déficit hídricos anteriores, que pueden llevar consigo modificaciones morfológicas y/o anatómicas de las hojas.

La disminución de la transpiración cuticular en los tratamientos de riego deficitario podría relacionarse con un incremento en el espesor de las capas de la pared celular externa (Baig y Tranquillini, 1976). Una reducción de la transpiración cuticular puede incrementar las posibilidades de supervivencia de las plantas ante situaciones de estrés hídrico, como las que a menudo se dan después del transplante, ya que ante un completo cierre de los estomas, los individuos de menor transpiración cuticular serán capaces de mantener sus reservas hídricas durante un mayor tiempo. Dinakar y col. (2011) enumeran algunas respuestas observadas en plantas ornamentales cuando crecen en condiciones de déficit hídrico: plegamientos de las hojas para reducir los daños por radiación y para disminuir la transpiración, modificaciones en las paredes celulares y aumento de la flexibilidad y resistencia para poder reducir el volumen celular durante el estrés sin sufrir daños. 

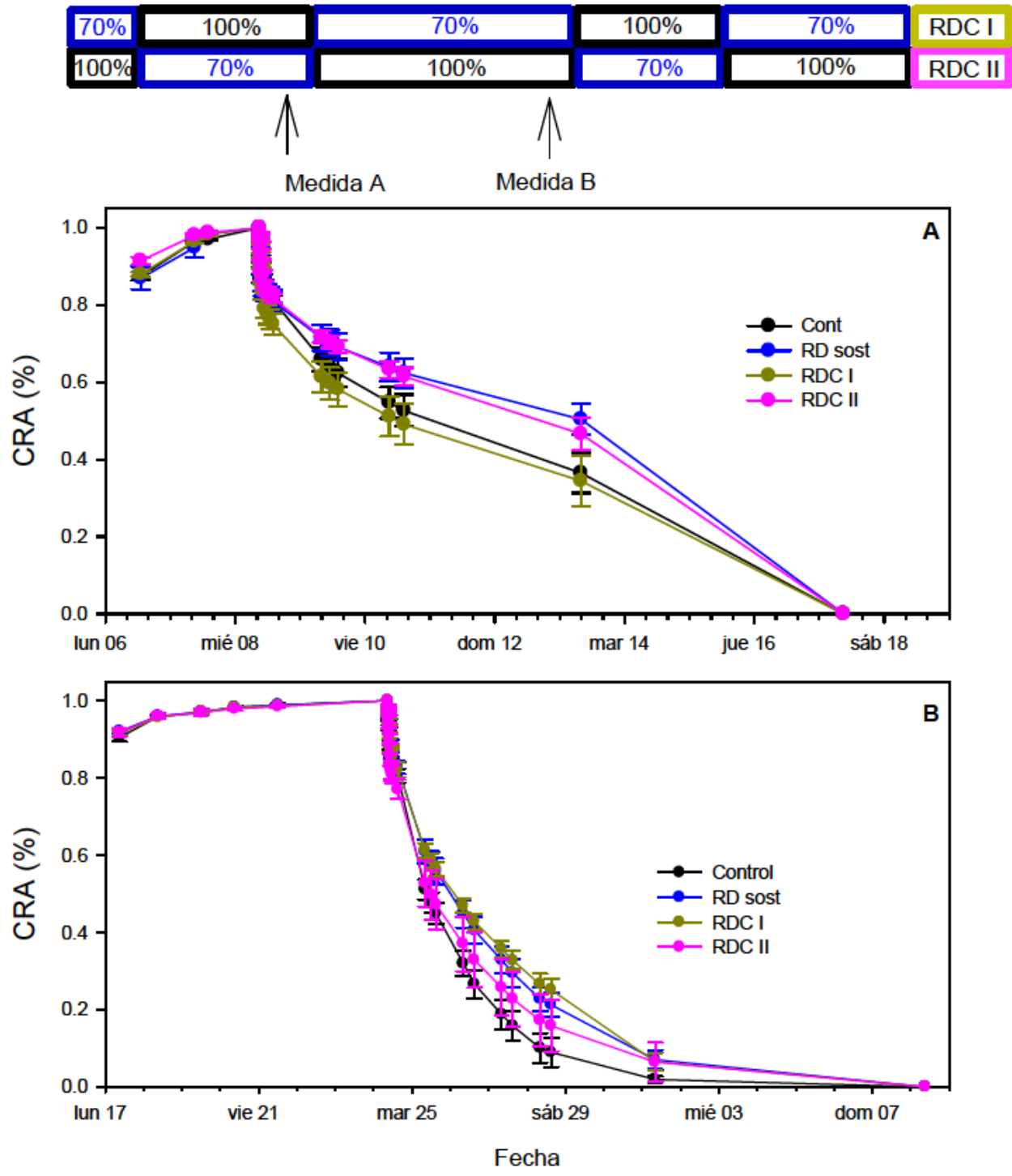

Figura 4.31- Evolución de la pérdida de agua en hojas de geranio en maceta sometidas a distintos tratamientos de riego en dos momentos distintos del ensayo, fase floración (A) y fase de no floración (B).

Si analizamos los resultados de la resistencia hidráulica en las distintas partes de la planta (raíz, tallo y parte aérea) de los distintos tratamientos (Tabla 4.5), vemos como aunque no se detectaron diferencias en la resistencia radical por efecto de los tratamientos de riego, se produjo una tendencia a incrementar en las plantas de los tratamientos RDCI y II. Ello provoca un pequeño aumento de resistencia en el paso de agua a los tallos, y, en general, a la parte aérea. 
Tabla 4.5- Resistencia hidráulica en plantas de geranio en maceta sometidas a diferentes tratamientos de riego al final del período experimental.

\begin{tabular}{lcccccccc}
\multicolumn{1}{c}{ Resistencia } & \multicolumn{8}{c}{ Tratamientos } \\
(MPa s m Kg-1 $^{-1}$ ) & Control & RD Sostenido & RDC I & RDC II \\
\hline Raíz & 792 & a & 714 & a & 1084 & a & 819 & a \\
Parte aérea & 518 & a & 579 & a & 787 & b & 827 & b \\
Tallo & 458 & a & 479 & a & 712 & b & 803 & b \\
\hline
\end{tabular}

Distintas letras dentro de una misma columna indican diferencias significativas según el test de Duncan $_{0} 05$.

El comportamiento de la conductancia estomática y la fotosíntesis neta a lo largo del ensayo se muestra en la Figura 4.32. En general, los valores de $g_{s}$ fueron mayores en las plantas control y menores en las plantas sometidas a déficit hídrico (Figura 4.32A). Los cambios observados en la conductancia estomática de las plantas de los tratamientos RDC respondieron al riego aplicado en cada momento en las plantas de los distintos tratamientos. En los tratamientos de RDC, cuando el cambio de riego supone reducir el agua, la conductancia estomática disminuye, como consecuencia de una regulación en la apertura de los estomas. Cuando el cambio de riego es de una situación de déficit a riego al $100 \%$, los valores de conductancia estomática aumentan, aunque no llegaron a alcanzar los valores de las plantas control, lo que podría ser debido a un acondicionamiento de las plantas por las situaciones de déficit hídrico vividas previamente (Leskovar, 1998; Liptay y col, 1998; Franco y col., 2001; Vilagrosa y col., 2003; Bruce y col., 2007; Cameron y col., 2008; Walter y col., 2011). 


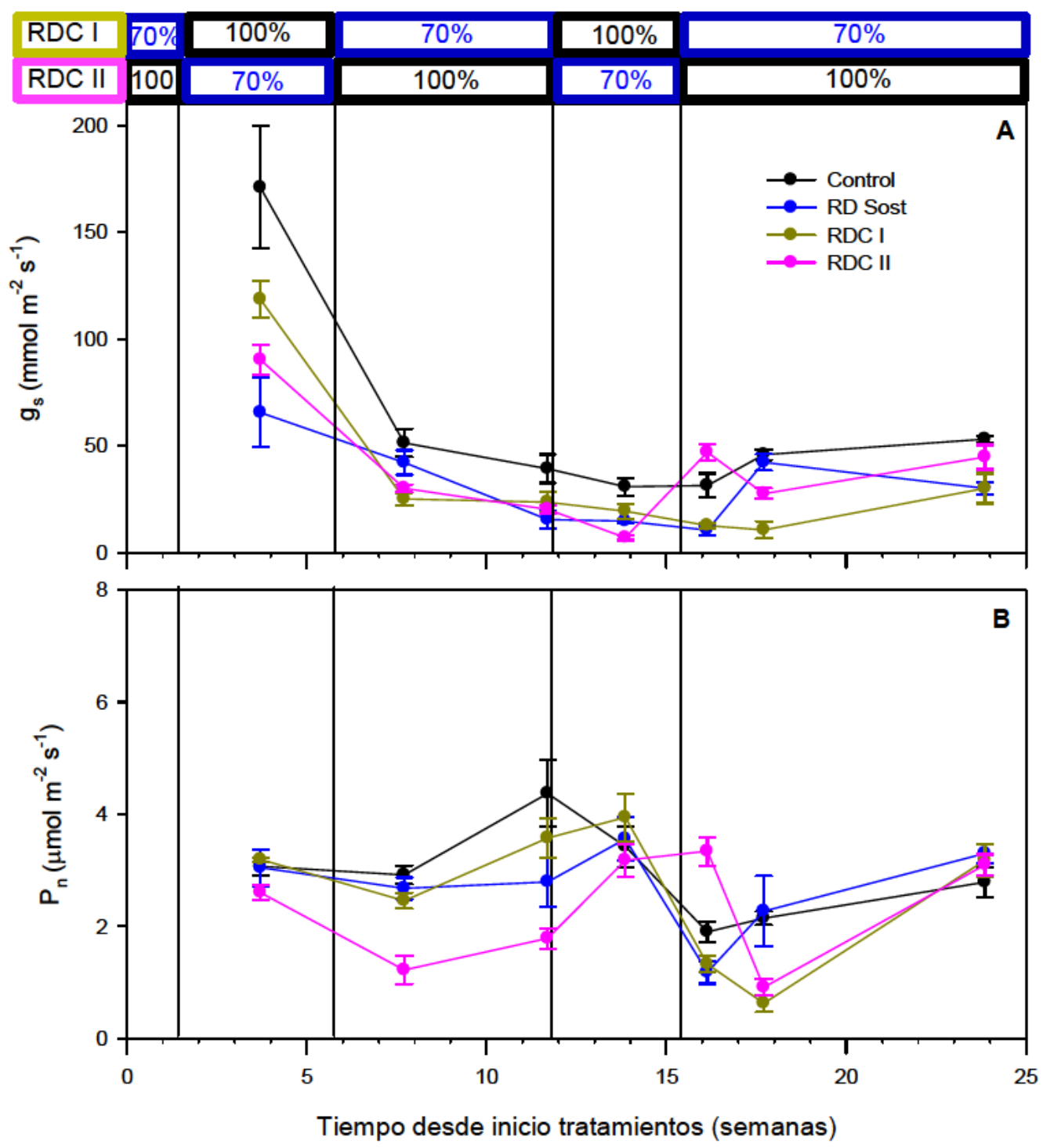

Figura 4.32- Evolución del intercambio gaseoso; conductancia estomática $\left(\mathrm{g}_{\mathrm{s}} ; \mathrm{A}\right)$ y tasa de fotosíntesis neta $\left(P_{n} ; B\right)$ en plantas de geranio sometidas a distintos tratamientos de riego durante el período experimental. Las líneas verticales indican los cambios de riego en las plantas de los tratamientos de RDC.

Hay que destacar, que en el ultimo cambio de riego en el RDC II, se aprecia cómo el aumento del agua aportada a las plantas hizo que la conductancia estomática superase a la de las plantas control y consecuentemente estas plantas tuvieron un mayor nivel de transpiración durante los cinco primeros días de esta fase, para posteriormente igualarse y finalmente reducir el consumo de agua (Figura 4.26B).

También, podemos apreciar cómo al inicio del ensayo, los valores de conductancia estomática fueron mucho mas altos que en el resto del ensayo, especialmente en el tratamiento control. La evapotranpiración que, como hemos dicho anteriormente, equivale prácticamente a la transpiración, pues suponemos que la evaporación desde el sustrato es 
baja en todos los tratamientos y más o menos constante a lo largo del ensayo, también, en las primeras cuatro semanas, fue mucho más alta que en el resto del ensayo (Figura 4.25A y Figura 4.33). Además hay que tener en cuenta que al inicio del ensayo el área foliar de todas las plantas es mucho menor, con lo que las tasas de transpiración por área foliar son mucho mayores en estas primeras semanas con respecto al resto del ensayo. Este comportamiento puede explicar porqué los potenciales hídricos (Figura 4.28A) medidos en las primeras semanas en todas la plantas fueron más negativos.

Los mayores niveles de conductancia estomática en las plantas bien regadas frente a las regadas deficitariamente se relacionan también con las mayores tasas de evapotranspiración diaria (Figura 4.32B y Figura 4.25B). Las diferencias encontradas en los valores de conductancia entre las plantas del tratamiento control y RD varían a lo largo del ensayo y lo mismo sucede con el consumo de agua (Figura 4.33 y Figura 4.34). En este sentido, tenemos que en la primera medida las diferencias en los distintos parámetros entre ambos tratamientos fueron mayores así la $\mathrm{g}_{\mathrm{s}}$ alcanza valores de 170 y $65 \mathrm{mmol} \mathrm{m}^{2} \mathrm{~s}^{-1}$ para el control y RD y el consumo de agua es de 78 y $55 \mathrm{ml}$ para el control y RD, respectivamente. La evolución en el consumo de agua a lo largo de un día fue también diferente entre ambos tratamientos (Figura 4.34A) correspondiendo durante la fase luminosa a valores de $2.5 \mathrm{ml} /$ planta cada $30 \mathrm{~min}$ para el tratamiento bien regado frente a los $1.5 \mathrm{ml} /$ planta cada $30 \mathrm{~min}$ para el deficitario. En la segunda medida los valores de $\mathrm{g}_{\mathrm{s}}$ fueron similares entre ambos tratamientos $\left(50 \mathrm{mmol} \mathrm{m} \mathrm{m}^{-1}\right)$, y más bajos que en la primera medida, al igual que los valores de transpiración (42 y $40 \mathrm{ml}$ ), lo que provoca valores más altos de potencial hídrico foliar (Figura 4.28). El consumo de agua a lo largo de un día en esta etapa fue similar en ambos tratamientos en torno a $1.2 \mathrm{ml} /$ planta cada 30 minutos (Figura 4.34B). Las relaciones observadas entre el potencial hídrico, la conductancia estomática y la ET diaria y horaria suceden en el resto de los momentos medidos (Colom y Vazzana, 2003; Jaleel y col., 2008; Lenzi y col., 2009; Bolla y col., 2010). 


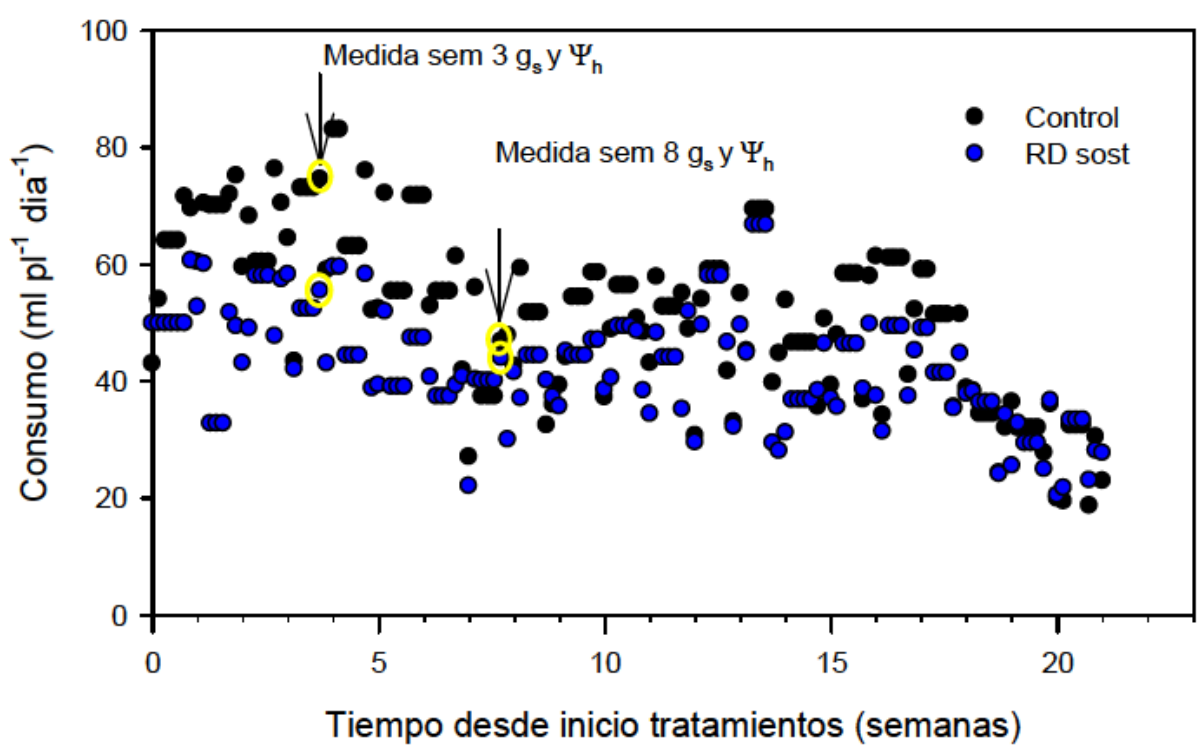

Figura 4.33- Evolución del consumo diario de plantas de geranio en maceta sometidas a tratamiento control y RD sostenido durante el período experimental, (datos recogidos por mitra). Los valores marcados corresponden a días de medida de $\Psi_{\mathrm{h}}$ y $\mathrm{g}_{\mathrm{s}}$. 

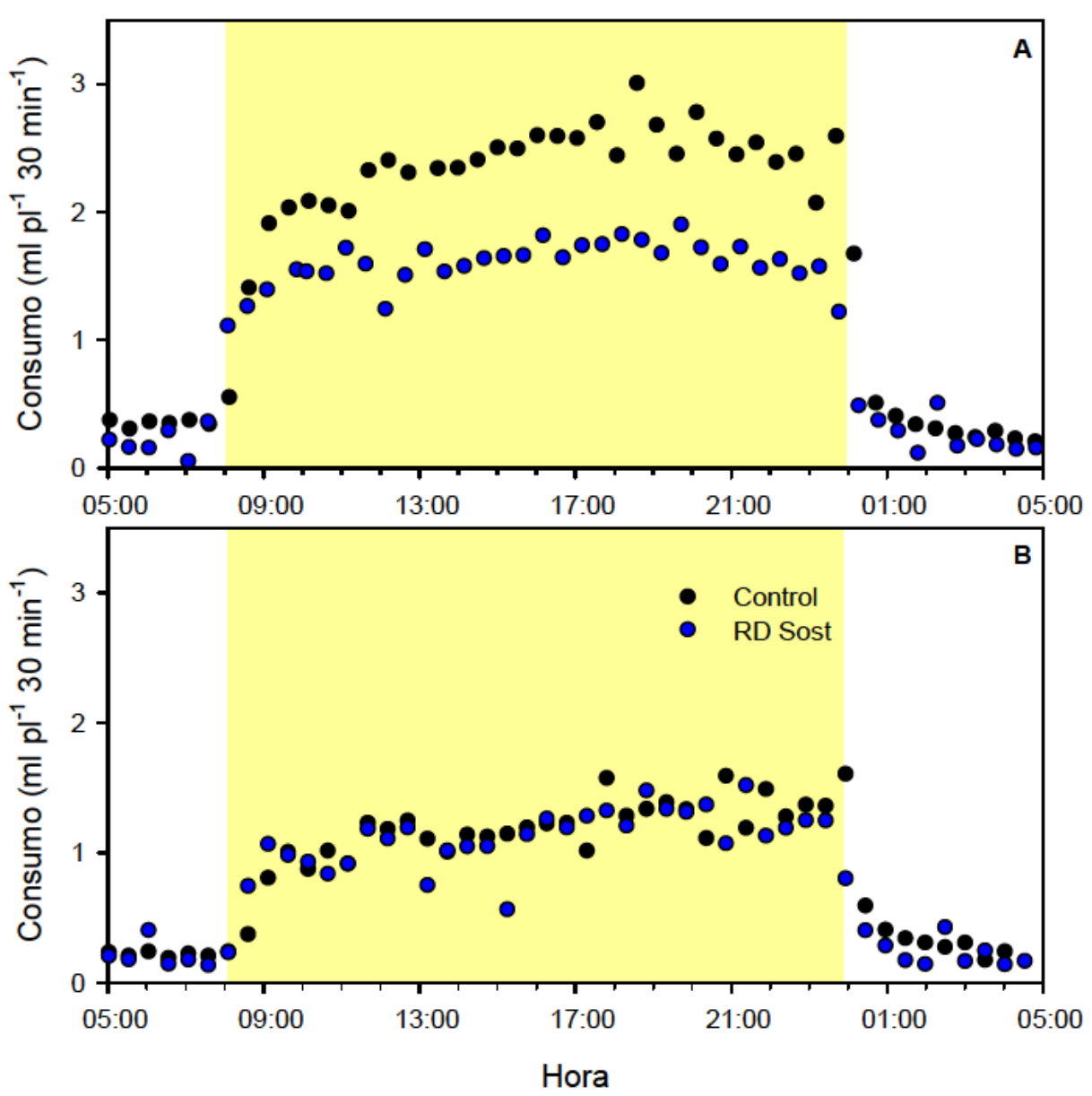

Figura 4.34- Evolución del consumo horario en plantas de geranio en maceta de los tratamientos control y riego deficitario sostenido (mitras). Medida A (31 julio, semana 3.7 desde inicio tratamientos: A) y Medida B (28 agosto, semana 7.7 desde inicio tratamientos, B).

En definitiva, el riego deficitario reduce el consumo de agua comparado con las plantas control, como consecuencia de una reducción del área foliar y de una mejor regulación estomática (Fernández y col., 2006). Estas dos respuestas inducirían a una menor transpiración y, consecuentemente, un menor consumo de agua (Pinhero y col., 1997).

La menor apertura de los estomas en las plantas de los tratamientos de RD pudo llevar consigo una menor tasa fotosintética, a pesar de que los resultados obtenidos nos indican que el efecto de los tratamientos de riego no fueron tan significativos como aquellos encontrados para la conductancia estomática. Según Winner y col. (1985) la fotosíntesis puede afectarse bien por una alteración de la conductancia estomática o por cambios en la capacidad metabólica de las células del mesófilo. 
De los resultados obtenidos podemos concluir que a pesar de que las plantas de los tratamientos deficitarios recibían similares cantidades de agua, observamos comportamientos distintos dependiendo de la fase en donde se aplican dichos tratamientos. El riego deficitario aplicado fuera de la fase de floración adelanta, pero no reduce la intensidad de la floración, incrementa la proporción parte radical/ parte aérea y aumenta la relación anchura/ altura, con lo que se consigue una planta de mayor calidad, además de un ahorro de agua del $20 \%$. Se desaconseja el empleo del riego deficitario durante la fase de floración porque reduce la intensidad y la duración de la floración. Todo esto habrá que tenerlo en cuenta en la elaboración de estrategias de riego en este tipo de plantas. 
Capítulo 5

Respuesta de plantas de callistemon al riego deficitario en distintas condiciones medioambientales 



\subsection{Introducción}

El género Callistemon pertenece a la familia Myrtaceae y posee algunas de las especies ornamentales australianas más importantes, debido a sus interesantes características (rápido crecimiento, floración abundante con formas inusuales y colores brillantes y gran variedad de formas y volúmenes) (Mitchem, 1993; Lao y Jiménez, 2002). La mayoría de las especies de Callistemon se han adaptado y se usan en condiciones mediterráneas, donde presentan cierto grado de tolerancia a los estreses ambientales como la sequía y la salinidad (Lippi y col., 2005; Lippi y col., 2003). Es por estas razones por las que Callistemon ha tenido un éxito considerable como un arbusto de flor para su uso en jardines y paisajismo urbano en el área mediterránea.

Sin embargo, el estrés hídrico prolongado resultante de la escasa precipitación y de las altas temperaturas en verano en esta zona puede alterar el comportamiento fisiológico y morfológico de la planta, especialmente en especies importadas. Tales cambios pueden suponer complejas adaptaciones funcionales y estructurales, las cuales incluyen regulaciones del crecimiento de la planta, ajuste osmótico, descensos de la conductancia estomática y cambios en las propiedades de la pared celular (Tyree y Jarvis, 1982; Zollinger y col., 2006). Todas estas adaptaciones pueden mejorar el estado hídrico de la planta y su resistencia al estrés hídrico limitando la pérdida de agua ante la alta demanda evaporativa (Sánchez-Blanco y col., 2004).

De entre estos factores, la disminución de la conductancia estomática supone un descenso de la concentración interna de $\mathrm{CO}_{2}\left(C_{i}\right)$, que limita la fotosíntesis. Actualmente, la limitación estomática de la fotosíntesis, provocada por el déficit hídrico, es considerada como uno de los principales factores limitantes de la producción agraria en los ecosistemas semiáridos (Díaz-Espejo y col., 2007). Así, bajo condiciones de un déficit hídrico moderado, se han encontrado múltiples evidencias de que la conductancia del mesófilo también juega un papel fundamental en la limitación de la fotosíntesis (Grassi y Magnani, 2005; Warren, 2006), ya que es finita, y por tanto, introduce otro factor adicional al de la conductancia estomática, en la limitación de la fotosíntesis (Evans y col., 1986; Loreto y col., 1992). De este modo, la suma de las limitaciones de la conductancia estomática $\left(\mathrm{l}_{\mathrm{gs}}\right)$ y las del mesófilo $\left(\mathrm{I}_{\mathrm{gm}}\right)$ representan las 
limitaciones difusionales de la hoja a la fotosíntesis. Sin embargo, bajo un déficit hídrico severo, ha sido descrito también un efecto negativo de tipo bioquímico a la asimilación de $\mathrm{CO}_{2}$ por la hoja (Flexas y col., 2004), provocando una disminución de la tasa máxima de carboxilación $\left(\mathrm{V}_{\mathrm{cmax}}\right)$. Así, la suma de esta limitación bioquímica de la fotosíntesis más la del mesófilo define la limitación por causas no estomáticas de la fotosíntesis. En Callistemon, las tres limitaciones ( $\mathrm{I}_{\mathrm{gs}}, \mathrm{I}_{\mathrm{gm}}, \mathrm{y}$ bioquímicas) han sido estudiadas para ver el grado de importancia que desempeñan bajo condiciones de un déficit hídrico prolongado sobre las limitaciones totales de la hoja a la fotosíntesis (la suma de difusionales y bioquímicas).

El estrés hídrico severo también puede disminuir el crecimiento de hojas y brotes o retrasar y reducir el número de flores, tamaño y/o calidad (Cameron y col., 1999) lo que afectaría a la apariencia visual de la planta, un factor especialmente importante en plantas ornamentales que se destinan a uso en jardinería y paisajismo. En estas condiciones, el manejo del riego es un factor importante y existe una presión considerable en el sector de la industria de planta ornamental para producir cultivos de manera más eficiente, reduciendo la cantidad de agua aportada sin perder el valor ornamental (Cameron y col., 2006). En este sentido, supervisar los regímenes de humedad de los viveros y comprender las respuestas morfológicas y fisiológicas de la parte aérea y radical a la gestión del agua es crítico para optimizar la producción de plantas de alta calidad (Franco y col., 2006). No obstante, poco se conoce sobre estas respuestas en plantas arbustivas ornamentales, tales como el Callistemon.

Atendiendo a todo lo expuesto, se desarrollaron los presentes ensayos, profundizando en el conocimiento de aspectos fisiológicos y morfológicos relacionados con el consumo y eficiencia en el uso del agua, estado hídrico, intercambio gaseoso, ajuste osmótico, cambios en la elasticidad de las paredes celulares y distribución del crecimiento y procesos de floración de plantas de Callistemon bien regadas y en condiciones de riego deficitario. 


\subsection{Efecto de distintos niveles de riego en aspectos fisiológicos en plantas de callistemon en condiciones controladas}

\subsubsection{Material y métodos}

\subsubsection{Material vegetal y condiciones experimentales}

Para este ensayo, se emplearon 64 plantas de seis meses de edad de Callistemon citrinus splendens Staff (Callistemon laevis Anon) que se trasplantaron a macetas de $14 \times 12 \mathrm{~cm}$ (1.2 I) con una mezcla de fibra de coco, turba negra y perlita (2:1:1) a la que se añadió un abono de lenta liberación, osmocote plus (2 $\mathrm{g} \mathrm{l}^{-1}$ substrato) (14:13:13 N,P,K + microelementos).

El experimento se llevó a cabo en una cámara de crecimiento durante 20 semanas (Fotografía 5.1). Las condiciones ambientales de la cámara se seleccionaron para simular los cambios naturales de temperatura y luz (Figura 5.1). Ambos parámetros aumentaron gradualmente desde $6: 00 \mathrm{~h}$ hasta $13: 00 \mathrm{~h}$, alcanzando valores de $28^{\circ} \mathrm{C}$ y $350 \mu \mathrm{mol} \mathrm{m} \mathrm{m}^{-2} \mathrm{~s}^{-1} \mathrm{y}$ después disminuían progresivamente hasta $20^{\circ} \mathrm{C}$ y oscuridad (22:00 h). La humedad relativa osciló entre 40 y $60 \%$.

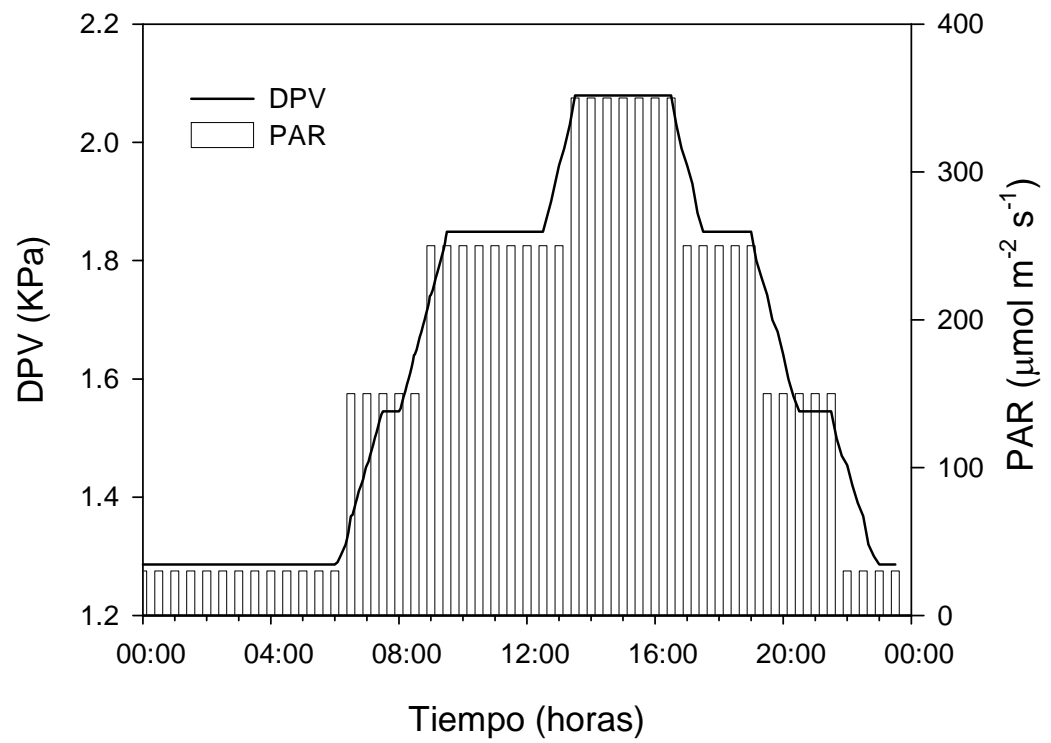

Figura 5.1- Condiciones de la cámara de crecimiento a lo largo del día durante el período experimental. 


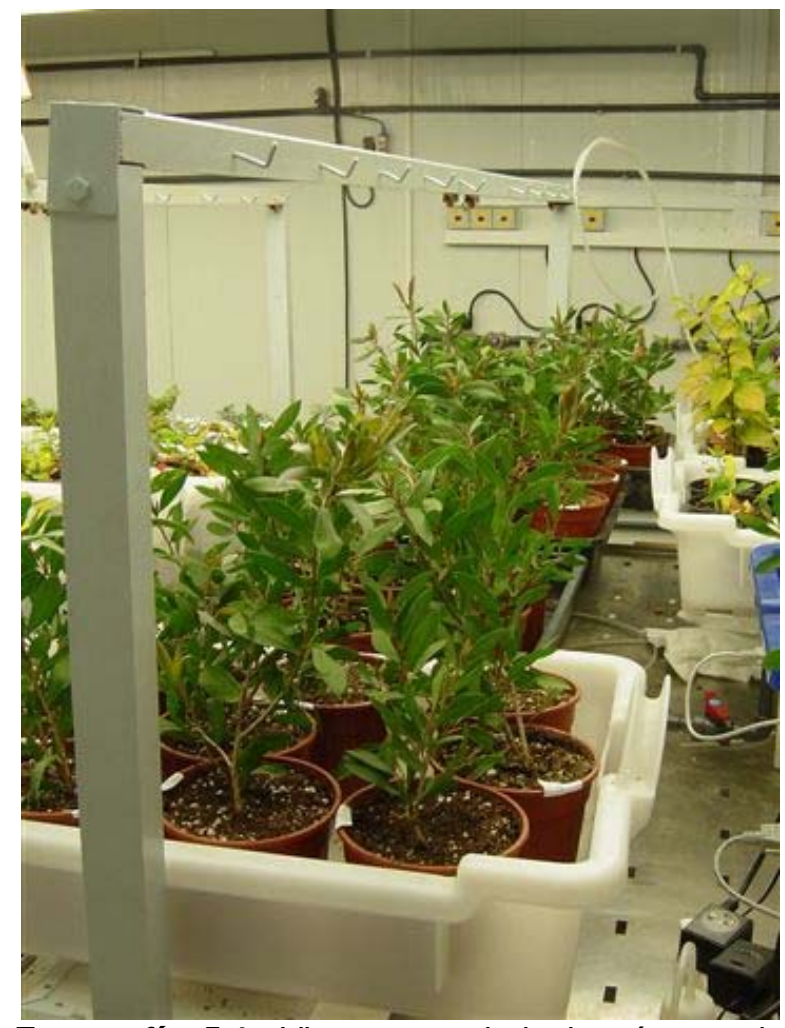

Fotografía 5.1- Vista general de la cámara de crecimiento en la que se llevo a cabo el ensayo.

\subsubsection{Tratamientos y diseño experimental}

Las plantas se regaron diariamente hasta capacidad de campo durante dos semanas antes de iniciar los tratamientos. Las plantas fueron distribuidas en cuatro repeticiones de ocho plantas por tratamiento (64 plantas en total) y se sometieron a dos tratamientos de riego: control (C) y tratamiento deficitario (RD) (Fotografía 5.2).

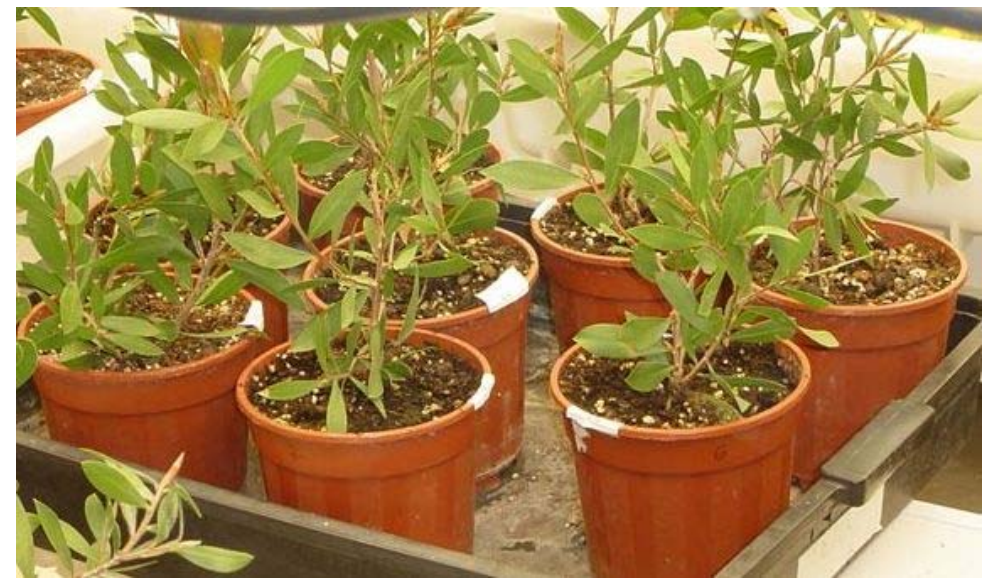

Fotografía 5.2- Plantas de callistemon al inicio del ensayo.

Para determinar la máxima capacidad de retención de agua del sustrato, se rellenaron tres macetas con una mezcla uniforme de substrato y se compactaron hasta una densidad aparente de 0.165 
$\mathrm{g} / \mathrm{cm}^{3}$. La superficie de las macetas fue cubierta con una hoja de aluminio para evitar la evaporación del agua y las macetas se sumergieron en agua hasta cubrir la mitad de las macetas. Al día siguiente, las macetas se sacaron del agua y se dejó drenar libremente hasta que el drenaje llegó a ser insignificante. Después de esto, se registró el peso fresco del substrato y después se introdujo en una estufa a $105^{\circ} \mathrm{C}$ hasta peso constante. Posteriormente se midió la diferencia entre el peso fresco y el peso seco y consecuentemente, se calculó el contenido volumétrico de agua (54\%) y se consideró como capacidad de campo del substrato.

En el tratamiento control, la humedad del substrato se mantuvo cercana a capacidad de campo mediante 5 riegos semanales (95-100\% del peso a capacidad de campo). De este modo, no se obtuvo drenaje significativo en el tiempo que duró el experimento. El tratamiento deficitario se mantuvo al $50-55 \%$ del peso a capacidad de campo, también con 5 días de riego a la semana (Figura 5.2). La conductividad eléctrica del agua de riego utilizada fue de $0.8 \mathrm{dS} \mathrm{m}^{-1}$.

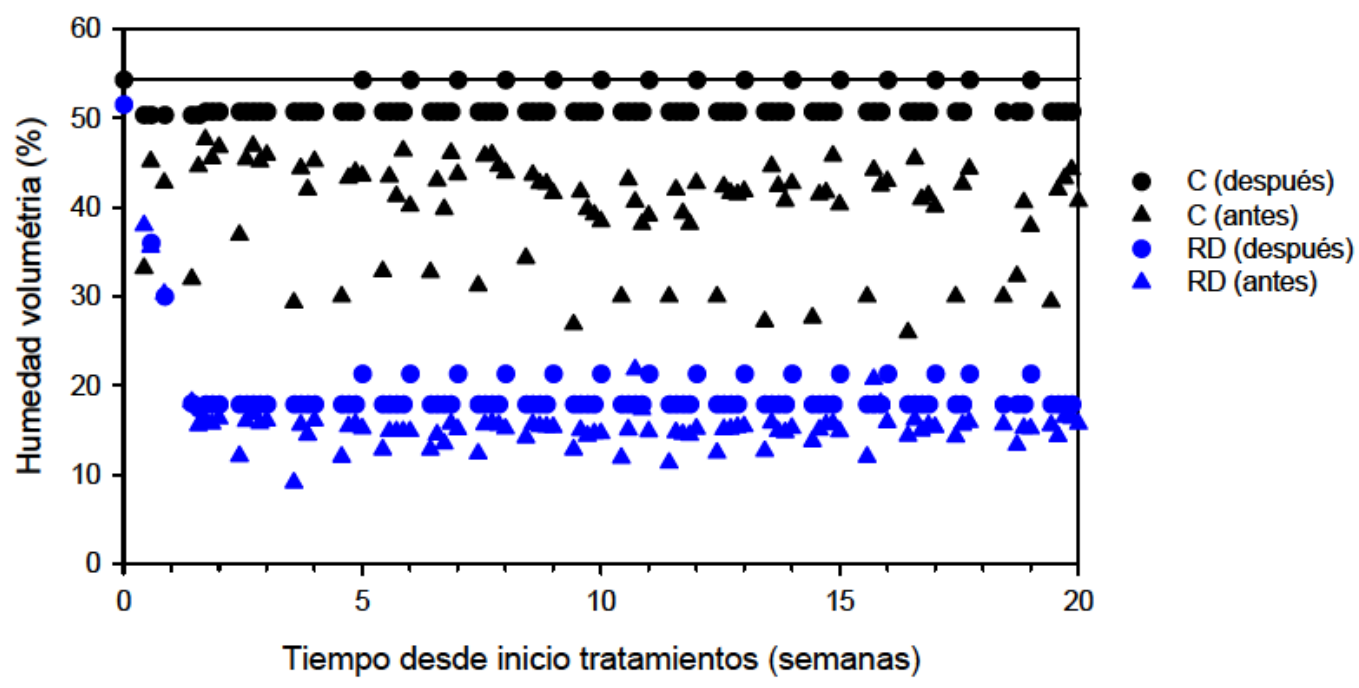

Figura 5.2- Evolución de la humedad volumétrica antes y después del riego,de plantas de callistemon en maceta sometidas a distintos tratamientos de riego durante el período experimental. La línea horizontal representa el valor de la humedad del sustrato a capacidad de campo en condiciones controladas.

El riego se determinó por diferencia de pesos (peso de las macetas antes del riego y el correspondiente porcentaje del peso de esas macetas a capacidad de campo) usando una balanza (capacidad $5.2 \mathrm{Kg}$ y precisión de $0.01 \mathrm{~g}$, Sartorius, modelo 5201). Diariamente se 
pesaban 4 macetas de cada tratamiento y se calculaba la cantidad de agua necesaria para llegar al umbral establecido (Fotografía 5.3).

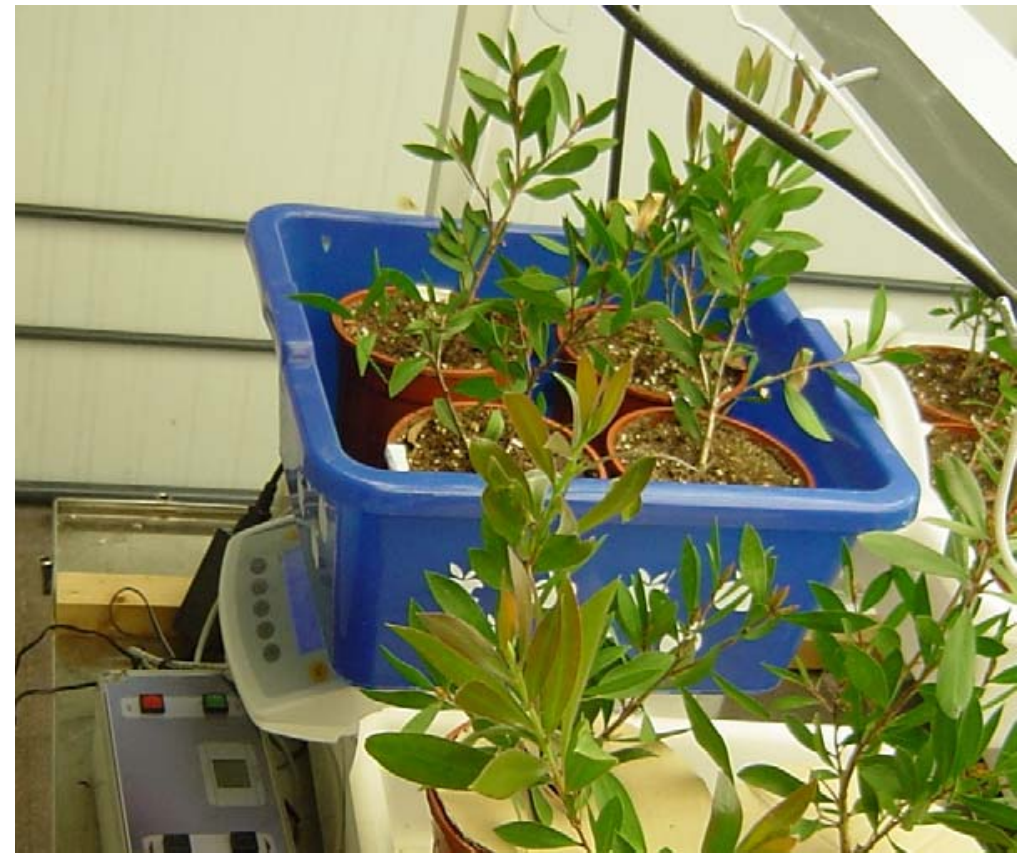

Fotografía 5.3- Medida y registro del peso de las macetas de callistemon para la determinación del riego.

Durante las 20 semanas que duró el ensayo las plantas estresadas recibieron el $35 \%$ de la cantidad de agua que recibieron las plantas del tratamiento control.

\subsubsection{Cuantificación de la biomasa de la planta y medida de la pérdida de electrolitos}

Al término de ambos tratamientos de riego, se realizó un muestreo final en 5 plantas por tratamiento tal y como se explica en el apartado 3.2.1.3. La suculencia fue calculada como la relación entre el peso fresco y el peso seco de las hojas. Además de la medida final, el área foliar se calculó en otros cuatro momentos del ensayo (semana 0, 5, 10 y 15 desde el inicio de los tratamientos) en tres plantas por tratamiento.

El sistema radical, una vez separado del substrato, se colocó en una bandeja de plástico transparente acoplada a un escáner conectado a un ordenador con un software con el que se evaluó la distribución de las raíces (Winrhizo LA 1600 Regent Inc., USA). Después de medir la longitud de las raíces (L) en los distintos intervalos de diámetro considerados y su volumen, el sistema radical se introdujo en la estufa para obtener su peso seco. La densidad del sistema radical se calculó 
como el cociente entre el peso seco de las raíces $(\mathrm{g}$ ) y el volumen radical $\left(\mathrm{cm}^{3}\right)$.

Durante el período experimental, en todas las plantas del ensayo, se midió semanalmente la altura de las plantas (apartado 3.2.1.3) y se hizo un seguimiento del número de hojas caídas por planta (apartado 4.2.1.3). La tasa de crecimiento relativo se calculó como el incremento de altura por unidad de altura inicial de la planta y tiempo transcurrido entre dos medidas consecutivas.

Para la pérdida de electrolitos (PE), parámetro que informa sobra la alteración de la permeabilidad de las membranas celulares se estimó al final del ensayo, y se utilizó la técnica descrita por Lafuente y col. (1991) (Fotografía 5.4). Se utilizaron 30 discos foliares de cada planta, de $2 \mathrm{~mm}$ de diámetro, con ocho replicas por tratamiento, que se introdujeron en viales con $10 \mathrm{ml}$ de manitol $0.3 \mathrm{M}$ y se pusieron en agitación durante $24 \mathrm{~h}$ a temperatura ambiente, midiéndose la conductividad eléctrica de la solución al final de ese período, usando un conductivímetro digital Crisol Modelo 524 (Crison Instruments S.A., Barcelona, España). El contenido se pesó y se puso a hervir, durante 10 minutos, tras enfriar dicho contenido, a temperatura ambiente y en agitación, se volvieron a pesar los viales y se repuso con agua destilada el volumen evaporado, manteniendo la agitación durante media hora. Transcurrido ese tiempo, se midió la conductividad eléctrica total. La pérdida de electrolitos fue expresada en porcentaje de la conductividad total.
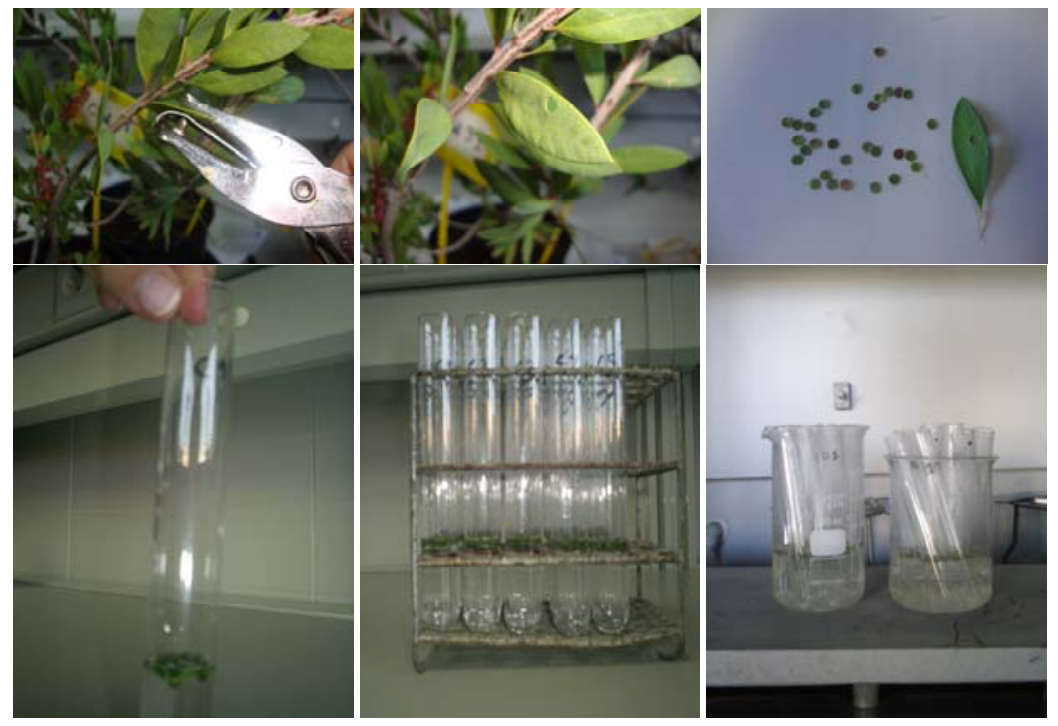

Fotografía 5.4- Determinación de la pérdida de electrolitos en plantas de callistemon al final del período experimental. 


\subsubsection{Nivel de transpiración, conductancia estomática y respuesta fotosintética}

La transpiración (T) y evapotranspiración (ET) se midieron gravimétricamente durante todo el período experimental, siendo determinada por diferencia de pesos (peso de las macetas después del riego y peso de las mismas macetas antes del riego siguiente) usando una balanza (capacidad $5.2 \mathrm{Kg}$ y preción de $0.01 \mathrm{~g}$, Sartorius, modelo 5201). Para el cálculo de la transpiración se utilizaron cuatro macetas por tratamiento en las que la superficie del sustrato estaba cubierta para evitar pérdidas de agua por evaporación. Además, estas macetas (tapadas) se colocaron sobre una balanza con una MITRA que registraba el peso cada media hora (Fotografía 5.5).

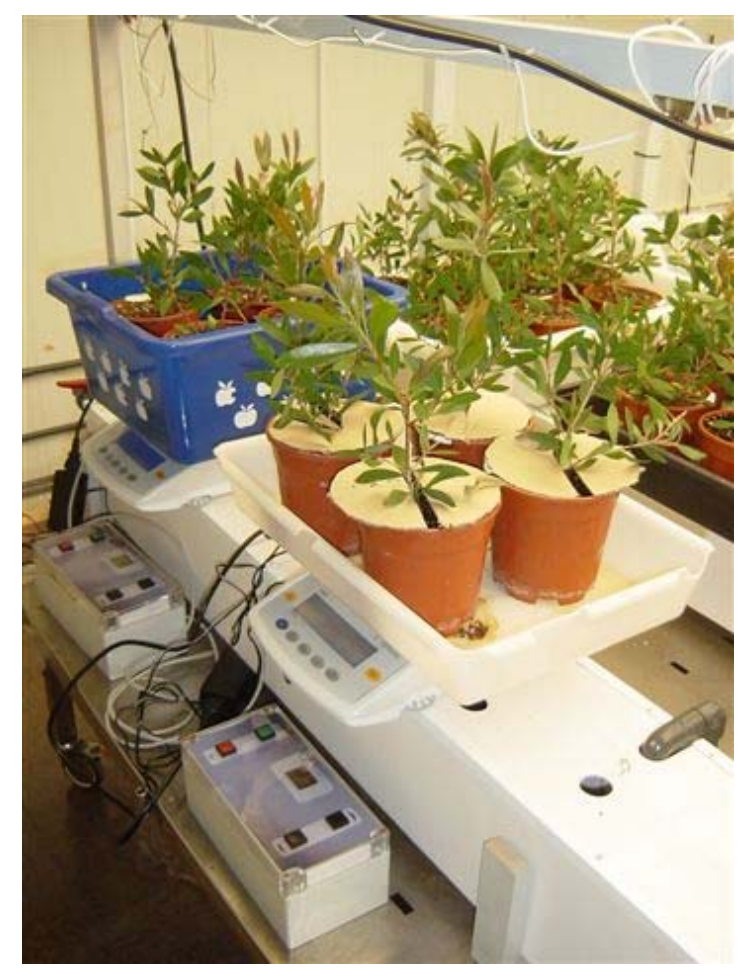

Fotografía 5.5- Macetas empleadas para el cálculo de la transpiración y MITRA que registraba las variaciones del peso.

La evapotranspiración corresponde al riego de las plantas destapadas y la transpiración al riego de las macetas tapadas, ya que en este ensayo las plantas se regaban en función de su consumo, se restablecía la cantidad de agua que habían perdido desde el riego anterior La eficiencia productiva en el uso del agua (WUE) se calculó al final del experimento dividiendo el aumento en el peso seco total entre el agua aplicada $\left(\mathrm{g} \mathrm{l}^{-1}\right)$. 
La conductancia estomática $\left(g_{s}\right)$ y la tasa de fotosíntesis neta $\left(P_{n}\right)$ se determinaron en cinco plantas por tratamiento durante las horas de máxima iluminación en varios momentos del ensayo. Las medidas de estos parámetros fueron realizadas de acuerdo a la metodología ya descrita en el apartado 3.2.1.4. Los parámetros de fluorescencia se midieron de forma periódica en la superficie foliar $\left(F_{v} / F_{m}\right)$ y se tomaron según la técnica ya explicada en el apartado 4.2.1.4.

\subsubsection{Curvas $A-C_{i}$ y limitaciones de la tasa de fotosíntesis máxima}

En tres momentos del ensayo, al inicio, mediados y al final del mismo, se realizaron curvas de respuesta de la fotosíntesis al $\mathrm{CO}_{2}$ (curvas $A-C_{i}$ ) en 5 hojas por tratamiento utilizando un equipo portátil de fotosíntesis (LI-6400, Li-Cor, Lincoln, NE, USA), equipado con una cámara de fluorescencia LI-6400-40 y un inyector de $\mathrm{CO}_{2}$ LICOR 640001. Previamente a la realización de las curvas $A-C_{i}$, se hicieron curvas de respuesta de la fotosíntesis a la luz (A-Q) en 5 hojas por tratamiento para calcular la luz saturante a utilizar en las mismas. Para las $A-C_{i}$, se tomaron puntos de fotosíntesis con valores de $\mathrm{CO}_{2}$ de $700,550,400$, $300,200,100,70,400,700,1000,1250$ y $1500 \mathrm{mmol} \mathrm{m}^{-2} \mathrm{~s}^{-1}$ (Fotografía 5.6). Los parámetros fotosintéticos derivados de las curvas $A-C_{i}$, fueron normalizados a $25^{\circ} \mathrm{C}$, siendo los valores de la constante de MichealisMenten para el $\mathrm{CO}_{2}, \mathrm{O}_{2}$, punto de compensación de $\mathrm{CO}_{2}$ en ausencia de respiración mitocondrial y los parámetros que describen su dependencia de la temperatura basados en los valores "in vivo" de Bernachi y col. (2002). Estas curvas fueron definidas mediante el ajuste con una hipérbola no rectangular de acuerdo a la versión del modelo bioquímico de la fotosíntesis foliar de Ethier y Livington (2004). El punto de corte para el cálculo del Ci fue realizado según el método propuesto por Ethier y col. (2006). De este análisis se obtuvieron los valores de $V_{c \max }, J_{\max }$ (tasa máxima de transporte de electrones) y conductancia del mesófilo $\left(g_{m}\right)$. Las hojas utilizadas en cada curva fueron muestreadas y llevadas inmediatamente al laboratorio para determinar el área foliar usando un medidor de área foliar AM 200 (ADC BioScientific Ltd., Herts, England). Posteriormente, las hojas se secaron para la determinación de su peso seco y finalmente se midió el contenido foliar de nitrógeno total mediante un analizador elemental de cromotografía iónica en el Servicio de Ionómica del CEBAS (ICP ICP-OES IRIS INTREPID II XDL). 


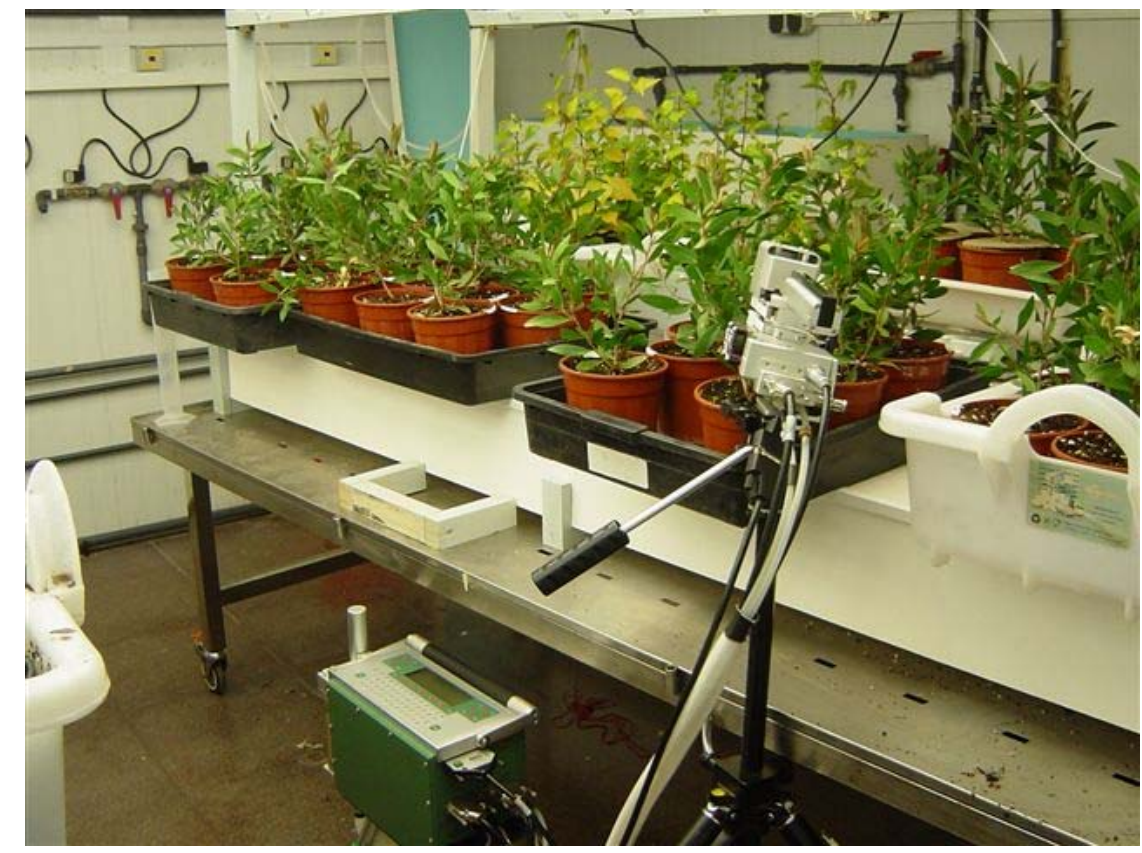

Fotografía 5.6- Determinación de las curvas $A-C_{i}$ en plantas de callistemon.

\subsubsection{Relaciones hídricas}

Durante el experimento, se midió periódicamente el potencial hídrico foliar $\left(\Psi_{\mathrm{h}}\right)$ y potencial hídrico de tallo $\left(\Psi_{\mathrm{t}}\right)$ en cinco plantas por tratamiento. El potencial hídrico foliar se midió en hojas maduras antes del inicio de la fase luminosa $\left(\Psi_{\mathrm{pd}}\right)$ y en las horas de máxima luminosidad $\left(\Psi_{\mathrm{md}}\right)$. El potencial de tallo se midió en hojas que no estaban transpirando, que previamente se habían envuelto en una bolsa de plástico y de aluminio, durante al menos 2 horas antes de la medida, de este modo el potencial hídrico foliar se iguala el potencial hídrico de tallo (Begg y Turner, 1970; Choné y col., 2001).

Los potenciales hídricos se estimaron de acuerdo con el método descrito en apartado 3.2.1.4. Al final del ensayo, se determinó el potencial osmótico saturado ( $\Psi_{\text {os }}$ ) en 5 hojas por tratamiento. El equipo y la metodología seguida para la realización de esta medida vienen ampliamente explicados en el apartado 3.2.1.4 (Fotografía 5.7). 

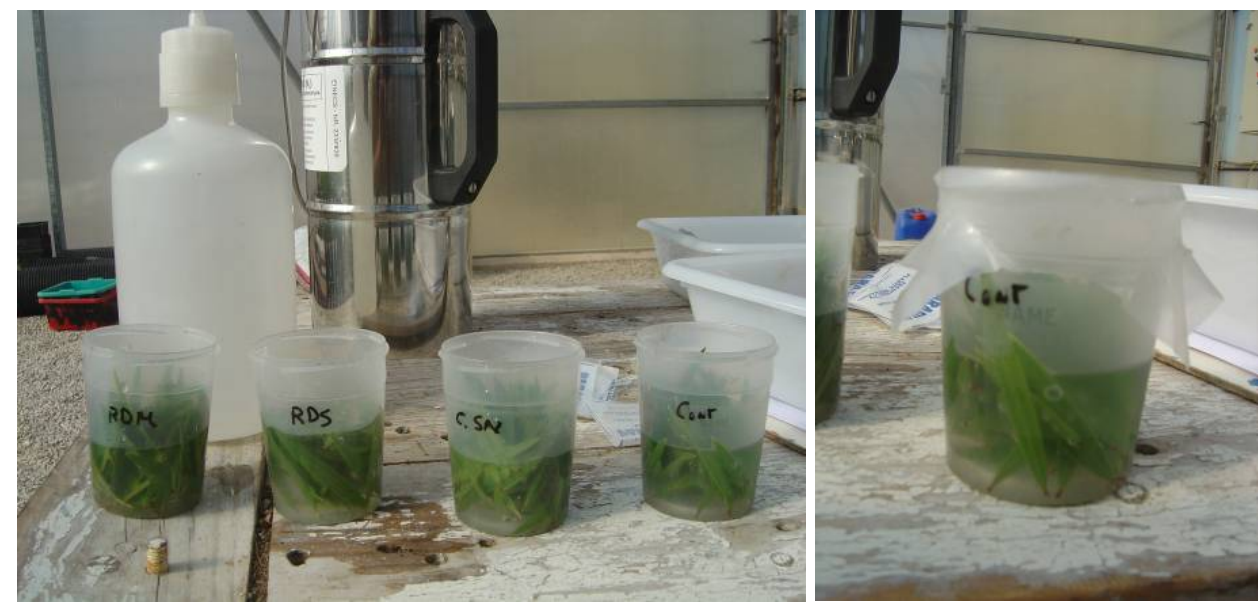

Fotografía 5.7- Recogida de hojas y puesta en saturación para la determinación del potencial osmótico saturado.

Las estimaciones del módulo de elasticidad $(\varepsilon)$, el potencial hídrico en el punto de pérdida de turgencia $\left(\Psi_{\mathrm{ppt}}\right)$ y el potencial osmótico a plena saturación $\left(\Psi_{\mathrm{os}}\right)$ se obtuvieron en el final de los tratamientos de riego en cuatro hojas por planta y cinco plantas por tratamiento, a través del análisis de las curvas presión-volumen (Fotografía 5.8). Esta técnica ya ha sido descrita en el apartado 3.2.1.4. El tiempo de elaboración de cada curva fue aproximadamente de 6-7 horas y en es este tiempo las hojas de callistemon alcanzaron valores de potencial hídrico próximos a 5.0 MPa y el CRA descendió hasta el 50\%.

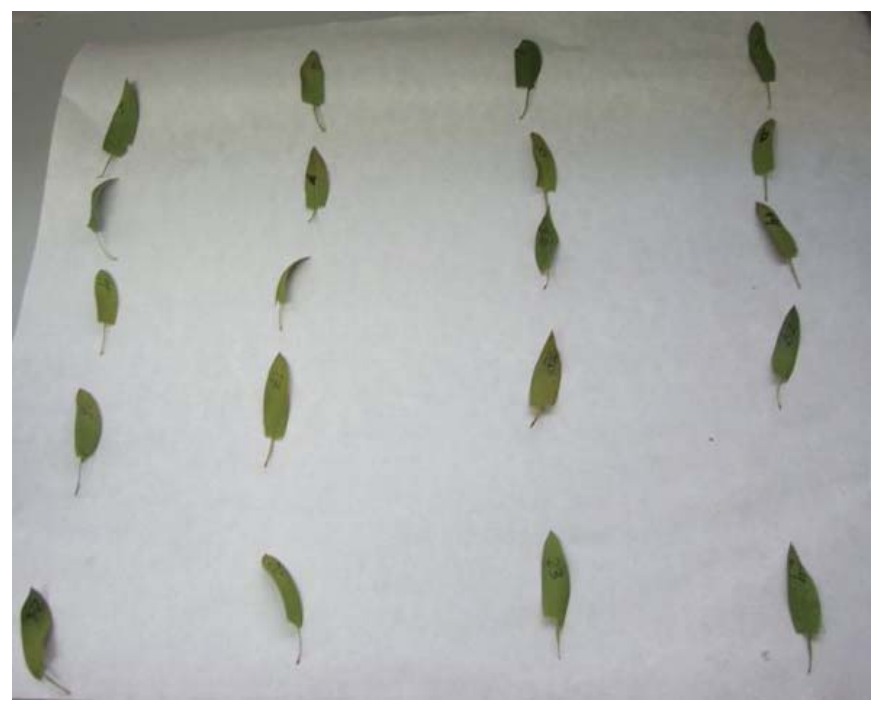

Fotografía 5.8- Realización de curvas P-V en hojas de callistemon sometidas a distintos tratamientos de riego al final del período experimental.

La resistencia hidráulica de las raíces $\left(1 / L_{p}\right)$ se determinó al final del período experimental en cinco plantas por tratamiento, siendo la inversa de la conductividad hidráulica de las raíces $\left(L_{p}\right)$ y medida según 
lo expuesto por Ramos y Kaufmann (1979). Se utilizó esta técnica por la comodidad que presentaba el pequeño tamaño de las raíces, ya que las plantas de callistemon sólo tenían un año de edad. El sistema radical de las plantas se separó de la parte aérea, mediante un corte a unos $3 \mathrm{~cm}$ de la base del tallo, y se lavó cuidadosamente hasta eliminar completamente los restos de sustrato e inmediatamente se sumergió en agua destilada en un recipiente, el cual se colocó en una cámara de presión dejando al aire el extremo superior del extremo radical. La presión se incrementó a razón de $0.4 \mathrm{MPa} \min ^{-1}$ hasta una presión final de 0.7 MPa. Después de varios minutos de estabilización del flujo, el exudado fue recogido en viales Ependorff cada cinco minutos, mediante la utilización de un tubo de plástico colocado en el extremo exterior del sistema radical (Fotografía 5.9), pesándose posteriormente para conocer la cantidad de exudado por unidad de tiempo. Esta operación se repitió tres veces, para obtener una media correcta del exudado. Seguidamente se introdujo el sistema radical a secar en una estufa a $80^{\circ} \mathrm{C}$ hasta peso constante para la determinación del peso seco de la raíz. La conductividad hidráulica de las raíces se calculó mediante la fórmula:

$$
L_{p}=J /(P \times W)
$$

donde $L_{p}$ viene expresado en $\mathrm{mg} \mathrm{g}^{-1} \mathrm{~s}^{-1} \mathrm{MPa}^{-1}, \mathrm{P}$ es la presión aplicada en MPa, W es el peso seco del sistema radical en $\mathrm{g}$ y $\mathrm{J}$ es el flujo de agua a través del sistema radical $\left(\mathrm{mg} \mathrm{s}^{-1}\right)$.

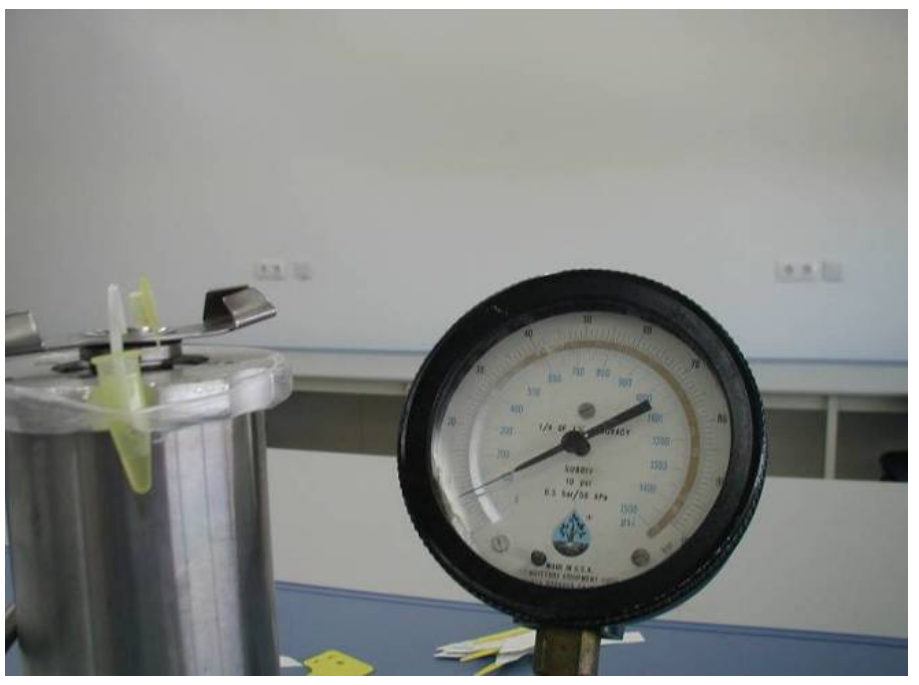

Fotografía 5.9- Medida de la conductividad hidráulica de las raíces con la cámara de presión en plantas de callistemon en maceta al final del período experimental. 


\subsubsection{Análisis estadístico}

La significación de los efectos de la dosis de riego fue analizada mediante un análisis de varianza simple (ANOVA), usando Statgraphics Plus para Windows. Las medias de los tratamientos fueron separadas con la Prueba de Rango Múltiple de Duncan $(P<0.05)$. Antes del análisis estadístico, cocientes y datos en porcentajes fueron previamente transformados mediante una transformación arcoseno raíz cuadrada, para asegurar la homogeneidad de la varianza.

\subsubsection{Resultados y discusión}

\subsubsection{Efectos del riego deficitario en la acumulación de biomasa y pérdida de electrólitos en plantas de callistemon en condiciones controladas}

El déficit hídrico alteró el crecimiento de las plantas al final del experimento; aunque estos cambios fueron distintos en función de la parte de la planta estudiada (Figura 5.3). La mayor acumulación de materia seca en relación al peso seco total de la planta se vio en las hojas de las plantas control y en las raíces de las plantas estresadas. El peso seco total de las plantas sometidas a estrés fue el $47 \%$ de los valores de las plantas control (Tabla 5.1), mientras el área foliar total y el número de hojas descendió hasta el 41 y 50\%, respectivamente, comparado con las plantas control. En numerosos trabajos, en otras especies ornamentales, se ha estudiado cómo el RD reduce el crecimiento: Hassanein y Dorion (2006), Jaleel y col. (2008), Mugnai y col. (2009) y Andersson (2011). Sin embargo, el cociente PS raíz/PS aéreo aumentó en las plantas crecidas bajo condiciones de sequía. Esto se ha confirmado en otros ensayos en Cistus por Sánchez-Blanco y col. (2002) y en mirto por Navarro y col. (2009). La suculencia también disminuyó en las plantas sometidas a riego deficitario (Tabla 5.1). En otras especies ornamentales se ha observado este efecto (Andersson, 2011). 


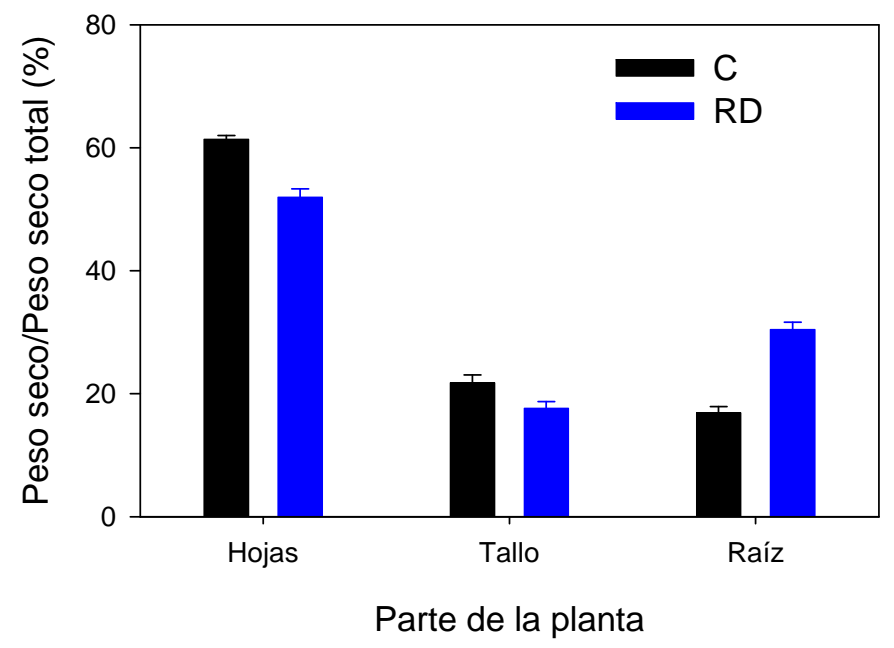

Figura 5.3- Distribución de la biomasa en plantas de callistemon en maceta sometidas a distintos tratamientos de riego al final del período experimental en condiciones controladas.

Tabla 5.1- Parámetros de crecimiento y pérdida de electrolitos en plantas de callistemon en macetas sometidas a diferentes tratamientos de riego al final del período experimental.

\begin{tabular}{lccc}
\hline Parámetros & \multicolumn{2}{c}{ Tratamientos } & P \\
\hline Peso seco total (g planta $\left.{ }^{-1}\right)$ & $51.01 \pm 2.03$ & $24.36 \pm 0.30$ & $* * *$ \\
Cociente PS raíz/PS aéreo & $0.20 \pm 0.01$ & $0.42 \pm 0.02$ & $* * *$ \\
Número de hojas & $444 \pm 51.7$ & $224 \pm 15.5$ & $* *$ \\
Área foliar total $\left(\mathrm{cm}^{2}\right)$ & $2913.7 \pm 125.0$ & $1183.0 \pm 55.9$ & $* * *$ \\
Suculencia (hojas) & $2.64 \pm 0.04$ & $2.47 \pm 0.04$ & $*$ \\
Pérdida de electrolitos $(\%)$ & $23.96 \pm 0.04$ & $34.19 \pm 0.07$ & $*$ \\
\hline
\end{tabular}

$\mathrm{P}$ : nivel de significación, ${ }^{\star} \mathrm{P}<0.05,{ }^{* \star} \mathrm{P}<0.01,{ }^{\star * \star} \mathrm{P}<0.001$. 

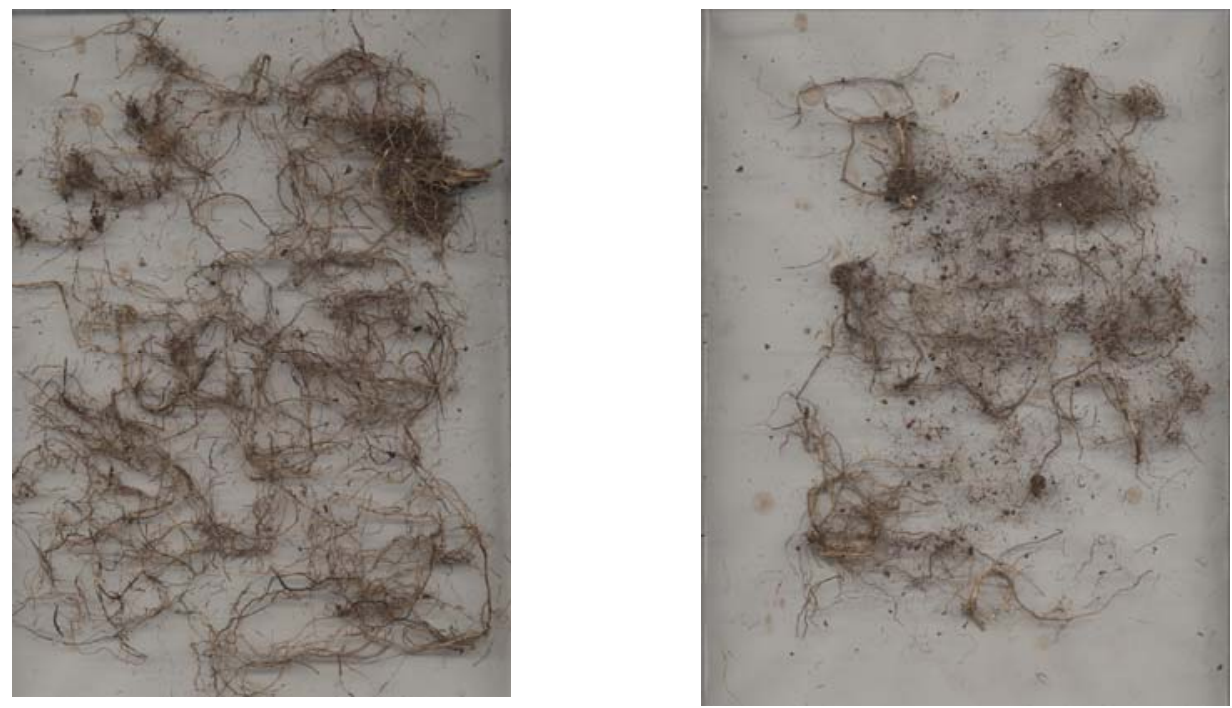

Fotografía 5.10- Sistema radical en plantas de callistemon en condiciones control (Izda) y sometidas a riego deficitario (Dcha) al final del período experimental en condiciones controladas.

El déficit hídrico tuvo un efecto significativo en la morfología del sistema radical (Tabla 5.2). La longitud total de las raíces descendió con el estrés hídrico (27\%), (Bañón y col., 2004), una reducción que se observó en todos los tamaños de raíces (Fotografía 5.10). En relación a la distribución de las raíces, el déficit hídrico aumentó el porcentaje de raíces finas (menos de $0.5 \mathrm{~mm}$ de diámetro) y disminuyó aquellas con un diámetro mayor de $0.5 \mathrm{~mm}$. El volumen radical de las plantas sometidas a riego deficitario también se redujo con respecto a las plantas control, aunque el peso seco de las raíces no se vio modificado por el riego, con lo que la densidad de las raíces de las plantas aumentó con el déficit hídrico, es decir las raíces de las plantas sometidas a déficit hídrico tenían menor proporción de agua que las de las plantas control.

El número de raíces, en particular, la cantidad de raíces finas es importante ya que permite aprovechar mejor la cantidad de agua disponible, especialmente en condiciones limitantes de agua (Shao y col., 2008). De hecho la conductividad hidráulica de las raíces se ha relacionado más con la morfología radical que con la biomasa (Zobel, 2007). Además se observa que las de las plantas sometidas a riego deficitario presentaban mayor densidad radical, es decir raíces más robustas, posiblemente debido a la acumulación de reservas. Esto mejora el soporte físico, fortalece las raíces y disminuye la posibilidad de ruptura durante el trasplante, con lo que se obtiene un sistema radical más endurecido (Bañón y col., 2006). Además la acumulación de solutos podría permitir a las raíces mantener el gradiente osmótico necesario 
para absorber agua. Procesos de ajuste osmótico en el sistema radical han sido descritos en otras especies expuestas a déficit hídrico, y han sido explicados como mecanismos de tolerancia a través de los cuales los procesos de osmorregulación en las células de las raíces es realizado por acumulación activa de solutos orgánicos desde la parte aérea (Misra y col., 1996; Khavari Nejad y Najafi, 1990). Posiblemente, el efecto producido por el déficit hídrico produjo una ligera deshidratación de los tejidos de las plantas, como más adelante veremos al considerar los parámetros hídricos. Un adecuado sistema radical permite mejorar la extracción de agua desde suelo para compensar las pérdidas por evapotranspiración y ayuda a un establecimiento más rápido de las plantas ornamentales en su uso en jardines o paisajismo (Cameron y col., 2006; Franco y col., 2006).

Tabla 5.2- Morfología del sistema radical en plantas de callistemon en maceta sometidas a distintos tratamientos de riego al final del período experimental en condiciones controladas.

\begin{tabular}{lccc}
\hline \multicolumn{1}{c}{ Parámetros } & \multicolumn{2}{c}{ Tratamientos } & P \\
\hline Longitud raíces total $(\mathrm{cm})$ & $3556 \pm 151$ & $2595 \pm 154$ & $* *$ \\
$\mathrm{~L}_{\phi<0.5 \mathrm{~mm}}(\%)$ & $49.28 \pm 0.02$ & $55.33 \pm 0.01$ & $*$ \\
$\mathrm{~L}_{0.5<\phi<2.0 \mathrm{~mm}(\%)}(\%)$ & $38.09 \pm 0.01$ & $33.86 \pm 0.01$ & $*$ \\
$\mathrm{~L}_{\phi>2.0 \mathrm{~mm}}(\%)$ & $12.15 \pm 0.01$ & $10.24 \pm 0.01$ & $*$ \\
Volumen radical $\left(\mathrm{cm}^{3}\right)$ & $47.4 \pm 4.6$ & $29.6 \pm 1.3$ & $*$ \\
Peso seco raíces $(\mathrm{g})$ & $8.59 \pm 0.50$ & $7.42 \pm 0.37$ & $\mathrm{~ns}$ \\
Densidad raíces $\left(\mathrm{g} \mathrm{cm}^{-3}\right)$ & $0.19 \pm 0.02$ & $0.26 \pm 0.01$ & $* *$ \\
\hline P:
\end{tabular}

$\mathrm{P}$ : nivel de significación, ns: no significativo, ${ }^{*} \mathrm{P}<0.05,{ }^{\star *} \mathrm{P}<0.01$.

En la Figura 5.4 observamos como las plantas comienzan a perder hojas a partir de la semana 9, lo que puede ser debido a la edad de las hojas, esta pérdida es mayor en las plantas del tratamiento control ya que estas plantas poseen mayor número de hojas. Al final del ensayo, a partir de la semana 16, las plantas del tratamiento deficitario tienen un aumento brusco en el número absoluto de hojas caídas y se igualan a la perdida de hojas de las plantas del tratamiento control. Al final del ensayo el porcentaje de hojas caídas en relación al número de hojas de la planta es el doble en las plantas del tratamiento RD que en las plantas control. A partir de la semana 16 hay una importante caída de hojas en las plantas del tratamiento RD. Esto es debido al estrés acumulado, que al final del ensayo llega a ser severo. 


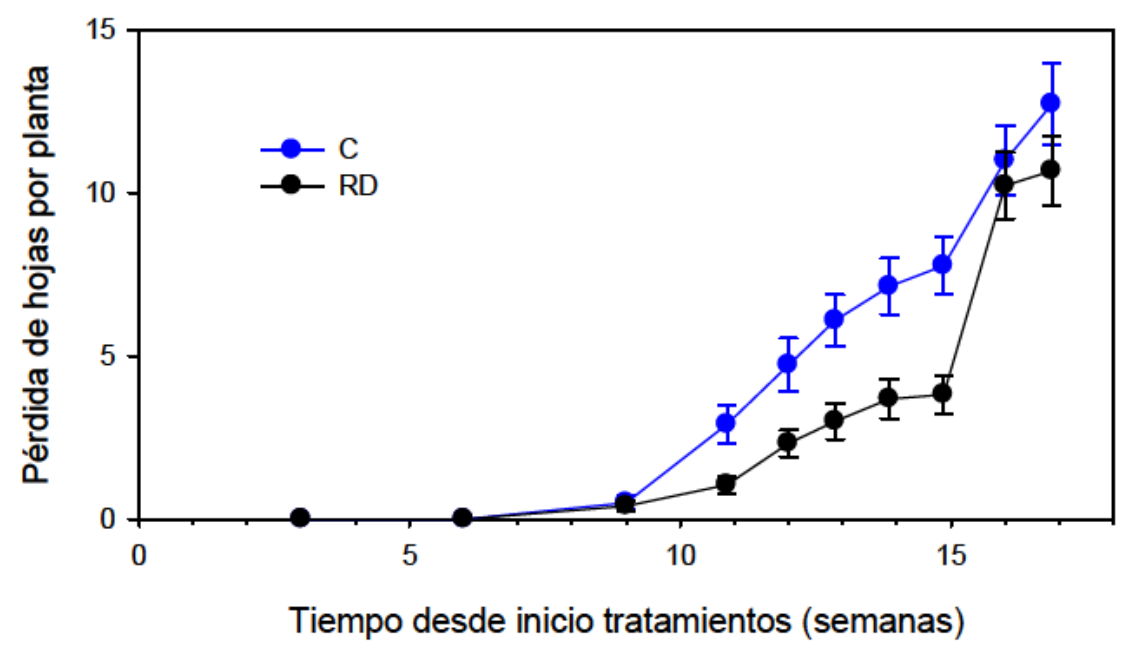

Figura 5.4- Evolución del número de hojas caídas en plantas de callistemon en maceta sometidas a distintos tratamientos de riego a lo largo del período experimental en condiciones controladas.

La altura de las plantas del tratamiento deficitario se redujo significativamente desde el inicio de los tratamientos (Figura 5.5A), lo que dio como resultado plantas más pequeñas a lo largo del ensayo. Al final del experimento las reducciones alcanzaron el 30\% comparado con el control (Fotografía 5.11). Se observó un comportamiento similar en la tasa relativa de crecimiento de ambos tratamientos (Figura 5.5B) y se distinguieron dos períodos de crecimiento durante el experimento (semana 0-5 y semana 8-11), también se observa un tercer período de crecimiento al final del ensayo, aunque este es menos pronunciado (semana 14-17). Las plantas estresadas mostraron un cierto retraso en el crecimiento con respecto al control. Estas mismas respuestas son encontradas en otras especies ornamentales por Bernal y col. (2001), Mugnai y col. (2009), y De Lucía y col. (2009). 

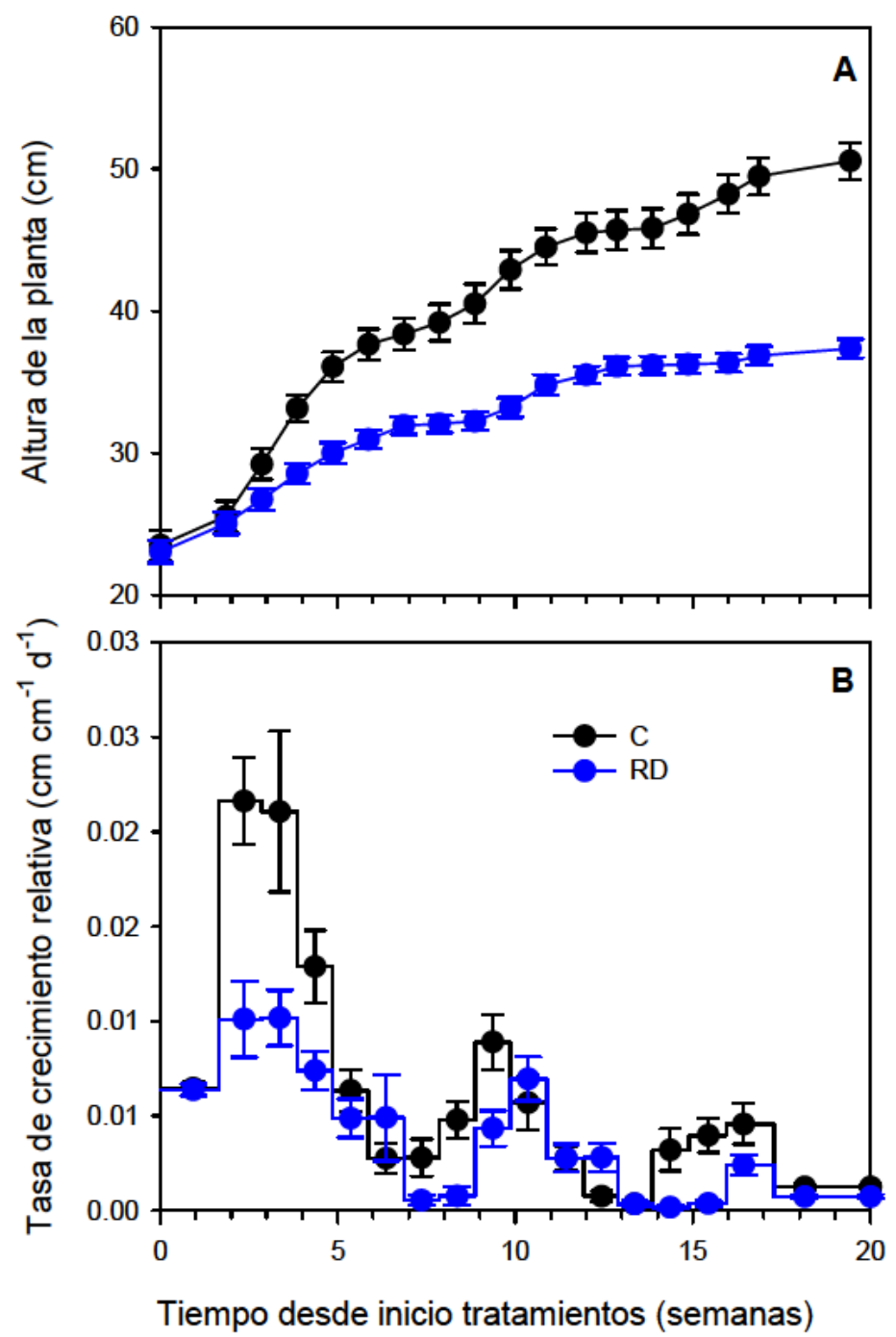

Figura 5.5- Evolución de la altura (A) y de la tasa de crecimiento relativa (B) en plantas de callistemon en maceta sometidas a distintos tratamientos de riego durante el período experimental en condiciones controladas. 


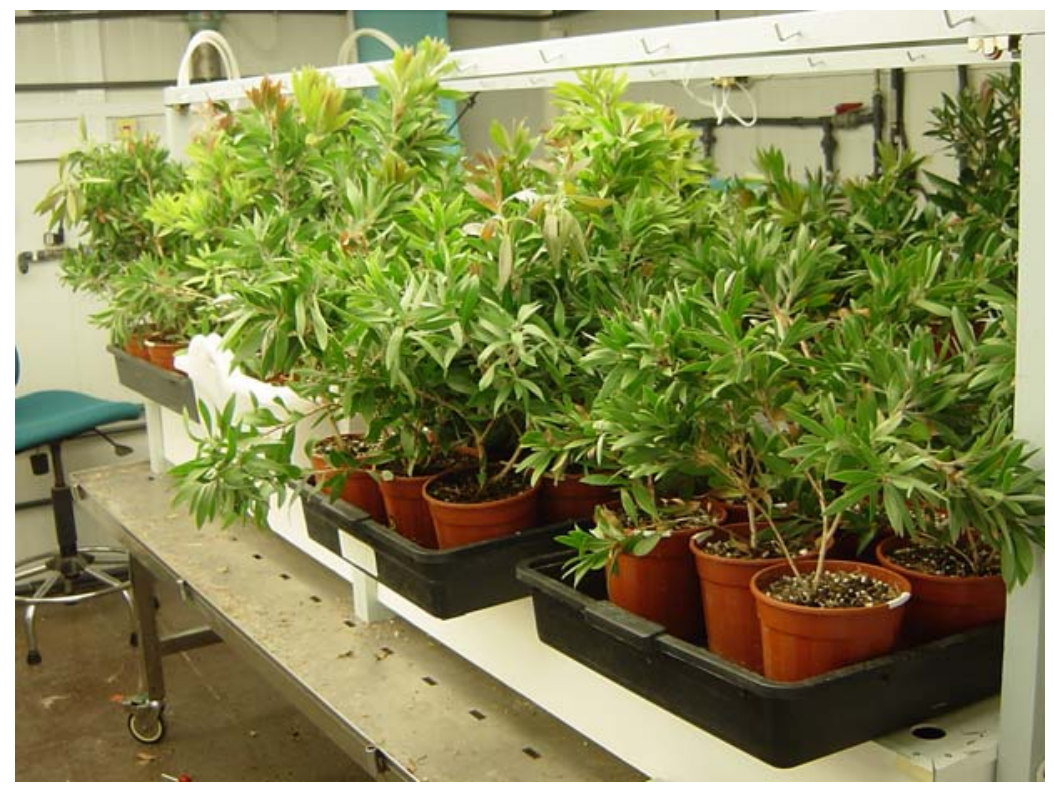

Fotografía 5.11- Vista general de las plantas de callistemon al final del período experimental en condiciones controladas.

La pérdida de electrolitos de las plantas estresadas fue algo mayor que en las plantas control (Tabla 5.1). Este parámetro se usa como medida de las alteraciones de la permeabilidad de la membrana y puede utilizarse como estimación de daños en las membranas.

Por otro lado, las plantas crecidas en macetas bajo riego deficitario tuvieron una rápida y apreciable respuesta en la tasa de crecimiento relativa, la altura de la planta descendió incluso bajo condiciones climáticas de demanda evaporativa moderada. Algunos autores han sugerido que detectar el estrés hídrico en plantas puede ser diferente cuando las plantas crecen en macetas, pues tienen un volumen radical más limitado que las plantas cultivadas en suelo (Gallardo y col., 2006; Miralles y col., 2009). Estos resultados son útiles porque la aplicación de tratamientos deficitarios durante la fase de vivero, los cuales pueden ser usados para reducir el crecimiento excesivo en plantas ornamentales sin aplicar retardadores del crecimiento (Morvant y col., 1998). 


\subsubsection{Efectos del riego deficitario en la transpiración, conductancia estomática y respuesta fotosintética en plantas de callistemon en condiciones controladas}

En la Figura 5.6 se muestra la evolución de la evapotranspiración (ET) y la transpiración (T) a lo largo del ensayo en las plantas de los dos tratamientos de riego. Los valores de $T$ y ET fueron similares debido a que la evaporación del suelo fue baja, las macetas tenían una superficie de sustrato muy pequeña en relación con el área foliar total y consecuentemente, la transpiración fue la mayor componente de la ET $(88 \%)$ en ambos tratamientos.

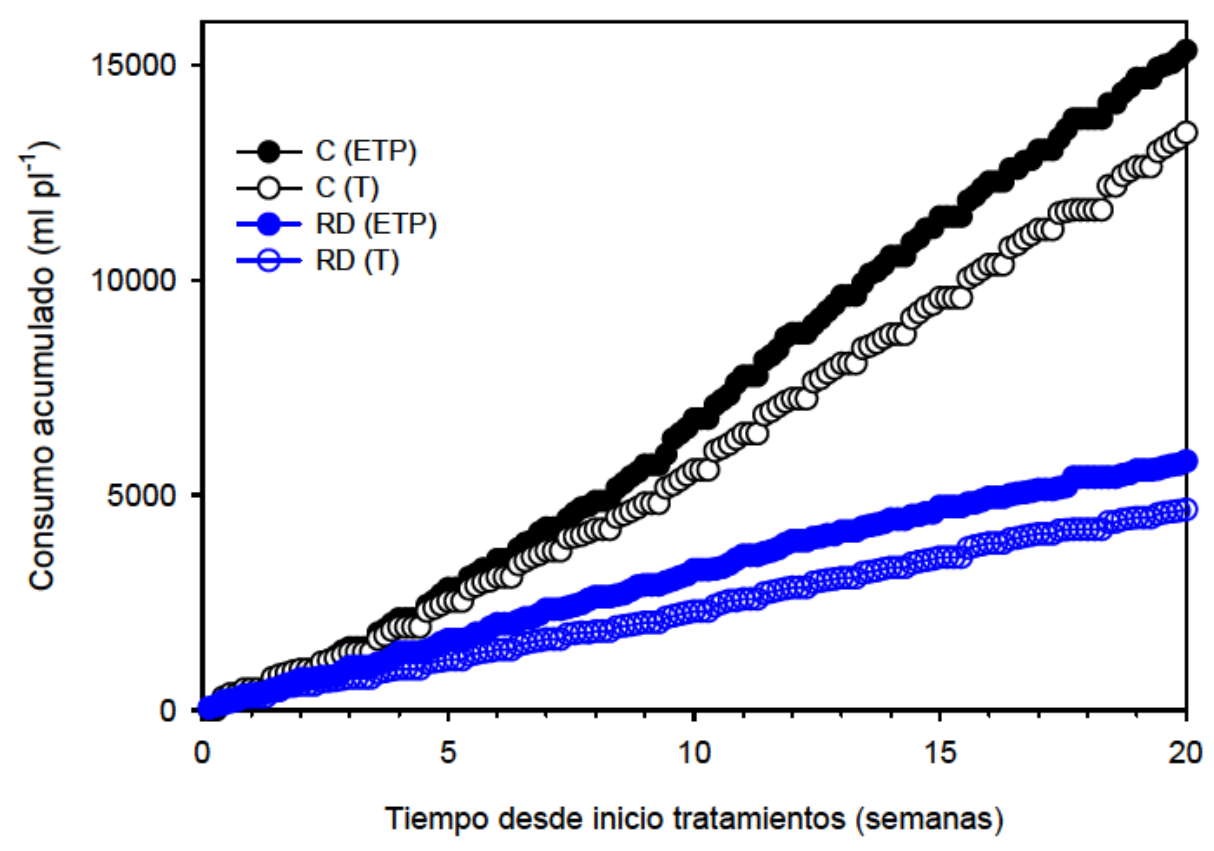

Figura 5.6- Evolución de la evapotranspiración (ETP) y transpiración (T) en plantas de callistemon en maceta sometidas a distintos tratamientos de riego durante el período experimental en condiciones controladas.

El agua añadida a cada maceta durante todo el ensayo fue de 15.3 y 5.8 I para las plantas control y estresadas, respectivamente. Las plantas del riego deficitario redujeron su transpiración, y consecuentemente su evapotranspiración, lo que supuso una reducción del $62 \%$, es decir, la transpiración de las plantas del tratamiento RD fue un $38 \%$ de los valores de las plantas control. 


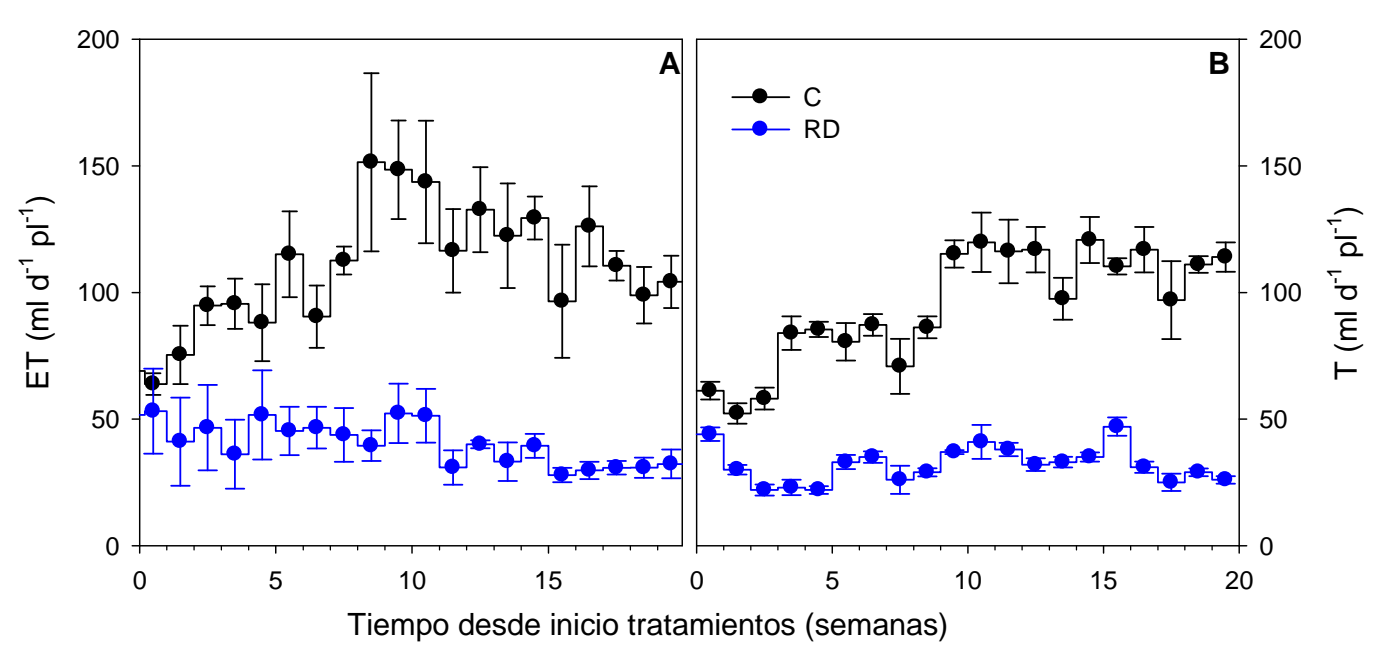

Figura 5.7- Evolución de la evapotranspiración (ET; A) y transpiración (T; B) diaria promediada semanalmente, en plantas de callistemon en maceta sometidas a distintos tratamientos de riego durante el período experimental en condiciones controladas.

La evolución de T y ET a lo largo del período de estudio se representa en la Figura 5.7. Los dos parámetros siguen un patrón similar a lo largo del ensayo, aunque los valores de $\mathrm{T}$ (Figura 5.7B) son algo más bajos que los de ET (Figura 5.7A). En ambos parámetros, los valores de las primeras semanas fueron más bajos que durante la fase final del ensayo experimental, cuando las plantas tenían mayor área foliar, y por tanto más superficie transpirante. Los valores diarios de transpiración fluctuaron entre 52 y $120 \mathrm{ml} \mathrm{pl}^{-1}$ a lo largo del experimento (Figura 5.7B). Por el contrario, en el tratamiento deficitario, el nivel de transpiración diaria se mantuvo más constante durante todo el ensayo, mostrando valores medios en torno a $32 \mathrm{ml} \mathrm{pl}^{-1}$. Los aumentos en la transpiración coinciden con los períodos de crecimiento en altura (Figura 5.5).

Las reducciones en el consumo de agua son atribuidas en parte a una menor superficie transpirante (Atkinson y Crips, 1983), ya que las condiciones ambientales ( $\mathrm{T}^{\mathrm{a}}$, HR y radiación), parámetros estrechamente relacionados con la ET (Montero y col., 2001; Bañón y col., 2009), fueron constantes a lo largo del periodo experimental. Las oscilaciones de los valores del consumo diarios a lo largo del ensayo están relacionados con los incrementos de la superficie foliar y los períodos de crecimiento más intenso. 
La diferencia entre el consumo de las plantas del control y las plantas sometidas a riego deficitario depende de la especie, además del porcentaje de reducción del agua aplicada. Según García-Navarro y col. (2004), el tiempo en el que las plantas sometidas a RD tardan en reducir el consumo también depende de la especie, en nuestro caso, C. citrinus se adapta rápidamente, pues reduce el consumo de agua desde la primera semana de aplicación de los tratamientos.

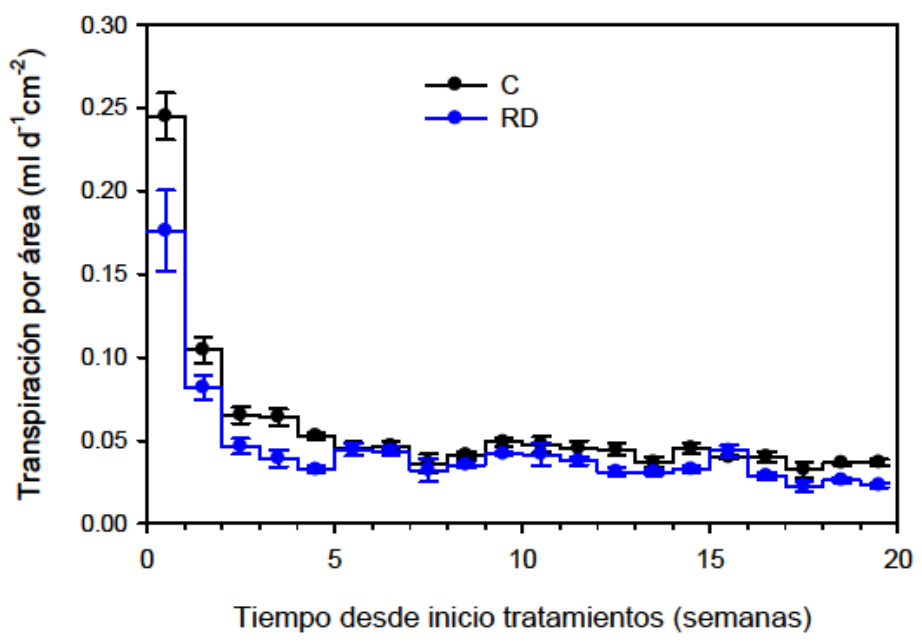

Figura 5.8- Evolución de la tasa de transpiración en relación al área foliar en plantas de callistemon en maceta sometidas a distintos tratamientos de riego durante el período experimental en condiciones controladas.

Si la transpiración se calcula en relación al área foliar de las plantas (Figura 5.8), se ve como va disminuyendo según avanza el ensayo en ambos tratamientos, siendo los primeros días del ensayo los que muestran los valores más altos y un descenso más rápido. Las diferencias entre tratamientos son más evidentes las primeras semanas, en las que las plantas estresadas tienen una tasa de transpiración por unidad de área menor que las plantas control. A partir de la semana 5, las plantas del tratamiento RD siguen teniendo menor transpiración que las plantas del tratamiento control ( $\mathrm{ml}$ por planta), pero las diferencias de la tasa de transpiración en relación al área son menores. Esto se ve también en los valores de conductancia estomática, como veremos más adelante. 

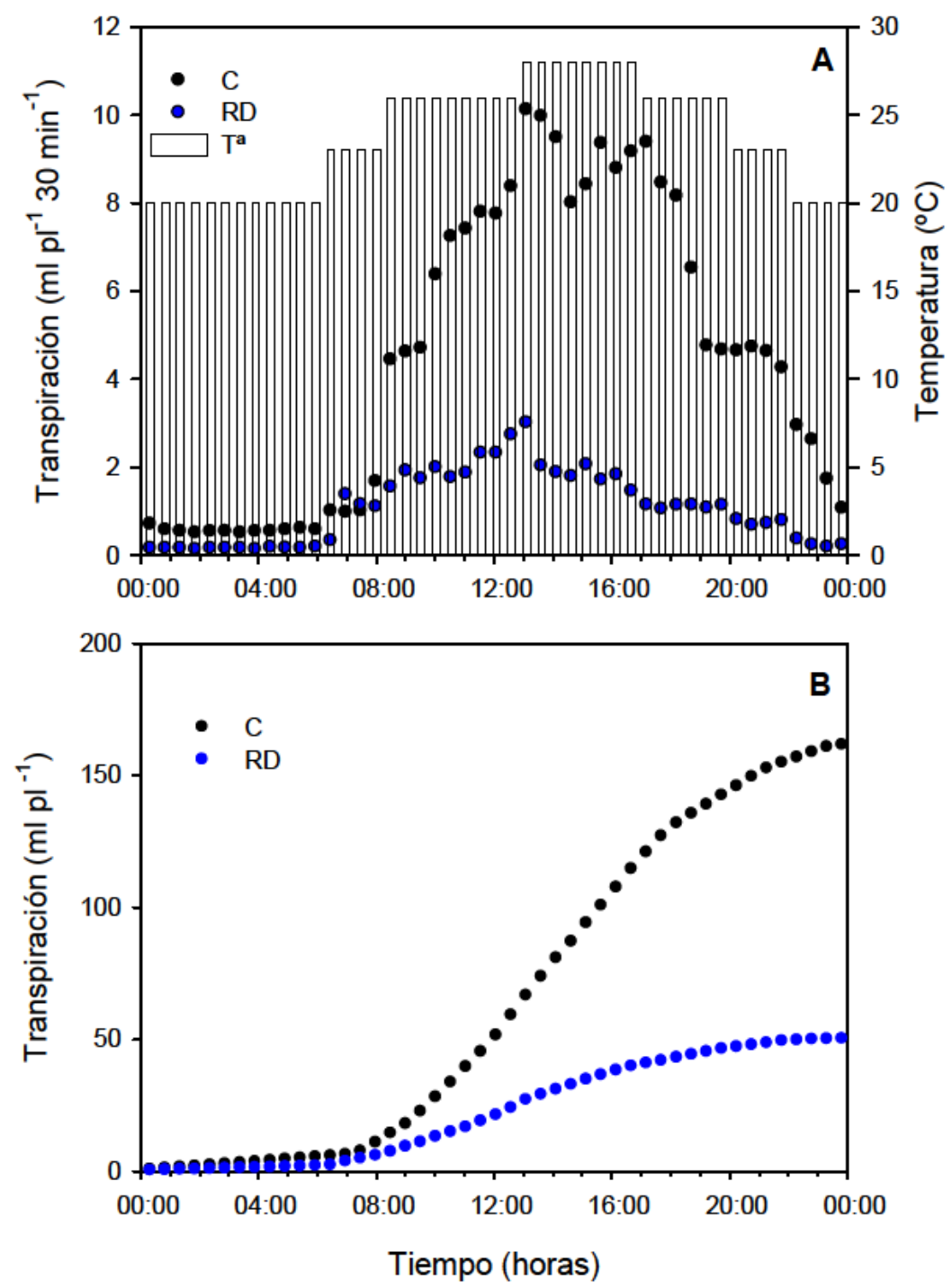

Figura 5.9- Evolución de la transpiración a lo largo de un día representativo, valores horarios (A) y transpiración acumulada (B) en plantas de callistemon en maceta sometidas a distintos tratamientos de riego en condiciones controladas.

En la Figura 5.9 se puede observar el comportamiento de la transpiración de un día representativo del período experimental, a las 10 semanas de iniciar el ensayo. La $T$ fue mayor durante la mañana y descendió durante la tarde, los valores más altos se registraron entre las 13 y $17 \mathrm{~h}$, especialmente en las plantas control (10.1 ml/30 minutos), coincidiendo con la temperatura más alta $\left(28^{\circ} \mathrm{C}\right)$ y las horas de máxima luminosidad. Después de este máximo, la transpiración desciende (Figura 5.9A), lo que está de acuerdo con la observación de numerosos autores (Montero y col., 2001; Alarcón y col., 2000; Nicolás y col., 2005). En las plantas estresadas, los valores de transpiración son más bajos, 
aunque el comportamiento a lo largo del día es similar (Figura 5.9B) y, consecuentemente, el consumo de agua disminuyó de forma importante.

En la Figura 5.10 y Figura 5.11 se muestra la transpiración y tasa de transpiración horaria en relación al área a lo largo de un día en varios momentos representativos del ensayo, que coinciden con los días en los que se han realizado medidas hídricas, de intercambio gaseoso y curvas $A-C_{i}$. 

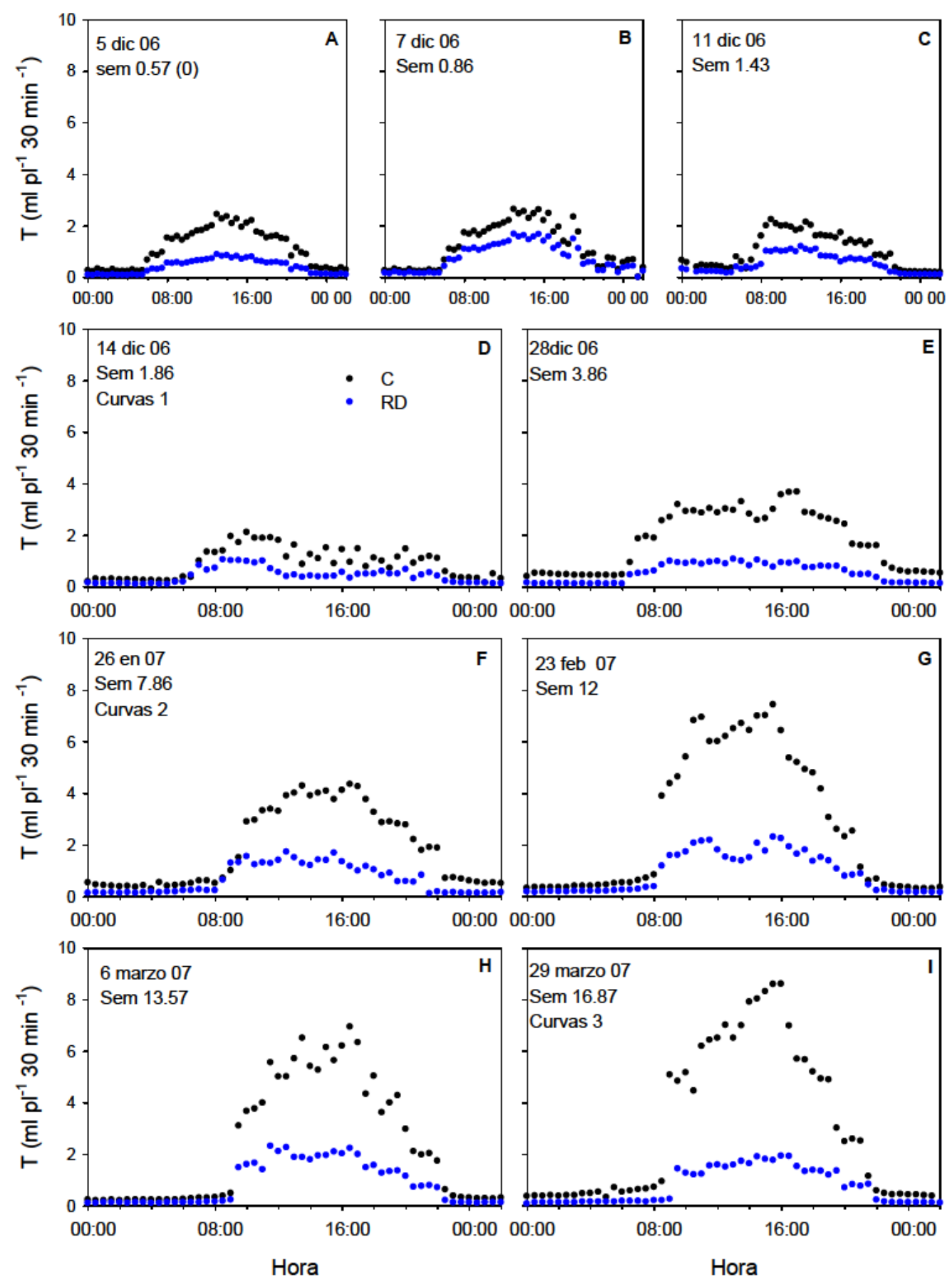

Figura 5.10- Transpiración cada 30 minutos en plantas de callistemon sometidas a distintos tratamientos de riego en varios días representativos durante el período experimental en condiciones controladas.

En ambos tratamientos el patrón a lo largo del día es similar, pero los valores son diferentes a lo largo del ensayo, las tasas de T aumentan según avanza el ensayo, las plantas son más grandes y tienen más superficie transpirante (Figura 5.10). Los valores de $\mathrm{T}$ de las plantas del tratamiento RD son menores que los de las plantas control, aunque estas diferencias son más evidentes cuando la transpiración es mayor, 
en las horas de máxima luminosidad, cuando DPV es mayor o cuando las plantas se encuentran en período de crecimiento más activo (Liu y col., 2006).

Si el nivel de transpiración se expresa en relación al área foliar, ésta es muy alta las primeras semanas en ambos tratamientos, pero va disminuyendo según avanza el ensayo (Figura 5.11). Los primeros días la tasa de $\mathrm{T}$ de plantas del tratamiento RD es menor que la de las plantas control, pero luego estas diferencias se van reduciendo hasta casi desaparecer. Según García-Navarro y col. (2004) en distintas especies ornamentales, todas las plantas sometidas a RD reducen el consumo en comparación con las plantas bien regadas, aunque esta reducción depende de la especie. Algunas disminuyen el área foliar (superficie evaporativa), pero no el consumo por área foliar, otras, sin embargo presentan un descenso del consumo por área foliar, pero no disminuyen el área foliar, y otras especies reducen ambos parámetros (área y transpiración en relación al área foliar). 

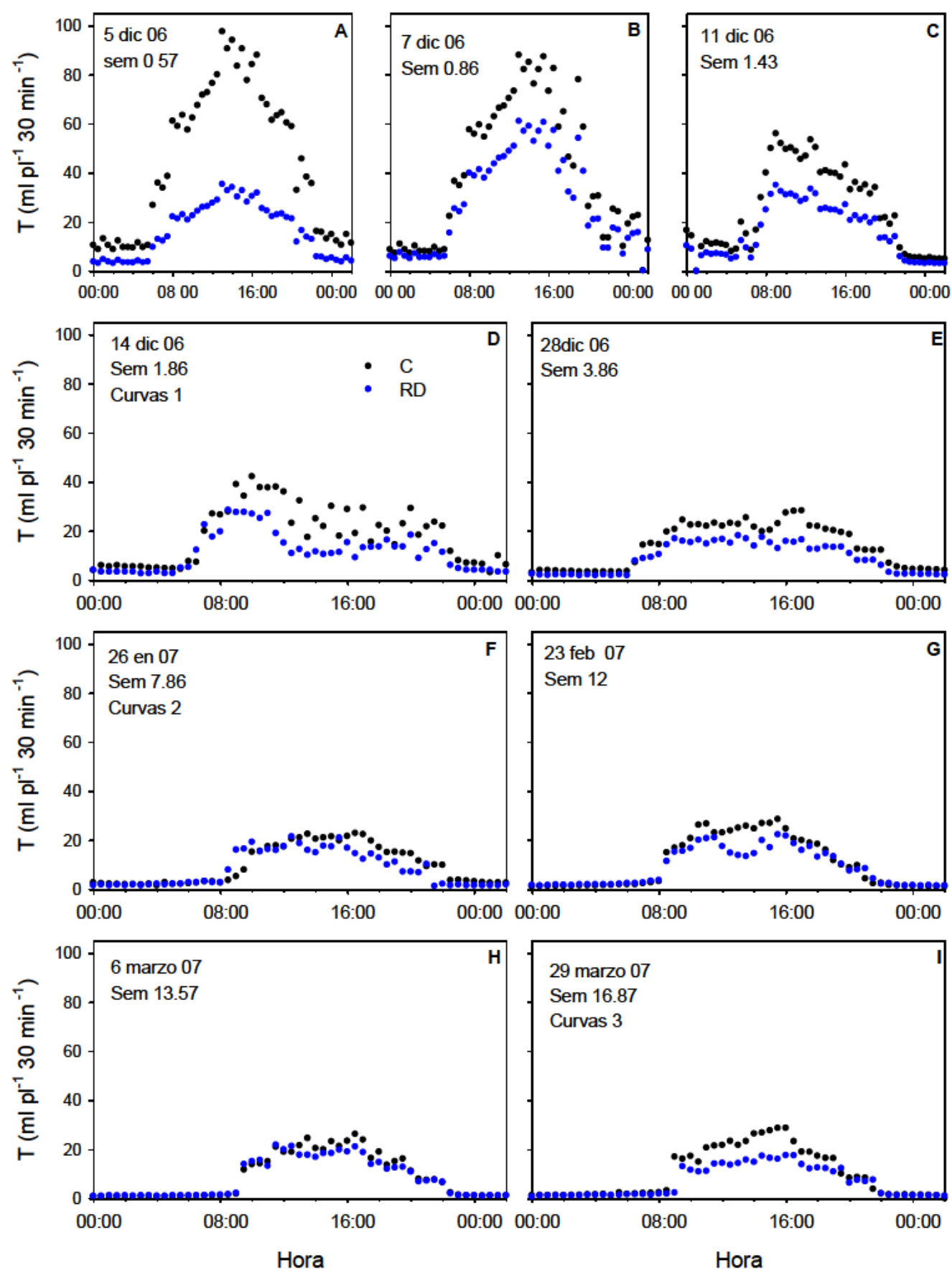

Figura 5.11- Tasa de transpiración en relación al área foliar cada 30 minutos en varios días representativos en plantas de callistemon en maceta sometidas a distintos tratamientos de riego durante el período experimental en condiciones controladas. 
El déficit hídrico afectó a la funcionalidad de los estomas (Figura 5.12). La conductancia estomática $\left(g_{s}\right)$ y la tasa de fotosíntesis $\left(P_{n}\right)$ descendió en las plantas sometidas a riego deficitario en relación con las del tratamiento control, aunque este descenso fue más marcado en $\mathrm{g}_{\mathrm{s}}$ (Figura 5.12A y B). La conductancia estomática presenta valores más altos en las primeras semanas con respecto al resto del ensayo, como hemos visto también con la tasa de transpiración en relación al área foliar (Figura 5.13). Los valores de $\mathrm{P}_{\mathrm{n}} / \mathrm{g}_{\mathrm{s}}$ en el tratamiento de déficit hídrico fueron mayores que en el tratamiento control durante el período experimental (Figura 5.12C). Según el experimento iba avanzando, mayor era la eficiencia intrínseca en el uso del agua $\left(P_{n} / g_{s}\right)$ de las plantas estresadas. 

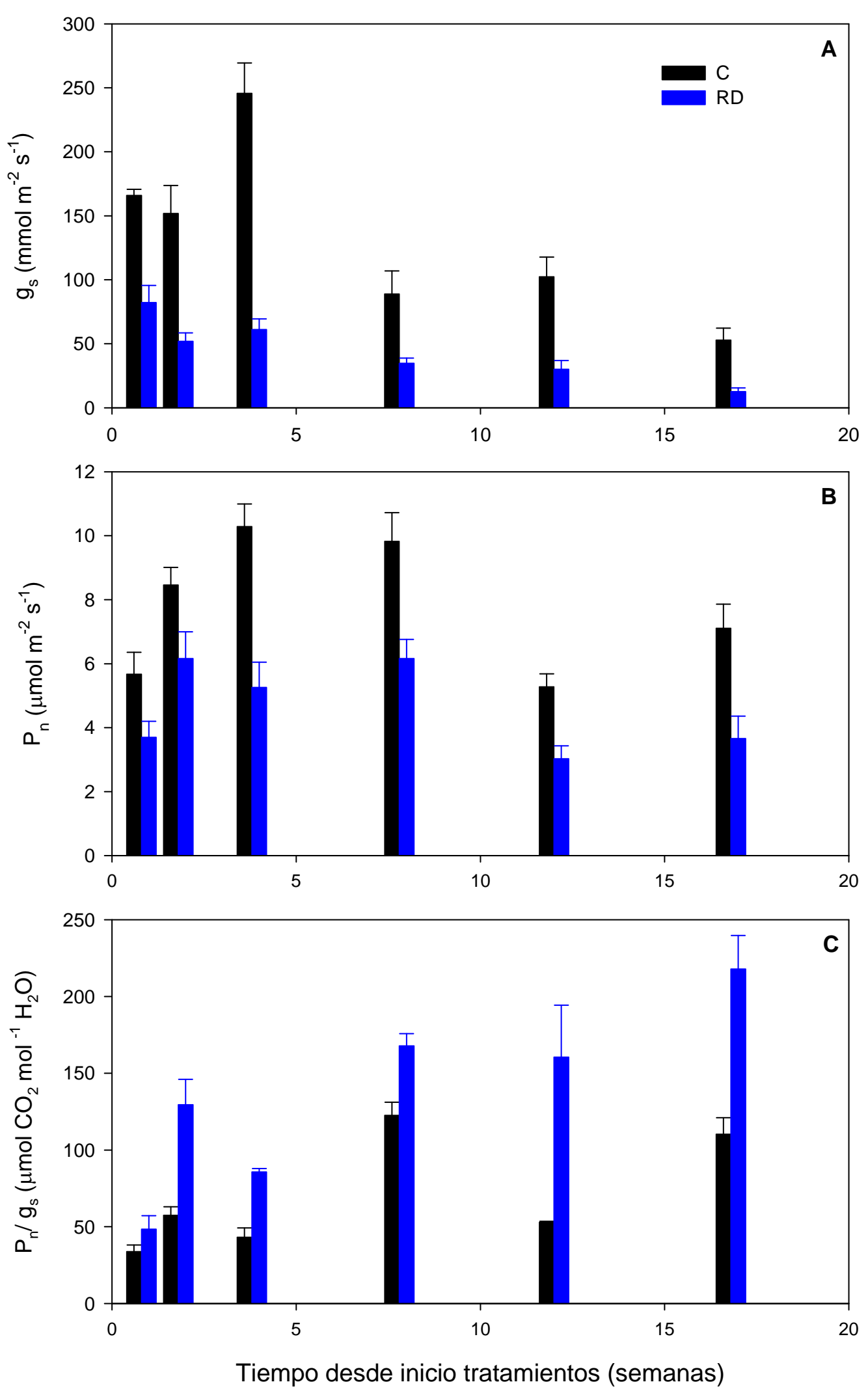

Figura 5.12- Evolución de la conductancia estomática $\left(g_{s} ; A\right)$, tasa de fotosíntesis neta $\left(P_{n} ; B\right)$ y eficiencia intrínseca en el uso del agua $\left(P_{n} / g_{s} ; C\right)$ en plantas de callistemon en maceta sometidas a distintos tratamientos de riego durante el período experimental en condiciones controladas. 


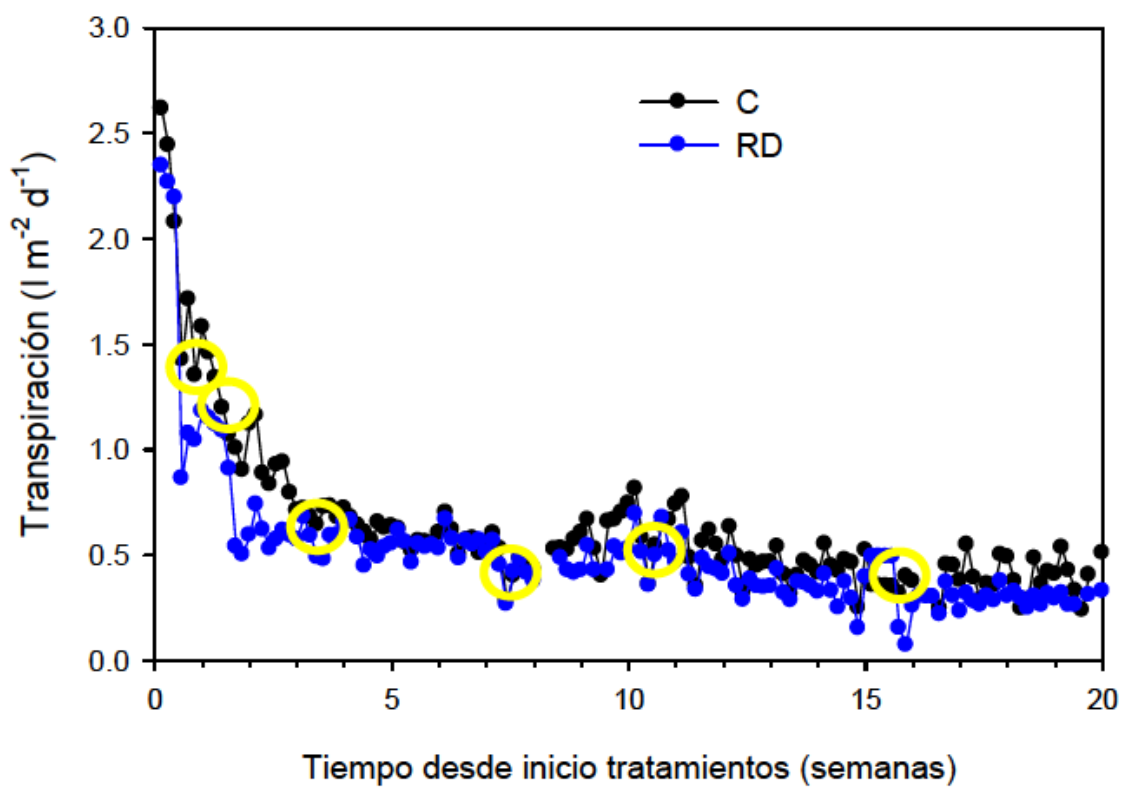

Figura 5.13- Evolución de la tasa de transpiración diaria en relación al área en plantas de callistemon en maceta sometidas a distintos tratamientos de riego durante el período experimental en condiciones controladas. Los círculos amarillos señalan los días en los que se realizaron las medidas de intercambio gaseoso.

Las plantas expuestas a déficit hídrico también aumentaron la eficiencia productiva en el uso del agua (WUE), expresada como unidad de peso seco de la planta por unidad de agua aportada (3.6 g/l y $4.68 \mathrm{~g} / \mathrm{l}$ para plantas control y estresadas, respectivamente). Esta respuesta ha sido observada en numerosas plantas ornamentales (Cameron y col., 2006; Jaleel y col., 2008; Álvarez y col., 2009; Mugnai y col., 2009). Aunque según otros autores este parámetro no se modifica por el riego deficitario (Andersson, 2001) o incluso desciende, mostrando esta respuesta una gran dependencia de la especie y de la variedad estudiada (Anyia y Herzog, 2004; Jaleel y col., 2008).

La actividad del fotosistema II (PSII) juega un papel importante en la respuesta de la fotosíntesis a los estreses ambientales (Martínez-Ferri y col., 2000). En nuestro ensayo, los valores de $F_{v} / F_{m}$ no se afectaron por el tratamiento de estrés (Figura 5.14). En trabajos realizados por Mugnai y col. (2009), en plantas de callistemon, el RD (50\%) tampoco redujo $F_{v} / F_{m}$. La actividad de PSII ha sido estudiada cómo método no destructivo para evaluar la funcionalidad de las plantas sometidas a estrés. Las hojas de las plantas estresadas, normalmente, muestran una menor eficiencia en capturar la luz fotosintética y transferir energía. Muchos estudios usan un descenso en la eficiencia máxima de PSII en hojas previamente adaptadas a oscuridad $\left(F_{v} / F_{m}\right)$ como un fiable 
indicador que diagnostica la fotoinhibición en respuesta al estrés. Se ha sugerido que $F_{v} / F_{m}$ debajo de 0.83 puede ser normalmente referido a plantas estresadas (Maxwell y Johnson, 2000), sin embargo, otros estudios sugieren que los arbustos pueden no estar estresados hasta valores de $F_{\mathrm{v}} / F_{m}$ por debajo de 0.76 (Percival, 2004).

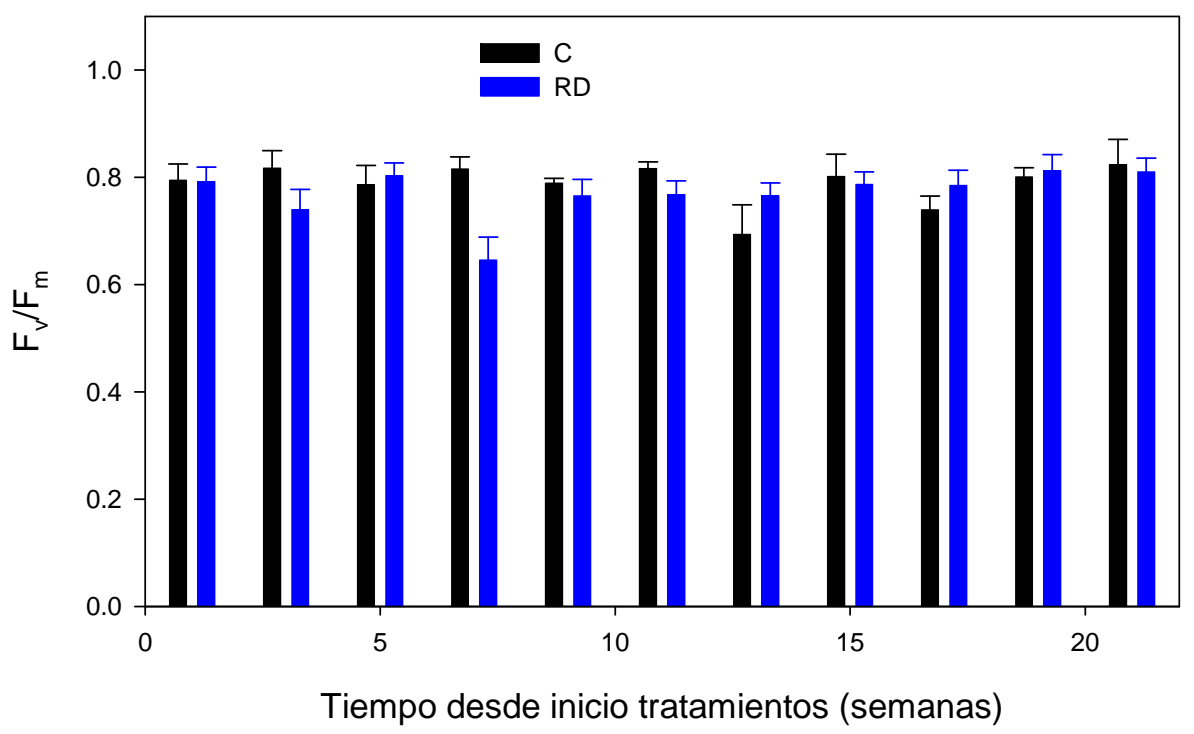

Figura 5.14- Evolución de la fluorescencia en plantas de callistemon en maceta sometidas a distintos tratamientos de riego durante el período experimental en condiciones controladas.

El déficit hídrico produjo una disminución sustancial en la conductancia estomática en estas plantas durante el período experimental, lo que podría afectar a la tasa neta de asimilación de $\mathrm{CO}_{2}$, conduciendo a una menor producción de biomasa (Mugnai y col., 2009; Brugnoli y Bjorkman, 1992). De este modo, el hecho que los valores de $\mathrm{F}_{\mathrm{v}} / \mathrm{F}_{\mathrm{m}}$ se mantuvieran en torno a 0.8 durante el experimento en ambos tratamientos demuestra la falta de daño producidos por el déficit hídrico en el fotosistema PSII, lo que sugiere que Callistemon citrinus es una especie tolerante al estrés hídrico (Genty y col., 1987; Mugnai y col., 2009).

La eficiencia intrínseca en el uso del agua $\left(\mathrm{P}_{\mathrm{n}} / \mathrm{g}_{\mathrm{s}}\right)$ aumentó progresivamente según avanzaba el ensayo en las plantas estresadas, lo que indica un predominio del control estomático sobre la fotosíntesis (Gulías y col., 2009). El descenso constante de $g_{s}$ sugirió un eficiente y adaptativo control estomático de la transpiración en estas especies (Hessini y col., 2008). En este sentido, la mayoría de las especies 
arbustivas aumentan su eficiencia fotosintética, permaneciendo la asimilación de $\mathrm{CO}_{2}$ proporcionalmente mayor a la pérdida de vapor de agua de los estomas como una adaptación adicional a la sequía (Filella y col., 1998; Raviv y Blom, 2001; Jaleel y col., 2008; Shao y col., 2008; Bolla y col., 2010). Aunque en otras especies ornamentales se ha encontrado el efecto contrario, que las plantas han reducido su eficiencia fotosintética intrínseca como respuesta al riego deficitario (Rasoul Sharifi y Rundel, 1993; Mugnai y col., 2005; Lenzi y col., 2009).

La respuesta depende de varios factores: la especie y la variedad estudiada, la severidad del estrés o el momento del día en el que se realiza la medida (Costa França y col., 2000; Bacelar y col., 2007; Jaleel y col., 2008; Lenzi y col., 2009). Según Bacelar y col. (2007) en olivo, la eficiencia intrínseca en el uso del agua fue diferente entre tratamientos de riego, pero también cambió a lo largo del día. Por la mañana fue más alta en el tratamiento de RD más severo, mientras que al mediodía y por la tarde fue mayor el las plantas sometidas a RD moderado o las control. $\mathrm{P}_{\mathrm{n}} / \mathrm{g}_{\mathrm{s}}$ descendió a lo largo del día en RD severo y aumentó en los tratamientos de RD moderado, principalmente al mediodía. Según Lenzi y col. (2009) en adelfa, este parámetro, además depende del tiempo sin riego o severidad del estrés. En las primeras etapas, el efecto del RD en al conductancia es mayor que en la fotosíntesis, con lo que aumenta la eficiencia, pero según el estrés es más severo, $\mathrm{P}_{\mathrm{n}} / \mathrm{g}_{\mathrm{s}}$ normalmente decrece. Este parámetro $\left(\mathrm{P}_{\mathrm{n}} / \mathrm{g}_{\mathrm{s}}\right)$ podría utilizarse como un criterio de selección de plantas que mantienen la tasa de asimilación de $\mathrm{CO}_{2}$ a baja apertura estomática.

\subsubsection{Curvas $A-C_{i}$}

El resultado de las curvas de respuesta a la luz mostró claramente dos diferentes intensidades de luz saturante en cada tratamiento. Así, en el tratamiento control la luz saturante se alcanzó a $1800 \mu \mathrm{mol} \mathrm{m} \mathrm{m}^{-2} \mathrm{~s}^{-1}$ mientras bajo condiciones de riego deficitario, ésta fue menor, alcanzando la saturación de fotosíntesis a una intensidad de luz de 1500 $\mu \mathrm{mol} \mathrm{m} \mathrm{m}^{-2} \mathrm{~s}^{-1}$ (Figura 5.15). 

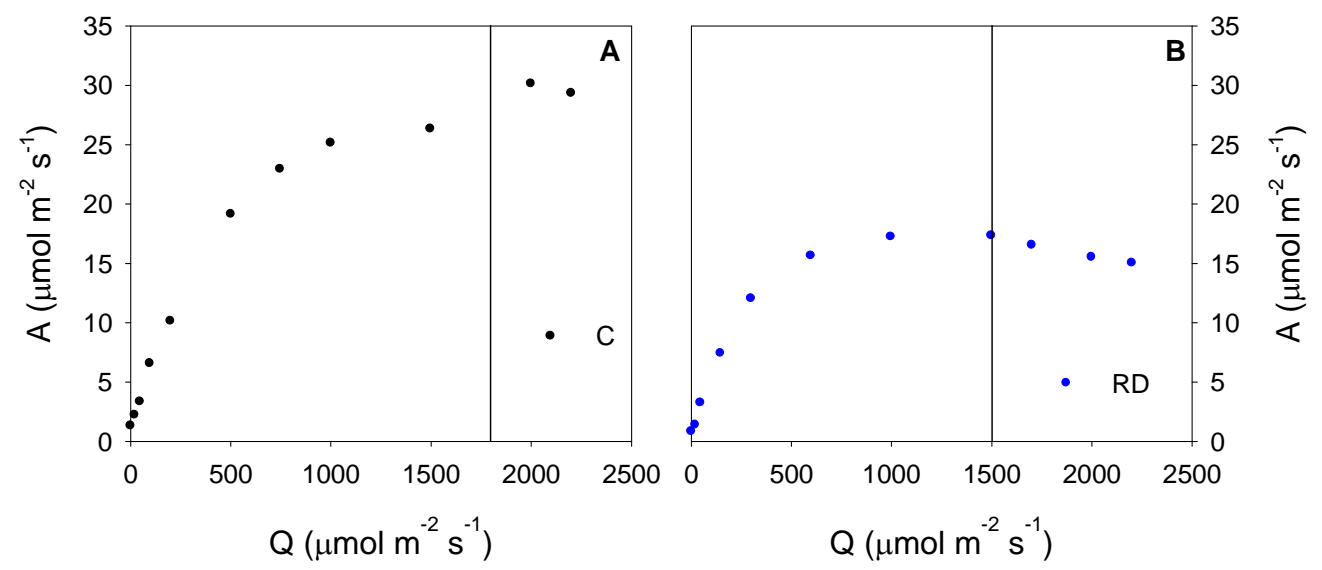

Figura 5.15- Determinación de la luz saturante en plantas de callistemon en maceta sometidas a distintos tratamientos de riego (Control, A y Riego deficitario, B).

La tasa máxima de carboxilación $\left(\mathrm{V}_{\mathrm{cmax}}\right)$ y la de transporte de electrones $\left(J_{\max }\right)$ sólo presentaron diferencias significativas entre tratamientos al final del período experimental (Tabla 5.3). Sin embargo, los niveles de conductancia del mesófilo $\left(\mathrm{g}_{\mathrm{m}}\right)$ fueron similares al principio y final del período experimental, difiriendo significativamente únicamente a mediados del ensayo. Por último, la eficiencia fotosintética en el uso del nitrógeno (EFUN) mostró diferencias significativas desde mediados del ensayo, presentando las plantas del tratamiento de RD niveles medios próximos a la mitad de las plantas del tratamiento control (Tabla 5.3).

Tabla 5.3- Evolución de la tasa máxima de carboxilación $\left(\mathrm{V}_{\mathrm{cmax}}, \mu \mathrm{mol} \mathrm{m}^{-2} \mathrm{~s}^{-1}\right)$, de transporte electrónico $\left(\mathrm{J}_{\max }, \mu \mathrm{mol} \mathrm{m} \mathrm{m}^{-2} \mathrm{~s}^{-1}\right)$, conductancia del mesófilo $\left(\mathrm{g}_{\mathrm{m}}, \mathrm{mmol} \mathrm{m}^{-2} \mathrm{~s}^{-1}\right)$ y eficiencia fotosintética en el uso del nitrógeno (EFUN, $\mu \mathrm{mol} \mathrm{CO}_{2} \mathrm{~mol}^{-1} \mathrm{~N}$ ) en plantas de callistemon en maceta sometidas a distintos tratamientos de riego durante el período experimental en condiciones controladas.

\begin{tabular}{|c|c|c|c|c|c|c|c|c|c|}
\hline \multirow{2}{*}{ Parámetro } & \multicolumn{3}{|c|}{ Sem 1} & \multicolumn{3}{|c|}{ Sem 7} & \multicolumn{3}{|c|}{ Sem 17} \\
\hline & C & $\mathrm{RD}$ & $P$ & $C$ & $\mathrm{RD}$ & $P$ & C & $\mathrm{RD}$ & $\mathrm{P}$ \\
\hline $\mathrm{V}_{\text {cmax }}$ & $62.7 \pm$ & $51.5 \pm 8.3$ & ns & $53.3 \pm 3.1$ & $51.2 \pm 7.5$ & $5 \mathrm{~ns}$ & $53.4 \pm 4.4$ & $38.2 \pm 2.4$ & $4 *$ \\
\hline$J_{\max }$ & $124.7 \pm$ & $35.3 \pm 13.3$ & 3 ns & $94.1 \pm 2.8$ & $87.1 \pm 6$. & $5 \mathrm{~ns}$ & $97.5 \pm 6.1$ & $68.1 \pm 2.0$ & ** \\
\hline$g_{m}$ & $223 \pm$ & $193 \pm 29$ & ns & $258 \pm 41$ & $98 \pm 16$ & & $79 \pm 5$ & $76 \pm 11$ & ns \\
\hline EFUN & $56.4 \pm$ & $39.3 \pm 5.1$ & $\mathrm{~ns}$ & $69.9 \pm 4.4$ & $39.5 \pm 7.3$ & $3 * *$ & $56.9 \pm 4.2$ & $30.1 \pm 1.6$ & $j^{* * *}$ \\
\hline
\end{tabular}

$\mathrm{P}$ : nivel de significación, ns: no significativo, ${ }^{\star} \mathrm{P}<0.05,{ }^{\star \star} \mathrm{P}<0.01,{ }^{\star \star *} \mathrm{P}<0.001$. 
Al analizar las limitaciones totales a la fotosíntesis máxima $\left(A_{\max }\right)$ se pudo observar como el tratamiento de RD casi dobló dichas limitaciones con respecto al tratamiento control (59.3 frente 33.9\%) (Tabla 5.4). Analizando cada una de las limitaciones, se pudieron distinguir distintas causas en la limitación de $A_{\max }$ para cada tratamiento y momento del ensayo. Así, para el tratamiento control no se presentaron limitaciones significativas de $A_{\max }$ hasta el final del período experimental, las cuales fueron principalmente causadas por limitaciones del mesófilo ( $56 \%$ del total) siendo las limitaciones difusionales $\left(l_{g s}+I_{g m}\right)$ las que justificaron más del $90 \%$ de la limitación total de $A_{\max }$ en este tratamiento. Sin embargo en el tratamiento de RD, tanto a mediados como al final del ensayo, las limitaciones de tipo estomático fueron las más importantes (justificando casi el 50\% del total de las limitaciones). Además, al final del período experimental, se pudo observar un efecto importante de tipo bioquímico en la limitación de la $A_{\max }(33 \%$ del total), indicando, por ello, que las plantas de Callistemon sometidas a RD alcanzaron un nivel severo de déficit hídrico (Tabla 5.4).

Tabla 5.4.- Evolución de las limitaciones de la fotosíntesis máxima $\left(A_{\max }\right)$ en plantas de callistemon en maceta sometidas a distintos tratamientos de riego durante el período experimental bajo condiciones controladas.

\begin{tabular}{lcccccc}
\hline \multirow{2}{*}{ Limtaciones } & \multicolumn{2}{c}{ Sem 1 } & \multicolumn{2}{c}{ Sem 7 } & \multicolumn{2}{c}{ Sem 17 } \\
& $\mathrm{C}$ & $\mathrm{RD}$ & $\mathrm{C}$ & $\mathrm{RD}$ & $\mathrm{C}$ & $\mathrm{RD}$ \\
\hline $\mathrm{Igs}_{\mathrm{ggm}}$ & 0.0 & 16.9 & 2.0 & 21.4 & 11.3 & 28.0 \\
Bioquímicas & 0.0 & 1.7 & 0.1 & 13.4 & 19.0 & 11.7 \\
No estomáticas & 0.0 & 6.1 & 6.9 & 6.2 & 3.7 & 19.6 \\
Difusionales & 0.0 & 7.8 & 6.9 & 19.6 & 22.6 & 31.3 \\
Totales (difus + bioq) & 0.0 & 18.6 & 2.1 & 34.7 & 30.3 & 39.7 \\
\hline Los valores son expresados como porcentaje respecto a los valores & máximos \\
encontrados en el tratamiento control al inicio del período experimental.
\end{tabular}

\subsubsection{Efectos del riego deficitario en las relaciones hídricas en plantas de callistemon en condiciones controladas}

Los valores del potencial hídrico foliar en oscuridad $\left(\Psi_{\mathrm{pd}}\right)$ y en el momento de máxima luminosidad $\left(\Psi_{\mathrm{md}}\right)$ y del potencial hídrico de tallo $\left(\Psi_{t}\right)$ se representan en la Figura 5.16 . 


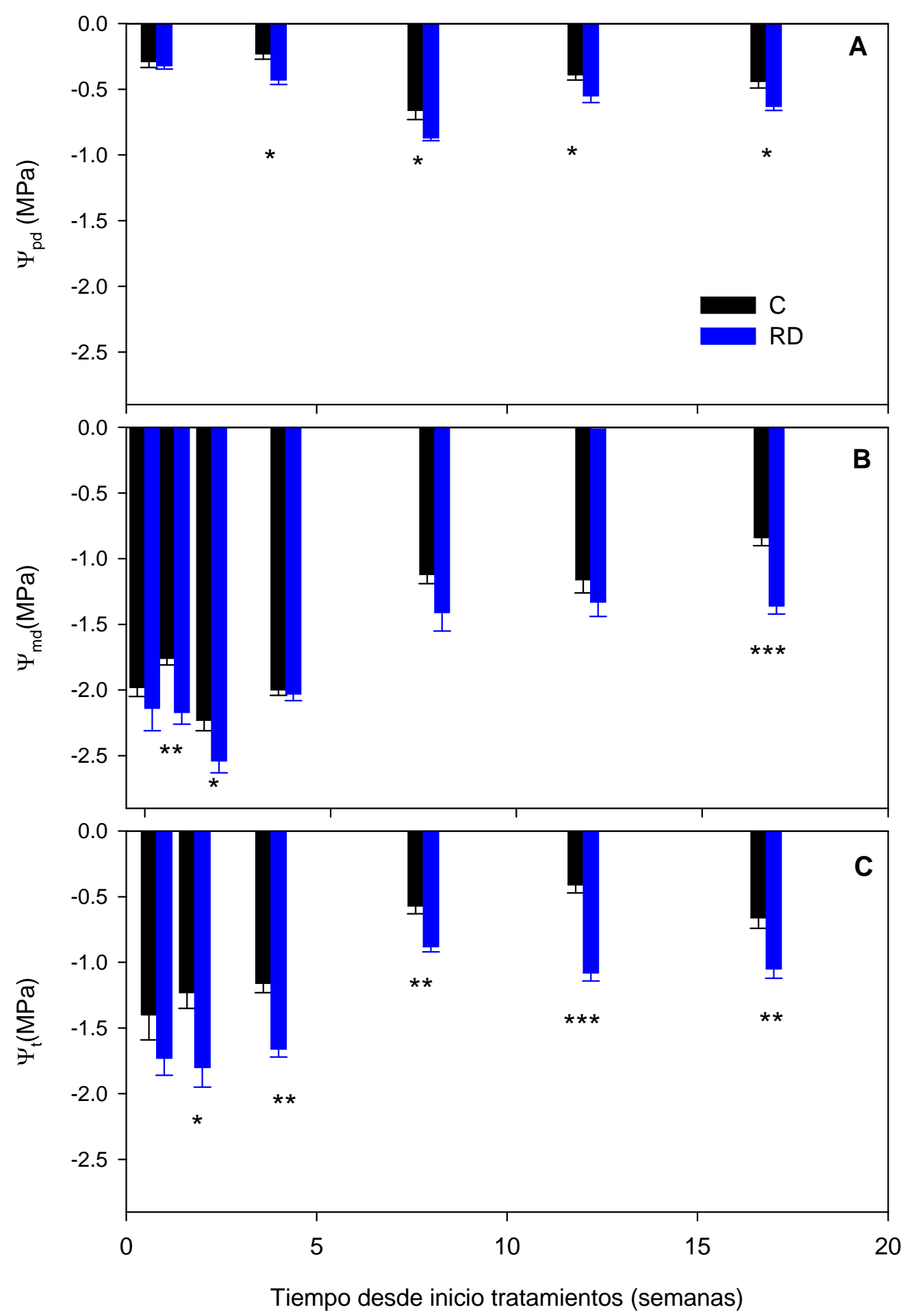

Figura 5.16- Evolución del potencial hídrico foliar antes de la fase luminosa ( $\Psi_{\mathrm{pd}}$ : A) y en las horas de máxima luminosidad $\left(\Psi_{\mathrm{md}}: \mathrm{B}\right)$ y potencial hídrico de tallo $\left(\Psi_{\mathrm{t}} ; \mathrm{C}\right)$ en plantas de callistemon en maceta sometidas a distintos tratamientos de riego durante el período experimental en condiciones controladas.

Los valores de potencial hídrico medido antes de iniciar la fase luminosa (Figura 5.16A) fueron más o menos constantes a lo largo del 
ensayo $y$, en general, fueron mayores en las plantas del tratamiento control, a excepción de la primera medida, momento en el que la humedad de las plantas del tratamiento RD todavía no había descendido hasta alcanzar el valor de humedad preestablecido (Figura 5.17). $\Psi_{\text {pd }}$ mide el estado hídrico de la planta cuando no existe prácticamente flujo de agua y da información del potencial hídrico del sustrato, ya que se considera que la medida de $\Psi_{\text {pd }}$ está en equilibrio con el estado hídrico del suelo (Choné y col., 2001).

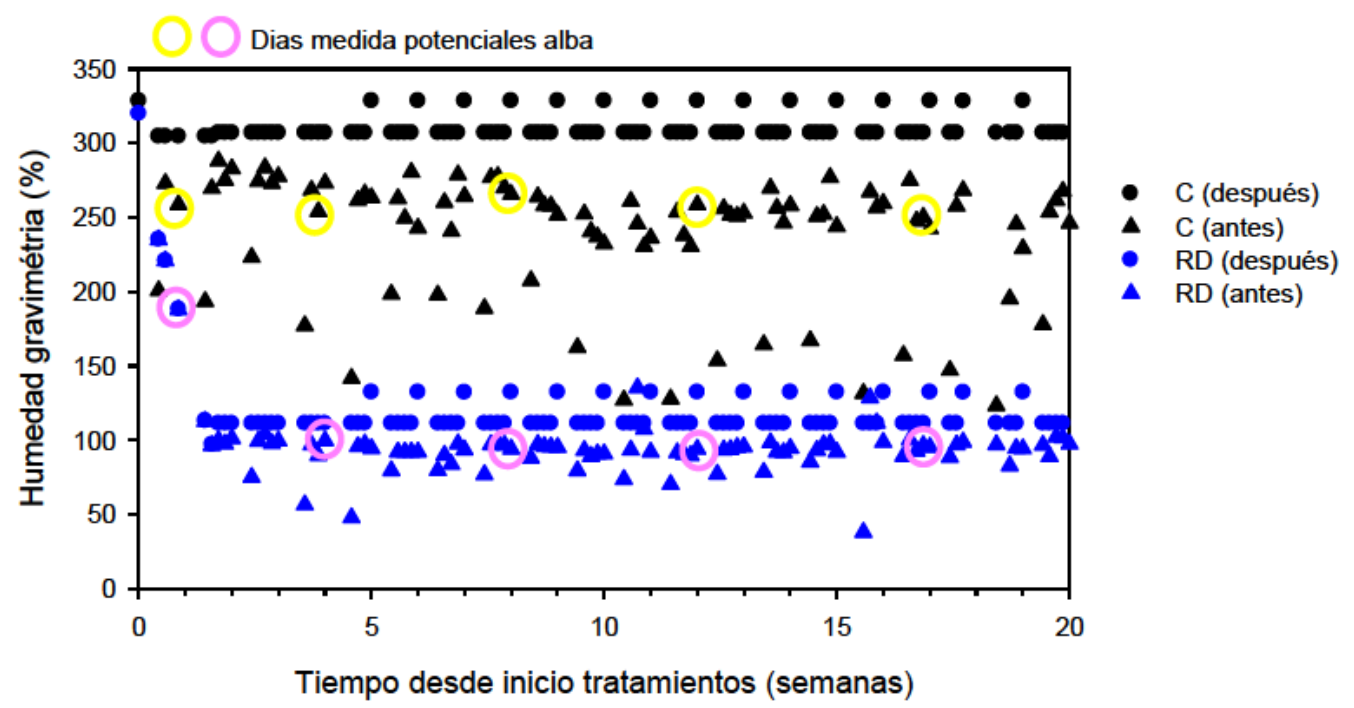

Figura 5.17- Evolución de la humedad gravimétrica antes y después del riego en plantas de callistemon en maceta sometidas a distintos tratamientos de riego durante el período experimental en condiciones controladas y su relación con la medida de $\Psi_{\text {pd }}$. Los círculos amarillos y rosas señalan los valores de humedad de los días de medida de $\Psi_{\mathrm{pd}}$ de las plantas del tratamiento control y RD, respectivamente.

La medida del potencial hídrico en hoja a máxima luminosidad refleja la combinación de varios factores: la demanda hídrica en la hoja, (DPV y radiación), disponibilidad de agua en el suelo, conductividad hidráulica interna en la planta y regulación estomática. El potencial hídrico de tallo es el resultado de la transpiración de toda la planta y la conductividad hidráulica de las raíces, indica la capacidad de la planta para conducir agua desde el suelo hasta la atmósfera (Choné y col., 2001).

Ambos parámetros, $\Psi_{\mathrm{h}}$ y $\Psi_{\mathrm{t}}$ fueron siempre más altos en las plantas del tratamiento control que en las del tratamiento de déficit hídrico (Figura 5.16B y C), aunque no siempre estas diferencias fueron significativas. Para cada tratamiento, $\Psi_{\mathrm{t}}$ tuvo siempre valores menos negativos que los encontrados para $\Psi_{\mathrm{h}}$ (Figura 5.18). 


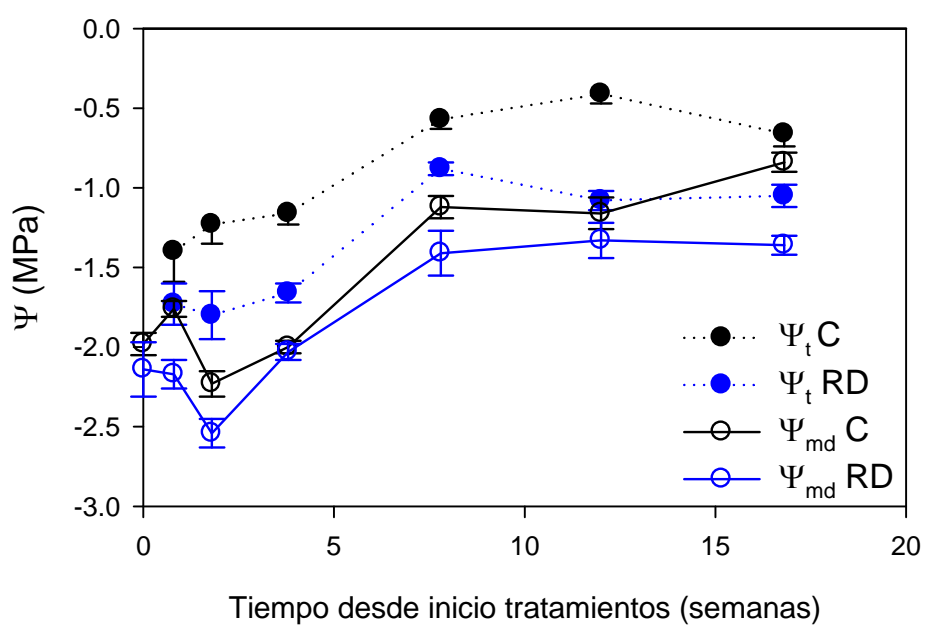

Figura 5.18- Evolución de la relación entre el $\Psi_{\mathrm{md}}$ y $\Psi_{\mathrm{x}}$ en plantas de callistemon en maceta sometidas a distintos tratamientos de riego durante el período experimental en condiciones controladas.

El error estándar fue mucho menor para el potencial de tallo que para el potencial de hoja medido a máxima luz (Choné y col., 2001), consecuentemente la medida de $\Psi_{\mathrm{t}}$ mostró diferencias entre tratamientos tan pronto como el suelo estuvo más seco y estas diferencias fueron mayores (Figura 5.16B y C). Las diferencias significativas entre tratamientos fueron menores para el potencial de hoja que para el potencial del tallo. Por lo que podemos concluir que $\Psi_{\mathrm{t}}$ es buen indicador del estado hídrico de Callistemon citrinus. Esto es debido a la baja variabilidad entre hojas que no transpiran, mientras que en las hojas que transpiran son mucho más variables, dependiendo de las condiciones ambientales locales. Además, cuando las plantas hacen regulación estomática, se reduce $g_{\mathrm{s}} \mathrm{y}$ el valor del $\Psi_{\mathrm{h}}$ a lo largo del día es menos variable entre tratamientos (desciende menos el $\Psi_{\mathrm{md}}$ respecto al $\Psi_{\mathrm{pd}}$ en las plantas que no cierran estomas). $\Psi_{\mathrm{t}}$ es más variable entre tratamientos que $\Psi$ de hoja debido a la regulación estomática de la transpiración para mantener el valor diario de potencial hídrico foliar y prevenir daños permanentes en las hojas (Figura 5.18). La medida de $\Psi_{\mathrm{t}}$ incluso muestra diferencias más significativas que $\Psi_{\text {pd. }}$ Según Choné y col. (2001) cuando el estrés es severo, los dos parámetros son capaces de mostrar las diferencias, pero $\Psi_{\mathrm{x}}$ las detecta antes y con más amplitud. El orden de estos indicadores en función de su idoneidad para detectar el estrés hídrico en Callistemon citrinus sería: $\Psi_{\mathrm{t}}, \Psi_{\mathrm{pd}} \mathrm{y} \Psi_{\mathrm{md}}$. 
Si tenemos en cuenta las diferencias entre $\Psi_{\mathrm{t}}$ y $\Psi_{\mathrm{md}}$, vemos que estas diferencias en general, son mayores al inicio del ensayo y se van reduciendo según avanza el ensayo, además son mayores en las plantas control, lo que está relacionado con el comportamiento de la tasa de transpiración, lo que sugiere que el índice $\Psi_{\mathrm{t}}$ menos $\Psi_{\mathrm{md}}$ puede ser usado como un indicador de la transpiración instantánea (Figura 5.8 y Figura 5.11).

Las diferencias entre $\Psi_{\mathrm{pd}}$ y $\Psi_{\mathrm{md}}$ medidos un mismo día fueron mayores al inicio del ensayo (Figura 5.19). El descenso diario en el potencial hídrico está relacionado con la tolerancia a la sequía y el cierre estomático además de la cantidad de agua acumulada en el sustrato (Bargali y Tewari, 2004). Según avanza el ensayo los cambios diarios en el potencial descienden, la conductancia es menor, y eso supone que hay menos cambio entre alba y mediodía (Figura 5.12A).

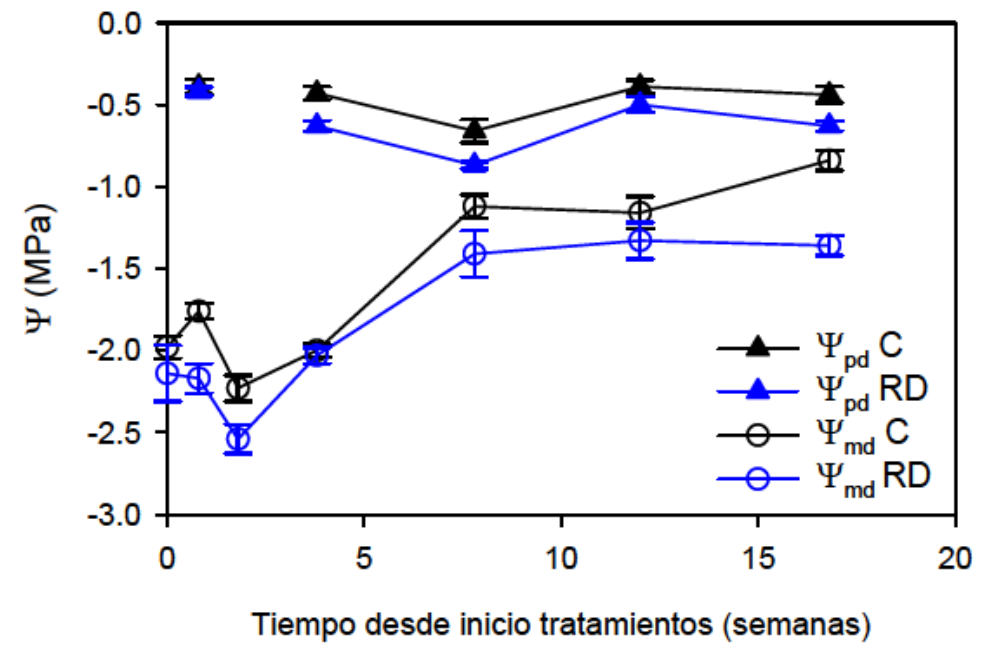

Figura 5.19- Evolución de la relación entre el potencial hídrico foliar medido antes de la fase de luz y en condiciones de máxima luminosidad en plantas de callistemon en maceta sometidas a distintos tratamientos de riego durante el período experimental en condiciones controladas.

Teniendo en cuenta el gradiente entre alba y tallo, estas diferencias son mayores en las plantas del tratamiento RD a lo largo de todo el ensayo, lo que es relacionado con una reducida conductividad hidráulica en la planta (Figura 5.20). El déficit hídrico aplicado aumentó la resistencia hidráulica de las raíces, con valores de 1.02 y $3.20 \mathrm{~g} \mathrm{MPa}$ $\mathrm{s} \mathrm{mg}^{-1}$ para el tratamiento control y deficitario, respectivamente (Tabla 
5.5). Comportamiento observado en otras especies (Sánchez-Blanco y col., 2002).

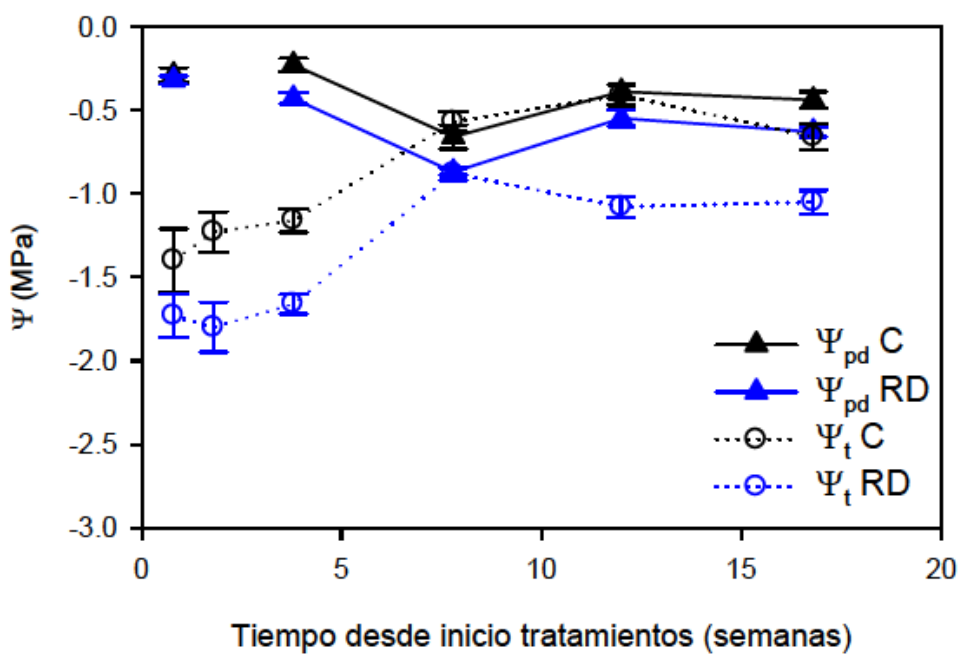

Figura 5.20- Relación entre el potencial hídrico foliar medido antes de la fase de luz y el potencial hídrico de tallo en condiciones de máxima luminosidad en plantas de callistemon en maceta sometidas a distintos tratamientos de riego durante el período experimental en condiciones controladas.

Tabla 5.5- Parámetros de relaciones hídricas derivados de las curvas presión volumen y resistencia hidráulica de las raíces $\left(1 / L_{p}\right)$ en plantas de callistemon en maceta sometidas a distintos tratamientos de riego al final del período experimental.

\begin{tabular}{|c|c|c|c|}
\hline \multirow{2}{*}{ Parámetros } & \multicolumn{2}{|c|}{ Tratamientos } & \multirow{2}{*}{$\mathbf{P}$} \\
\hline & c & RD & \\
\hline$\Psi_{\mathrm{os}}(\mathrm{MPa})$ & $-1.77 \pm 0.07$ & $-3.35 \pm 0.07$ & $\overline{* * *}$ \\
\hline$\Psi_{\mathrm{ppt}}(\mathrm{Mpa})$ & $-2.27 \pm 0.11$ & $-4.09 \pm 0.10$ & *** \\
\hline$\varepsilon(\mathrm{Mpa})$ & $8.27 \pm 0.87$ & $14.40 \pm 1.57$ & * \\
\hline $1 / L_{p}\left(g_{s} M^{2} m^{-1}\right)$ & $1.02 \pm 0.10$ & $3.20 \pm 0.44$ & ** \\
\hline
\end{tabular}

Los parámetros derivados de las curvas presión volumen para las plantas control y estresadas se representan en la Tabla 5.5. Tanto el potencial osmótico a saturación ( $\Psi_{\mathrm{os}}$ ), como el potencial en el punto de pérdida de turgencia $\left(\Psi_{\mathrm{ppt}}\right)$ descendieron considerablemente en las plantas deficitarias. La diferencia entre los valores de $\Psi_{\text {os }}$ obtenidos para las plantas control y regadas deficitariamente fueron tomados como una estimación del ajuste osmótico en las plantas del tratamiento RD (1.58 
MPa). Los valores del $\Psi_{\text {os }}$ medidos en el osmómetro (-1.67 MPa para las plantas del tratamiento control y $-3.12 \mathrm{MPa}$ para las plantas del tratamiento deficitario) fueron similares los valores estimados mediante las curvas presión volumen, lo que indica que es un método fiable. El punto de pérdida de turgencia en plantas sometidas a riego deficitario ocurrió a valores de potencial hídrico mucho más bajos (-4.09 $\mathrm{MPa})$ (Tabla 5.5).

Sin embargo, el modulo de elasticidad $(\varepsilon)$ aumentó en el tratamiento de déficit hídrico (75\%). Algunas especies muestran descensos significativos en la elasticidad de las paredes celulares y ajuste osmótico como respuesta al déficit hídrico (Álvarez y col., 2009; Sánchez-Blanco y col., 2009). 


\subsection{Efecto del riego deficitario moderado y severo en plantas de callistemon en condiciones de vivero}

\subsubsection{Material y métodos}

\subsubsection{Material vegetal y condiciones experimentales}

En esta experiencia se emplearon 80 plantas de Callistemon citrinus de 1-2 años de edad suministradas por viveros Roque, en el término municipal de Molina de Segura, provincia de Murcia. Las plantas estaban cultivadas en macetas de $14 \mathrm{~cm}$ de diámetro (Fotografía 5.12). Se utilizó material vegetal lo más homogéneo posible en el ensayo (plantas de $30 \mathrm{~cm}$ de altura).
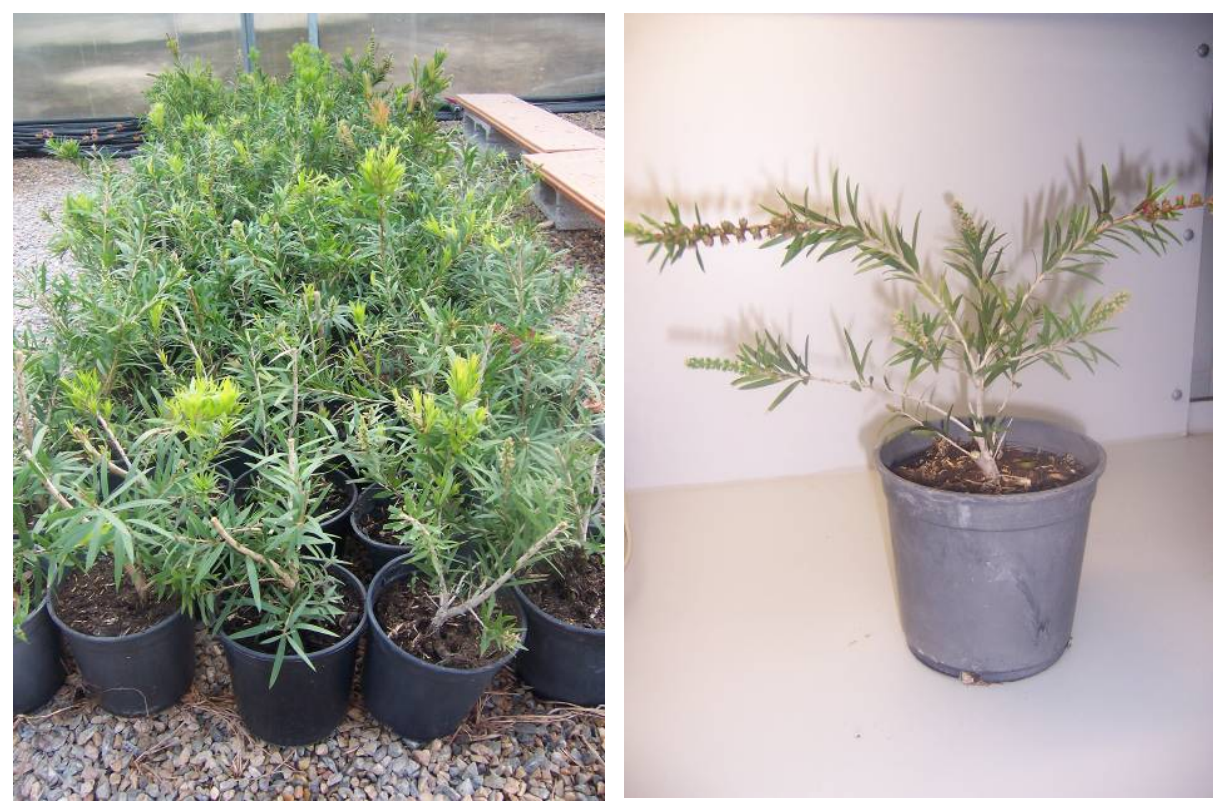

Fotografía 5.12- Recepción desde el vivero de las plantas de callistemon al inicio del ensayo.

Los ejemplares fueron transplantados el 26 de marzo de 2009 a macetas negras redondas de $20 \mathrm{~cm}$ de diámetro y $16 \mathrm{~cm}$ de altura (5 I de volumen). El sustrato fue una mezcla de fibra de coco, turba negra + turba rubia y perlita (8:7:1 en volumen) y enriquecida con un fertilizante de liberación lenta (Osmocote 5-11-22 + microelementos, a los 6 meses se volvió a echar abono) a razón de $2 \mathrm{~g} \mathrm{I}^{-1}$ de sustrato. Estas macetas fueron trasladadas al invernadero de la finca experimental del CEBAS, ubicada en Santomera (apartado 3.2.1.1), donde crecieron durante tres semanas regándose hasta completar el $100 \%$ de las necesidades 
hídricas antes de ser sometidas a los diferentes tratamientos de riego (Fotografía 5.13).

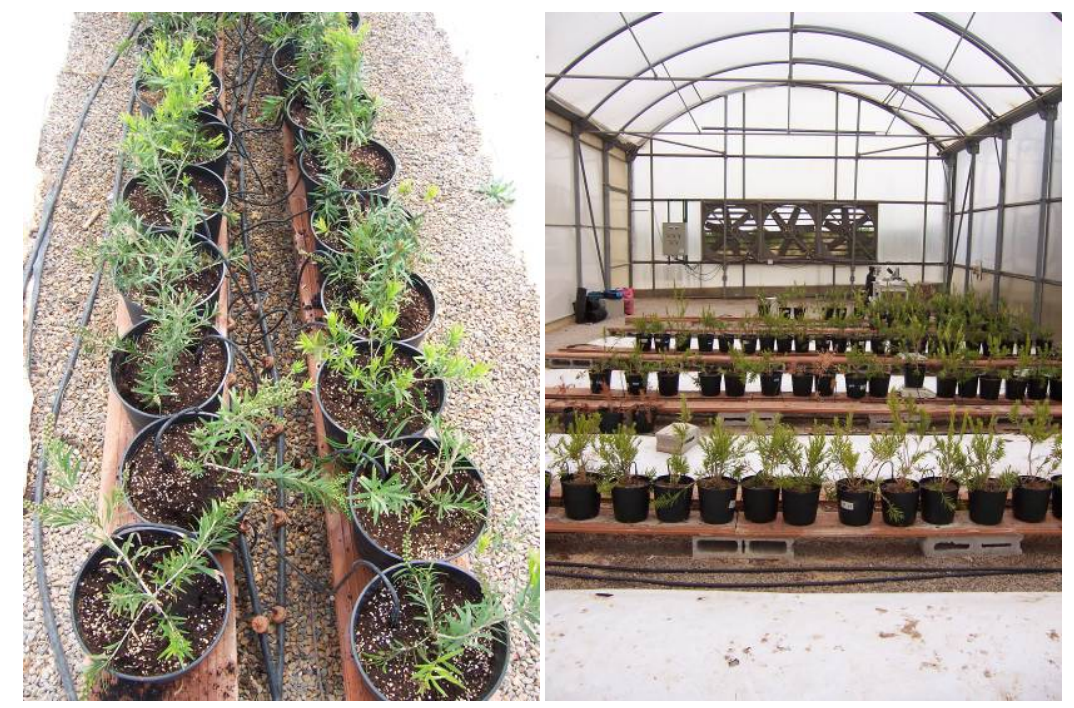

Fotografía 5.13- Vista general del invernadero al inicio del ensayo.

El experimento se llevó a cabo de marzo de 2009 a abril de 2010. Las condiciones climáticas fueron registradas con un medidor de datos (apartado 3.2.1.1), (Fotografía 5.14). Las condiciones de temperatura y humedad a lo largo del ensayo se reflejan en la Figura 5.21. La temperatura media de las máximas fue de $25.6{ }^{\circ} \mathrm{C}$, la media de las mínimas fue de $14.8^{\circ} \mathrm{C}$ y la temperatura media durante todo el periodo experimental fue de $19.3^{\circ} \mathrm{C}$. Con los datos de temperatura y humedad relativa se calcularon los valores de déficit de presión de vapor (DPV) (Figura 5.22).

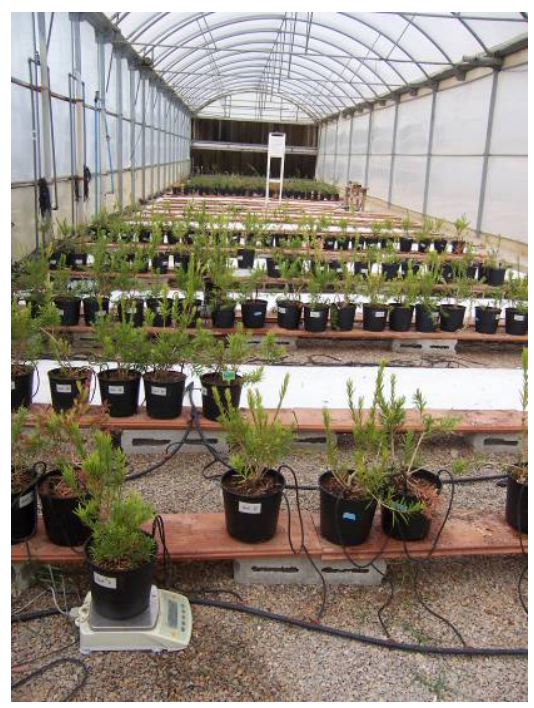

Fotografía 5.14- Hobo en el interior del invernadero que registra datos de temperatura y humedad relativa. 

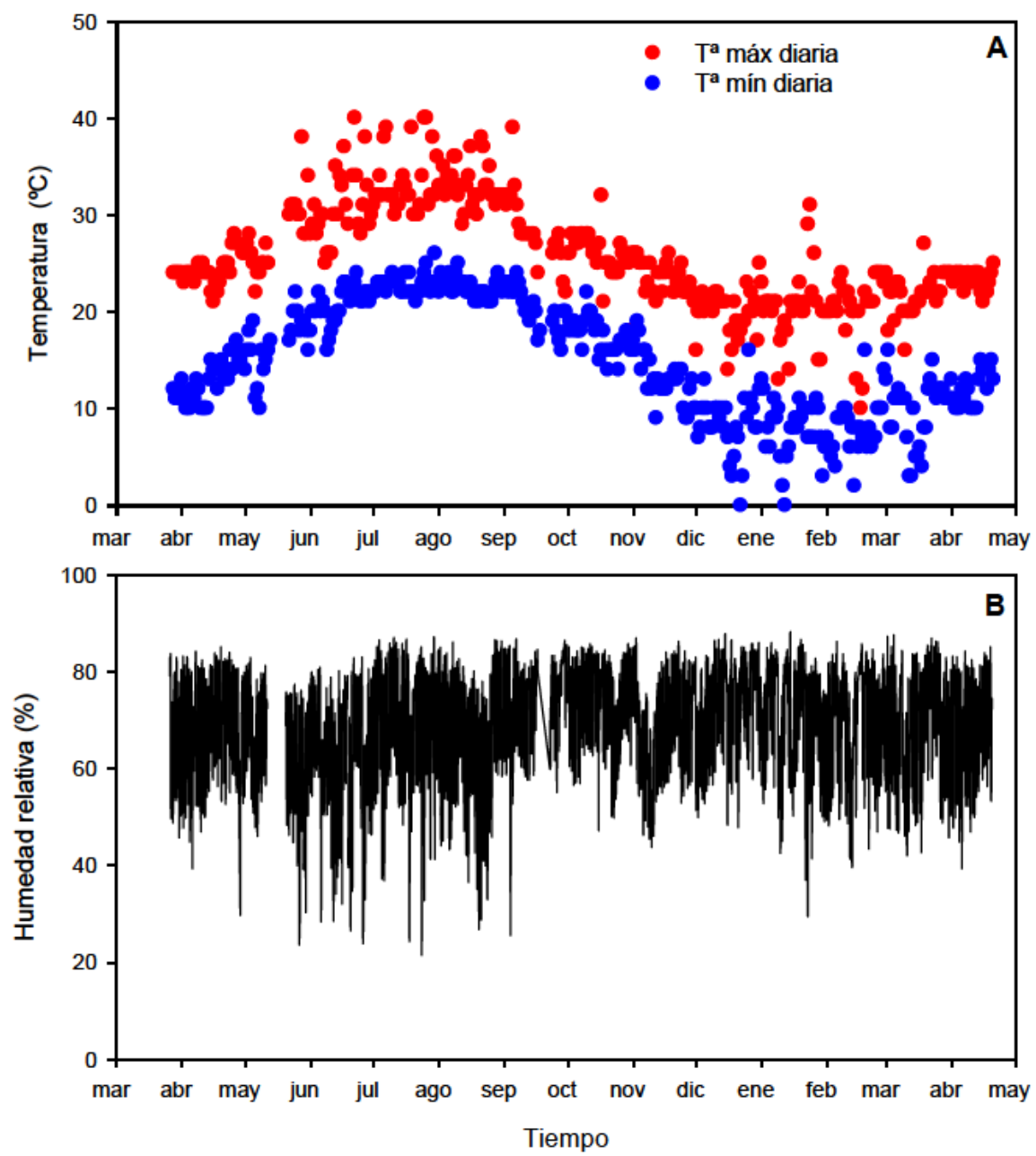

Figura 5.21- Evolución de la temperatura máxima y mínima diaria $(A)$ y humedad relativa cada 30 minutos (B) a lo largo del período experimental en invernadero

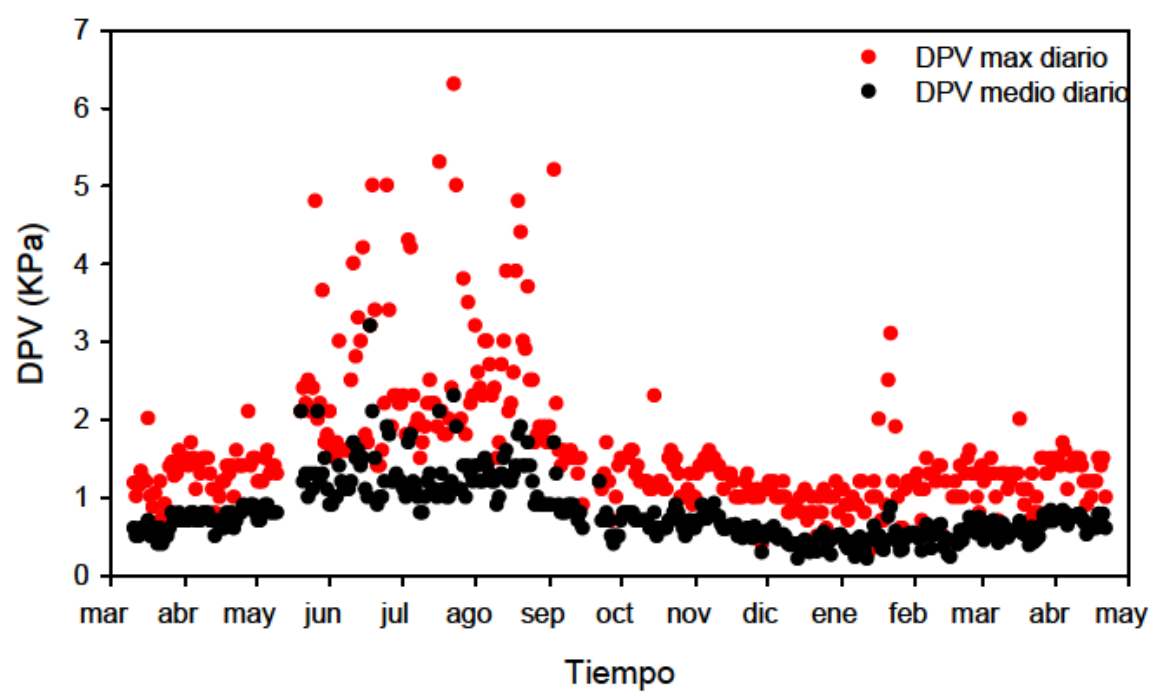

Figura 5.22- Evolución del déficit de presión de vapor (DPV) máximo y medio diaria a lo largo del período experimental en invernadero 


\subsubsection{Tratamientos y diseño experimental}

Las plantas se repartieron en tres grupos correspondientes a los tres tratamientos de riego: Control, riego deficitario moderado (RDM) y riego deficitario severo (RDS). Las plantas del tratamiento control se regaban hasta cubrir sus necesidades hídricas, manteniendo el peso de las plantas después del riego cercano a su peso a capacidad de campo, y obteniendo drenaje después del riego, las plantas sometidas a RDM tuvieron un riego del $50 \%$ de las plantas del control, y las plantas del tratamiento RDS del $25 \%$ de la cantidad de agua aplicada a las plantas control. Los distintos tratamientos de riego se realizaron por medio del manejo del riego aplicando distintas cantidades de agua de riego, a través de goteros autocompensantes con un caudal de $2 \mathrm{I} \mathrm{h}^{-1}$. Se colocó un gotero por planta con dos microtubos (Fotografía 5.15).

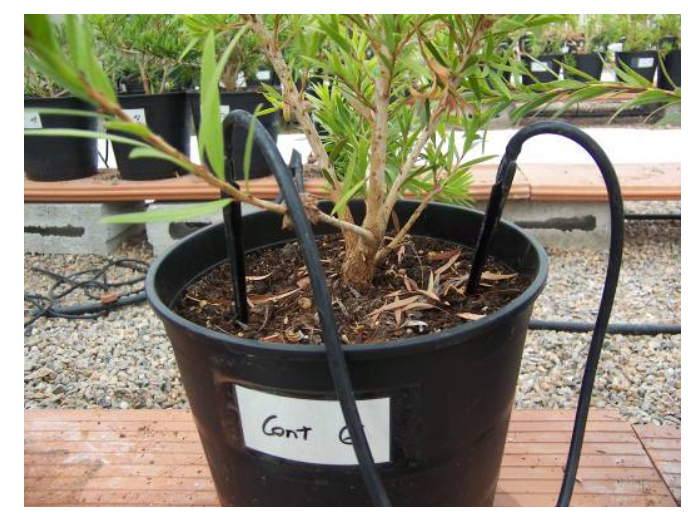

Fotografía 5.15- Detalle de la planta de callistemon con gotero con dos microtubos.

El ensayo duró 53 semanas desde el inicio de los tratamiento y las plantas eran regadas diariamente mediante un sistema automático de riego programable, el tiempo de riego se modificaba según la climatología y el desarrollo de las plantas, buscando aplicar la cantidad de agua necesaria para obtener alrededor de un $20-25 \%$ de drenaje después de cada riego tomando como referencia las plantas control. El

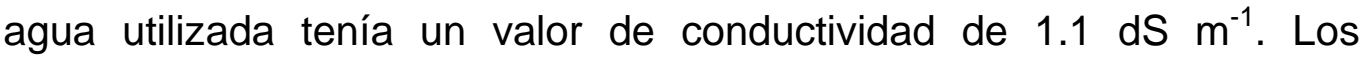
drenajes se recogieron periódicamente por medio de bandejas de plástico, debajo de 12 macetas. No se produjo drenaje en las plantas de los tratamientos deficitarios. 


\subsubsection{Crecimiento y parámetros ornamentales}

Para la evaluación del crecimiento en biomasa seca de los distintos órganos de la planta, al inicio y al término del ensayo, se realizó un muestreo en 10 plantas por tratamiento (apartado 3.2.1.3), (Fotografía 5.16). En estas plantas también se midió el área promedio del limbo foliar (apartado 3.2.1.3) y se determinó el diámetro del tallo al final del ensayo.

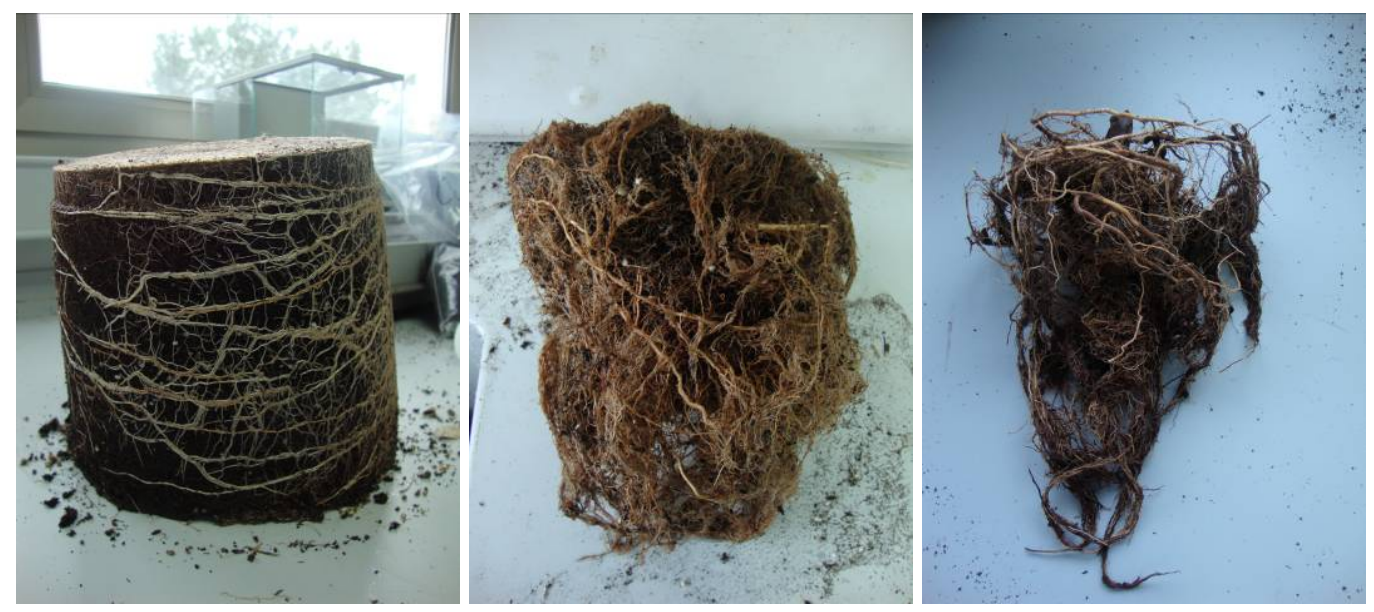

Fotografía 5.16- Retirada del sustrato de las raíces en plantas de callistemon al final del período experimental.

Con los datos del aumento de biomasa, se calcularon los siguientes índices de crecimiento: SLA, (Specific Leaf Area o área especifica foliar), LWR (Leaf Weight Ratio o la inversa de SLA) y LAR (Leaf Area Ratio o relación de superficie foliar).

SLA, que indica la relación entre el área y el peso foliar, se calculó mediante la expresión: SLA= área foliar /PS hojas, LWR, que informa de la fracción de la biomasa total invertida en las hojas y se calcula de acuerdo con la expresión: LWR= PS hojas/ área foliar y LAR, que refleja el tamaño de la superficie fotosintética con relación a la masa respiratoria y se calculó mediante la fórmula: LAR= área foliar/ PS total. 


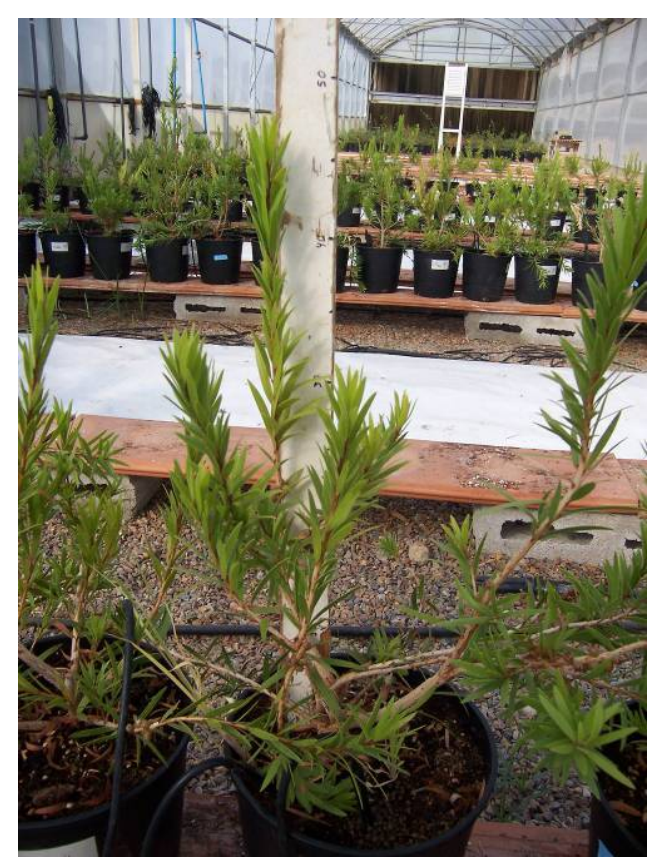

Fotografía 5.17- Medida de la altura en plantas de callistemon en invernadero.

Periódicamente, cada 1-2 semanas según la intensidad del periodo activo de crecimiento, se midió la altura máxima de la planta en 25 plantas por tratamiento (Fotografía 5.17).

A lo largo del ensayo se realizó también un seguimiento de la floración en 25 plantas por tratamiento. Se midió el número de inflorescencias por planta durante todo el período experimental, se tenían en cuenta las inflorescencias desde que se observaban los estambres hasta que éstos se caían (Fotografía 5.18). 

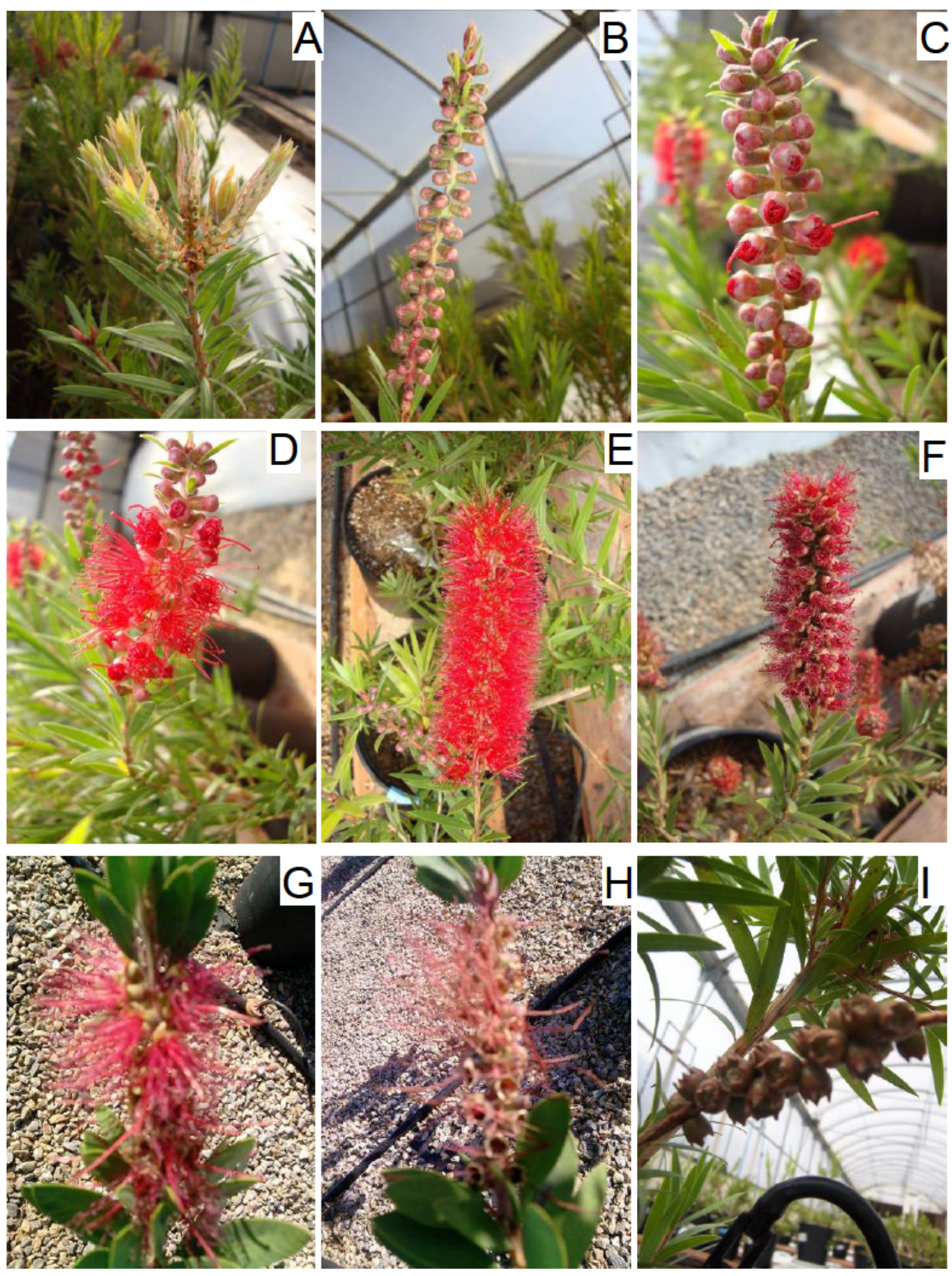

Fotografía 5.18- Evolución de las inflorescencias. En el seguimiento de la floración (número de inflorescencias por planta), se tenían en cuenta cuando las inflorescencias se encontraban entre las fases $\mathrm{C}$ y $\mathrm{G}$ (incluidas).

Al final del ensayo se determinaron los parámetros relacionados con el color y el contenido relativo de clorofila (CRC) en hojas, 10 plantas por tratamiento (Fotografía 5.19). La descripción de las coordenadas de color y la medida de CRC se explica detalladamente en el apartado 3.2.1.3. 


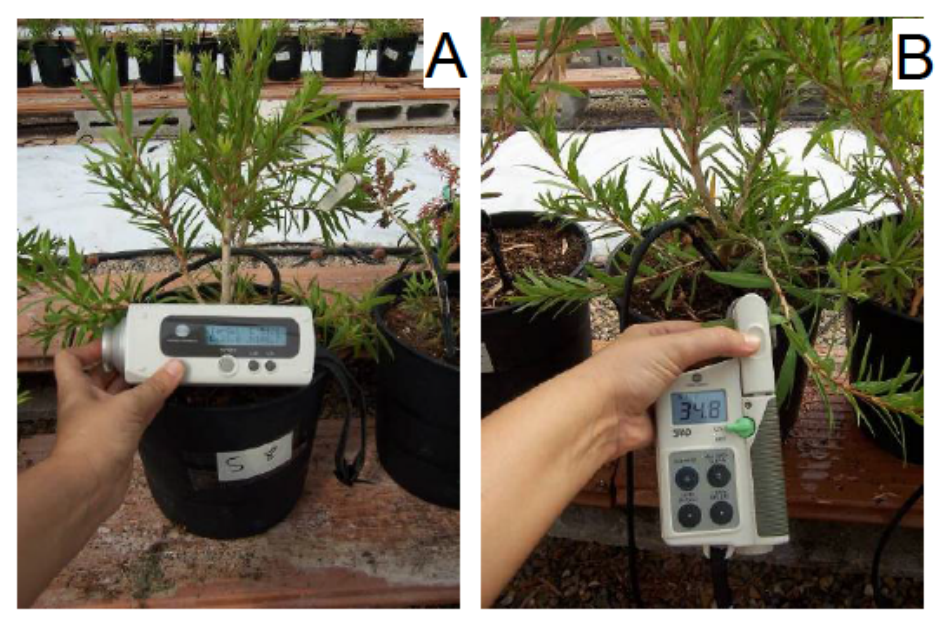

Fotografía 5.19- Medida del color y de la clorofila en hojas de callistemon al final del período experimental en invernadero.

\subsubsection{Riego, humedad volumétrica y consumo}

El riego o agua aportada se calculó en función del tiempo de riego y teniendo en cuenta el caudal nominal del emisor.

Para el cálculo de la humedad volumétrica, se hizo un seguimiento del peso de 7 macetas de cada tratamiento antes y después del riego, en estas macetas se obtuvo el volumen y el peso seco del sustrato. Para calcular la cantidad de agua de cada maceta, a cada medida de peso fresco en campo se le restaba el peso de la maceta vacía, el peso seco del sustrato y el peso fresco de la planta estimado en función del peso fresco al inicio y al final y el tiempo transcurrido desde el inicio del ensayo. Al inicio del ensayo se hizo una prueba para determinar el contenido en humedad de este sustrato a capacidad de campo, que correspondió al $60 \%$ de humedad volumétrica. La determinación de la máxima capacidad de retención de agua del sustrato se realizó de acuerdo el apartado 5.2.1.2 de esta memoria. 


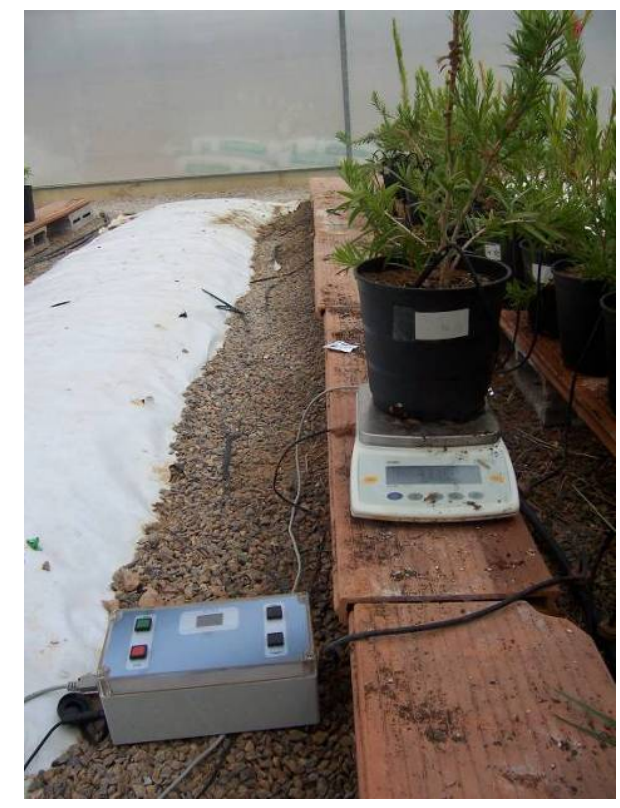

Fotografía 5.20- Maceta sobre la balanza unida a mitra que registra los valores del peso cada 30 minutos.

Además, había dos balanzas conectadas a dos mitras que registraban cada 30 minutos el peso de una maceta del tratamiento control y otra maceta del tratamiento RDS durante todo el período experimental (Fotografía 5.20). El consumo diario por planta en estas macetas se calculó como pérdida de peso entre dos riegos consecutivos (peso después del riego menos peso antes del riego del día siguiente). La evolución del consumo a lo largo del día en plantas del tratamiento control y RDS se determinó por diferencia de pesos entre dos medidas consecutivas, 30 minutos.

\subsubsection{Potencial hídrico e intercambio gaseoso}

Se midió periódicamente el potencial hídrico foliar $\left(\Psi_{\mathrm{h}}\right)$ y el potencial hídrico de tallo $\left(\Psi_{\mathrm{t}}\right)$ (apartado 5.2.1.6), (Fotografía 5.21 y Fotografía 5.22). La conductancia estomática y la tasa de fotosíntesis neta se determinaron los mismos días de medida de los potenciales y según la metodología explicada en el apartado 3.2.1.4 (Fotografía 5.23). Estas medidas se realizaron al mediodía solar en 6 plantas por tratamiento. 

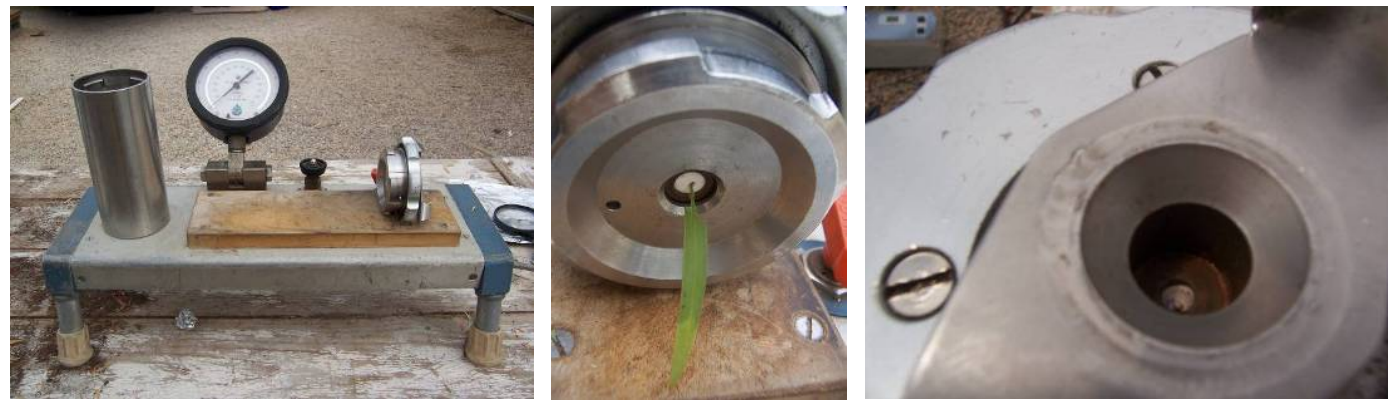

Fotografía 5.21- Medida del potencial hídrico foliar con la cámara de presión.

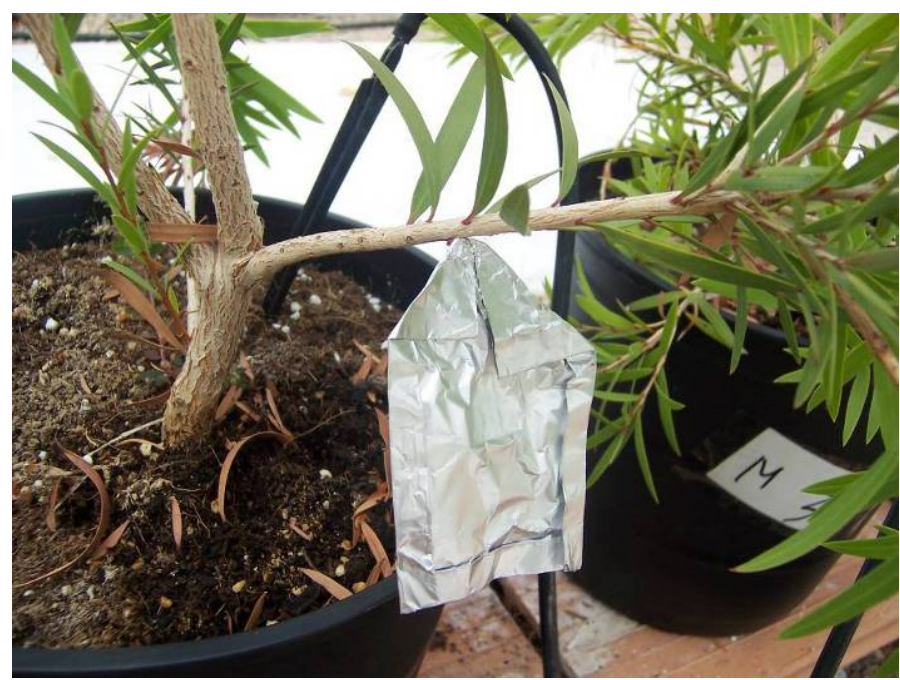

Fotografía 5.22- Detalle de hoja previamente tapada para la medida del potencial hídrico de tallo.

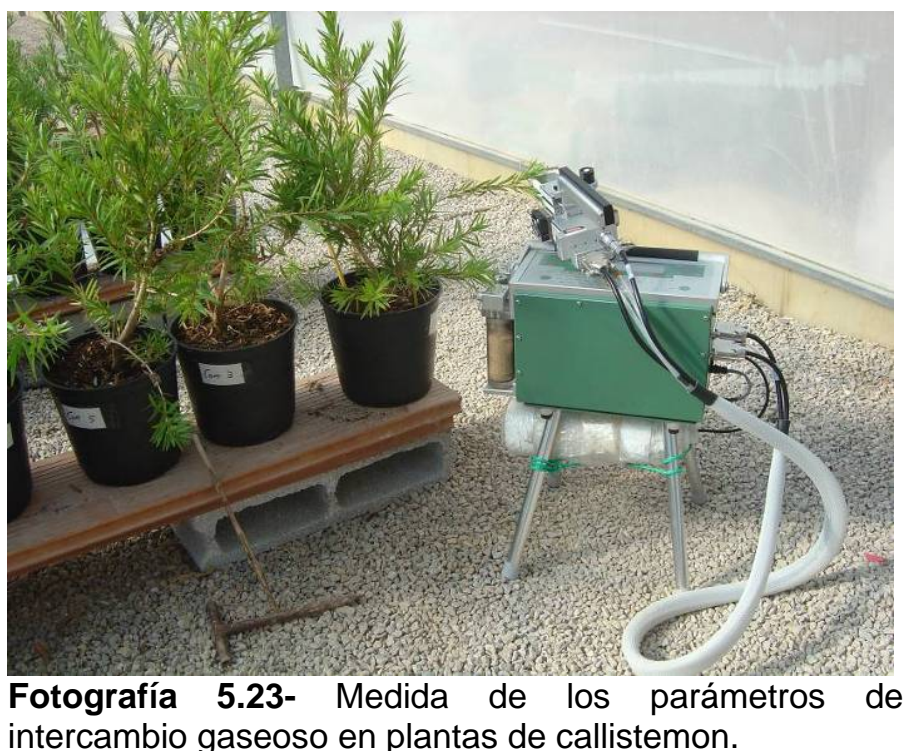

\subsubsection{Análisis estadístico}

La significación de los efectos de la dosis de riego fue analizada mediante un análisis de varianza simple (ANOVA), usando Statgraphics Plus para Windows. Las medias de los tratamientos fueron separadas con la Prueba de Rango Múltiple de Duncan $(P<0.05)$. Antes del análisis 
estadístico, cocientes y datos en porcentajes fueron previamente transformados mediante una transformación arcoseno raíz cuadrada, para asegurar la homogeneidad de la varianza.

\subsubsection{Resultados y discusión}

\subsubsection{Efectos del riego deficitario moderado y severo en el crecimiento y parámetros ornamentales en plantas de callistemon en invernadero}

La reducción de los parámetros foliares (peso seco hoja, numero de hojas totales y área foliar) de las plantas regadas deficitariamente fue, por lo general, significativa y proporcional al nivel de déficit aplicado (Tabla 5.6), (Fotografía 5.24). El RD disminuyó el diámetro tallo, suculencia, área limbo de igual manera en ambos tratamientos deficitarios. Mientras que el PS del tallo, aéreo, raíz y total sólo se vio reducido en las plantas sometidas a RD severo. El cociente PS hojas/PS raíz aumenta proporcional al déficit hídrico. Según Mugnai y col. (2009) en plantas de callistemon, el RD reduce la altura de la planta, el peso seco y el área foliar.

Tabla 5.6- Crecimiento y desarrollo aéreo en plantas de callistemon en maceta sometidas a distintos tratamientos de riego al final del período experimental en invernadero.

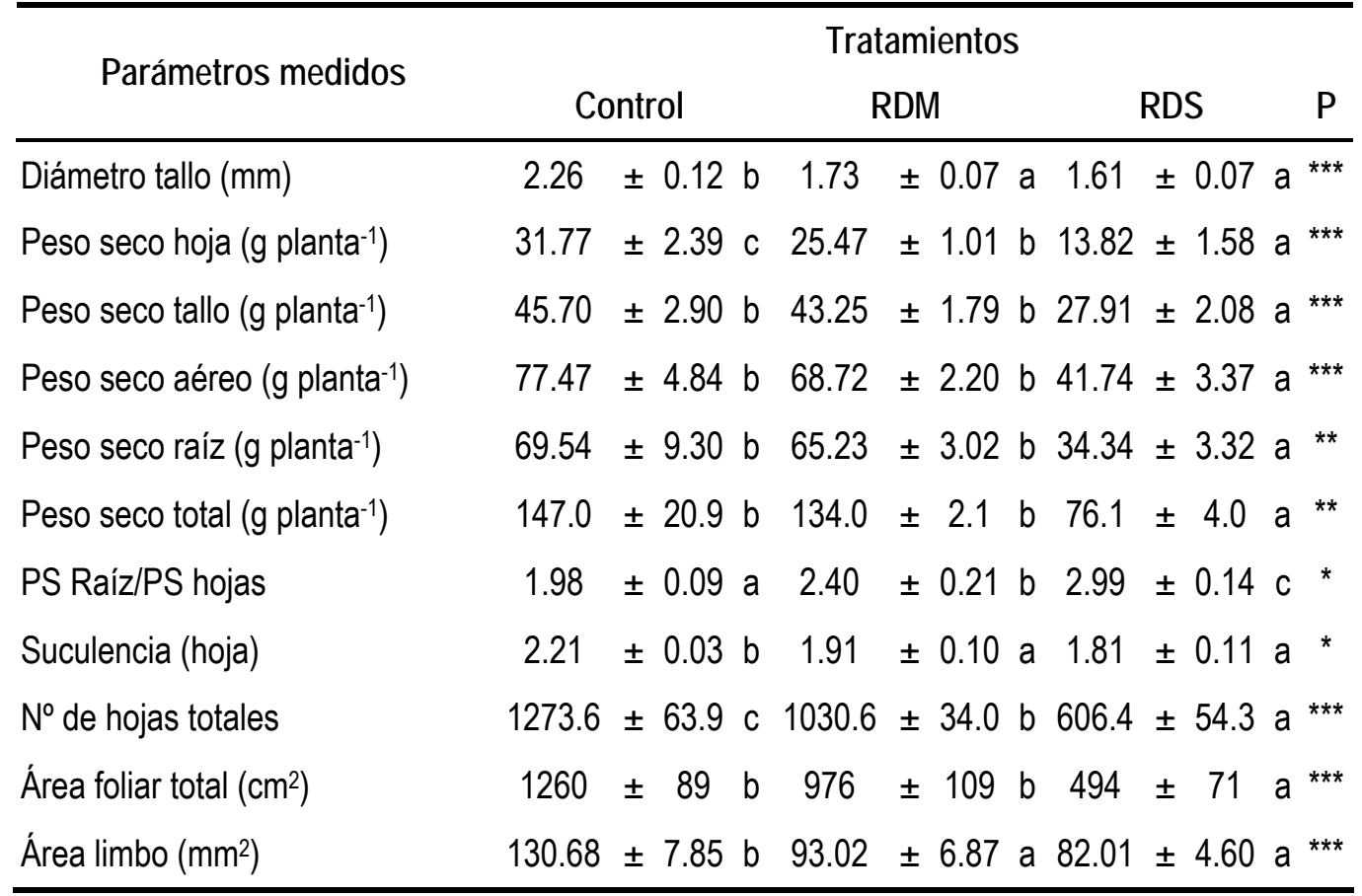

Distintas letras dentro de una misma fila indican diferencias significativas según el test de Duncan. (P: nivel de significación, ${ }^{\star} P<0.05$, ${ }^{\star *} P<0.01$, ${ }^{* \star} P<0.001$ ). 


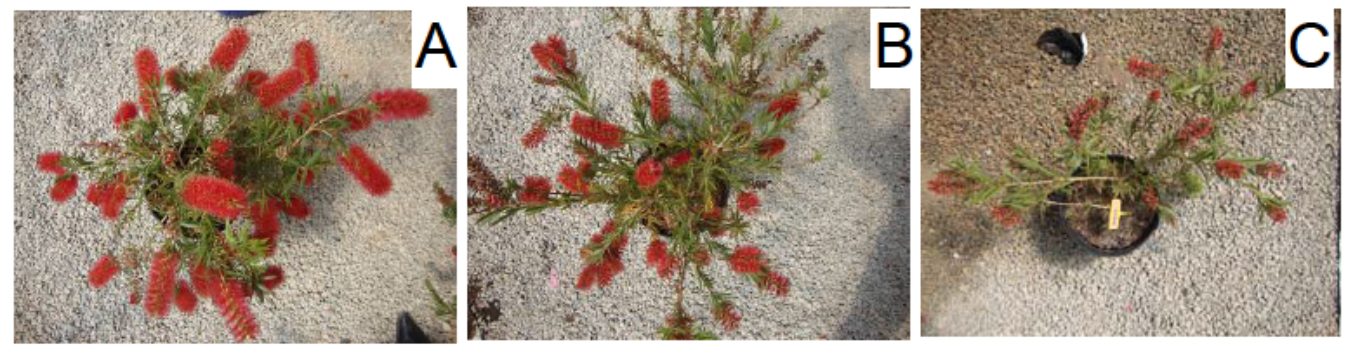

Fotografía 5.24- Desarrollo de las plantas de callistemon al período experimental en invernadero. Plantas sometidas a tratamiento control (A), RDM (B) y RDS (C).

Algunas variables que analizan el crecimiento se muestran en la Tabla 5.7. El área especifica foliar (Specific Leaf Area, SLA), expresa la conversión de la biomasa creada que se invierte en superficie de nuevas hojas, este parámetro es fundamental en la modelización de los cultivos. En los tratamientos deficitarios, SLA tuvo los valores más bajos, más materia seca foliar por unidad de área foliar o menos superficie foliar por cada unidad de peso seco de hojas, las plantas sometidas a RD reducen la superficie evaporativa con hojas más gruesas. Estos resultados han sido aportados por Rodríguez y col. (2005) en plantas de Asteriscus maritimus y por Bacelar y col. (2006) en olivo, sometidas a estrés hídrico. La inversa de la SLA conocida como LWR (Leaf Weight Ratio) también se utilizada para conocer como se redistribuyen los asimilados. En este caso, los valores más altos correspondieron a las plantas deficitarias (Tabla 5.7). La relación de superficie foliar (LAR, Leaf Area Ratio) expresa la cantidad de biomasa que la planta invierte en área foliar. Si calculamos este índice en relación al peso seco total de la planta, la relación de superficie foliar (LAR) no existen diferencias entre los tratamientos.

Tabla 5.7- Índices de crecimiento en plantas de callistemon en maceta sometidas a distintos tratamientos de riego al final del periodo experimental en invernadero.

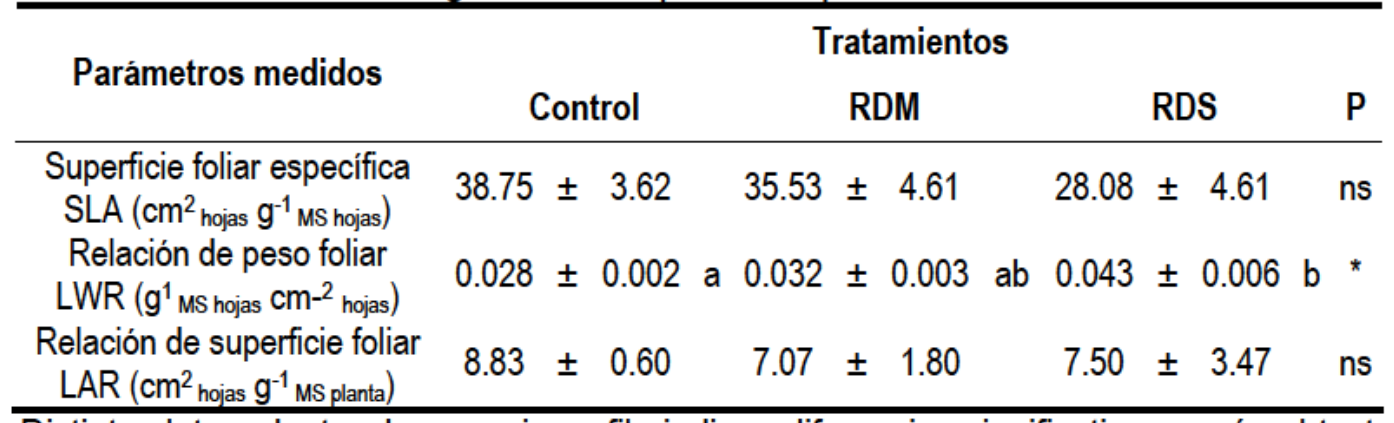

Distintas letras dentro de una misma fila indican diferencias significativas según el test de Duncan ( $P$ : nivel de significación, ns: nivel de significación, ${ }^{*} \mathrm{P}<0.05$ ). 
Respecto a la eficiencia productiva en el uso del agua, las plantas sometidas a RD fueron más eficientes, obtuvieron más peso seco de cada parte de la planta (hojas, tallo, y raíz) por cada litro de agua aportada (Tabla 5.8), (Álvarez y col., 2011). Esta respuesta fue independiente del nivel de estrés. En el aumento del área foliar, las plantas estresadas de ambos tratamientos también aumentaron la eficiencia con respecto a las plantas que no tenían limitado su aporte hídrico, pero en este caso, las plantas del tratamiento RDS aumentaron su eficacia con respecto a las plantas del tratamiento RDM.

Tabla 5.8- Eficiencia productiva del uso de agua en plantas de callistemon en maceta sometidas a distintos tratamientos de riego al final del periodo experimental en invernadero.

\begin{tabular}{|c|c|c|c|c|c|}
\hline \multirow{2}{*}{ Parámetros medidos } & \multicolumn{5}{|c|}{ Tratamientos } \\
\hline & Control & & RDM & RDS & $\mathbf{P}$ \\
\hline Hojas ( $\Delta$ mg hoja l-1 agua) $^{-1}$ & $18.80 \pm 1.52$ & a 31.30 & \pm 1.35 b 29.04 & $\pm 3.93 b$ & ** \\
\hline Tallo ( $\Delta \mathrm{mg} / \mathrm{l})$ & $27.77 \pm 1.84$ & a 55.45 & \pm 2.40 b 64.64 & $\pm 5.19 b$ & *** \\
\hline Aéreo $(\Delta \mathrm{mg} / \mathrm{l})$ & $46.57 \pm 3.07$ & a 86.76 & \pm 2.95 b 93.67 & $\pm 8.40 \quad b$ & $* * *$ \\
\hline Raíz ( $\Delta \mathrm{mg} / \mathrm{ll})$ & $41.41 \pm 5.91$ & a 81.82 & \pm 4.70 b 66.45 & $\pm 11.12 a b$ & * \\
\hline Total $(\Delta \mathrm{mg} / \mathrm{l})$ & $95.57 \pm 13.28$ & 8 a 170.19 & \pm 3.34 b 150.90 & $\pm 13.06 b$ & ** \\
\hline Área foliar $\left(\Delta \mathrm{mm}^{2} / l\right)$ & $2.46 \pm 0.23$ & a 4.78 & \pm 0.62 b 7.00 & $\pm 1.15 \mathrm{c}$ & ** \\
\hline
\end{tabular}

Distintas letras dentro de una misma fila indican diferencias significativas según el test de Duncan. ( $P$ : nivel de significación, ${ }^{*} P<0.05$, ${ }^{\star *} P<0.01$,

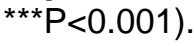

Si atendemos a la evolución de la altura de la planta, independientemente del tratamiento, se observan tres períodos de crecimiento, uno al inicio del ensayo, otro en agosto y otro al final en marzo (Figura 5.23). 

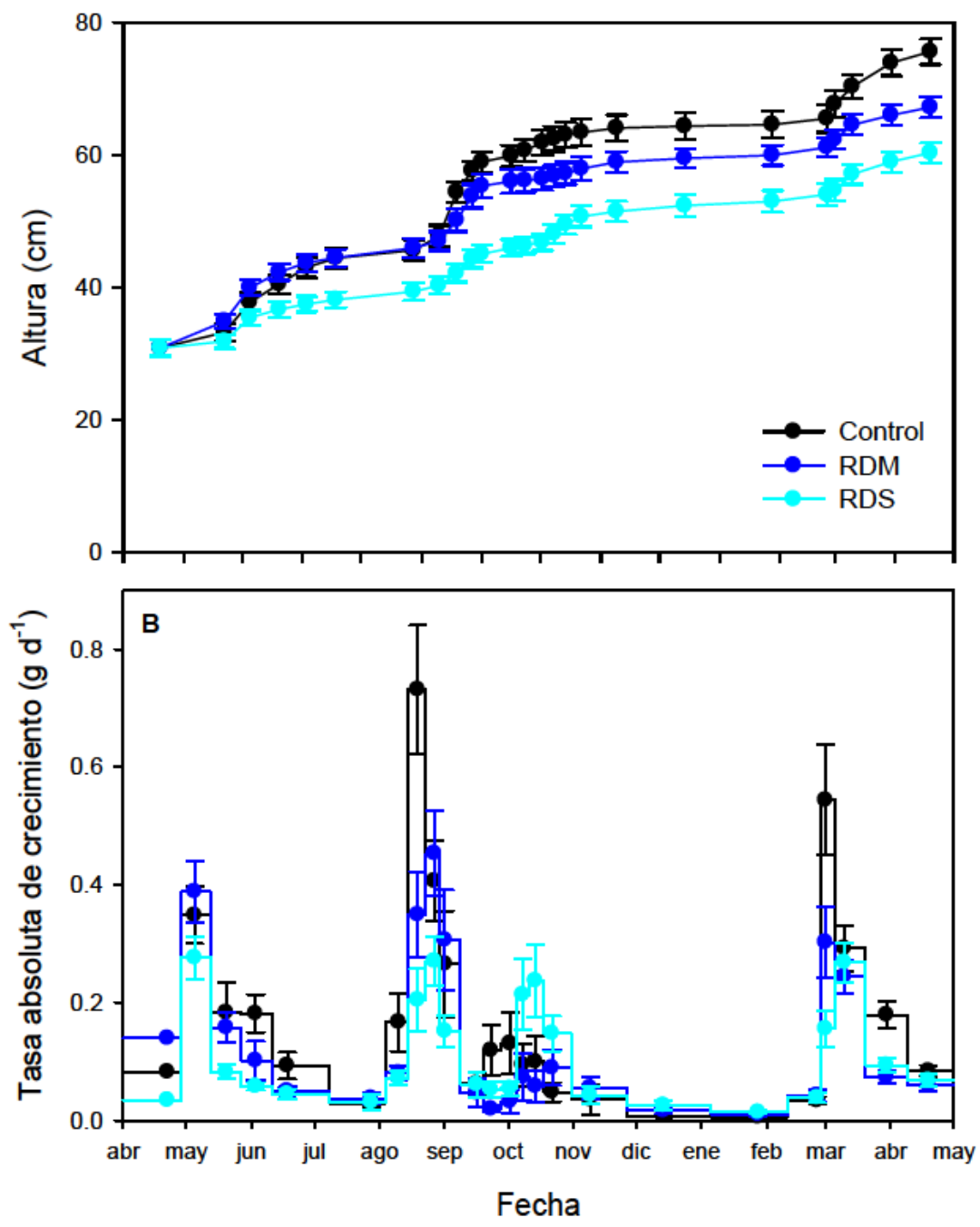

Figura 5.23- Evolución de la altura (A) y tasa absoluta de crecimiento (B) en plantas de callistemon en maceta sometidas a distintos tratamientos de riego durante el período experimental en invernadero.

La reducción de la altura media fue significativa en las plantas del tratamiento de riego deficitario severo desde el inicio del ensayo, a partir de la semana 3 desde la aplicación de los tratamientos, en el primer período de crecimiento (mayo). Las plantas del tratamiento RDM no alteraron su altura comparadas con las plantas control hasta finales de Septiembre, tras el segundo período de crecimiento, semana 23 desde el inicio de los tratamientos. Al final del ensayo se encontraron diferencias en todos los tratamientos, presentando el tratamiento control las plantas más altas $(75 \mathrm{~cm})$ y el tratamiento de riego deficitario más severo las más bajas $(60 \mathrm{~cm}$ ) (Fotografía 5.25). En este momento, las plantas del tratamiento RDM y RDS alcanzaron un 89 y $78 \%$ de la altura de las plantas control. 


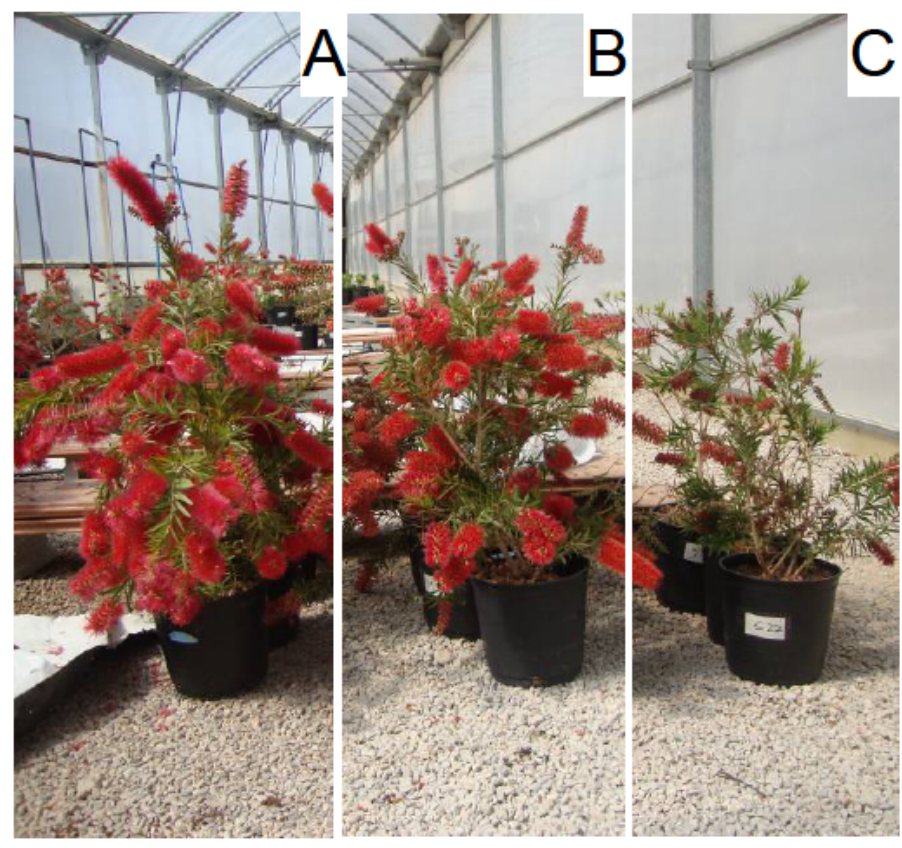

Fotografía 5.25- Efecto de los tratamientos de riego en la altura de las plantas de callistemon al final del ensayo en invernadero, planta del tratamiento control (A), RDM (B) y RDS (C).

Atendiendo a la tasa de crecimiento absoluta y relativa de la altura de la planta observamos al final del primer período de crecimiento, una caída significativa en las plantas de ambos tratamientos deficitarios, lo mismo sucede en el segundo periodo de crecimiento (Agosto), en el que las plantas regadas deficitariamente tienen una tasa de crecimiento menor. En las plantas que recibían menos riego (RDS) se produce una pequeña recuperación de la tasa de crecimiento en el mes de Octubre, situación no observada en el resto de las plantas. El efecto del déficit hídrico fue significativo en este parámetro, comportamiento que se ha podido observar en condiciones controladas en esta especie y en otras especies ornamentales (Sánchez-Blanco y col., 2009; Álvarez y col., 2011). Aunque no demasiado si tenemos en cuenta la drástica reducción del riego con respecto al control (50 y 75\%).

Las plantas presentaron flores prácticamente durante todo el ensayo, aunque es al final del ensayo cuando se produce la floración de mayor intensidad (Figura 5.24). Debido a este comportamiento, no pudimos aplicar la estrategia de RDC. 
En nuestras condiciones, pocas semanas después del inicio del ensayo, la mayoría de las plantas tenía flores, con lo que se procedió al cambio del riego en las plantas del previsto RDC y se empezaron a regar en condiciones control. Esta situación se mantuvo hasta el final del ensayo, con lo que las plantas del tratamiento RDC se regaron de forma casi idéntica a las plantas del tratamiento control.

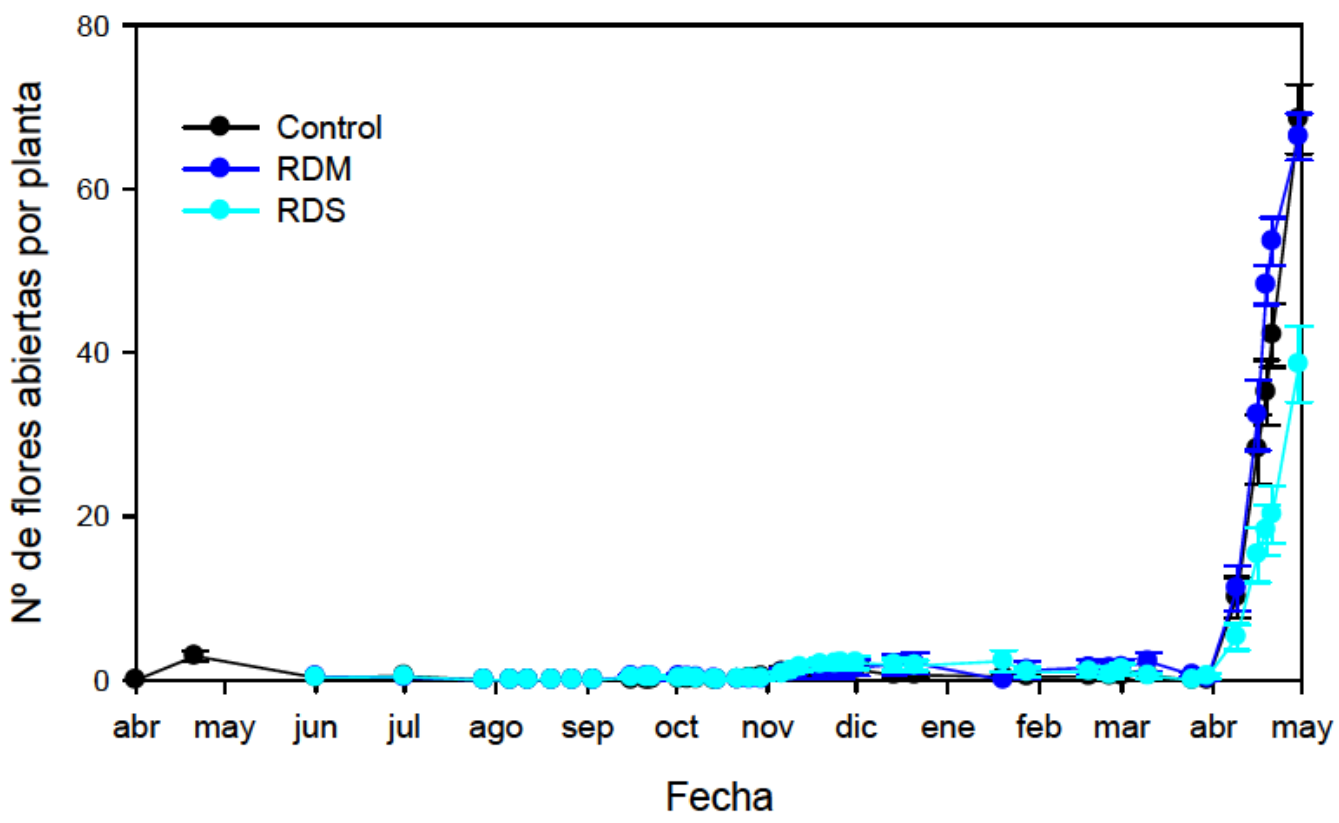

Figura 5.24- Evolución de la floración en plantas de callistemon en maceta sometidas a distintos tratamientos de riego durante el período experimental en invernadero.

Después de 54 semanas de riego deficitario se produjo un gran aumento de la intensidad de la floración (Fotografía 5.26). El riego deficitario severo redujo la floración, pero el RDM no vio reducido el numero de flores respecto a las plantas control, e incluso fue mayor en algunos momentos del ensayo. También se apreciaron visualmente diferencias en el tamaño de las flores (Fotografía 5.27). 


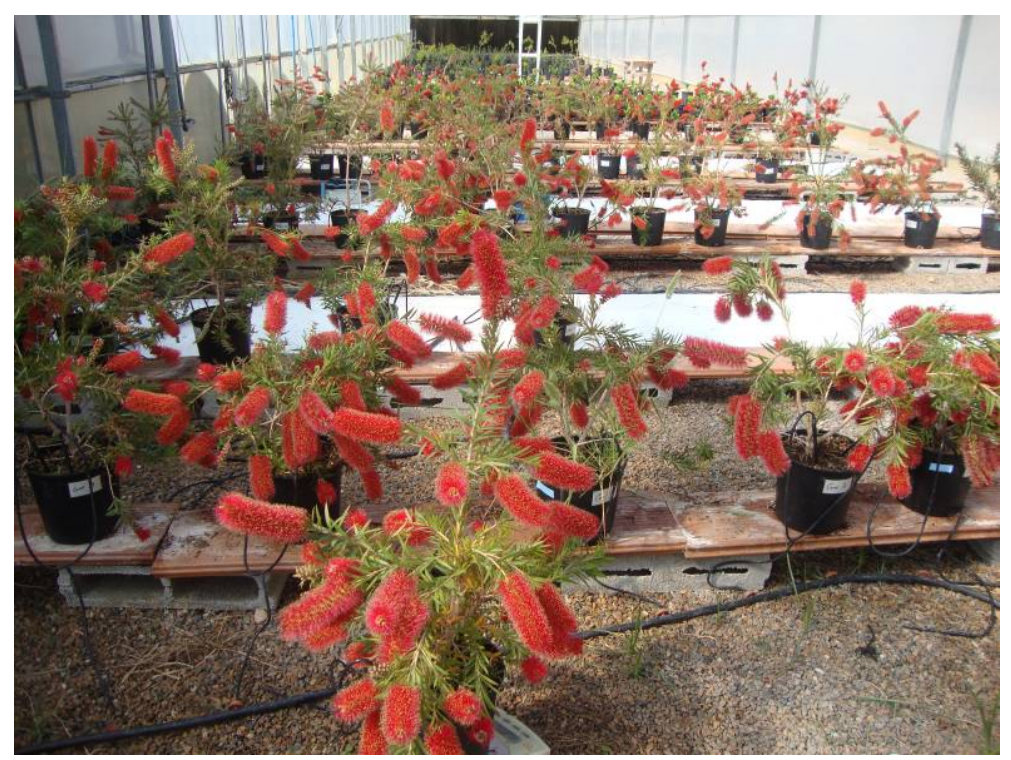

Fotografía 5.26- Estado de la floración de plantas de callistemon al final del período experimental en invernadero

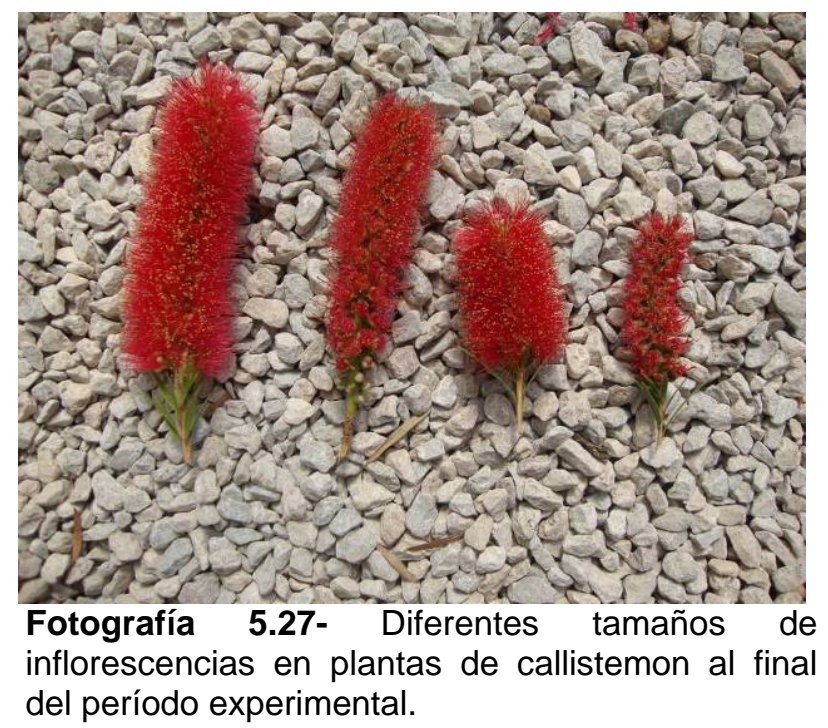

El contenido relativo de clorofila (CRC) fue mayor en las plantas del tratamiento RDS y las hojas de estas plantas presentan un mayor valor de HUE y menor valor de $\mathrm{C}$, es decir hojas más verdes pero con un color más mate, menos vivo, menos intenso que las de las plantas control (Tabla 5.9). Todo ello supone que el valor ornamental de las plantas del tratamiento RDS disminuye por producir plantas de menor calidad visual (menos flores y hojas de un color más mate). Mientras que las plantas del tratamiento RDM mantienen la intensidad de la floración y el color de las hojas a pesar de la drástica reducción del aporte hídrico. Por todo ello, podemos decir que el grado de déficit hídrico influyó en el desarrollo floral, pero que en nuestras condiciones las plantas de callistemon pueden enfrentarse a situaciones moderadamente limitantes 
de agua, sin perder su valor ornamental. No hubo diferencias en cuanto a los valores de pérdida de electrolitos (Tabla 5.10). En el ensayo anterior en cámara, el riego si afectó a este parámetro, pero pudo ser debido a que en este ensayo las plantas eran más grandes (de tamaño y de edad) y por eso no hubo daños a pesar de que las reducciones de riego fueron mayores.

Tabla 5.9- Parámetros de color (L, C y HUE) y contenido relativo de clorofila (CRC) de la hoja en plantas de callistemon en maceta sometidas a distintos tratamientos de riego al final del período experimental en invernadero.

\begin{tabular}{|c|c|c|c|c|c|c|c|c|c|c|c|c|c|}
\hline \multirow{2}{*}{\multicolumn{2}{|c|}{ Parámetro }} & \multicolumn{11}{|c|}{ Tratamientos } & \\
\hline & & \multicolumn{3}{|c|}{ Control } & & \multicolumn{3}{|c|}{ RDM } & \multicolumn{4}{|c|}{ RDS } & \\
\hline$L$ & 41.5 & \pm & 2.9 & & 44.5 & \pm & 2.1 & & 43.2 & \pm & 1.4 & & ns \\
\hline C & 17.9 & \pm & 1.8 & $b$ & 15.4 & \pm & 2.5 & b & 13.7 & \pm & 0.9 & a & * \\
\hline HUE & 108.9 & \pm & 2.1 & a & 107.2 & \pm & 2.0 & a & 118.4 & \pm & 2.9 & $b$ & * \\
\hline $\mathrm{CRC}$ & 36.14 & \pm & 0.82 & a & 37.37 & \pm & 1.48 & a & 45.80 & \pm & 1.11 & $b$ & *** \\
\hline
\end{tabular}

Distintas letras dentro de una misma fila indican diferencias significativas según el test de Duncan. ( $P$ : nivel de significación, ns: no significativo, ${ }^{*} P<0.05$, $\left.{ }^{* * *} \mathrm{P}<0.001\right)$.

Tabla 5.10- Pérdida de electrolitos en plantas de callistemon sometidas a distintos tratamientos de riego al final del período experimental en invernadero.

\begin{tabular}{lcccccccc}
\hline \multirow{2}{*}{ Parámetro } & \multicolumn{5}{c}{ Tratamientos } & & & P \\
& Control & \multicolumn{2}{c}{ RDM } & \multicolumn{2}{c}{ RDS } & \\
\hline $\mathrm{PE}(\%)$ & 29.44 & \pm 1.21 & 30.71 & \pm 1.85 & 28.74 & \pm & 0.87 & ns \\
\hline (ns: no significativo).
\end{tabular}

\subsubsection{Efectos del riego deficitario moderado y severo en la humedad del sustrato y consumo en plantas de callistemon en invernadero}

El agua total aportada a las plantas desde el inicio de los tratamientos fue de $164 \mathrm{I} \mathrm{pl}^{-1}$ para las plantas del tratamiento control, $82 \mathrm{I}$ para las plantas del RDM y 47 I para las del tratamiento RDS, que corresponde al $50 \%$ y $25 \%$ de la cantidad aportada a las plantas del control (Figura 5.25). 


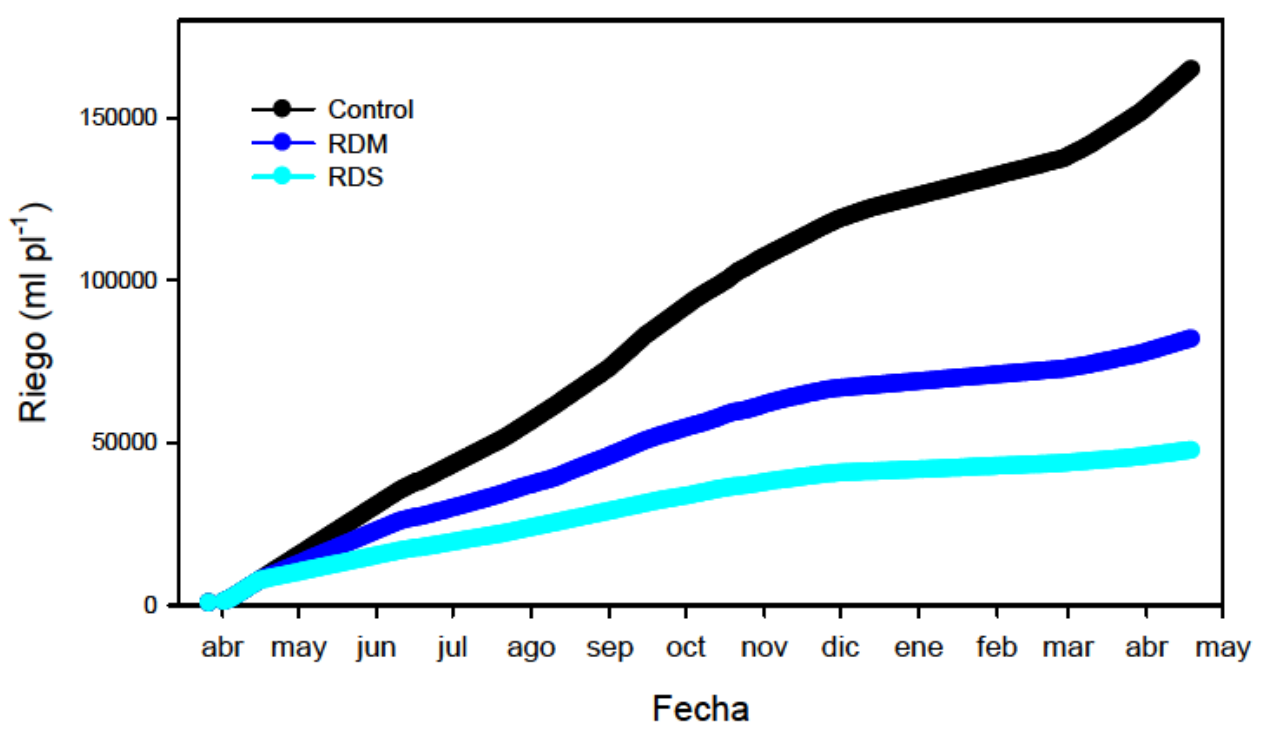

Figura 5.25- Evolución del riego acumulado en plantas de callistemon en maceta sometidas a distintos tratamientos de riego durante el período experimental en invernadero.

En la Figura 5.26 vemos la evolución de la humedad volumétrica promedio antes y después del riego de 7 macetas por tratamiento. La humedad volumétrica de las plantas control después del riego estuvo durante todo el ensayo cercana a capacidad de campo (60\%), las plantas del tratamiento RDM se mantuvieron en torno al 30\% y las de RDS se situaron cercanas al $20 \%$. Las plantas del tratamiento control son también las que presentan mayor diferencia entre los valores de humedad antes y después del riego, esto es debido a que estas plantas son las que tenían mayores tasas de evapotranspiración, el consumo o pérdida de agua era mayor que en las plantas sometidas a riego deficitario, que tenían valores de humedad más estables a lo largo del día. 


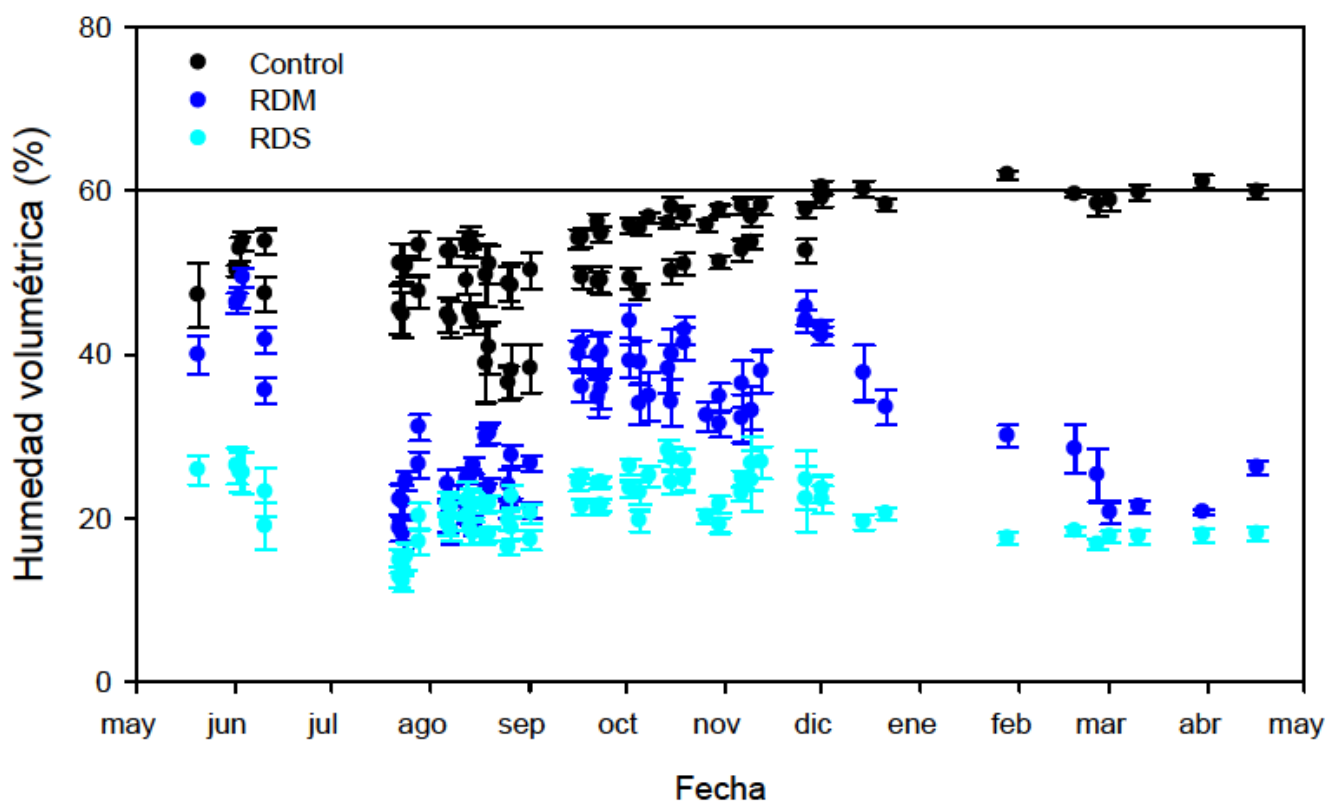

Figura 5.26- Evolución de la humedad volumétrica (antes y después del riego) en plantas de callistemon en maceta sometidas a distintos tratamientos de riego durante el período experimental en invernadero.

El consumo diario de las plantas del tratamiento control y las de RDS se muestra en la Figura 5.27. El consumo varía a lo largo del ensayo y es mayor en los meses de verano y disminuye en invierno (diciembre- enero), está estrechamente relacionado con las variables climáticas, temperatura y DPV. Aunque no sigue exactamente el mismo patrón, la máxima demanda climática ocurre en los meses de junio, julio y agosto y el máximo consumo a finales agosto, primeros de septiembre, lo que indica que además de las variables ambientales, también influyen en el consumo las fases de crecimiento activo. En la segunda quincena de agosto, coincide una alta demanda con una alta tasa de crecimiento relativo y absoluto de la planta (Figura 5.23). También el consumo de las plantas de callistemon aumenta de forma progresiva a partir de febrero hasta el final del ensayo, a pesar de que los valores de DPV en este período son similares a los registrados en los meses anteriores. Este mayor consumo es debido a un aumento en la tasa de crecimiento en altura y al período de formación de las inflorescencias, en el mes de abril hay una floración muy intensa (Figura 5.24). 


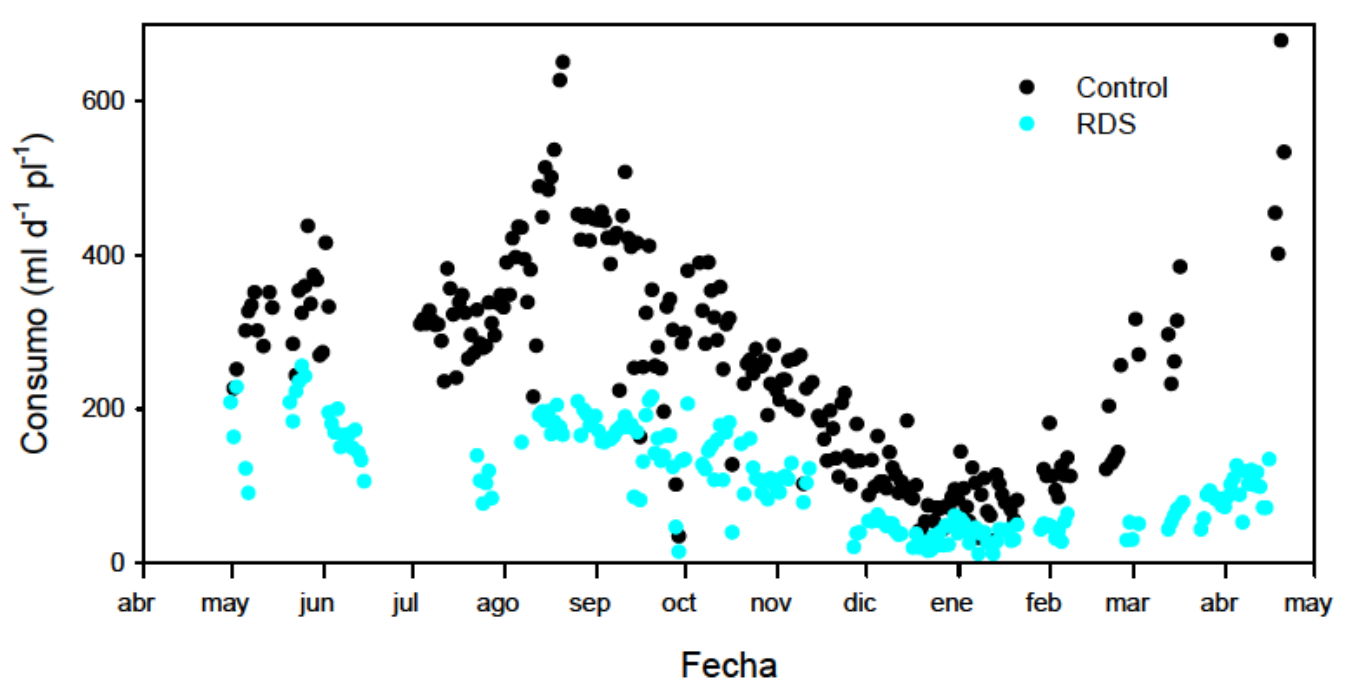

Figura 5.27- Evolución del consumo en plantas de callistemon en maceta sometidas a riego control y RDS durante el período experimental invernadero. Datos recogidos de la mitra y calculados como descenso de peso.

En la Figura 5.28 se muestra el consumo y el DPV medio diario, se puede observar como además de las condiciones climáticas, existen otros factores que afectan al consumo. En los periodos de crecimiento (primera quincena mayo, agosto y primera quincena marzo), la tasa de evapotranspiración aumenta en proporción al DPV, pero también el mes de marzo y abril, el aumento del consumo es mayor en relación al DPV, debido a que en este periodo se produce una floración muy intensa.

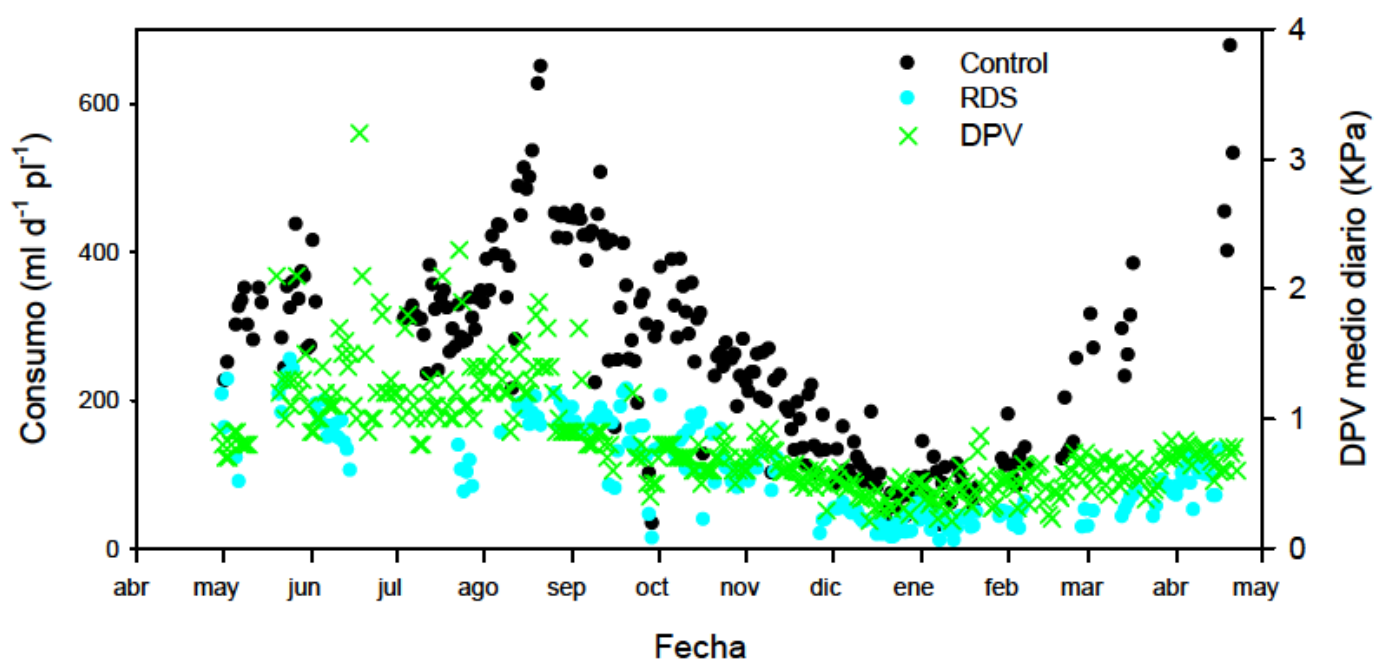

Figura 5.28- Relación del DPV medio diario y el consumo de plantas de callistemon en maceta sometidas a tratamiento control y RDS durante el período experimental en invernadero. 
Las plantas del tratamiento control tienen mayor consumo durante todo el ensayo que las plantas del tratamiento RDS, aunque estas diferencias no son iguales en todo el ensayo. Cuando el consumo el alto, estas diferencias son mayores, y cuando las tasas de evapotranspiración son bajas, los consumos son más similares entre si, no existen tantas diferencias entre las plantas de los distintos tratamientos.

El consumo horario de las plantas de callistemon a lo largo de varios días significativos está relacionado con el DPV (Figura 5.29), el cual es mínimo durante la noche y va aumentando desde el amanecer hasta alcanzar un consumo máximo en las horas centrales del día, momento en el que las condiciones ambientales son más exigentes. Aunque la tasa de evapotranspiración también está influenciada por los períodos activos de crecimiento y por la fase de formación y apertura de las inflorescencias. 

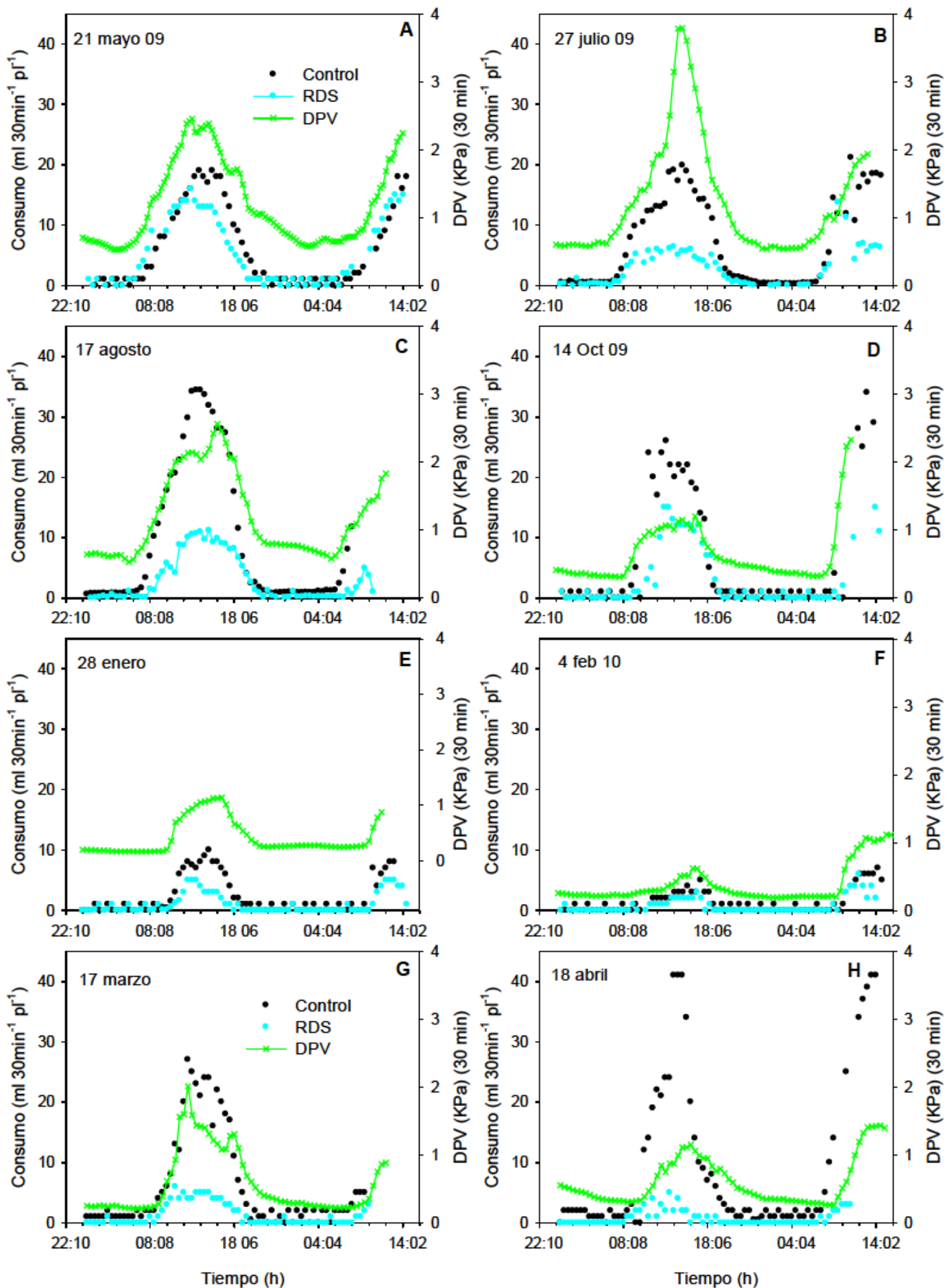

Figura 5.29- Evolución del consumo horario y su relación con el déficit de presión de vapor (DPV) en plantas de callistemon en maceta sometidas a riego control y RDS en distintos días durante el período experimental en invernadero.

La Figura 5.29B tiene un valor de DPV al mediodía cercano a 4 $\mathrm{kPa}$, sin embargo en la figura $\mathrm{C}$ el consumo de las plantas es mucho mayor, aunque el DPV máximo esta en torno a $2 \mathrm{kPa}$, ya que este momento es un periodo activo de crecimiento en altura (Figura 5.23B). La Figura $5.29 \mathrm{H}$ presenta los valores de ET más elevados a pesar de 
tener un DPV moderado, puesto que esta medida coincide con el período de formación de nuevas inflorescencias y apertura de las mismas. En la medida E había un consumo de la planta muy bajo, es un periodo en el que no se produce ni crecimiento vegetativo ni formación de brotes. Las medidas $\mathrm{B}, \mathrm{E}$ y $\mathrm{F}$ son las que tienen una tasa de crecimiento menor y el consumo está "mas bajo" que DPV, en proporción. Las figuras C, G y D son las que presentan mayor tasa de crecimiento, y el consumo está proporcionalmente más alto que el DPV. La figura $\mathrm{H}$ tiene un DPV y tasa de crecimiento relativamente bajas, pero está en fase formación brotes, por eso aumenta tanto el consumo. Esto se reflejará también en los valores de $g_{s}$ y potenciales, que veremos más adelante.

\subsubsection{Efectos del riego deficitario moderado y severo en las relaciones hídricas en plantas de callistemon en invernadero}

La evolución del potencial hídrico foliar $\left(\Psi_{h}\right)$ a mediodía a lo largo del ensayo (Figura 5.30), además del efecto de los tratamientos de riego, refleja las condiciones ambientales, con valores máximos en diciembre y los mínimos en agosto, cuando las condiciones de temperatura y DPV son mayores (Figura 5.21 y Figura 5.22). 


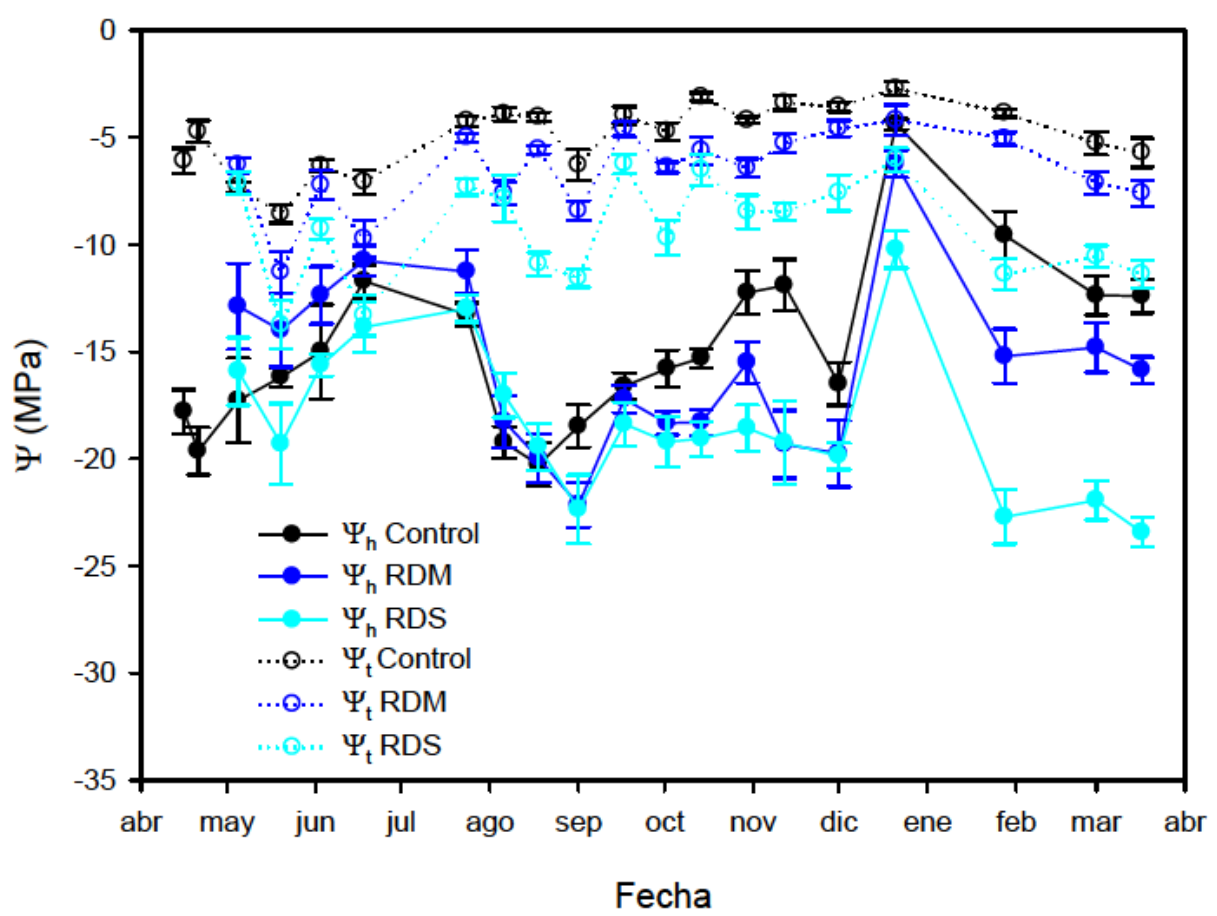

Figura 5.30- Evolución del potencial hídrico foliar $\left(\Psi_{\mathrm{h}}\right)$ y de tallo $\left(\Psi_{\mathrm{t}}\right)$ al mediodía en plantas de callistemon en maceta sometidas a distintos tratamientos de riego durante el período experimental en invernadero.

Los valores más altos de $\Psi_{\mathrm{h}}$ correspondieron a las plantas del tratamiento control seguido de las plantas que recibieron riego deficitario moderado, y los valores más bajos correspondieron a las plantas que recibieron menos agua. Las plantas con riego deficitario severo presentan valores más negativos con niveles entre -1.0 y -2.4 MPa.

A pesar de que el contenido en humedad de las plantas estuvo claramente diferenciado a lo largo del ensayo, las diferencias en el potencial hídrico foliar al mediodía al inicio del ensayo no son significativas, comienzan a serlo a partir del mes de Octubre, lo que sugiere que este parámetro no es un buen indicador del déficit hídrico en plantas de callistemon debido al efecto del riego, especialmente en épocas de alta demanda evaporativa. Ello es debido a que los efectos de las condiciones climáticas pueden enmascarar aquellos debidos a los de la aportación del agua. Así el nivel alto de transpiración en las plantas control hace que desciendan los valores de $\Psi_{\mathrm{h}}$, incluso por debajo de las plantas regadas deficitariamente. En los últimos meses del ensayo, las diferencias entre los valores de $\Psi_{\mathrm{h}}$ en los distintos tratamientos son muy marcadas. 
Los valores de $\Psi_{\mathrm{t}}$ son mayores que los medidos en hojas destapadas y mucho más estables a lo largo del ensayo (Figura 5.30), no dependen tanto de las condiciones climáticas y oscilan entre -0.3 y $0.8 \mathrm{MPa}$ en las plantas del tratamiento control, alcanzando -1.1 y -1.3 MPa en las plantas de los tratamientos RDM y RDS, respectivamente. Además, este parámetro es un buen indicador del déficit hídrico en plantas de callistemon, puesto que en todas las medidas (excepto la primera) existen diferencias significativas entre tratamientos, al igual que sucedía en el ensayo de la cámara (Álvarez y col., 2011).

Los meses de Agosto y Septiembre donde se registran unas mayores tasas de ET (Figura 5.27), las diferencias entre el $\Psi_{\mathrm{h}}$ y el $\Psi_{\mathrm{t}}$ son mayores. En diciembre, ambos potenciales son muy parecidos, en estas fechas el consumo (ET) de la planta era muy bajo en todos los tratamientos, había poca transpiración, poco flujo de agua a través de la planta.

El efecto del riego se refleja en los valores de conductancia estomática $\left(g_{s}\right)$ en las plantas de callistemon (Figura 5.31). El riego deficitario produjo una reducción de los valores de $g_{s}$ desde las primeras semanas de la aplicación de los tratamientos. Esta reducción fue más acusada en el tratamiento más deficitario y se mantuvo hasta el final del ensayo. En plantas de geranio, según Montero y col. (2001), la conductancia estomática aumenta según se incrementa la temperatura y el DPV, pero con temperaturas mayores de 30 grados o valores de DPV a partir de $1.5 \mathrm{KPa}$, estos parámetros ya no guardan relación, la conductancia se mantiene estable, no aumenta más, aunque la demanda climática sea mayor. En nuestro ensayo los valores de $\Psi_{\mathrm{h}}$ al mediodía, por lo general, son inversamente proporcionales en estos intervalos. Sin embargo, a mayores temperaturas $\left(36^{\circ} \mathrm{C}\right)$ y/o altos DPV $(3.4 \mathrm{kPa})$, las plantas reducen su apertura estomática y los valores de $\Psi$ no descienden más. 


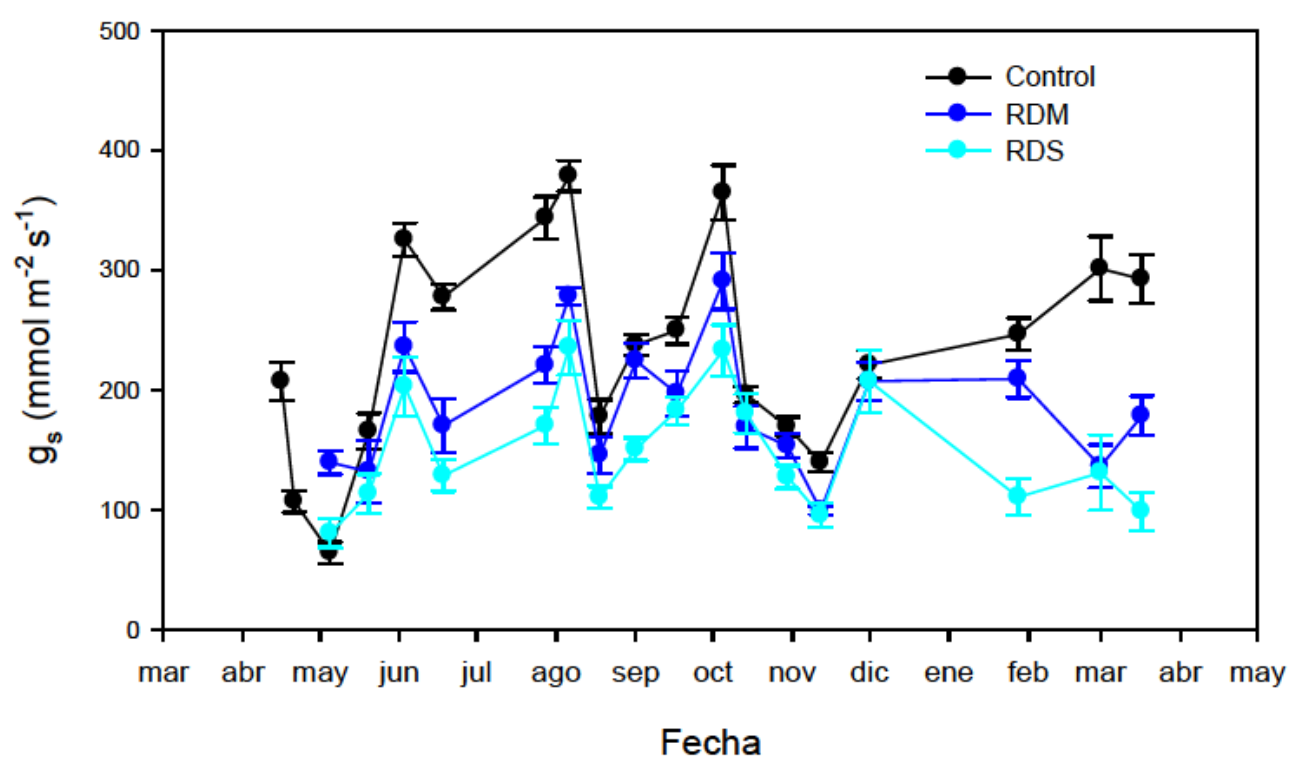

Figura 5.31- Evolución de la conductancia estomática $\left(\mathrm{g}_{\mathrm{s}}\right)$ en plantas de callistemon en maceta sometidas a distintos tratamientos de riego durante el período experimental en invernadero

En la Figura 5.32 se representa la fotosíntesis y la eficiencia intrínseca en el uso del agua en función de los valores de conductancia. La tasa de fotosíntesis aumenta según se incrementa el grado de apertura estomática, aunque este efecto es mucho más evidente con niveles de conductancia menores de $150-200 \mathrm{mmol} \mathrm{m}^{-2} \mathrm{~s}^{-1}$, a partir de estos niveles, el aumento de la fotosíntesis es mucho menos claro (Figura 5.32A). 

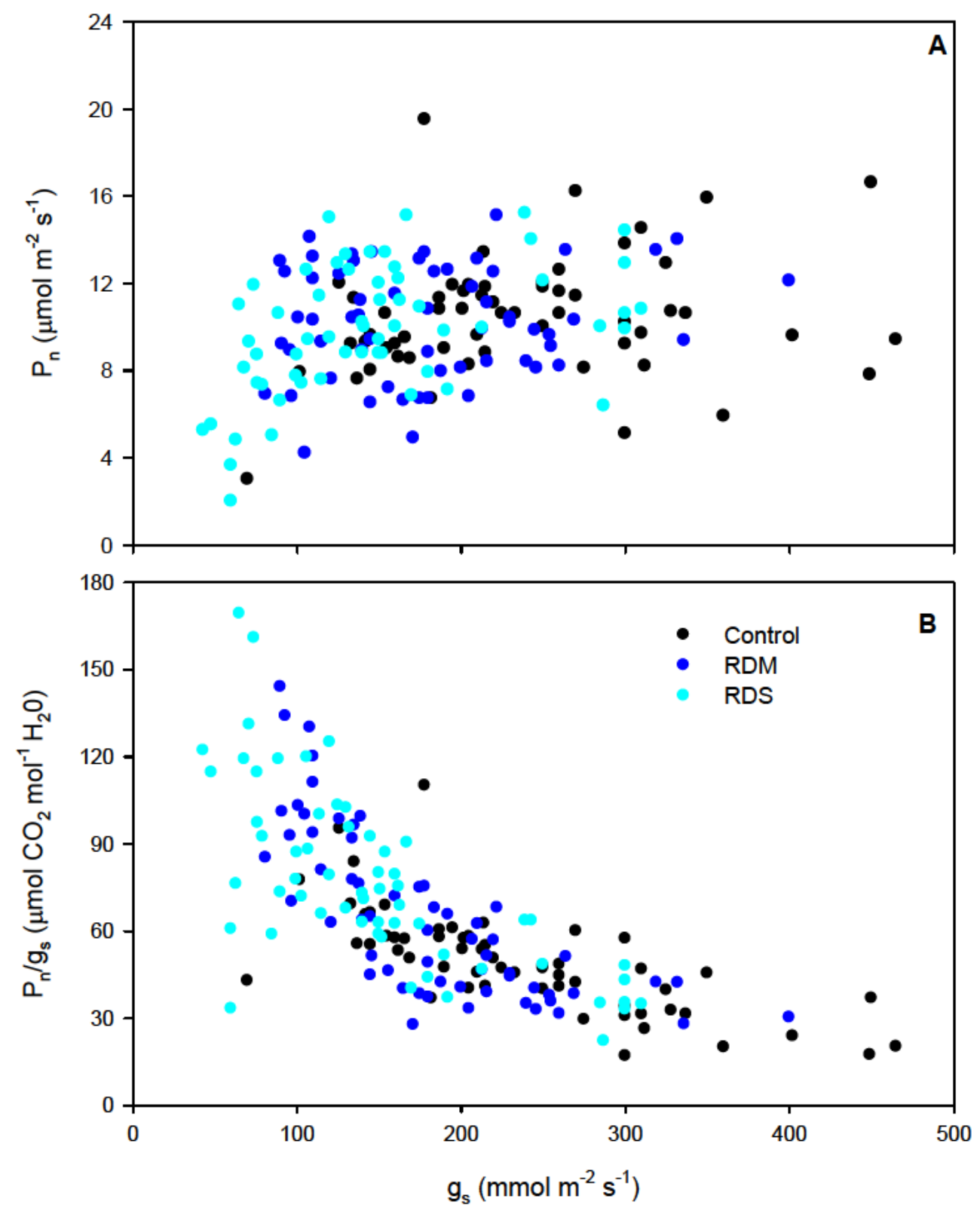

Figura 5.32- Relación entre tasa de fotosíntesis neta $\left(P_{n}\right)$ y conductancia estomática $\left(g_{s}\right),(A)$ y relación entre eficiencia intrínseca del uso del agua $\left(P_{n} / g_{s}\right)$ y conductancia estomática $\left(g_{s}\right)$, $(B)$ en plantas de callistemon en maceta sometidas a distintos tratamientos de riego durante el ensayo en invernadero.

La mayor eficiencia se alcanza con valores de apertura estomática en torno a $100 \mathrm{mmol} \mathrm{m}^{-2} \mathrm{~s}^{-1}$ (Figura 5.32B). La eficiencia intrínseca del uso del agua $\left(\mathrm{P}_{\mathrm{n}} / \mathrm{g}_{\mathrm{s}}\right)$ aumenta en todos los tratamientos cuando $\mathrm{g}_{\mathrm{s}}$ desciende desde el máximo hasta aproximadamente 100 $\mathrm{mmol} \mathrm{m} \mathrm{m}^{-2} \mathrm{~s}^{-1}$, lo que indica un predominante control estomático sobre la fotosíntesis. Pero cuando $\mathrm{g}_{\mathrm{s}}$ es menor de $100 \mathrm{mmol} \mathrm{m} \mathrm{m}^{-2} \mathrm{~s}^{-1}, \mathrm{P}_{\mathrm{n}} / \mathrm{g}_{\mathrm{s}}$ desciende bruscamente, sugiriendo que son limitaciones no estomáticas 
de la fotosíntesis las que predominan bajo estas condiciones (Flexas y col., 2001), tal y como sucede en otros arbustos mediterráneos (Gulías y col., 2009). Las plantas de callistemon presentan una mayor eficiencia cuando los valores de conductancia se sitúan en torno a 75-100 $\mathrm{mmol} \mathrm{m}^{-}$ ${ }^{2} \mathrm{~s}^{-1}$, según aumenta el grado de apertura estomática $\left(g_{\mathrm{s}}\right)$, la eficiencia disminuye progresivamente. Las plantas regadas en condiciones control presentan en la mayoría del ensayo valores superiores a estos umbrales. Son las plantas regadas deficitariamente, especialmente las plantas del tratamiento RDS, las que oscilan entre los valores de conductancia estomática que presentan mayor eficiencia intrínseca en el uso del agua, con lo que tienen mayor $\mathrm{P}_{\mathrm{n}} / \mathrm{g}_{\mathrm{s}}$ en relación a las plantas control (Mugnai y col., 2009).

En conclusión, la tolerancia a la sequía de $C$. citrinus se relacionó con adaptaciones morfológicas y fisiológicas. La capacidad de realizar ajuste osmótico, para aumentar la rigidez y modificar el intercambio gaseoso de las hojas, es acompañado por una capacidad para mantener niveles aceptables de fotosíntesis y reducir las pérdidas de agua vía transpiración. Las reducciones del peso seco aéreo (área foliar, número de hojas y altura), junto con aumentos en la densidad del sistema radical, el cociente PS raíz/PS aéreo y la proporción de raíces finas, podrían promover un establecimiento más rápido de estas especies en condiciones mediterráneas. El riego deficitario moderado puede usarse de forma satisfactoria en la producción de plantas de callistemon, lo que reduce el consumo de agua, mientras mantiene una buena calidad global en su valor ornamental. El riego deficitario severo disminuye la calidad ornamental del callistemon debido principalmente a la reducción del número de flores.

La especie callistemon es bastante tolerante al déficit hídrico, pero debido a su efecto acumulativo, el grado de déficit alcanzado fue muy elevado al final del período experimental. Este hecho fue evidenciado tanto por la pérdida de hojas, como por la aparición de importantes limitaciones de tipo bioquímico a la $A_{\max }$, que se sumaron a las principales limitaciones de origen estomático ya existentes desde mediados del ensayo. 

Capítulo 6

Conclusiones 



\section{Clavel}

- El grado de estrés impuesto, por la aplicación de riego deficitario, afecta al desarrollo floral de las plantas de clavel, las cuales pueden enfrentarse a situaciones moderadamente limitantes de agua, sin perder su valor ornamental.

- La cantidad de agua aportada a las plantas influye en su morfología, fisiología y distribución de la biomasa, así las plantas con menor riego presentan mayor proporción de parte radical en relación a la parte aérea.

- Una apropiada programación del riego deficitario en relación al estado de desarrollo (fuera de la máxima floración) produce una planta compacta con una estructura proporcionada a su tamaño final y no reduce la intensidad de floración.

- Las adaptaciones de la planta ante un aporte de agua reducido implican descenso de la conductancia estomática y, a más largo plazo, una reducción en el área de las hojas. El descenso de los niveles de agua en las hojas viene acompañado por ajuste osmótico y cambios en la elasticidad de la pared celular, que previenen la pérdida de turgencia y daños visuales ante períodos de déficit hídrico.

\section{Geranio}

- El riego deficitario moderado puede usarse de forma satisfactoria en la producción de plantas de geranio, reduciendo el consumo de agua, y manteniendo su valor ornamental. El riego deficitario severo disminuye la calidad ornamental del geranio debido a la reducción del número de flores.

- El riego deficitario tiene un mayor efecto sobre el crecimiento vertical que sobre el horizontal, aspecto positivo, ya que la reducción de la altura facilita el manejo de la planta en el transporte y posterior transplante.

- Después de un periodo de déficit hídrico, cuando se restablece el riego, las plantas de geranio recuperan los parámetros del 
estado hídrico e intercambio gaseoso a corto plazo, sin embargo los parámetros de crecimiento necesitan más tiempo.

- La intensidad de floración no solo depende de la cantidad de agua aplicada a la planta, si no también del momento en el que se aplique la reducción del riego. La fase de floración resultó ser la más sensible al déficit hídrico.

- El comportamiento estomático de las plantas, y por tanto el consumo de agua, no solo están influenciados por el riego aplicado en ese momento, si no, también, por los ciclos de estrés previos.

\section{Callistemon}

- Las diferencias en los niveles de transpiración y de consumo diario de agua entre las plantas bien regadas y deficitarias son más evidentes cuando la transpiración es mayor, en horas de máxima luminosidad, mayor DPV y/o en períodos de crecimiento más activo y formación de las inflorescencias.

- La diferencia entre el potencial de hoja y el potencial de tallo es un indicador de la transpiración instantánea. El orden en función de la idoneidad para detectar el estrés hídrico en Callistemon citrinus es: $\Psi_{\mathrm{t}}, \Psi_{\mathrm{pd}} \mathrm{y} \Psi_{\mathrm{md}}$.

- Una reducción del 50\% del agua aplicada mantiene una calidad aceptable de la planta, reducciones del $75 \%$ no son recomendables por disminuir la intensidad de floración y producir hojas con menor intensidad de color.

- En plantas bien regadas las limitaciones a la fotosíntesis máxima son causadas por las limitaciones del mesófilo, siendo las limitaciones difusionales las que produjeron más del $90 \%$ de la limitación total de la fotosíntesis máxima. En plantas regadas deficitariamente estas limitaciones son de tipo estomático y conforme avanza el estrés, de tipo bioquímico (33\% del total). 
Capítulo 7

Bibliografía 

Abo El-Nil, M.M. 1990. Geranium (Pelargonium). En: Handbook of Plant Cell Culture Vol. 5. Ornamental species. (Ammirato, P.V., Evans, D.A., Sharp, W.R., Bajaj, Y.P.S. Eds). MacMillan Publishing Company, New York. USA, 439-460.

Ackerson, R.C., 1985. Osmoregulation in cotton in response to water stress. HortScience, 28: 50-52.

Alarcón, J.J., Domingo, R., Green, S., Sánchez-Blanco, M.J., Rodríguez, P., Torrecillas, A. 2000. Sap flow as an indicator of transpiration and the water status of young apricot trees. Plant Soil, 227: 77-85.

Álvarez, S., Navarro, A., Bañón, S., Sánchez-Blanco, M.J. 2009. Regulated deficit irrigation in potted dianthus plants: effects of severe and moderate water stress on growth and physiological responses. Scientia Horticulturae, 122: 579-585.

Álvarez, S., Navarro, A., Nicolás, E., Sánchez-Blanco, M.J. 2011. Transpiration, photosynthetic responses, tissue water relations and dry mass partitioning in Callistemon plants during drought conditions. Scientia Horticulturae, 129: 306-312.

Amer, F.A., Williams, W.T. 1958. Drought-resistance in Pelargonium zonale. Annals of Botany, 22(3): 369-379.

Andersen, M.N., Jersen, C.R, Lösch, R. 1991. Derivations of pressurevolume curves by a non-linear regression procedure and determination of apoplastic water. Journal of Experimental Botany, 42:159-165.

Andersson, N.E. 2001. Weight controlled irrigation of potted plants. Acta Horticulturae, 559: 371-375.

Andersson, N.E. 2011. The influence of water stress and air velocity on growth of Impatiens walleriana and Petunia $\mathrm{x}$ hybrid. Scientia Horticulturae, 128: 146-151.

Anónimo,. 2001. Marché du geranium: qui achète quoi? Lien horticole, 18: 20-21.

Anyia, A.O., Herzog, H. 2004. Water-use efficiency, leaf area and leaf gas exchange of cowpeas under mid-season drought. European Journal of Agronomy, 20: 327-339.

Arcas, N., Romero, M. 2000. El sector de la flor cortada de la Región de Murcia en el contexto nacional: claves para mejorar su competitividad. Acta Horticultura, 31: 133-154.

Armitage, A.M., Carlson, W,H,, Flores, J.A. 1981. The effect of temperature and quantum flux density on the morphology, physiology and flowering of hybrid geranium. Journal of the American Society for Horticultural Science, 106: 643-647.

Arora, R., Dharmalingam, S.P., Bradford, C.B. 1998. Water-stress-induced heat tolerance in geranium leaf tissues: A possible linkage through stress proteins?. Physiologia Plantarum, 103: 24-34. 
Augé, M.R., Stodola, A.J.W., Moore, J.L., Klingeman, W.E., Duan, X. 2003. Comparative dehydration tolerance of foliage of several ornamental crops. Scientia Horticulturae, 98: 511-516.

Atkinson, D., Crisp, C.M. 1983. The effect of some plant growth regulators and herbicides on root system morphology and activity. Acta Horticulturae, 136: 21-28.

Bacelar, E.A., Santos L.D., Moutinho-Pereira, J.M., Ferreira, H.F, Correia, C.M. 2006. Inmediate responses and adaptative strategies of three olive cultivars under contrasting water availability regimes: Changes on structure and chemical composition of foliage and oxidative damage. Plant Science, 170: 596-605.

Bacelar, E.A., Santos, D.L., Moutinho-Pereira, J.M., Lopes, J.L., Gonçalves, B.C., Ferreira, T.C., Correia, C.M. 2007. Physiological behaviour, oxidative damage and antioxidative protection of olive trees grown under different irrigation regimes. Plant Soil, 292: 1-12.

Baig, M.N., Tranquillini, W. 1976. Studies on the upper timberline: morphology and anatomy of Norway spruce (Picea abies) and stone pine (Pinus cembra) needles from various habitat conditions. Canadian Journal of. Botany, 54:1622-1632.

Bañón, S., González, A., Cano, E.A., Franco, J.A., 2002. Growth, development and colour response of potted Dianthus caryophyllus cv. Mondriaan to paclobutrazol treatment. Scientia Horticulturae, 94: 371-377.

Bañón, S., Fernández, J.A., Franco, J.A., Torrecillas, A., Alarcón, J.J., Sánchez-Blanco, M.J. 2004. Effects of water stress and night temperature pre-conditioning on water relations and morphological and anatomical changes of Lotus creticus plants. Scientia Horticulturae, 101: 333-342.

Bañón, S.,Ochoa, J., Franco, J.A., Alarcón, J.J., Sánchez-Blanco. 2006. Hardening of oleander seedling by deficit irrigation and low air humidity. Environmental and Experimental Botany, 56: 36-43.

Bañón, S, Miralles J, Navarro A, Sánchez-Blanco MJ. 2009. Influence of paclobutrazol and substrate on daily evapotranspiration of potted geranium. Scientia Horticulturae ,122: 572-578.

Bargali, K, Tewari, A. 2004. Growth and water relation parameters in drought-stressed Coriaria nepalensis seedlings. Journal of Arid Environments, 58: 505-512.

Barrs, H.D. 1968. Determination of water deficit in plant tissues. Water deficits and plant growth, vol 1. Academic Press, New Delhi.

Begg, J.E., Turner, N.C. 1970. Water potential gradients in field tobacco. Plant Physioly, 46: 343-346.

Bernacchi, C.J., Portis, A.R., Nakano, H., von Caemmere,r S., Long, S.P. 2002. Temperature response of mesophyll conductance. Implications for the determination of Rubisco enzyme kinetics and for limitations to photosynthesis in vivo. Plant Physiology, 130: 1992-1998. 
Bernal, M., Estiarte, M., Peñuelas, J. 2011. Drought advances spring growth phenology of the Mediterranean shrub Erica multiflora. Plant Biology, 13: 252-257.

Blanchard, M.G., Runkle, E.S. 2011. Quantifying the thermal flowering rates of eighteen species of annual bedding plants. Scientia Horticulturae, 128: 30-37.

Bolla, A., Voyiatzis, D., Koukourikou-Petridou, M., Chimonidou, D. 2010. Photosynthetic parameters and cut-flower yield of rose 'Eurored' (H.T.) are adversely affected by mild water stress irrespective of substrate composition. Scientia Horticulturae, 126: 390-394.

Bowman, W.D., Roberts, S.W. 1985. Seasonal changes in tissue elasticity in chaparral shrubs. Physiologia Plantarum ,65: 233-263.

Blanchard, M.G., Runkle, E.S. 2011. Quantifying the thermal flowering rates of eighteen species of annual bedding plants. Scientia Horticulturae, 128: 30-37.

Bradford, K.J., Hsiao, T.C. 1982. Physiological response to moderate water stress. En: Physiological Plant Ecology II. (Lange, O.L., Novel, P.S., Osmond, C.M., Ziegler, H. Ed.). Springer Verlag, Berlin, vol. 12B, 263-324.

Brawner, F. 2003. Geraniums: the complete encyclopedia. Schiffer Publishing Ltd. PA, USA. Bailey Hortorium Staff. 1976. Hortus Trird, Liberty Hyde Bailey Hortorium. Macmilan, New York, USA, 832836.

Bruce, T.J.A., Matthes, M.C., Napier, J.A., Pickett, J.A. 2007. Stressful "memories" of plants: Evidence and possible mechanisms. Plant Science, 173: 603-608.

Brugnoli, E., Bjorkman, O. 1992. Growth of cotton under continuous salinity stress: influence on allocation pattern, stomatal and notstomatal components of photosynthesis and dissipation of excess light energy. Planta, 187: 335-347.

Calvo Vergés, I. 2001. Geranio. En: La Horticultura Española. (Ed. Nuez, Yacer, G. Ed.). SECH, Madrid,.422-423.

Camejo, D., Rodríguez, P., Morales, M.A., Dell'Amico, J., Torrecillas, A., Alarcón, J.J. 2005. High temperature effects on photosynthetic activity of two tomato cultivars with different heat susceptibility. Journal of Plant Physiology, 162: 281-289.

Cameron, R.W.F., Harrison-Murray, R.S., Scott, M.A. 1999. The use of controlled water stress to manipulate growth of container-grown Rhododendron cv. Hoppy. Journal of Horticultural Science \& Biotechnology, 74 (2): 161-169.

Cameron, R.W.F., Harrison-Murray, R.S., Atkinson, C.J., Judd, H.L. 2006. Regulated deficit irrigation: a means to control growth in woody ornamentals. Journal of Horticultural Science \& Biotechnology, 81(3): 435-443. 
Cameron, R., Harrison-Murray, R., Fordham, M., Wilkinson, S., Davies, W., Atkinson, C., Else, M. 2008. Regulated irrigation of woody ornamentals to improve plant quality and precondition against drought stress Annals of Applied Biology, 153: 49-61.

Carden, D.E. 1995. Factors limiting the performance of Kalmia latifolia L. in containers. Thesis, Wye College, University of London.

Cerny, T., Faust, J.E., Layne, D.R., Rajapakse, N.C. 2003. Influence of photoselective filters and growing season on stem growth and flowering of six plant species. Journal of the American Society for Horticultural Science, 128(4): 486-491.

Chandravadana, M.V., Nidiry, E.S.J. 1994. Antifungal activity of essential oil of Pelargonium graveolens and its constituents against Colletotrichum gloeosporioides. Indian Journal of Experimental Biology 32(12): 908-909.

Chandravadana, M.V., Sebastian, E., Nidiry, J., Lella, N.K., Reddy, P.P., Khan, R.M., Rao, M.S. 1996. Nematicidal activity of some plant extracts. Indian Journal of Nematology 26(2): 148-151.

Chaves, M.M., Pereira, J.S., Maroco, J., Rodrigues, M.L., Ricardo, C.P.P., Osório, M.L. 2002. How plants cope with water stress in the field. Photosynthesis and growth. Annals of Botany, 89: 907-916.

Cheung, Y.N.S., Tyree, M.T., Dainty, J. 1975. Water relation parameters on single leaves obtained in a pressure bomb and some ecological considerations. Canadian Journal of Botany, 53: 1342-1346.

Cheung, Y.N.S., Tyree, M.T., Dainty, J. 1976. Some possible sources of error in determining bulk elastic moduli and other parameters from pressure-volume curves of shoots and leaves. Canadian Journal of Botany, 54: 758-795.

Choné, X., Van Leeuwen, C., Dubourdieu, D., Gaudillère, J.P. 2001. Stem water potential is a sensitive indicator of Grapevine Water status. Annals of Botany, 87: 477-483.

Chyliński, W.K., Łukaszewska, A.J., Kutnik, K. 2007. Drought response of two bedding plants. Acta Physiologiae Plantarum, 29(5): 399-406.

Clary, J., Savé, R., Biel, C., De Herralde, F. 2004. Water relations in competitive interactions of Mediterranean grasses and shrubs. Annals of Applied Biology, 144: 149-155.

Clifford, S.C., Arndt, S.K., Corlett, J.E., Joshi, S., Sankhla, N., Popp, M., Jones, H.G. 1998. The role of solute accumulation, osmotic adjustment and changes in cell wall elasticity in drought tolerance in Ziziphus mauritiana (Lamk). Journal of Experimental Botany, 49: 967-977.

Colom, M.R., Vazzana, C. 2003. Photosynthesis and PSII functionality of drought-resistant and drought-sensitive weeping lovegrass plants. Environmental and Experimental Botany, 49: 135-144. 
Corcuera, L. 2003. Comparación de dos métodos para generar curvas presión-volumen en especies del género Quercus. Investigación Agraria : Sistemas y Recursos Forestales, 12: 111-121.

Cornic, G. Drought stress and high light effects on leaf photosynthesis. In: Baker NR, Bowyer JR, editors. Photoinhibition of photosynthesis: from molecular mechanisms to the field. Oxford: Bios Scientific Publishers, 1994. pp 297-313.

Costa, J.M., Ortuño, M.F., Chaves M.M. 2007. Deficit irrigation as a strategy to save water: physiology and potential application to horticulture. Journal of Integrative Plant Biology, 49(10): 1421-1434.

Costa França, M.G., Pham Thi, A.T., Pimentel, C., Pereyra Rossiello, O.P., Zuily-Fodil, Y., Laffray, D. 2000. Differences in growth and water relations among Phaseolus vulgaris cultivars in response to induced drought stress. Environmental and Experimental Botany, 43: 227-237.

Cuevas, J., Pinillos, V., Cañet,e M.L., González, M., Alonso, F., Fernández, M.D., Hueso, J.J. 2009. Optimal levels of postharvest deficit irrigation for promoting early flowering and harvest datas in loquat (Eriobotrya japonica Lindl.). Agricultural Water Management, 96: 831-838.

DaMatta, F.M., Chaves, A.R.M., Pinheiro, H.A., Ducatti, C., Loureiro, M.E. 2003. Drought tolerance of two field-grown clones of Coffea canephora. Plant Science, 164: 111-117.

Davies, S.D., Money, H.M. 1986. Tissue water relations on four coocurring chaparral shrubs. Oecologia, 70: 527-535.

Davies, W.J., Wilkinson, S., Loveys, B.R., 2002. Stomatal control by chemical signalling and the exploitation of this mechanism to increase water use efficiency in agriculture. New Phytologist. 153: 449-460.

De Herralde, F., Biel, C., Savé, R., Morales, M.A., Torrecillas, A., Alarcón, J.J., Sánchez-Blanco, M.J. 1998. Effect of water and salt stresses on the growth, gas exchange and water relations in Argyranthemum coronopifolium plants. Plant Science, 139: 9-17.

De Lucía, B. 2009. Response of potted australian ornamental plants to different soil water conditions. Acta Horticulturae, 807(1): 277-282.

Díaz-Espejo, A., Nicolás, E., Fernández, J.E. 2007. Seasonal evolution of diffusional limitations and photosynthetic capacity in olive under drought. Plant, Cell and Environment, 30: 922-933.

Dinakar, C., Djilianov, D., Bartels, D. 2011. Photosynthesis in desiccation tolerant plants: Energy metabolism and antioxidative stress defense. Plant Science, in press.

Eiasu, B.K., Steyn, J.M., Soundy, P. 2009. Rose-sceted geranium (Pelagonium capitatum $\times$ P. radens) growth and essential oil yield response to different soil water depletion regimes. Agricultural Water Management, 96: 991-1000. 
Ethier, G.J., Livingston, N.J. 2004. On the need to incorporate sensitivity to $\mathrm{CO}_{2}$ transfer conductance into the Farquhar-von CaemmererBerry leaf photosynthesis model. Plant, Cell and Environment, 27: 137-153.

Ethier, G.J., Livingston, N.J., Harrison, D.L., Black T.A., Moran, J.A. 2006. Low stomatal and internal conductance to $\mathrm{CO}_{2}$ versus Rubisco deactivation as determinants of the photosynthetic decline of ageing evergreen leaves. Plant, Cell and Environment, 29: 2168-2184.

Evans, J.R., Sharkey, T.D., Berry, J.A., Farquhar, G.D. 1986. Carbon isotope discrimination measured concurrently with gas exchange to investigate $\mathrm{CO}_{2}$ diffusion in leaves of higher plants. Australian Journal of Plant Physiology, 13: 281-292.

Evans, R. 2004. Hands-On irrigation Training for Nursery Growers. GROWING Points, 8(1): 4-5.

Fernández, J.A., Balenzategui, L., Bañón, S., Franco, J.A. 2006. Induction of drought tolerance by paclobutrazol an irrigation deficit in Phillyrea angustifolia during the nursery period. Science Horticulurae, 107: 277-283.

Fernández-Zamudio, M.A., Roca, D., Bartual, J., Verdeguer, A., Martínez, P.F. 2010. Los cultivos ornamentales en el mediterráneo español. www.horticom.com.

Filella, I., Llusià, J., Piñol, J., Peñuelas, J. 1998. Leaf gas exchange and fluorescence of Phillyrea latifolia, Pistacia lentiscus and Quercus ilex saplings in severe drought and hight temperature conditions .Environmental and Experimental Botany, 39: 213-220.

Flexas, J., Gulías, J., Jonasson, S., Medrano, H., Mus, M. 2001. Seasonal patterns and control of gas exchange in local populations of the Mediterranean evergreen shrub Pistacia lentiscus L. Acta Oecologia, 22: 33-43.

Flexas, J., Bota, J., Loreto, F., Cornic, G., Sharkey, T.D. 2004. Diffusive and metabolic limitations to photosynthesis under drought and salinity in C3 plants. Plant Biology, 6: 269-279.

Fonteno, W.C. 1992. Geraniums. En: Floriculture. (Larson, R.L.. Ed.). Academic Press, Inc., San Diego,.451-475.

Franco, J.A., Bañón, S., Fernández, J.A., Leskovar, D.I. 2001. Effect of nursery regimes and establishment irrigation on root development of Lotus creticus seedlings following transplanting. Journal of Horticultural Science \& Biotechnology, 76: 174-179.

Franco, J.A., Martínez-Sánchez, J.J., Fernández, J.A., Bañón, S. 2006. Selection and nursery production of ornamental plants for landscaping and xerogardening in semi-arid environments Journal of Horticultural Science \& Biotechnology, 81: 3-17. 
Franco, J.A., Arreola, J., Vicente, M.J., Martínez-Sánchez, J.J. 2008. Nursery irrigation regimes affect the seedling characteristics of Silene vulgaris as they relate to potential performance following transplanting into semi-arid conditions. Journal of Horticultural Science \& Biotechnology, 83: 15-22.

French, A.N., Hunsake,r D., Thorp, K., Clarke, T. 2009. Evapotranspiration over a camelina crops at Maricopa, Arizona. Industrial crops and products, 29: 289-300.

Genty, B., Briantais, J.M., Viera da Silva, J.B. 1987. Effects of drought on primary photosynthetic processes of cotton leaves. Plant Physiology, 83: 360-374.

Gallardo, M., Thompson, R.B., Valdez, L.C., Fernández, M.D. 2006. Response of stem diameter variations to water stress in greenhouse-grown vegetables crops. Journal of Horticultural Science \& Biotechnology, 81: 483-495.

García-Navarro, M.C., Evans, R.Y., Savé Montserrat, R. 2004. Estimation of relative water use among ornamental landscape species. Scientia Horticulturae, 99: 163-174.

Gebre, G.M., Kuhns, M.R. 1993. Effects of water stress preconditioning on gas exchange and water relations of Populus deltoides clones. Canadian Journal of Forest Research. 23(7); 1291-1297.

Genty, B., Briantais, J.M., Viera da Silva, J.B. 1987. Effects of drought on primary photosynthetic processes of cotton leaves. Plant Physiology, 83: 360-374.

Goldhamer, D.A., Beede, R.H. 2004. Regulated deficit irrigation effects on yield, nut quality and water-use efficiency of mature pistachio trees. Journal of Horticultural Science \& Biotechnology, 79: 538-545.

Gollan, T., Turner, N.C., Schulze, E.D., 1985. The responses of stomatal and leaf gas exchange to vapour pressure deficits and soil water content. III. In the sclerophyllous woody species Nerium oleander. Oecologia, 65(3): 356-362.

González, A., Hernández, M.D., López, J., Rodríguez, R., Bañón, S., Fernández, J.A. 2002. Clavel para maceta: ciclos de cultivo realizados en invernadero y al aire libre. PLANTFOR, Cultivo\&Comercio, 88: 57-63.

Gucci, R., Xiloyannis, C., Flore, J.A. 1991. Gas exchange parameters, water relations and carbohydrate partitioning in leaves of fieldgrown Prunus domestica following fruit removal. Physiologia Plantarum, 83: 497-505.

Grassi, G., Magnani, F. 2005. Stomatal, mesophyll conductance and biochemical limitations to photosynthesis as affected by drought and leaf ontogeny in ash and oak trees. Plant, Cell and Environment, 28: 834-849. 
Gulía,s J., Cifre, J., Jonasson, S., Medrano, H., Flexas, J. 2009.. Seasonal and inter-annual variations of gas exchange in thirteen woody species along a climatic gradient in the Mediterranean island of Mallorca. Flora, 204: 169-181.

Hall, A.E., Mutters, R.D., Farquhar, G.D. 1992. Genotypic and droughtinduced differences in carbon isotope discrimination and gas exchange of copea. Crop Science, 32: 1-6.

Hassanein, A., Dorion, N. 2006. Determining morphological and physiological parameters for the selection of drought-tolerant geraniums (Pelargonium x hortorum L. H. Bailey). Journal of Horticultural Science \& Biotechnology, 81(4): 707-713.

Hansen, C.W., Petersen, K.K. 2004 Reduced nutrient and water availability to Hibiscus rosa-sinensis 'Cairo Red' as a method to regulate growth and improve post -production quality. European Journal of Horticultural Science, 69(4): 159-166.

Henson, D.Y., Newman, S.E, Hartley, D.E. 2006. Performance of selected herbaceous annual ornamentals grown at decreasing levels of irrigation. HortScience, 41(6): 1481-1486.

Hessini, K., Ghandour, M., Albouchi, A., Soltani, A., Werner, K.H., Abdelly, C. 2008. Biomass production, photosynthesis, and leaf water relations of Spartina alterniflora under moderate water stress. Journal of Plant Research, 121: 311-318.

Hinckley, T.M., Duhme, F., Hinckley, A.R., Richter, H. 1980. Water relations of drought hardy shrubs: osmotic potential and stomatal reactivity. Plant Cell and Environment , 3: 131-140.

Hsiao, T.C. 1973. Plant response to water stress. Annual Review Plant Physiology, 24: 519-570.

Jaleel, C.A., Gopi, R., Sankar, B., Gomathinayagam, M. 2008. Differential responses in water use efficiency in two varieties of Catharanthus roseus under drought stress. Comptes Rendus Biologies, 331: 4247.

Joly, R.J., Zaerr, J.B. 1987. Alterations of cell-wall water content and elasticity in Douglas-fir during period of water deficit. Plant Physiology, 83: 418-422.

Kang, S., Shi, W., Zhang, J. 2000. An improved water-use efficiency for maize grown under regulated deficit irrigation. Field Crops Research, 67: 207-214.

Katsoulas, N., Kittas, C., Dimokas, G., Lykas, Ch. 2006. Effect of irrigation frecuency on rose flower production and quality. Biosystems Engineering, 96(2): 237-244.

Khavari Nejad, R.A., Najafi, F. 1990. Growth parameters in sunflowers plants as affected by $\mathrm{Ca} / \mathrm{Na}$ interactions under $\mathrm{NaCl}$ salinity. Photosynthetica, 24: 155-162. 
Kikuta, S.B., Kyriakopoulous, E., Ritcher, H. 1985. Leaf hygrometer vs pressure chamber: a comparison of pressure-volume data obtained on single leaves by alternating measurements. Plant Cell and Environment, 8: 363-367.

Kozlowski, T.T.; Pallardy, S.G. 2002. Acclimation and adaptative response of woody plants to environmental stresses. Botanical Review, 68: 270-334.

Lemcoff, J.H., Guarnaschelli, A.B., Garau, A.M., Prystupa, P. 2002. Elastic and osmotic adjustments in rooted cuttings of several clones of Eucalyptus camaldulensis Dehnh. from southeastern Australia after a drought. Flora, 197: 134-142.

Lafuente, M.T., Belver, A., Guye, M.G., Saltveit, Jr. M.E. 1991. Effect of the temperature conditioning on chilling injury of cucumber cotyledons. Plant Physiology, 95: 443-449.

Lang, H., Trellinger, K. 2001. Geraniums. En: Gaston M, Konjoian P, Kunkle L, Wilt $M$ (Eds.), Tips on regulating growth of floriculture crops. Ohio Florists' Associations Servies Inc., Columbus, USA, pp.88-95.

Lao, M.T., Jiménez, S. 2002. Estudio comparativo del comportamiento productivo de Callistemon citrinus. En: I Jornadas Ibéricas de plantas ornamentales. Servicio de Publicaciones y Divulgación. Consejería de Agricultura y Pesca. Junta de Andalucía, 113-120.

Lenzi, A., Palandri, A., Bovelli, R., Tesi, R.1999. L'oleandro (Nerium oleander L.) per la coltura in contenitore. Colture Protette, 9: 10112.

Lenzi, A., Pittas, L., Martinelli, T., Lombardi, P., Tesi, R. 2009. Response to water stress of some oleander cultivars suitable por pot plant production. Scientia Horticulurae, 122: 426-431.

Leskovar, D.I. 1998. Root and shoot modification by irrigation. HortTechnology, 13: 562-568.

Leskovar, D., Stoffella, P.J. 1995. Vegetable seedling root systems: morphology, development, and importance. HortScience, 30: 11531159.

Lippi, G., Serra, G., Vernieri, P., Tognoni, F. 2003. Response of potted Callistemon species to high salinity. Acta Horticulturae, 609: 247250.

Lippi, G., Vernieri, P., Serra, G., Carrai, C. 2005. Callistemon sppResistenza agli stress ambientali. Clamer Informa, 11: 7-12.

Liptay, A., Sikkema, P., Fonteno, W. 1998. Transplant growth control through water deficit stress-A review. HortTechnology, 8: 540-543.

Lis Balchin, M., Hart, S.L., Deans, S.G., Eaglesham, E. 1995. Potential agrochemical and medicinal usage of essential oils of Pelargonium species. Journal of Herbs, Spices and Medicinal Plants 3(2): 11-22. 
Liu, F., Shahnazari, A., Andersen, M. N., Jacobsen, SE., Jensen, C.R. 2006. Effects of déficit irrigation (DI) and partial root drying (PRD) on gas exchange, biomasa partitioning, and water use efficiency in potato. Scientia Horticulturae, 109:113-117.

Lo Gullo, M.A., Salleo, S., Rosso, R.. 1986. Drought avoidance strategy in Ceratonia siliqua L., a mesomorphic-leaved tree in the xeric Mediterranean area. Annals of Botany, 58: 745-756.

Lombardi, P., Lenzi, A., Tesi, R. 2003. Cultivar di oleandro (Nerium oleander L.) a taglia contenuta per vasi fioriti. Colture Protette, 4: $75-80$

Lorenzo, P., Medran, E., Sánchez-Guerreto, M.C., Muñoz, R. 1996. Grenhouse crop transpiration, an implement to soilless irrigation managemet. Acta Horticulturae, 458: 113-119.

Loreto, F., Harley, P.C., Di Marco, G., Sharkey, T.D. 1992. Estimation of mesophyll conductance to $\mathrm{CO}_{2}$ flux by 3 different methods. Plant Physiology, 98: 1437-1443.

Lozhnikova, V., Krekule, J., Seidlova, F., Bavrina, T., Chailakhyan, M.K. 1981. Promotive effects of Abscisic acid inflowering of Chenopodium rubrum as the results of decreasing apical dominance. Biologia Plantarum,. 23: 36-40.

MARM, 2009 Anuario de Estadística de 2009 (actualizado mayo 2011). Ministerio de Medio Ambiente y Medio Rural y Marino. Madrid.

MARM, Ministerio de Medio Ambiente y Medio Rural y Marino. 2010. www. marm.es.

Martínez-Ferri, E., Balague, L., Valladares, F., Chico, J.M., Manrique,.E. 2000. Energy dissipation in drought-avoiding and drought-tolerant tree species at midday during the Mediterranean summer. Tree Physiology, 20:.131-138.

Maxwell, K., Johnson, G.N. 2000. Chlorophyll fluorescence: A practical guide. Journal and Experimental Botany, 51:.659-668.

McGuire, R.G. 1992. Reporting of objective colour measurements. HortScience, 27: 1254-1255.

Meinzer, F.C., Grantz, D.A., Goldstein, G., Saliendra, N.Z., 1990. Leaf water relations and maintenance of gas exchange in coffee cultivars grown in drying soil. Plant Physiology, 94: 1781-1787.

Metwally, A.W., Esthe,r S.B., Beck, G.E. 1970. Effect of three soil moisture regimes on the growth and anatomy of Pelargonium hortorum. Journal of the American Society of Horticultural Science, 95: 803808.

Million, J.B., Yeager, T.H., Albano, J.P. 2010. Evapotranspiration-based irrigation scheduling for container-grown Viburnum odoratissimum (L.) Ker Gawl. HortScience, 45(11): 1741-1746. 
Mingeau, M., Perrier, C., Ameglio, T. 2001. Evidence of drought-sensitive periods from flowering to maturity on highbush blueberry. Scientia Horticulturae, 89: 23-40.

Miralles, J., Nortes, P., Sánchez-Blanco, M.J., Martínez-Sánchez, J.J., Bañón, S. 2009. Above ground and pot-in-pot production systems in native Myrtle. Transactions of the ASABE, 52,: 93-101.

Misra, A.N., Murmu, B., Singh, P., Misra, M. 1996. Growth and proline accumulation in mungbean seedlings as affected by sodium chloride. Biología Plantarum, 38: 531-536.

Mitchem, C.M. 1993. Callistemon the beautiful bottlebrushes. Plantsman, 15: 29-41.

Mithila,J., Murch, S.J., Krishnaraj, S., Saxena, P.K. 2001. Recent advances in Pelargonium in vitro regeneration systems. Plant Cell, Tissue and Organ Culture, 67: 1-9.

Montero, J.L., Antón, A., Muñoz, P., Lorenzo, P. 2001. Transpiration from geranium grown under high temperatures and low humidities in greenhouses. Agricultural and Forest Meteorology, 107(4): 323332.

Montgomery, B.L., Silva Casey, E., Grossman, A.R., Kehoe, D.M. 2004. AplA, a member of a new class of phycobiliproteins lacking a traditional role in photosynthetic light harvesting. Journal of Bacteriology, 186(21): 7420-7428.

Morvant, J.K., Dole, J.M., Cole, J.C. 1998. Irrigation frequency and system affect Poinsettia growth, water use and runoff. HortScience, 33: 4246.

Mugnai S., Pardossi A, Serra G, Tognoni F. 1995. Leaf water relations and gas exchange in container-grown plants of two genotypes of Nerium oleander L. as affected by water deficiency. Advances in hortitulral science, 9: 27-32.

Mugnai, S., Vernieri, P., Malorgio, F., Serra, G. 2005. Response of some ornamental shrubs to different soil water conditions. Advances in Horticultural Science, 19: 94-100.

Mugnai, S., Ferrante, A., Petrognani, L., Serra, G., Vernieri, P. 2009. Stres-Induced Variation in Leaf Gas Exchange and Chlorophyll a Fluorescence in Callistemon Plants. Research Journal of Biological Sciences, 4: 913-921.

Munné-Bosch, S., Nogués, S., Alegre, L., 1999. Diurnal variations of photosynthesis and dew absorption by leaves in two evergreen shrubs growing in Mediterranean field conditions. New Phytologist, 144: 109-119.

Muñoz, F.J., Dopico, B., Labrador, E. 1993. Effect of osmotic stress on growth of epicotyls of Cicer arietinum in relation to changes in cell wall composition. Physiologia Plantarum, 87: 552-560. 
Myster, J., Moe, R. 1995. Effect of diurnal temperature alternations on plant morphology in some greenhouse crops-a mini review. Scientia Horticulturae, 62: 205-215.

Nabil, M., Coudret, A., 1995. Effects of sodium chloride on growth, tissue elasticity and solute adjustment in two Acacia nilotica subspecies. Physiologia Plantarum, 93: 217-224.

Navarro, A., Sánchez-Blanco, M.J., Bañón, S. 2007. Influence of paclobutrazol on water consumption and plant performance of Arbutus unedo seedlings. Scientia Horticulturae, 111(2):133-139.

Navarro, A., Álvarez, S., Castillo, M., Bañón, S., Sánchez-Blanco, M.J. 2009. Changes in tissue-water relations, photosynthetic activity, and growth of Myrtus communis plants in response to different conditions of water availability Journal of Horticultural Science \& Biotechnology, 84(5): 541-547.

Navarro, A., Bañón, S., Morte, A., Sánchez-Blanco, M.J. 2011. Effects of nursery preconditioning through mycorrhizal inoculation and drought in Arbutus unedo L. plants. Mycorrhiza, 21: 53-64.

Nessmann, P. 1998. Los geranios. Jardinería práctica. Susaeta ediciones S.A., Madrid. 69 pp.

Nicolás, E., Torrecillas, A., Ortuño, M.F., Domingo, R., Alarcón, J.J. 2005. Evaluation of transpiration in adult apricot trees from sap flow measurements. Agricultural Water Management, 72: 131-145.

Ochoa, J., López Marín, J., González, A., Bañón, S., Fernández, J:A., Franco, J.A., Martínez-Sánchez, J.J. 2008. Estado actual de la horticultura ornamental en Murcia. Horticultura, 204. Vol. XXVI-N¹: 24-27.

Patakas, A., Nikolaou, N., Zioziou, E., Radoglou, K., Noitsakis, B. 2002. The role of organic solute and ion accumulation in osmotic adjustment in drought-stresses grapevines. Plant Science, 163: 361-367.

Percival, G.C., Kearby, I.P., Al-Habsib, S. 2006. An assessment of the drought tolerance of Fraxinus genotypes for urban landscaping plantings. Urban For Urban Green, 5: 17-27.

Pereira, J.S., Chaves, M.M. 1993. Plant water deficits in Mediterranean ecosystems. En: Smith, J.A.C., Griffiths, H. (Eds.), Water Deficits Plant Responses from Cell to Community. Bios Scientific Publishers Ltd. Oxford, UK, pp. 237-251.

Pinhero, R.G., Rao, M., Paliyath, G., Mur, D., Fletcher, R. 1997. Changes in activities of antioxidant enzymes and their relationship to genetic and paclobutrazol induced chilling tolerance of maize seedling. Plant Physiology, 114: 659-704.

Pramuk, L.A., Runkle, E.S. 2005 Photoynthetic daily integral during the seedling stage influences subsequent growth and flowering of Celosia, Impatiens, Salvia, Tagetes, and Viola. HortScience, 40: 1336-1339. 
Radin, J.W. 1983. Physiological consequences of cellular water deficits: osmotic adjustment. En: Taylor, H.M., Jordan, W.R., Sinclair, J.R. (Eds.) Limitation to Efficient Water Use in Crop Production. American Society for Agronomy, Madison, WI, USA, 267-276.

Rascio, A., Cedola, M.C., Toponi, M., Flagella, Z., Wittmer, G. 1990. Leaf morphology and water status in Tritticum durum under water stress. Physiologia Plantarum, 78: 462-467.

Ramos, C., Kaufman, M.R. 1979. Hydraulic resistance of rouge lemon roots. Physiologia Plantarum, 45: 311-314.

Raviv, M., Blom, T.J. 2001. The effect of water availability and quality on photosynthesis and productivity of soilless-grown cut roses. Scientia Horticulturae, 88: 257-276.

Rasoul Sharifi, M., Rundel, P.W. 1993. The effect of vapour pressure deficit on carbon isotope discrimination in the desert shrub Larrea tridentata (Creosote Bush). Journal of Experimental Botany, 44(2): 481-487.

Ritcher, H., Duhme, F., Glatzel, G., Hinckley, T.M., Karlic, T.M. 1979. Some limitations and applications of the pressure-volume technique in ecophysiological research. En: Plants and their Atmospheric Environment (Grace, J., Ford, E.D., Jarvis, P.G., Ed.). Blackwell, Boston, 263-272.

Rodríguez, P., Torrecillas, A., Morales, M.A., Ortuño, M.F., SánchezBlanco, M.J. 2005. Effects of $\mathrm{NaCl}$ salinity and water stress on growth and leaf water relations of Asteriscus maritimus plants Environmental and Experimental Botany, 53: 113-123.

Rouphael, Y., Cardarelli, M., Rea, E., Colla, G. 2008. The influence of irrigation system and nutritient solution concentration on potted geranium production under various conditions of radiation and temperature. Scientia Horticulturae, 118: 328-337.

Ruiz-Sánchez, M.C., Domingo, R., Castel, J.R. 2010. Review. Deficit irrigation in fruit trees and vines in Spain. Spanish Journal of Agricultural Research, 8: 5-20.

Sach, R.M., Evans, R.Y., Shaw, D.A. 1992. Reduced water consumption by acclimatized landscaped. Journal of Arboriculture, 19: 99-105.

Sánchez-Blanco, M.J., Rodríguez, P., Morales, M.A., Ortuño, M.F., Torrecillas, A. 2002. Comparative growth and water relation of Cistus albidus and Cistus monspeliensis plants during water deficit conditions and recovery. Plant Science, 162: 107-113.

Sánchez-Blanco, M.J., Ferrández, T., Navarro, A., Bañón, S., Alarcón, J.J. 2004. Effects of irrigation and air humidity preconditioning on water relations, growth and survival of Rosmarinus officinalis plants during and after transplanting. Journal of Plant Physiology, 161: 11331142. 
Sánchez-Blanco, M.J., Álvarez, S., Navarro, A., Bañón, S. 2009. Changes in leaf water relations, gas exchange, growth and flowering quality in potted geranium plants irrigated with different water regimes. Journal of Plant Physiology, 166: 467-476.

Santakumari, M., Berkowitz, G.A. 1989. Protoplast volume: water potential relationship and bound water fraction in spinach leaves. Plant Physiology, 91: 13-18.

Sarawatari, H.W., Davies, S.D. 1989. Tissue water relations of three chaparral shrub species after wildfire. Oecologia (Berlin), 80: 303308.

Savé, R., Peñuelas, J., Marfà, O., Serrano, L. 1993. Changes in leaf osmotic and elastic properties and canopy structure of strawberries under mild water stress. HortScience, 28(9): 925-927.

Savé, R., Biel, C., De Herralde, F. 2000. Leaf pubescence, water relations and chlorophyll fluorescence in two subspecies of Lotus creticus L. Biologia Plantarum, 43: 239-244.

Scholander, P.F., Hammel, H.T., Bradstreet, E.D., Hemingsen, E.A. 1965. Sap pressure in vascular plants. Science, 148: 339-346.

Schulte, E.D. 1993. Tissue hydraulic properties and the water relations of desert shrubs. En: Smith, J.A.C., Griffiths, H. (Eds.), Water deficits, plant responses from cell to community. Environmental Plant Biology Series. Bios Scientific Press Ltd., Oxford, UK, pp. 177-192.

Serrano, L., Peñuelas, J., Ogaya, R., Savé, R. 2005. Tissue-water relations of two co-occurrring evergreen Mediterranean species in response to seasonal and experimental drought conditions. Journal of Plant Research, 118: 263-269.

Shao, H.B., Chu, L.Y., Jaleel, C.A., Zhao, C.X. 2008. Water-deficit stressinduced anatomical changes in higher plants. Comptes Rendus Biologies, 331: 215-225.

Sharp, R.G., Else, M.A., Cameron, R.W., Davies, W.J. 2009. Water deficitis promote flowering in Rhododendron via regulation of pre and post initiation development. Scientia Horticulturae, 120: 511517.

Silber, A., Levi, M., Cohen, M., David, N., Shtaynmetz, Y., Assouline, S. 2007. Response of Leucadendron 'Safari Sunset' to regulated déficit irrigation: Effects of stress timing on growth and yield quality. Agricultural water management, 87: 162-170.

Sionit, N., Patterson, D.T., Coffin, R.D., Mortenson, D.A. 1987. Water relations and growth of the wees, goosegrass (Eleusine indica), under drought stress. Field Crops Research, 17: 163-173.

Stoll, M., Jones, H.G., Infante, J.M. 2000. Leaf gas exchange and growth in red raspberry is reduced when part of the root system is dried. Acta Horticulturae, 585: 671-676. 
Sweatt, M.R., Davies, F.T.Jr. 1984. Mycorrhizae, water relations, growth, and nutrient uptake of geranium grown under moderately high phosphorus regimes. Journal of American Society for Horticultural Science, 109: 210-213.

Topp, G.C., Davis, J.L. 1985. Measurement of soil water content using time domain reflectometry (TDR): A field evaluation. Soil Science Society of American Journal, 49:19-24.

Topp, G.C., Davis, J.L., Annan, A.P. 1980. Electromagnetic determination of soil water content: measurements in coaxial transmission lines. Water Resources Research, 16(3):571-582.

Topp, G.C., Davis, J.L., Annan, A.P. 1982. Electromagnetic determination of soil water content using TDR: II evaluation of installation and configuration of parallel transmission lines. Soil Science Society of American Journal, 46: 678-684.

Turner, N.C. 1988. Measurement of plant water status by the pressure chamber technique. Irrigation Science, 9: 289-308.

Turner, N.C., Sterm, W.R., Evans, P. 1987. Water relations and osmotic adjustment of leaves and roots of lupins in response to water deficit. Crop Science, 27: 977-983.

Tyree, M.T., Hammel, H.T. 1972. The measurement of the turgor pressure and the water relations of plants by a pressure-bomb technique. Journal and Experimental Botany, 23: 267-282.

Tyree, M.T., Jarvis, P.G. 1982. Water in tissue and cells. En: Lange, O.L., Nobel, P.S., Osmond, C.B., Ziegler, H. (Eds), Encyclopedia of Plant Physiology New Series, Vol 12B. Physiological Plant Ecology II. Springer Verlag, Berlin, Germany, 35-77.

Valdes, R,. López, J., González, A., Navarro, A., Sánchez-Blanco, M.J., Bañón, S. 2007. Influencia del medio de cultivo sobre el desarrollo y consumo hídrico de plantas de clavel en maceta. Agrícola Vergel, abril, 213-220.

Van lersel, M.W., Nemali, K.S. 2004. Drought stress can produce small but not compact marigolds. HortScience, 39(6): 1298-1301.

Vilagrosa, A., Bellot, J., Vallejo, V.R., Gil-Pelegrín, E. 2003. Cavitation, stomatal conductance, and leaf dieback in seedlings of two coocurring Mediterranean shrubs during an intense drought. Journal of Experimental Botany, 54(390): 2015-2024.

Walter, J., Nagy, L., Hein, R., Rascher, U., Beierkuhnlein, C., Willne,r E., Jentsc,h A. 2011. Do plants remember drought? Hints towards a drought-memory in grasses. Environmental and Experimental Botany, 71: 34-40.

Warren C. 2006. Why does photosynthesis decrease with needle age in Pinus pinaster? Trees, 20: 157-164. 
Wenkert, W., Lemon, E.R., Sinclair, T.R. 1978. Water content-potential relationships in soya bean: changes in components potentials for mature and immature leaves under field conditions. Annals of Botany, 42: 295-307.

Wilson, J.R., Fisher, M.J., Schulze, E.D., Dolby, G.R., Ludlow, M.M. 1979. Comparison between pressure-volume and dewpoint-hygrometry techniques for determining the water relations characteristics of grass and legume leaves. Oecologia, 41: 77-88.

Wilson, J.R., Ludlow, M.M., Fischer, M.J., Schulze, E.D. 1980. Adaptation to water stress of the leaf water relations of four tropical forage species. Australian Journal of Plant Physiology, 7: 207-220.

Winner, W.E , Mooney, H.A., Williams, K., VonCraemmerer, S. 1985. En Sulfur Dioxide and Vegetation: Physiology, Ecology and Policy Issues (Winner. W.E., Mooney. H.A., Goldstein, R.A., Eds.), Stanford University Press ,118-132,.

Wurr, D.C.E., Fellows, J.R., Andrews, L. 2000. The effects of temperature and daylight on flower initiation and development in Dianthus allwoodii and Dianthus alpinus. Scientia Horticulturae, 86: 57-70.

Yoon, T.M., Ritcher,, H. 1990. Seasonal changes in stomatal responses of sweet cherry and plum to water states in detached leaves. Physiologia Plantarum, 80: 520-526.

Zimmerman, C. 1998a. Geraniaceae. Geranium. Disponible: http://biologogy.nwc.whecn.edu/biology/bot2100/.

Zobel, R.W., Kinraide, T.B.; Baligar. 2007. Fine root diameters can change in response to changes in nutrient concentrations. Plant Soil, 297: 243-254.

Zollinger, N., Kjelgren, R., Cerny-Koenig, T., Kopp, K., Koenig, R. 2006. Drought responses of six ornamental herbaceous perennials. Scientia Horticulturae, 109(3): 267-274. 
Capítulo 8

Índice de tablas, figuras y fotografías 



\section{Índice de tablas}

Tabla 3.1- Crecimiento de plantas de clavel en maceta sometidas a distintos tratamientos de riego al final del período experimental.

Tabla 3.2- Parámetros ornamentales en plantas de clavel en maceta sometidas a distintos tratamientos de riego al final del período experimental.

Tabla 3.3- Parámetros derivados de las curvas P-V en plantas de clavel en maceta sometidas a distintos tratamientos de riego al final del período experimental.

Tabla 4.1- Evolución diaria de las condiciones de luz y temperatura en la cámara de crecimiento.

Tabla 4.2- Crecimiento en plantas de geranio en maceta sometidas a distintos tratamientos de riego al final del período de estrés y de recuperación.

Tabla 4.3- Parámetros derivados de las curvas P-V en plantas de geranio en maceta sometidas a distintos tratamientos de riego al final de periodo de estrés

Tabla 4.4- Estudio del crecimiento en plantas de geranio en maceta sometidas a diferentes tratamientos de riego al final del período experimental.

Tabla 4.5- Resistencia hidráulica en plantas de geranio en maceta sometidas a diferentes tratamientos de riego al final del período experimental.

Tabla 5.1- Parámetros de crecimiento y pérdida de electrolitos en plantas de callistemon en macetas sometidas a diferentes tratamientos de riego al final del período experimental. ..... 138

Tabla 5.2- Morfología del sistema radical en plantas de callistemon en maceta sometidas a distintos tratamientos de riego al final del período experimental en condiciones controladas.

Tabla 5.3- Evolución de la tasa máxima de carboxilación carboxilación $\left(\mathrm{V}_{\mathrm{cmax}}, \mu \mathrm{mol} \mathrm{m} \mathrm{m}^{-2} \mathrm{~s}^{-1}\right)$, de transporte electrónico $\left(\mathrm{J}_{\mathrm{cmax}}, \mu \mathrm{mol}\right.$ $\left.\mathrm{m}^{-2} \mathrm{~s}^{-1}\right)$, conductancia del mesófilo $\left(\mathrm{g}_{\mathrm{m}}, ., \mathrm{mmol} \mathrm{m} \mathrm{m}^{-2} \mathrm{~s}^{-1}\right)$ y eficiencia fotosintética en el uso del nitrógeno (EFUN, $\mu \mathrm{mol} \mathrm{CO} 2 \mathrm{~mol}^{-1} \mathrm{~N}$ ) en plantas de callistemon en maceta sometidas a distintos tratamientos de riego durante el período experimental en condiciones controladas.

Tabla 5.4- Evolución de las limitaciones de la fotosíntesis máxima $\left(A_{\max }\right)$ en plantas de callistemon en maceta sometidas a distintos tratamientos de riego durante el período experimental bajo condiciones controladas. 
Tabla 5.5- Parámetros de relaciones hídricas derivados de las curvas presión volumen y resistencia hidráulica de las raíces $\left(1 / L_{p}\right)$ en plantas de callistemon en maceta sometidas a distintos tratamientos de riego al final del período experimental.

Tabla 5.6- Crecimiento y desarrollo aéreo en plantas de callistemon en maceta sometidas a distintos tratamientos de riego al final del período experimental en invernadero.

Tabla 5.7- Índices de crecimiento en plantas de callistemon en maceta sometidas a distintos tratamientos de riego al final del periodo experimental en invernadero.

Tabla 5.8- Eficiencia productiva del uso de agua en plantas de callistemon en maceta sometidas a distintos tratamientos de riego al final del periodo experimental en invernadero... 177

Tabla 5.9- Parámetros de color (L, C y HUE) y contenido relativo de clorofila (CRC) de la hoja en plantas de callistemon en maceta sometidas a distintos tratamientos de riego al final del período experimental en invernadero.

Tabla 5.10- Pérdida de electrolitos en plantas de callistemon sometidas a distintos tratamientos de riego al final del período experimental en invernadero 


\section{Índice de figuras}

Figura 2.1- Evolución de la superficie española de ornamentales.

Figura 2.2- Distribución de la producción y la superficie de especies ornamentales en España. Año 2008.

Figura 3.1- Potencial hídrico foliar ( $\left.\Psi_{\mathrm{h}}, \mathrm{A}\right)$, potencial osmótico foliar ( $\Psi_{\mathrm{o}}$, B) y potencial de presión foliar $\left(\Psi_{p}, C\right)$ al mediodía en plantas de clavel en maceta sometidas a distintos tratamientos de riego al final del período experimental.

Figura 3.2- Conductancia estomática $\left(\mathrm{g}_{\mathrm{s}}, \mathrm{A}\right)$ y tasa de fotosíntesis neta $\left(P_{n}, B\right)$ al mediodía en plantas de clavel en maceta sometidas a distintos tratamientos de riego al final del período experimental.

Figura 3.3- Datos climáticos correspondientes al periodo del ensayo, temperatura media, máxima y mínima diaria $(\mathrm{A})$ y déficit de presión de vapor medio diario (B).

Figura 3.4- Evolución del peso seco aéreo (A), peso seco raíz (B), cociente PS raíz/PS aéreo (C) y peso seco flores (D) en plantas de clavel en maceta sometidas a distintos tratamientos de riego durante el período experimental. Las zonas sombreadas indican el riego deficitario en las plantas del tratamiento RDC.

Figura 3.5- Evolución del número de flores abiertas $(\mathrm{A})$ y número de brotes (B) en plantas de clavel en maceta sometidas a distintos tratamientos de riego durante el período experimental. Las zonas sombreadas indican el riego deficitario en las plantas del tratamiento RDC

Figura 3.6- Evolución de los parámetros de color: luminosidad $(L, A)$, croma (C, B) y ángulo hue (HUE, C) en flores (Izda) y hojas (Dcha) de clavel en maceta sometidas a distintos tratamientos de riego durante el período experimental. Las zonas sombreadas indican el riego deficitario en las plantas del tratamiento RDC.

Figura 3.7- Evolución del área foliar (A), altura de la roseta (B),anchura de la planta (C) y altura de la planta (D) en plantas de clavel en maceta sometidas a distintos tratamientos de riego durante el período experimental Las zonas sombreadas indican el riego deficitario en las plantas del tratamiento RDC.

Figura 3.8- Evolución de la humedad volumétrica al mediodía en plantas de clavel en maceta sometidas a distintos tratamientos de riego durante el período experimental. Las zonas sombreadas indican el riego deficitario en las plantas del tratamiento RDC. 
Figura 3.9- Evolución del potencial hídrico foliar ( $\left.\Psi_{\mathrm{h}} ; \mathrm{A}\right)$, osmótico ( $\Psi_{\mathrm{o}}$; B) y de presión $\left(\Psi_{\mathrm{p}} ; \mathrm{C}\right)$ al mediodía en plantas de clavel en maceta sometidas a distintos tratamientos de riego durante el período experimental. Las zonas sombreadas indican el riego deficitario en las plantas del tratamiento RDC

Figura 3.10- Evolución del potencial osmótico saturado ( $\left.\Psi_{\mathrm{os}}\right)$ al mediodía en plantas de clavel en maceta sometidas a distintos tratamientos de riego durante el período experimental. Las zonas sombreadas indican el riego deficitario en las plantas del tratamiento RDC.

Figura 4.1- Evolución del peso (promedio de 5 macetas por tratamiento) antes y después de cada riego en plantas de geranio sometidas a distintos tratamientos de riego durante el periodo experimental. La zona sombreada indica la fase de recuperación.

Figura 4.2- Evolución de los parámetros de crecimiento (altura, A; anchura, B) en plantas de geranio en maceta sometidas a distintos tratamientos de riego durante el periodo experimental. La zona sombreada indica la fase de recuperación.

Figura 4.3- Evolución de la floración en plantas de geranio. número de inflorescencias sin abrir $(A)$, número de inflorescencias abiertas (B), y número de hojas caídas por planta(C), en plantas de geranio sometidas a distintos niveles de riego. La zona sombreada indica la fase de recuperación.

Figura 4.4- Evolución de los parámetros de color: luminosidad ( $\mathrm{L}$; $A$ y $B$ ), croma ( $C$; $C$ y D) y ángulo hue (HUE; $E$ y $F$ ) en flores (A, C y E/Izda) y hojas (B, D y F/Dcha) de plantas de geranio en macetas sometidas a diferentes tratamientos de riego durante el período experimental. La zona sombreada indica la fase de recuperación.

Figura 4.5- Evolución del consumo diario (evapotranspiración) de plantas de geranio en maceta sometidas a distintos tratamientos de riego durante el período experimental. La zona sombreada indica la fase de recuperación.

Figura 4.6- Evolución a lo largo de un día (horaria) y diaria (a lo largo del ensayo) del potencial hídrico foliar $\left(\Psi_{h} ; A\right)$, potencial osmótico $\left(\Psi_{0} ; B\right)$ y de presión $(\Psi p ; C)$ en plantas de geranio en maceta sometidas a distintos tratamientos de riego en varios momentos de la fase de estrés: semana 0.57 desde inicio tratamientos (i), semana 2.57 (ii) y semana 4.86 (iii). 
Figura 4.7- Evolución del peso promedio de varias macetas en plantas de geranio sometidas a distintos tratamientos de riego, donde aparecen marcado el valor correspondiente a los días de medida de potenciales hídricos. La zona sombreada indica la fase de recuperación.

Figura 4.8- Evolución del potencial hídrico foliar $\left(\Psi_{\mathrm{h}} ; \mathrm{A}\right)$, potencial osmótico $\left(\Psi_{\mathrm{o}} ; \mathrm{B}\right)$ y de presión $\left(\Psi_{\mathrm{p}} ; \mathrm{C}\right)$ antes de la luz y en plena luminosidad en plantas de geranio en maceta, que previamente habían estado expuestas a distintos niveles de riego, en distintos momentos de la fase de recuperación: semana 7 desde inicio tratamientos (i), semana 8 (ii) y semana 10 (iii), (1,2 o 4 semanas desde cambio de riego).

Figura 4.9- Evolución del potencial osmótico saturado ( $\left.\Psi_{\mathrm{os}}\right)$ en plantas de geranio en maceta sometidas a distintos tratamientos de riego durante el período experimental La zona sombreada indica la fase de recuperación.

Figura 4.10- Evolución del contenido relativo de agua (CRA) en plantas de geranio sometidas a distintos tratamientos de riego durante el período experimental. La zona sombreada indica la fase de recuperación.

Figura 4.11- Evolución a lo largo de un día de la conductancia estomática $\left(g_{s} ; A\right)$ y tasa de fotosíntesis neta $\left(P_{n} ; B\right)$ en plantas de geranio en maceta sometidas a distintos tratamientos de riego en varios momentos de la fase de estrés, semana 0.57 (i), semana 2.57 (ii) y semana 4.86 desde el inicio de los tratamientos (iii).

Figura 4.12- Evolución de la conductancia estomática $\left(g_{s} ; A\right)$ y tasa de fotosíntesis neta $\left(P_{n} ; B\right)$ en plantas de geranio en maceta sometidas previamente a varios niveles de estrés en tres momentos de la fase de recuperación: semana 7 (i), semana 8 (ii) y semana 10 desde el incio de los tratamientos (iii), semana 1, 2 y 4 desde el inicio de la fase de recuperación.

Figura 4.13- Evolución diaria de la eficiencia del fotosistema II, $F_{v} / F_{m}$, en plantas de geranio en maceta sometidas a distintos tratamientos de riego en tres momentos durante la fase de estrés; semana $0.57(A)$, semana $2.57(B)$ y semana 4.86 desde el inicio de los tratamientos (C).

Figura 4.14- Evolución de $F_{v} / F_{m}$ en plantas de geranio en maceta sometidas previamente a varios niveles de estrés en tres momentos durante la fase de recuperación, semana $7(A)$, semana 8(B) y semana 10 desde el inicio de los tratamientos $(\mathrm{C})$. 
Figura 4.15- Evolución del peso total de 12 macetas por tratamiento (A) y humedad volumétrica (B) en plantas de geranio sometidas a distintos tratamientos de riego durante el periodo experimental.

Figura 4.16- Evolución del porcentaje de plantas con inflorescencias sin abrir en plantas de geranio en maceta sometidas a distintos tratamientos de riego durante el período experimental. Las zonas sombreadas indican las fases de floración y las líneas verticales indican cambio de riego en las plantas de los tratamientos RDC, según nuestro protocolo de riego.

Figura 4.17- Esquema de las fases fenológicas de las plantas de geranio y umbrales de riego de los distintos tratamientos de riego a lo largo del ensayo.

Figura 4.18- Evolución de los parámetros de crecimiento (altura, A; anchura, B) en plantas de geranio en maceta sometidas a distintos tratamientos de riego durante el periodo experimental. Las líneas verticales indican los cambios de riego en los tratamientos de RDC.

Figura 4.19- Evolución de la floración: número de inflorescencias sin abrir (A), número de inflorescencias abiertas (B), numero de inflorescencias sin abrir acumuladas $(C)$, número de inflorescencias abiertas acumuladas (D) y numero de inflorescencias secas acumuladas $(E)$ en plantas de geranio en maceta sometidas a distintos tratamientos de riego durante el período experimental. Las líneas verticales indican los cambios de riego en los tratamientos de RDC.

Figura 4.20- Evolución de la pérdida de hojas acumuladas en plantas de geranio en maceta sometidas a distintos tratamientos de riego a lo largo del período experimental. Las líneas verticales indican los cambios de riego en los tratamientos de RDC.

Figura 4.21- Evolución de la tasa de crecimiento absoluto del número de inflorescencias en plantas de geranio en maceta sometidas a distintos tratamientos de riego a lo largo del período experimental. Las líneas verticales indican los cambios de riego en los tratamientos de RDC

Figura 4.22- Evolución del contenido relativo de clorofila (CRC) en plantas de geranio en maceta sometidas a distintos tratamientos de riego a lo largo del período experimental. Las líneas verticales indican los cambios de riego en los tratamientos de RDC. 
Figura 4.23- Evolución de los parámetros de color, luminosidad ( $L ; A)$, croma (C; B) y ángulo hue (HUE; C) en la zona exterior de las hojas (i), en la zona interior (ii), y en las flores (iii) de plantas de geranio en maceta sometidas a diferentes tratamientos de riego a lo largo del período experimental. . 104

Figura 4.24- Riego acumulado a lo largo del periodo experimental en plantas de geranio en maceta sometidas a diferentes tratamientos de riego.

Figura 4.25- Evolución del consumo diario (evapotranspiración) en plantas de geranio en maceta sometidas a distintos tratamientos de riego durante el período experimental. Valores de los 4 tratamientos (A), Control y deficitario $(B)$ y RDC I y RDC II (C). Las líneas verticales indican los cambios de riego en las plantas de los tratamientos de RDC.

Figura 4.26- Evolución del consumo en plantas de geranio en maceta sometidas a distintos tratamientos de riego. Comparación de las plantas de los tratamientos de RDC I (A) y RDC II (B) con las plantas de los tratamientos Control y RD sostenido y su comportamiento en los cambios de riego. Las líneas verticales indican los cambios de riego en las plantas de los tratamientos de RDC.

Figura 4.27- Evolución horaria del peso $(A)$, humedad volumétrica $(B)$, consumo (C), consumo acumulado (D) y distribución del consumo $(E)$ a lo largo de un día representativo en plantas de geranio en maceta de los tratamientos control y RD sostenido.

Figura 4.28- Evolución del potencial hídrico ( $\left.\Psi_{\mathrm{h}} ; \mathrm{A}\right)$, potencial osmótico actual $\left(\Psi_{0} ; \mathrm{B}\right)$ y potencial de presión $\left(\Psi_{\mathrm{p}} ; \mathrm{C}\right)$ en plantas de geranio en maceta sometidas a diferentes tratamientos de riego durante el período experimental. Las líneas verticales indican los cambios de riego en las plantas de los tratamientos de RDC.

Figura 4.29- Evolución del potencial osmótico saturado ( $\left.\Psi_{\mathrm{os}}\right)$ en plantas de geranio en maceta sometidas a diferentes tratamientos de riego durante el período experimental. Las líneas verticales indican los cambios de riego en las plantas de los tratamientos de RDC.

Figura 4.30- Evolución del contenido relativo de agua (CRA) en plantas de geranio en maceta sometidas a diferentes tratamientos de riego durante el período experimental. Las líneas verticales indican los cambios de riego en las plantas de los tratamientos de RDC.

Figura 4.31- Evolución de la pérdida de agua en hojas de geranio en maceta sometidas a distintos tratamientos de riego en dos momentos distintos del ensayo, fase floración (A) y fase de no floración (B) ..................................................... 116 
Figura 4.32- Evolución del intercambio gaseoso; conductancia estomática $\left(g_{s} ; A\right)$ y tasa de fotosíntesis neta $\left(P_{n} ; B\right)$ en plantas de geranio sometidas a distintos tratamientos de riego durante el período experimental. Las líneas verticales indican los cambios de riego en las plantas de los tratamientos de RDC.

Figura 4.33- Evolución del consumo diario de plantas de geranio en maceta sometidas a tratamiento control y RD sostenido durante el período experimental, (datos recogidos por mitra). Los valores marcados corresponden a días de medida de $\Psi_{\mathrm{h}} \mathrm{y} \mathrm{g}_{\mathrm{s}}$.

Figura 4.34- Evolución del consumo horario en plantas de geranio en maceta de los tratamientos control y riego deficitario sostenido (mitras). Medida A (31 julio, semana 3.7 desde inicio tratamientos: A) y Medida B (28 agosto, semana 7.7 desde inicio tratamientos, B).

Figura 5.1- Condiciones de la cámara de crecimiento a lo largo del día durante el período experimental.

Figura 5.2- Evolución de la humedad volumétrica antes y después del riego,de plantas de callistemon en maceta sometidas a distintos tratamientos de riego durante el período experimental. La línea horizontal representa el valor de la humedad del sustrato a capacidad de campo en condiciones controladas.

Figura 5.3- Distribución de la biomasa en plantas de callistemon en maceta sometidas a distintos tratamientos de riego al final del período experimental en condiciones controladas.

Figura 5.4- Evolución del número de hojas caídas en plantas de callistemon en maceta sometidas a distintos tratamientos de riego a lo largo del período experimental en condiciones controladas.

Figura 5.5- Evolución de la altura $(A)$ y de la tasa de crecimiento relativa $(B)$ en plantas de callistemon en maceta sometidas a distintos tratamientos de riego durante el período experimental en condiciones controladas.

Figura 5.6- Evolución de la evapotranspiración (ETP) y transpiración (T) en plantas de callistemon en maceta sometidas a distintos tratamientos de riego durante el período experimental en condiciones controladas.

Figura 5.7- Evolución de la evapotranspiración (ET; A) y transpiración ( $\mathrm{T}$; B) diaria promediada semanalmente, en plantas de callistemon en maceta sometidas a distintos tratamientos de riego durante el período experimental en condiciones controladas. 
Figura 5.8- Evolución de la tasa de transpiración en relación al área foliar en plantas de callistemon en maceta sometidas a distintos tratamientos de riego durante el período experimental en condiciones controladas.

Figura 5.9- Evolución de la transpiración a lo largo de un día representativo, valores horarios (A) y transpiración acumulada (B) en plantas de callistemon en maceta sometidas a distintos tratamientos de riego en condiciones controladas.

Figura 5.10- Transpiración cada 30 minutos en plantas de callistemon sometidas a distintos tratamientos de riego en varios días representativos durante el período experimental en condiciones controladas.

Figura 5.11- Tasa de transpiración en relación al área foliar cada 30 minutos en varios días representativos en plantas de callistemon en maceta sometidas a distintos tratamientos de riego durante el período experimental en condiciones controladas.

Figura 5.12- Evolución de la conductancia estomática $\left(\mathrm{g}_{\mathrm{s}} ; \mathrm{A}\right)$, tasa de fotosíntesis neta $\left(P_{n} ; B\right)$ y eficiencia intrínseca en el uso del agua $\left(P_{n} / g_{s} ; C\right)$ en plantas de callistemon en maceta sometidas a distintos tratamientos de riego durante el período experimental en condiciones controladas.

Figura 5.13- Evolución de la tasa de transpiración diaria en relación al área en plantas de callistemon en maceta sometidas a distintos tratamientos de riego durante el período experimental en condiciones controladas. Los círculos amarillos señalan los días en los que se realizaron las medidas de intercambio gaseoso.

Figura 5.14- Evolución de la fluorescencia en plantas de callistemon en maceta sometidas a distintos tratamientos de riego durante el período experimental en condiciones controladas.

Figura 5.15- Determinación de la luz saturante en plantas de callistemon en maceta sometidas a distintos tratamientos de riego

Figura 5.16- Evolución del potencial hídrico foliar antes de la fase luminosa ( $\left.\Psi_{\mathrm{pd}}: \mathrm{A}\right)$ y en las horas de máxima luminosidad ( $\Psi_{\text {md }}$ : B) y potencial hídrico de tallo $\left(\Psi_{\mathrm{x}} ; \mathrm{C}\right)$ en plantas de callistemon en maceta sometidas a distintos tratamientos de riego durante el período experimental en condiciones controladas. 
Figura 5.17- Evolución de la humedad gravimétrica antes y después del riego en plantas de callistemon en maceta sometidas a distintos tratamientos de riego durante el período experimental en condiciones controladas y su relación con la medida de $\Psi_{\text {pd }}$. Los círculos amarillos y rosas señalan los valores de humedad de los días de medida de $\Psi_{p d}$ de las plantas del tratamiento control y RD, respectivamente. 160

Figura 5.18- Evolución de la relación entre el $\Psi_{\mathrm{md}} \mathrm{y} \Psi_{\mathrm{x}}$ en plantas de callistemon en maceta sometidas a distintos tratamientos de riego durante el período experimental en condiciones controladas.

Figura 5.19- Evolución de la relación entre el potencial hídrico foliar medido antes de la fase de luz y en condiciones de máxima luminosidad en plantas de callistemon en maceta sometidas a distintos tratamientos de riego durante el período experimental en condiciones controladas.

Figura 5.20- Relación entre el potencial hídrico foliar medido antes de la fase de luz y el potencial hídrico de tallo en condiciones de máxima luminosidad en plantas de callistemon en maceta sometidas a distintos tratamientos de riego durante el período experimental en condiciones controladas.

Figura 5.21- Evolución de la temperatura máxima y mínima diaria $(A)$ y humedad relativa cada 30 mintuos (B) a lo largo del período experimental en invernadero

Figura 5.22- Evolución del déficit de presión de vapor (DPV) máximo y medio diaria a lo largo del período experimental en invernadero

Figura 5.23- Evolución de la altura $(A)$ y tasa absoluta de crecimiento (B) en plantas de callistemon en maceta sometidas a distintos tratamientos de riego durante el período experimental en invernadero.

Figura 5.24- Evolución de la floración en plantas de callistemon en maceta sometidas a distintos tratamientos de riego durante el período experimental en invernadero

Figura 5.25- Evolución del riego acumulado en plantas de callistemon en maceta sometidas a distintos tratamientos de riego durante el período experimental en invernadero

Figura 5.26- Evolución de la humedad volumétrica (antes y después del riego) en plantas de callistemon en maceta sometidas a distintos tratamientos de riego durante el período experimental en invernadero.

Figura 5.27- Evolución del consumo en plantas de callistemon en maceta sometidas a riego control y RDS durante el período experimental invernadero. Datos recogidos de la mitra y calculados como descenso de peso. 
Figura 5.28- Relación del DPV medio diario y el consumo de plantas de callistemon en maceta sometidas a tratamiento control y RDS durante el período experimental en invernadero..... 185

Figura 5.29- Evolución del consumo horario y su relación con el déficit de presión de vapor (DPV) en plantas de callistemon en maceta sometidas a riego control y RDS en distintos días durante el período experimental en invernadero.

Figura 5.30- Evolución del potencial hídrico foliar $\left(\Psi_{h}\right)$ y de tallo $\left(\Psi_{x}\right)$ al mediodía en plantas de callistemon en maceta sometidas a distintos tratamientos de riego durante el período experimental en invernadero.

Figura 5.31- Evolución de la conductancia estomática $\left(\mathrm{g}_{\mathrm{s}}\right)$ en plantas de callistemon en maceta sometidas a distintos tratamientos de riego durante el período experimental en invernadero

Figura 5.32- Relación entre tasa de fotosíntesis neta $\left(P_{n}\right)$ y conductancia estomática $\left(\mathrm{g}_{\mathrm{s}}\right)$, (A) y relación entre eficiencia intrínseca del uso del agua $\left(P_{n} / g_{s}\right)$ y conductancia estomática $\left(g_{s}\right)$, (B) en plantas de callistemon en maceta sometidas a distintos tratamientos de riego durante el ensayo en invernadero 


\section{Índice de fotografías}

Fotografía 2.1- Plantas de Dianthus caryophyllus ............................... 14

Fotografía 2.2- Plantas de Pelargonium x hortorum ..............................16

Fotografía 2.3- Plantas de Callistemon citrinus. .................................. 17

Fotografía 3.1- Plantas de clavel antes de iniciar el ensayo. ...................23

Fotografía 3.2- Vista general del invernadero. ..................................... 23

Fotografía 3.3- HOBO U12 que registra datos de temperatura y humedad relativa en el interior del invernadero. ...................24

Fotografía 3.4- Plantas de clavel y gotero.......................................24

Fotografía 3.5- Bandejas para la recogida del drenaje en plantas de clavel........................................................................... 25

Fotografía 3.6- Medidor de área foliar AM 200.................................26

Fotografía 3.7- Medidor de clorofila Minolta SPAD-502. .......................26

Fotografía 3.8- Colorímetro Minolta CR 10...................................... 27

Fotografía 3.9- Cámara de presión Soil Moisture modelo 3000 (Izda) y medida del potencial hídrico en plantas de clavel (Dcha). ...28

Fotografía 3.10- Osmómetro de presión de vapor Wescor $5520 \ldots \ldots \ldots \ldots . . . .28$

Fotografía 3.11- Aparato de intercambio gaseoso portátil LI-COR Inc., LI-400.....................................................................29

Fotografía 3.12- Aspecto de las plantas de clavel al final del ensayo. .....34

Fotografía 3.13- Vista general del ensayo en el interior del invernadero. 39

Fotografía 3.14- Plantas de clavel en el interior del invernadero.

Fotografía 3.15- Fases del clavel, fase de desarrollo inicial hasta botón floral (A y B: Fase I), flor abierta completamente ( $C$ y $D$ : Fase II) y fase de marchitamiento (E: Fase III). ................. 42

Fotografía 3.16- Equipo TEKTRONIX mod. 1502C.

Fotografía 4.1- Cámara de crecimiento, vista general de las plantas de geranio en la cámara de crecimiento durante el período experimental.

Fotografía 4.2- Muestreo destructivo en plantas de geranio al final de la fase de estrés y de recuperación.

Fotografía 4.3- Midiendo área foliar en hojas de geranio.

Fotografía 4.4- Esquema de la medida de altura máxima (longitud de los brotes) y anchura de la planta.

Fotografía 4.5- Inflorescencia sin abrir (A), inflorescencia abierta (B) y pérdida de hojas $(\mathrm{C})$

Fotografía 4.6- Medida del contenido relativo de agua en plantas de geranio. 
Fotografía 4.7- Fluorímetro portátil OptiScience, Modelo OS 30 y medida de fluorescencia en hojas de geranio.

Fotografía 4.8- Aspecto de plantas de geranio al final de la fase de estrés.

Fotografía 4.9- Medida diaria del peso de cada maceta antes del riego para calcular la cantidad de agua necesaria.

Fotografía 4.10- Control de la floración: inflorescencia sin abrir, abierta y seca.

Fotografía 4.11- Detalle de una hoja bicolor de geranio.

Fotografía 4.12- Medida del contenido relativo de clorofila en hojas de geranio con un medidor Minolta SPAD-502

Fotografía 4.13- Balanza que registraba el peso de las macetas de geranio cada 30 minutos................................................ 92

Fotografía 4.14- Equipo High Pressure Flow Meter para la medida de conductividad hidráulica

Fotografía 5.1- Vista general de la cámara de crecimiento en la que se llevo a cabo el ensayo.

Fotografía 5.2- Plantas de callistemon al inicio del ensayo.

Fotografía 5.3- Medida y registro del peso de las macetas de callistemon para la determinación del riego.

Fotografía 5.4- Determinación de la pérdida de electrolitos en plantas de callistemon al final del período experimental.

Fotogragía 5.5- Macetas empleadas para el cálculo de la transpiración y MITRA que registraba las variaciones del peso.

Fotografía 5.6- Determinación de las curvas $A-C_{i}$ en plantas de callistemon

Fotografía 5.7 - Recogida de hojas y puesta en saturación para la determinación del potencial osmótico saturado.

Fotografía 5.8- Realización de curvas P-V en hojas de callistemon sometidas a distintos tratamientos de riego al final del período experimental.

Fotografía 5.9- Medida de la conductividad hidráulica de las raíces con la cámara de presión en plantas de callistemon en maceta al final del período experimental

Fotografía 5.10- Sistema radical en plantas de callistemon en condiciones control (Izda) y sometidas a riego deficitario (Dcha) al final del período experimental en condiciones controladas.

Fotografía 5.11- Vista general de las plantas de callistemon al final del período experimental en condiciones controladas.

Fotografía 5.12- Recepción desde el vivero de las plantas de callistemon al inicio del ensayo 
Fotografía 5.13- Vista general del invernadero al inicio del ensayo 166

Fotografía 5.14- Hobo en el interior del invernadero que registra datos de temperatura y humedad relativa

Fotografía 5.15- Detalle de la planta de callistemon con gotero con dos microtubos.

Fotografía 5.16- Retirada del sustrato de las raíces en plantas de callistemon al final del período experimental.

Fotografía 5.17- Medida de la altura en plantas de callistemon en invernadero.

Fotografía 5.18- Evolución de las inflorescencias. En el seguimiento de la floración (número de inflorescencias por planta), se tenían en cuenta cuando las inflorescencias se encontraban entre las fases $\mathrm{C}$ y $\mathrm{G}$ (incluidas)

Fotografía 5.19- Medida del color y de la clorofila en hojas de callistemon al final del período experimental en invernadero.

Fotografía 5.20- Maceta sobre la balanza unida a mitra que registra los valores del peso cada 30 minutos.

Fotografía 5.21- Medida del potencial hídrico foliar con la cámara de presión.

Fotografía 5.22- Detalle de hoja previamente tapada para la medida del potencial hídrico de tallo.

Fotografía 5.23- Medida de los parámetros de intercambio gaseoso en plantas de callistemon.

Fotografía 5.24- Desarrollo de las plantas de callistemon al período experimental en invernadero. Plantas sometidas a tratamiento control (A), RDM (B) y RDS (C).

Fotografía 5.25- Efecto de los tratamientos de riego en la altura de las plantas de callistemon al final del ensayo en invernadero, planta del tratamiento control (A), RDM (B) y RDS (C) ....... 179

Fotografía 5.26- Estado de la floración de plantas de callistemon al final del período experimental en invernadero 181

Fotografía 5.27- Diferentes tamaños de inflorescencias en plantas de callistemon al final del período experimental. 
Capítulo 9

Abreviaturas y símbolos 



\section{Alfabetizables}

A

$A_{\max }$

Fotosíntesis

ANOVA

Fotosíntesis máxima

ANOVA

Análisis de varianza
C
Control
C
Croma

CEBAS Centro de edafología y biología aplicada del Segura

$C_{i}$

Concentración interna de $\mathrm{CO}_{2}$

$\mathrm{cm}$

Centímetro

col Colaboradores

$\mathrm{CO}_{2} \quad$ Dióxido de Carbono

CRA Contenido relativo de agua

$\mathrm{CRA}_{\mathrm{a}} \quad$ Contenido relativo de agua apoplástica

$\mathrm{CRA}_{\mathrm{ppt}} \quad$ Contenido relativo de agua en el punto de pérdida de turgencia

CRC Contenido relativo de clorofila

d Día

Dcha Derecha

DPV Déficit de presión de vapor

dS Decisiemen

ET Evapotranspiración

EE.UU Estados Unidos

$\mathrm{F}_{\mathrm{v}} / \mathrm{F}_{\mathrm{m}} \quad$ Eficiencia fotoquímica máxima del fotosistema II

g Gramo

$g_{s} \quad$ Conductancia estomática

$g_{m} \quad$ Conductancia del mesófilo

h Hora

HPFM High pressure flow meter

HR Humedad relativa 


\begin{tabular}{|c|c|}
\hline HUE & Ángulo hue \\
\hline Izda & Izquierda \\
\hline$J$ & Flujo de agua \\
\hline$J_{\max }$ & Tasa máxima de transporte de electrones \\
\hline K & Potasio \\
\hline $\mathrm{K}_{\mathrm{a}}$ & Constante dieléctrica del suelo \\
\hline $\mathrm{K}_{\mathrm{c}}$ & Coeficiente de cultivo \\
\hline $\mathrm{Kg}$ & Kilogramo \\
\hline $\mathrm{KPa}$ & Kilopascal \\
\hline I & Litro \\
\hline L & Luminosidad \\
\hline$L$ & Longitud de las raíces \\
\hline $\mathrm{L}_{g m}$ & Limitaciones de la conductancia del mesófilo \\
\hline$L_{g s}$ & Limitaciones de la conductancia estomática \\
\hline LAR & Leaf area ratio \\
\hline$L_{p}$ & Conductividad hidráulica \\
\hline LWR & Leaf weight ratio \\
\hline $\mathrm{m}$ & Metro \\
\hline M & Molar \\
\hline MARM & Ministerio de Medio Ambiente y Medio Rural y Marino \\
\hline $\mathrm{mg}$ & Miligramos \\
\hline $\min$ & Minuto \\
\hline $\mathrm{ml}$ & Mililitro \\
\hline $\mathrm{mm}$ & Milimetro \\
\hline $\mathrm{mmol}$ & Milimol \\
\hline $\mathrm{MPa}$ & Megapascal \\
\hline$N$ & Nitrógeno \\
\hline ns & No significativo \\
\hline
\end{tabular}




$\begin{array}{ll}\text { P } & \text { Fósforo/ significación/ probabilidad estadística/ presión } \\ \text { PS } & \text { Peso seco } \\ \text { PAR } & \text { Photosynthetic active radiation } \\ \text { PE } & \text { Pérdida de electrolitos } \\ \text { PF } & \text { Peso fresco } \\ \text { PFA } & \text { Producción final agraria } \\ \text { pl } & \text { Planta } \\ \text { PRD } & \text { Parcial root deficit } \\ \text { Pn } & \text { Tasa de fotosíntesis neta } \\ \text { PS II } & \text { Fotosistema II } \\ \text { PT } & \text { Peso turgente } \\ \text { P-V } & \text { Presión-volumen } \\ & \\ \text { Q } & \text { Quantum }\end{array}$

RD Riego deficitario

RDC Riego deficitario controlado

RDC I Riego deficitario controlado I

RDC II Riego deficitario controlado II

RDM Riego deficitario moderado

RDS Riego deficitario severo

RDsost Riego deficitario sostenido

S Segundo

Sem Semana

SLA Specific leaf area

T Transpiración

$\mathrm{T}^{\mathrm{a}} \quad$ Temperatura

TDR Time Domain Reflectometry

$\begin{array}{ll}\mathrm{V} & \text { Volumen } \\ \mathrm{V}_{\text {cmáx }} & \text { Tasa máxima de carboxilación }\end{array}$ 
VS

Versus

W Peso seco del sistema radical

WUE Eficiencia productiva en el uso del agua

\section{No alfabetizables}

$\begin{array}{ll}\Psi & \text { Potencial hídrico } \\ \Psi_{\mathrm{h}} & \text { Potencial hídrico foliar } \\ \Psi_{\mathrm{pd}} & \text { Potencial hídrico foliar antes de la fase luminosa } \\ \Psi_{\mathrm{md}} & \text { Potencial hídrico foliar en horas de máxima luminosidad } \\ \Psi_{\mathrm{ppt}} & \text { Potencial hídrico en el punto de pérdida de turgencia } \\ \Psi_{\mathrm{o}} & \text { Potencial osmótico foliar } \\ \Psi_{\mathrm{os}} & \text { Potencial osmótico a máxima saturación } \\ \Psi_{\mathrm{p}} & \text { Potencial de presión } \\ \Psi_{\mathrm{t}} & \text { Potencial hídrico de tallo } \\ { }^{\circ} \mathrm{C} & \text { Grados centígrados } \\ \mu \mathrm{mol} & \text { Micromol } \\ \Delta & \text { Variación } \\ 1 / L_{\mathrm{p}} & \text { Resistencia hidráulica } \\ \varepsilon & \text { Módulo de elasticidad } \\ \theta_{\mathrm{v}} & \text { Contenido volumétrico de agua }\end{array}$



